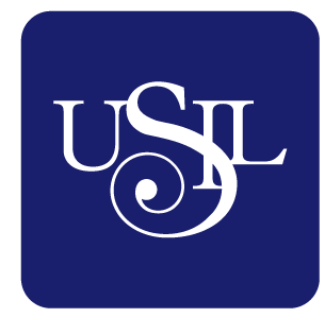

UNIVERSIDAD

SAN IGNACIO

DE LOYOLA

ESCUELA DE POSTGRADO

Maestría en Ciencias Empresariales

\title{
PLAN DE NEGOCIO PARA LA CREACION DE UNA EMPRESA CONSULTORA DE COACHING EJECUTIVO Y TEAM BUILDING EN LA CIUDAD DE AREQUIPA
}

Tesis para optar el grado de Maestro en Ciencias Empresariales

\author{
ANGÉLICA MARÍA ACURIO LÓPEZ \\ JOSEPH LUIGGI GÓMEZ OVIEDO \\ FLOR MARIELA SUCARI MORALES
}

Asesor:

Edmundo Casavilca Maldonado

Lima - Perú 


\section{ÍNDICE}

Capítulo I. Generalidades ...................................................................... 12

1.1. Antecedentes................................................................................. 12

1.2. Determinación del problema u oportunidad ............................................. 16

1.3. Justificación del proyecto...................................................................... 16

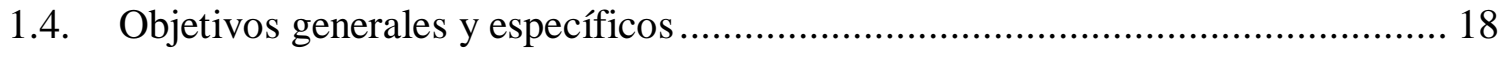

1.5. Alcances y limitaciones de la investigación................................................ 19

Capítulo II: Estructura económica del sector ................................................. 20

2.1. Descripción del estado actual de la industria ............................................. 20

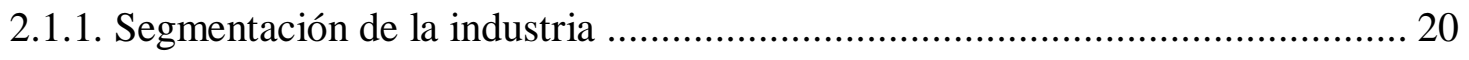

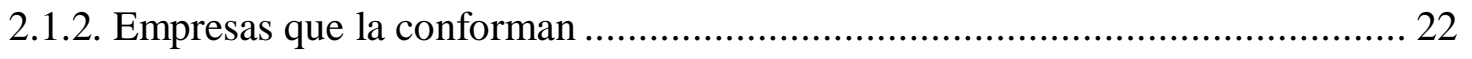

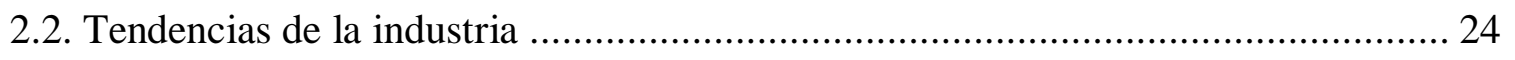

2.3. Análisis estructural del sector industrial................................................... 27

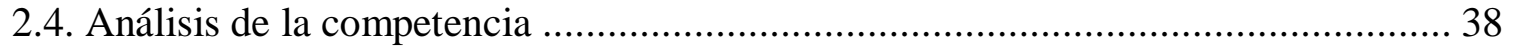

2.4.1. Empresas que ofrecen el mismo producto o servicio .............................. 39

2.4.2. Participación de mercado de cada uno de ellos. ................................... 42

2.4.3. Matriz de perfil competitivo......................................................... 44

2.5. Análisis del contexto actual y esperado .................................................. 45

2.5.1. Análisis político-gubernamental.................................................... 45 
2.5.2. Análisis económico........................................................................ 48

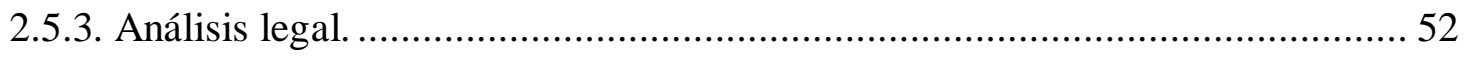

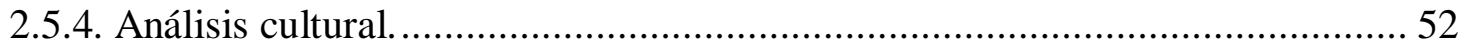

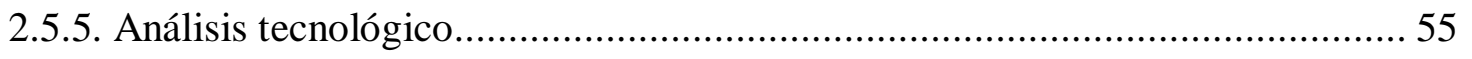

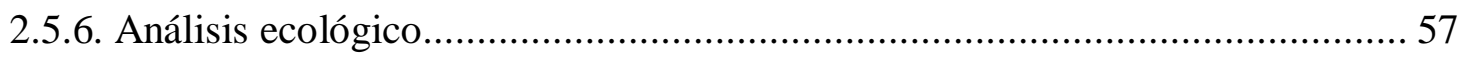

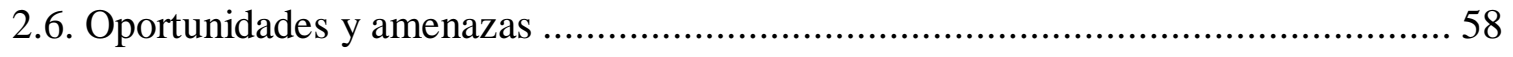

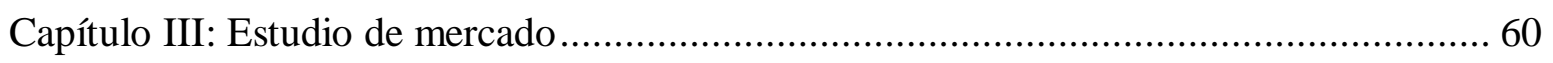

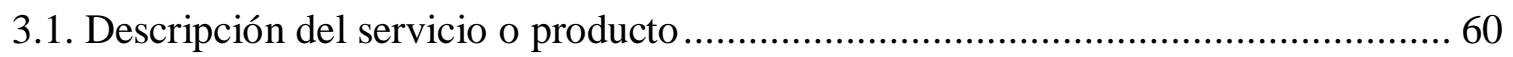

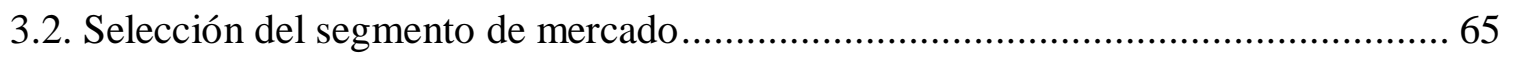

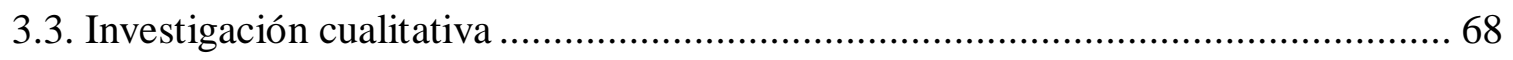

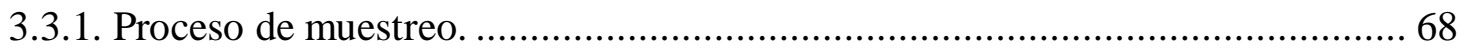

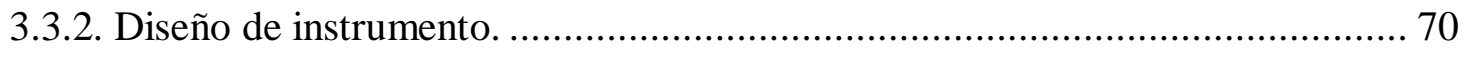

3.3.3. Análisis y procesamiento de datos. .................................................. 71

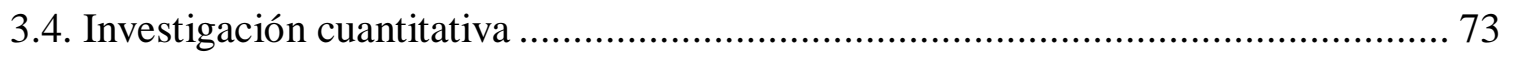

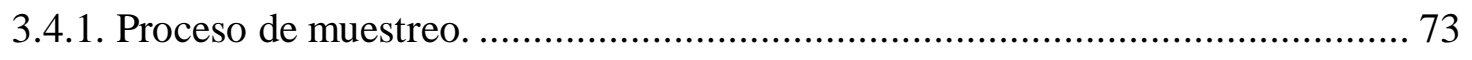

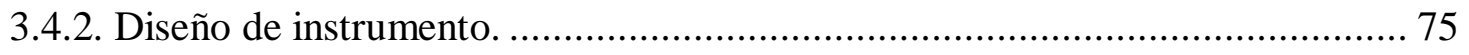

3.4.3. Análisis y procesamiento de datos. .................................................... 76

3.5. Conclusiones y recomendaciones del estudio cualitativo y cuantitativo ............. 90

Capítulo IV: Proyección del Mercado Objetivo .................................................... 93

4.1. El Ambito de la Proyección .................................................................. 93 
4.2. Selección del método de proyección .......................................................... 94

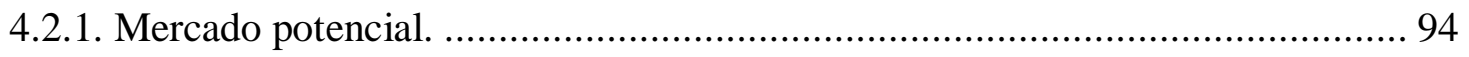

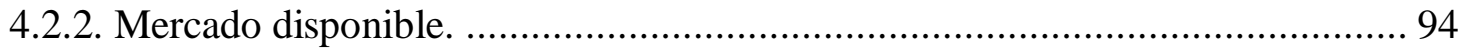

4.2.3. Mercado efectivo. ...................................................................... 95

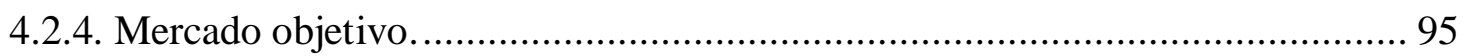

4.3. Pronóstico de ventas ................................................................................. 96

4.4. Aspectos críticos que impactan el pronóstico de ventas....................................... 97

Capítulo V: Ingeniería del Proyecto .................................................................. 99

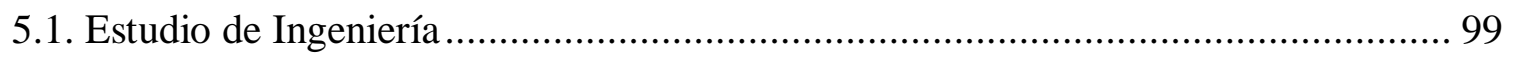

5.1.1. Modelamiento y selección de procesos productivos. ................................... 99

5.1.2. Selección del equipamiento.......................................................... 101

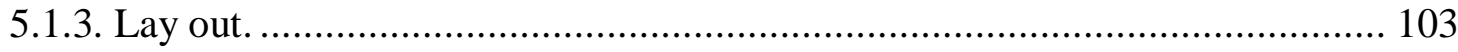

5.1.4. Distribución de equipos y maquinarias................................................. 103

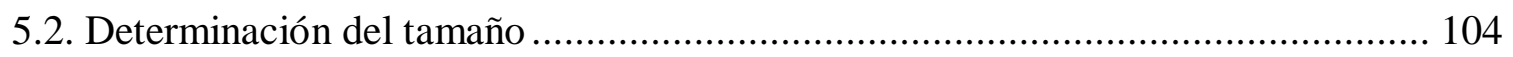

5.2.1. Proyección de crecimiento.............................................................. 105

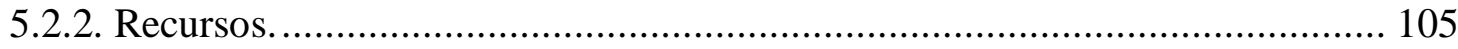

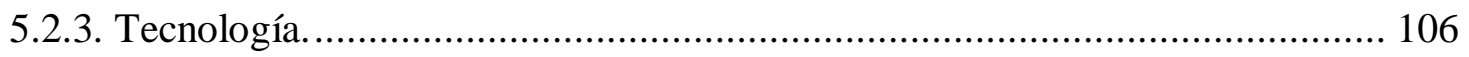

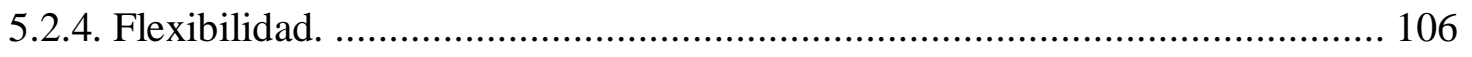

5.2.5. Selección del tamaño ideal........................................................... 107

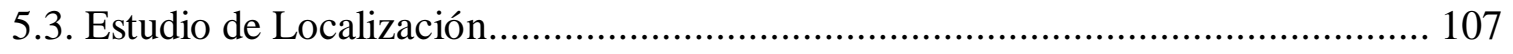


5.3.1. Definición de factores locacionales.............................................. 107

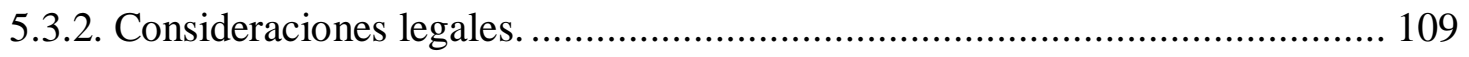

5.3.2.1. Identificación del marco legal. .................................................... 109

5.3.2.2. Ordenamiento jurídico de la empresa. ........................................ 111

5.4. Determinación de la localización óptima .................................................... 114

Capítulo VI: Aspectos Organizacionales ............................................................... 116

6.1. Caracterización de la Cultura Organizacional Deseada .................................. 116

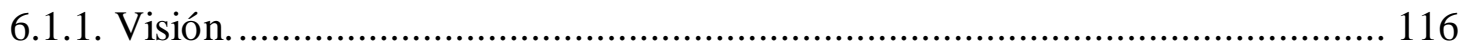

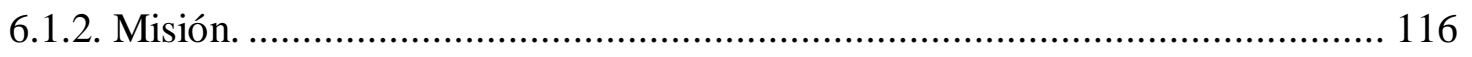

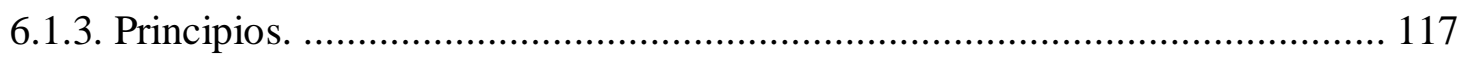

6.2. Formulación de Estrategias del Negocio ................................................. 118

6.3. Determinación de las Ventajas Competitivas Críticas ................................... 124

6.4. Diseño de la Estructura Organizacional Deseada .......................................... 126

6.5. Diseño de los Perfiles de Puestos Clave ......................................................... 126

6.6. Remuneraciones, Compensaciones e Incentivos.......................................... 131

6.7. Política de Recursos Humanos............................................................ 131

Capítulo VII: Plan de Marketing .................................................................... 133

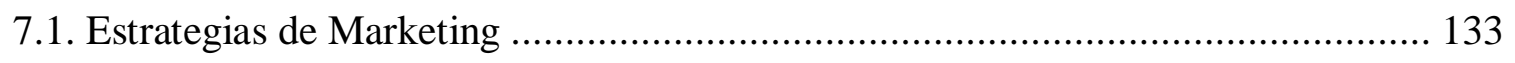

7.1.2. Estrategia de Producto. .................................................................... 136

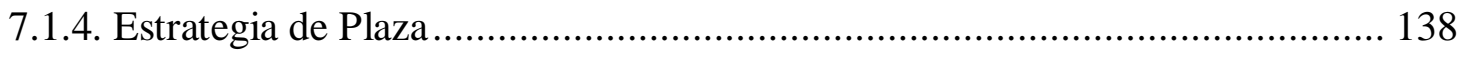


7.1.5. Estrategia de promoción y publicidad. …………………............................... 140

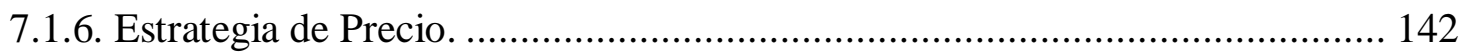

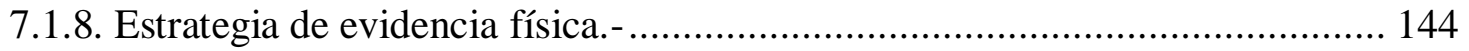

7.1.9. Estrategia de Procesos.- ............................................................................. 145

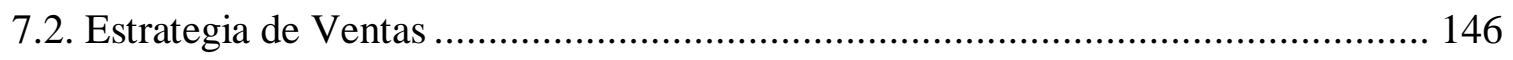

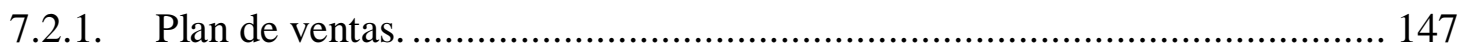

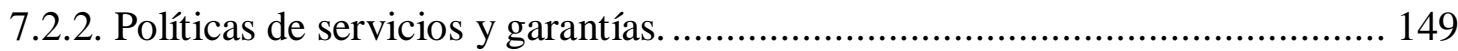

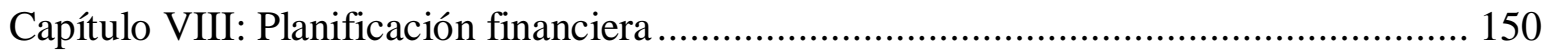

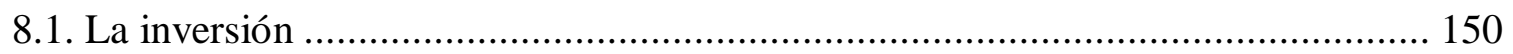

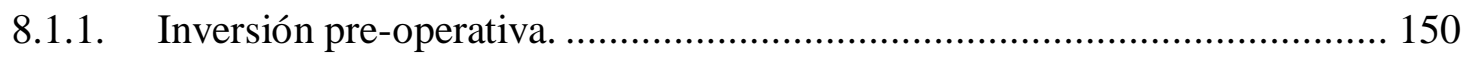

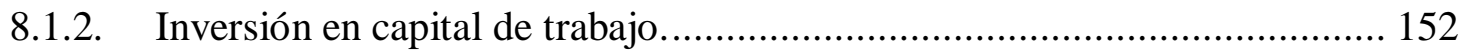

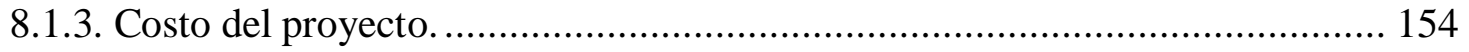

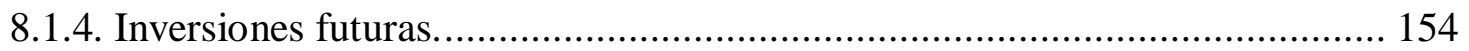

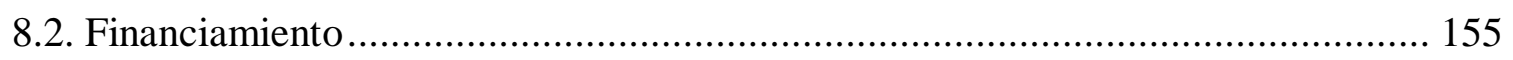

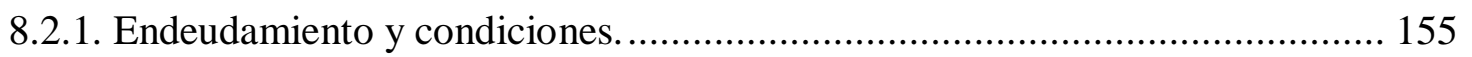

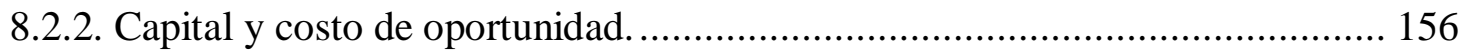

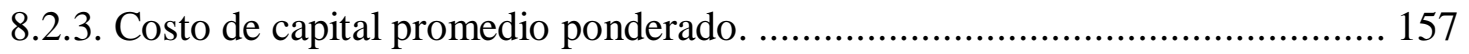

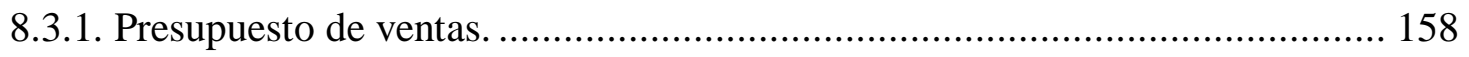

8.3.2. Presupuesto de costos de producción. ........................................................... 160

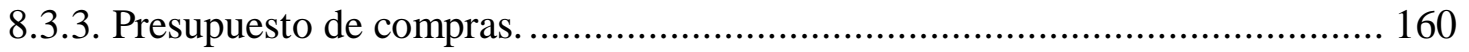


8.3.4. Presupuesto de costo de ventas. ...................................................... 161

8.3.5. Presupuesto de gastos administrativos............................................. 161

8.3.6. Presupuesto de marketing y ventas................................................ 163

8.3.7. Presupuesto de gastos financieros. ............................................... 163

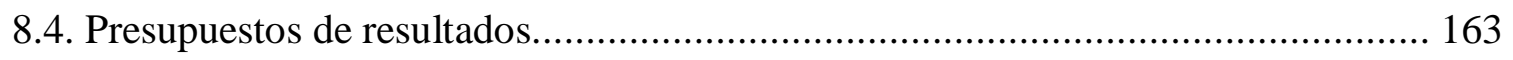

8.4.1. Estado de ganancias y pérdidas proyectado.......................................... 163

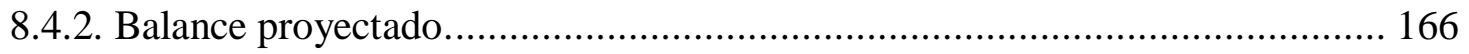

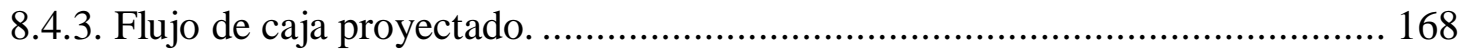

Capítulo IX: Evaluación Económico Financiera ................................................ 170

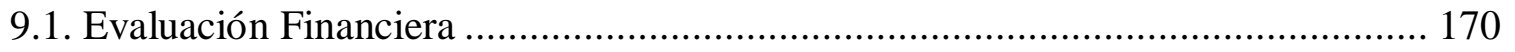

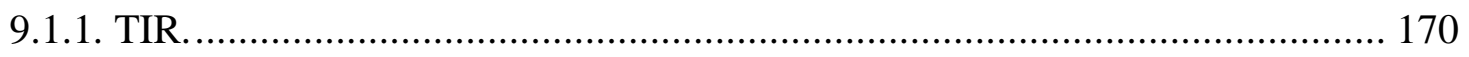

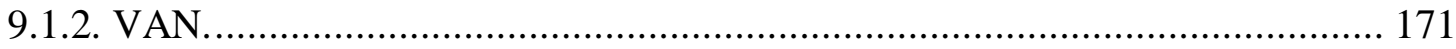

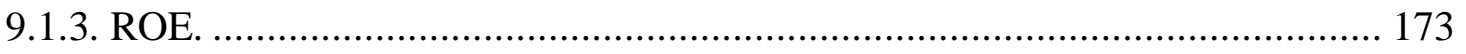

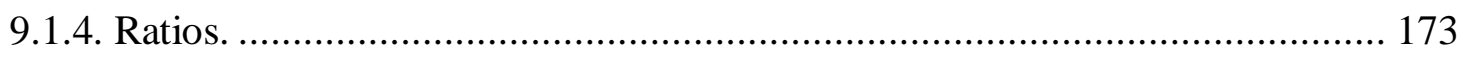

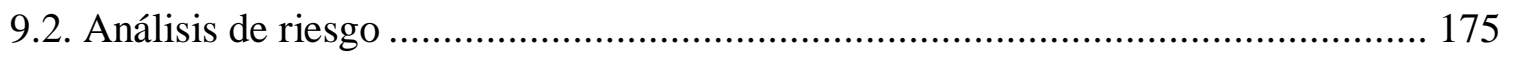

9.2.1. Análisis de punto de equilibrio.................................................... 175

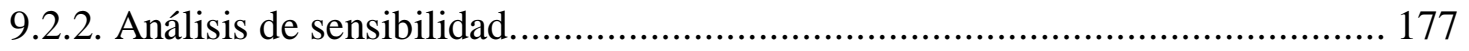

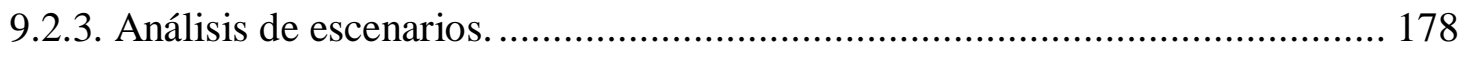

CONCLUSIONES Y RECOMENDACIONES ................................................. 181

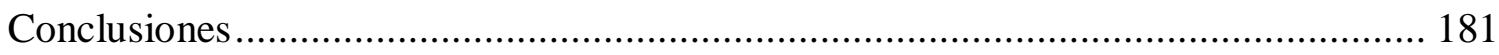




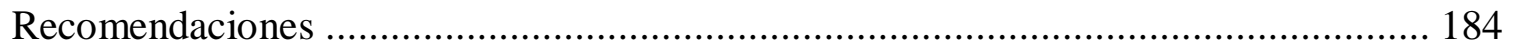

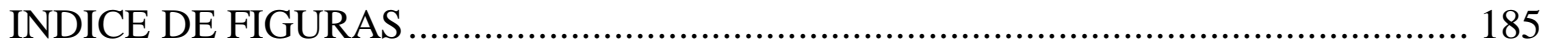

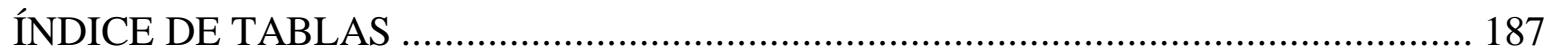

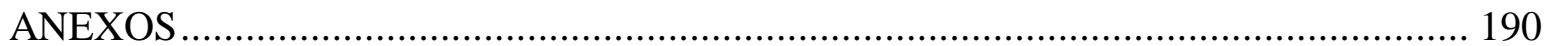

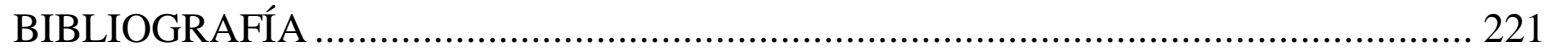

REFERENCIAS ELECTRÓNICAS ................................................................ 227 


\section{INTRODUCCIÓN}

En el competitivo mundo laboral de la actualidad, el potenciar solo las habilidades académicas ya no basta. Ahora es más importante, potencializar las llamadas habilidades blandas -dentro de las cuales destacan las habilidades sociales, la comunicación y la inteligencia emocional de los colaboradores de cualquier empresa es muy importante elevar la eficiencia y productividad de la organización. Para lograr esto, el coaching es una alternativa. Sin embargo, a pesar de la difusión del coaching como práctica de mejoramiento del desempeño, complementando y, otras veces, sustituyendo los procesos de formación y desarrollo tradicionales, en general, se conoce relativamente poco sobre cuáles son las prácticas de coaching más comunes en la región o las razones que determinan su uso.

Por ello, el presente plan de negocios analizó el conocimiento actual que tienen las pequeñas, medianas y grandes empresas de la ciudad de Arequipa acerca de las ventajas que ofrece el coaching ejecutivo para sus empresas, además de la estrategia de intervención del coaching para aumentar la productividad, motivación, trabajo en equipo y el desempeño de los empleados y como puede ayudar a sacar el mayor potencial en sus colaboradores, mejorando el rendimiento de sus equipos de trabajo y minimizar la rotación de personal en las compañías.

El presente Plan de negocios para la creación de una empresa consultora de coaching ejecutivo y team building en la ciudad de Arequipa, se diseñó para determinar la viabilidad 
del servicio de coaching ejecutivo y team building y al mismo tiempo desarrollar el proyecto de negocios de una manera objetiva.

CAPÍTULO I: Se describen los antecedentes, la oportunidad y justificación del plan de negocio, así como el objetivo, alcances y limitaciones existentes para ser evaluados al momento de llevar a cabo la implementación.

CAPÍTULO II: Este capítulo, describe el estado actual de la industria, la segmentación de la industria, las empresas que la conforman, las tendencias de la industria, el análisis estructural del sector industrial y de la competencia. Además se realizó la matriz de perfil competitivo. Junto al análisis del contexto actual y esperado y el análisis políticogubernamental, económico, legal, cultural, tecnológico, ecológico y las oportunidades y amenazas.

CAPÍTULO III: Contiene el estudio de mercado para los servicios que prestará la empresa. Se plantean los estudios cualitativo y cuantitativo, se muestra el análisis de la información lo cual permitirá una mejor toma de decisiones y se llega a conclusiones favorables que hacen ver este plan de negocio como una gran oportunidad.

CAPÍTULO IV: Se detalla la proyección del mercado para el servicio, la definición del Método de Investigación de mercados, determinación de los mercados (objetivo, potencial, efectivo y disponible), así como el pronóstico de ventas para los cinco años que cubre el presente plan de negocio.

CAPITULO V: Se revisa la ingeniería del proyecto, planteamiento, organización, diseño y ejecución de las instalaciones, sistemas, las interacciones derivadas del desarrollo y 
utilización del servicio. Se realiza el estudio del tamaño y la localización así como el ordenamiento jurídico de la empresa.

CAPITULO VI: En este capítulo se presentan los aspectos fundamentales de la empresa como organización, definiendo su misión, visión y formulación de estrategias del negocio. También se plantea la estructura organizacional deseada, el diseño de los perfiles del puesto y las remuneraciones y compensaciones pronosticadas.

CAPITULO VII: Se presenta el plan de marketing para la nueva línea, previa definición de los objetivos e investigación de mercado, planteamiento de las estrategias del marketing mix y ventas; para lograr así los objetivos propuestos en un período determinado. Asimismo, las estrategias de ventas y el plan de ventas.

CAPITULO VIII Y IX: Ambos capítulos tienen por finalidad identificar y calcular las inversiones, la forma cómo se financiará el proyecto, así como la determinación de los presupuestos de ingresos y gastos. Así mismo, este capítulo presenta la proyección de los principales estados financieros y el flujo de caja a cinco años. Se muestra también la evaluación financiera del plan de negocio, así como el estudio de rentabilidad y viabilidad del negocio. 


\section{Capítulo I. Generalidades}

\subsection{Antecedentes}

En el siglo XV, existía un pueblo llamado Kocs en Hungría. Este lugar se hizo muy conocido ya que en él se construían uno de los mejores carruajes de caballo y tenía un lema que mencionaba el traslado a destino de forma "rápida y cómoda". Se mencionaba a los carruajes de Kocs como "kocsi szekér" y eran símbolo de excelencia. El término "Coach" nace en Hungría y su significado es el de coche, por lo tanto, la palabra coach deriva de la función de transportar personas de un lugar a otro (Hall, 2010).

En el siglo XX ante la caída de la Psicología Humanista, el coaching emerge con una mayor presencia, valorando al individuo y trabajando con su conciencia mas no con el inconsciente, haciendo énfasis en buscar significados y no explicaciones. El "rapport" que es un fenómeno de sintonía junto con la empatía es un pilar en la relación de coaching. Los coachees son responsables del plan de acción en cada sesión, el coach no enseña, está orientado al desempeño, fabrica una realidad del presente hacia el futuro de lo que se quiere llegar a ser. La relación en el coaching es de confianza y credibilidad. (O`Connor \& Lages, 2005).

Como Whitmore (2011) menciona, el coaching se emplea para varios propósitos como: (a) Motivación de personal; (b) Delegación; (c) Resolución de problemas; (d) Relaciones interpersonales; (e) Refuerzo del equipo; (f) Valoraciones y evaluaciones; (g) Rendimiento; (h) Planificación y revisión; (i) Desarrollo del personal; y (j) Trabajo en equipo.

Es importante definir que entre el coaching, la psicología y el mentoring existe diferencia, la psicología busca situaciones del pasado para enmendar el presente, en cambio 
el coaching analiza el presente para darle forma al futuro. Por otro lado el mentoring es un proceso de mejora en una cualidad en específico del colaborador, el mentor enseña y aconseja en base a su experiencia. El coach se centra en el desempeño del individuo pero a diferencia del mentoring, este no necesita ser un experto en el área a desarrollar por parte del cliente (Guerrero, 2011)

Tabla 1

Tipología del coaching

\begin{tabular}{|c|c|c|}
\hline $\begin{array}{l}\text { Tipología de } \\
\text { Coaching }\end{array}$ & Contexto relacional & Subcategorías \\
\hline \multirow{3}{*}{$\begin{array}{l}\text { Coaching } \\
\text { Personal }\end{array}$} & 1. Uno a uno & \multirow{3}{*}{$\begin{array}{l}\text { Coaching para un tipo de público } \\
\text { concreto (adolescentes, amas de casa, } \\
\text { personas mayores de } 40 \text { años, etc.), o } \\
\text { funciones concretas (artistas, } \\
\text { políticos, deportistas, etc.) }\end{array}$} \\
\hline & 2. Objetivo personal & \\
\hline & 3. Vida diaria & \\
\hline \multirow{4}{*}{$\begin{array}{l}\text { Coaching } \\
\text { Ejecutivo }\end{array}$} & 1. Uno a uno & \multirow{4}{*}{$\begin{array}{l}\text { Coaching para emprendedores, } \\
\text { autónomos, o aspectos de la vida } \\
\text { profesional, coaching para mandos } \\
\text { intermedios, coaching para jefes de } \\
\text { sección, etc.) }\end{array}$} \\
\hline & 2. Objetivo profesional & \\
\hline & 3. Vida profesional y personal & \\
\hline & 4. Relación interpersonal indirecta & \\
\hline \multirow{3}{*}{$\begin{array}{l}\text { Coaching } \\
\text { Grupal }\end{array}$} & 1. Uno a varios & \multirow{3}{*}{$\begin{array}{l}\text { Coaching para equipos de ventas, } \\
\text { atención al cliente, equipo deportivo, } \\
\text { grupo de voluntarios, etc. }\end{array}$} \\
\hline & 2. Objetivo común & \\
\hline & $\begin{array}{l}\text { 3. Vida profesional y personal } \\
\text { 4. Relación interpersonal directa }\end{array}$ & \\
\hline \multirow{3}{*}{$\begin{array}{l}\text { Coaching } \\
\text { Organizacional }\end{array}$} & 1. Uno/s al sistema en su conjunto & \multirow{3}{*}{$\begin{array}{l}\text { Coaching estratégico, cambio de } \\
\text { cultura organizacional, } \\
\text { reestructuraciones, aumento de } \\
\text { rentabilidad, disminución de costes, } \\
\text { comunicación externa, etc. }\end{array}$} \\
\hline & 2. Objetivo corporativo & \\
\hline & $\begin{array}{l}\text { 3. Vidas profesionales y personales } \\
\text { 4. Relaciones interpersonales } \\
\text { directas e indirectas }\end{array}$ & \\
\hline
\end{tabular}

Nota. "Arte y ciencia del coaching. Su historia, filosofía y esencia", por Leo Ravier, 2012. http://leoravier.com/ 
Según menciona Ravier (2012), existen tres escuelas de coaching:

1. Coaching Práctico: Su método es utilizar un sistema reproducible y generar cambios que se acerquen a lo inmediato. Tiene tendencia americana y usa medidas correctivas sobre defectos evidenciados

2. Coaching Ontológico o filosófico: Busca una relación entre el cuerpo, lenguaje y emociones de la persona tratada para hallar el sentido del ser mismo, su tendencia es sudamericana.

3. Coaching Humanista: Enfocado en el respeto por la libertad de la persona y su conciencia. Basado en la psicología humanista y se origina en Europa.

El presente plan de negocios se enfocará en brindar el Coaching ejecutivo y Team building, dirigido a ejecutivos, gerentes de empresas y áreas dentro de una organización, generalmente a cargo de un coach profesional debidamente entrenado y certificado.

El coach profesional dispone de un gran número de herramientas y métodos que se mencionan a continuación. Algunas de las herramientas más comunes son:

1. Línea de la vida: Recapitular momentos entre fuertes y débiles en la persona, como se afrontaron y que característica propia motivo la resolución del mismo.

2. Crear mapas mentales: Búsqueda de talentos y valores analizando el interior y exterior de la persona para potenciar un área específica.

3. Feedforward: Herramienta que analiza lo que piensan los demás de la persona mediante la evaluación de cualidades y/o opciones para superar un problema.

4. Cero Parásitos: Explorar a la persona para identificar sus oportunidades de mejora con planes de acción con conocimiento de causa y criterios analizados para la continuidad. 
5. La Rueda de la vida: Profundizar en aspectos de la persona, los más débiles y cercanos a la situación deseada en los roles de la vida (Guerrero, 2011)

6. Team Building: En oportunidades los equipos en las empresas no tienen eficacia y por lo tanto no alcanzan resultados, entre varios factores están los conflictos, experiencia, capacidad. Todas se suman para ocasionar una productividad baja, malas relaciones, motivación nula e insatisfacción en el personal. Lograr tener equipos integrados hacia objetivos en común y que sean productivos es una de las prioridades que tiene una empresa, con mayor énfasis en estos momentos en los que la competencia es cada vez más dura.

Un líder deberá considerar para la creación de un equipo de alto rendimiento a) Marcar objetivos, b) definir un sistema de medición del nivel de alcance de los objetivos, c) definir sistemas de comunicación entre los miembros del equipo, d) definir procedimientos para que los miembros del equipo tomen decisiones y solucionen problemas y e) desarrollar sistemas de gestión de personal.

El Team building es un servicio que tiene tiempo llevándose a cabo. Team (equipo) y building (construcción) se puede mencionar como construcción de equipos. Para construir un equipo se pueden realizar un sinfín de procedimientos, pero este se orienta a actividades específicas para construir un equipo. Comúnmente esta actividad se realiza como un evento y se diseña acorde a la necesidad del cliente, en un lugar determinado. Suele ser un espacio ideal algo alejado de la vida cotidiana, que permite al colaborador liberarse de tensiones y relacionarse sin limitaciones (Dreams \& Adventures, 2015). 


\subsection{Determinación del problema u oportunidad}

1. Alta rotación de personal que genera mermas en las empresas.

2. Falta de motivación, trabajo en equipo y compromiso por parte de los colaboradores para con la empresa en la que trabajan

3. Necesidad por parte de las empresas por retener una cultura organizacional positiva, potenciar el talento humano, fomentar la motivación, trabajar en equipo y mejorar el nivel de compromiso.

4. Falta de empresas especializadas en Coaching ejecutivo y Team building en la ciudad de Arequipa, que hace que las empresas de Lima ingresen al mercado con precios elevados.

\subsection{Justificación del proyecto}

El motivo del presente plan de negocios fue analizar e investigar si las empresas de la ciudad de Arequipa presentan interés por adquirir los servicios del coaching ejecutivo y team building para su capital humano. Así mismo investigar si utilizan dichas herramientas para solucionar y/o mejorar temas relacionados al talento humano.

En la actualidad ya es conocido que el capital humano es el principal elemento de éxito en la gestión empresarial y que la administración de este talento puede generar un crecimiento exponencial o por el contrario, el fracaso y la quiebra de una empresa.

Uno de los principales retos en las empresas es la retención del personal, motivación, trabajo en equipo y compromiso de este. Es un problema latente el no contar con líderes para afrontar retos futuros del negocio. Los gerentes además de tener el mejor talento, 
desarrollarlo y motivarlo deben fidelizar a la fuerza laboral con el negocio y evitar la rotación de personal.

Según Harvard Bussiness Essencial (2005) los beneficios que ofrece el coaching a las organizaciones incluyen superar los problemas de rendimiento, desarrollar las habilidades de los empleados, aumentar la productividad, mejorar la retención y fomentar una positiva cultura laboral.

En el Perú, uno de los factores que genera inestabilidad laboral es la rotación de personal: en promedio la rotación de personal en el país, según la Asociación Peruana de Recursos Humanos (APERHU), es de un 15\% anual pese a que la cifra ideal es de un 7\%.Cada vez más frecuente que incrementa y genera no solo la pérdida de recursos económicos, físicos en tiempo y la fuga de talentos, sino que representa que los empleados que abandonan una empresa lleven consigo el crecimiento, habilidades y competencias adquiridas en la organización.

En el estudio ratificado por la Cámara de Comercio Americana del Perú (AmCham) se detalla que el sector industrial estima su tasa de rotación anual en un $6.4 \%$, por otro lado el sector servicios es el que presenta la tasa más alta de rotación con un (18,6\% en promedio), otro dato del estudio demostró que en el caso de los ejecutivos de primera línea, un $41 \%$ permanece entre 5 y 10 años mientras que los considerados en segunda línea permanecen entre tres y cinco años.

El principal desafío que hoy en día las organizaciones enfrentan radica en las personas, razón por la que en un contexto cambiante y competitivo la mayoría de las empresas buscan 
mayor eficiencia, y mejora continua para conseguir el éxito en el desarrollo de las estrategias que logren una mejor adaptación de sus empleados.

De esta manera el presente plan de negocios indagó sobre el conocimiento actual que tienen las pequeñas, medianas y grandes empresas de la ciudad de Arequipa sobre los beneficios que ofrece el coaching ejecutivo para sus organizaciones, así como la estrategia de la intervención del coaching para incrementar la productividad, motivación, trabajo en equipo y el desempeño de los empleados y como puede ayudar a sacar el mayor potencial en sus colaboradores, mejorando el rendimiento de sus equipos de trabajo y minimizar la rotación de personal en las compañías.

El coaching, es un proceso mediante el cual se acompaña a los ejecutivos, para transformar aquellas competencias que afectan los resultados, objetivos o metas. Sus beneficios se reflejan en las estadísticas que señalan que un $48 \%$ mejora su calidad, un $48 \%$ fortalece su organización, un 53\% incrementa su productividad y logran una retención de $32 \%$ de sus ejecutivos.

\subsection{Objetivos generales y específicos}

1. Objetivo general del proyecto.

- Elaborar un plan de negocios para la creación de una empresa consultora de coaching ejecutivo y team building en la ciudad de Arequipa.

2. Objetivos específicos del proyecto.

- Describir la estructura económica del sector, realizar un estudio de mercado, proyectar el mercado objetivo y desarrollar la ingeniería del proyecto

- Establecer los aspectos organizacionales y el plan de marketing del plan de negocio. 
- Desarrollar la planificación financiera del plan de negocios y realizar la evaluación financiera.

- Brindar conclusiones y aportar recomendaciones al plan de negocios

\subsection{Alcances y limitaciones de la investigación}

1. Alcance.

- Ámbito a nivel geográfico: empresas medianas y grandes conformadas por 20 colaboradores a más en la ciudad de Arequipa y un total de 14 sectores.

2. Limitaciones.

- Falta de información actualizada del análisis del sector servicios de consultoría en coaching ejecutivo y team building en el mercado.

- Falta de acceso a la información de nuestros competidores.

- Falta de empresas especializadas que brinden asesoría en coaching ejecutivo. 


\section{Capítulo II: Estructura económica del sector}

\subsection{Descripción del estado actual de la industria}

El Perú hoy en día es visto como uno de los países con la economía y el mercado más dinámicos de América Latina, por lo que cada vez se hace más necesario obtener información acerca de las técnicas nuevas sobre la gestión de las personas, la cuales funcionan como los pilares del desarrollo empresarial. La consultoría de recursos humanos ha tenido un cambio y su administración implica un conjunto de actividades orientadas a manejar la transición, que ayudan a que las organizaciones y las personas comprendan, acepten y puedan implementar los cambios necesarios para alcanzar una mejora en el desempeño de la organización. Una proyección ante el cambio de gobierno podría adoptar alguna medidas que se pueden concretar como un interés mayor en protección de despidos, mas fiscalizaciones e inspecciones laborales, la aprobación de la Ley general del trabajo y remuneraciones mínimas de S/ 850 lo cual ya se ha hecho una realidad. Según los resultados de una encuesta de expectativa de empleo realizada en nuestro país durante el tercer trimestre de este año, destaca que los empleadores peruanos mantienen positivas intenciones de empleo, con una tendencia neta de más de $16 \%$, y que un grupo importante de empleadores continúan prefiriendo no hacer cambios en su planilla de personal (Universidad de Lima, 2016).

\subsubsection{Segmentación de la industria}

De acuerdo al BBVA (2013), a medida que el volumen de la empresa es mayor el área de recursos humanos tomar mayor relevancia dentro de la institución. Persigue objetivos como la selección y formación de personas necesarias, facilitar a 
los trabajadores herramientas necesarias para su adecuado desenvolvimiento, y la satisfacción de cada trabajador cumpliendo su labor.

Diez funciones se consideran básicas para el área de recursos humanos a nivel empresarial:

1. Organización y planificación del personal: Consta de crear funciones y obligaciones para los puestos de trabajo, elaborar plantillas acorde a la necesidad de la empresa, atender necesidades para las personas, entre otras.

2. Reclutamiento: Técnicas utilizadas para captar el personal adecuado para un puesto de trabajo, puede realizarse de manera interna o externa.

3. Selección: Examinar de manera integral todos los beneficios con los que el postulante puede contribuir al puesto que desempeñara.

4. Planes de carrera y promoción profesional: Con el objetivo de brindar a los empleados la oportunidad de crecer profesionalmente y desempeñarse en cargos de mayor importancia.

5. Formación: La empresa es responsable de otorgar las facilidades necesarias a todos sus colaboradores para que el cumplimiento de sus tareas y obligaciones se realicen de la mejor manera.

6. Evaluación del desempeño y control del personal: El departamento de recursos humanos vela que en la organización se mantengan los parámetros estables y no existan disconformidades.

7. Clima y satisfacción laboral: Cuidar que exista equilibrio entre la vida cotidiana de las personas y sus funciones dentro de la empresa genera como resultado buen clima laboral. 
8. Administración del personal: Tramitar todos los documentos necesarios para el correcto funcionamiento y formalización de la empresa.

9. Relaciones laborales: Fomentar una conexión ideal entre todos los trabajadores para evitar así cualquier tipo de disputa y si se origina la mejor vía de solución.

10. Prevención de riesgos laborales: Llevar a cabo medidas que aseguren las condiciones adecuadas en el trabajo, garantizando la buena salud de los colaboradores.

\subsubsection{Empresas que la conforman}


Tabla 2

Empresas de Recursos Humanos en Arequipa

\begin{tabular}{ll}
\hline EMPRESAS & TIPO
\end{tabular}

Asc Consultora de RR.HH.

Selección de Personal

Agencia de Empleos Angelita Mega Norte

Selección de Personal

Aguilar \& Asociados Sociedad Civil

Asesorías de Empresas

Corporación de Negocio y Recursos Humanos

Selección de Personal

Psicotalentos

Selección de Personal

Team Work

Selección de Personal

Team Éxito Consulting

Asesorías de Empresas

Alianza Service S.R.L.

Selección de Personal

Grupo Moya E.I.R.L.

Selección de Personal

Golden Force S.A.C.

Selección de Personal

Mundo Laboral

Selección de Personal

Objetivo Lavoro

Selección de Personal

Cooperativa Santo Domingo

Selección de Personal

Manpower Perú S.A.

Selección de Personal

T-Impulsa coaching

Coaching

Coaching Mejora

Coaching

Nota. Elaboración Propia. "Búsqueda de empresas de recursos humanos en Arequipa". Tomado de https://www.google.com. 
Tabla 3

Empresas de Recursos Humanos en Lima

\begin{tabular}{lll}
\hline TIPO DE EMPRESA & CANTIDAD & PORCENTAJE \\
\hline Reclutamiento de personal & 211 & $43.1 \%$ \\
$\begin{array}{l}\text { Consultoría en Recursos } \\
\text { Humanos }\end{array}$ & 161 & $32.9 \%$ \\
Gestión del talento Humano & 74 & $15.1 \%$ \\
Capacitación & 15 & $3.1 \%$ \\
Coaching y Team building & 12 & $2.4 \%$ \\
Headhunter & 12 & $2.4 \%$ \\
Clima laboral & 3 & $0.6 \%$ \\
Planeamiento estratégico & 2 & $0.4 \%$
\end{tabular}

Nota. Elaboración Propia. "Búsqueda de empresas de recursos humanos en Lima". Tomado de https://www.google.com.

\subsection{Tendencias de la industria}

Últimamente se ha evidenciado muchos cambios y una revolución en la gestión de recursos humanos y aparentemente esto no se va a detener. Algunos de los factores relevantes son la tecnología, globalización y el impacto de las generaciones. El ámbito laboral estará controlado por estas ocho tendencias.

1. Aprendizaje social: Es el conocimiento que se alimenta de la vida diaria con ver e imitar, en donde la tecnología tomara protagonismo.

2. Big Data e inteligencia artificial: Esta herramienta permite el acceso a información que puede ser utilizada para maniobrar de manera óptima los recursos humanos.

3. Gestor de comunidades: La presencia de un líder será de vital importancia para promover e inculcar cambios positivos en los trabajadores. 
4. Knowmad: Compuesto de: Know (saber) y nomad (nómada). Explorar e incluir elementos con capacidades como la innovación y flexibilidad, trabajando en equipo en cualquier situación.

5. Inteligencia colectiva: La función de líder ya no se tratara de un objetivo a nivel individual, se desarrollara de manera colaborativa.

6. Nuevos entornos de trabajo: Los nuevos instrumentos digitales modificaran el ejercicio laboral por el entorno variable.

7. El foco en el talento: El propósito de los recursos humanos será la búsqueda de personas orientadas a objetivos en común que desarrollen su talento.

8. Redes sociales internas: El área comercial se fortalecerá con redes de comunicación interna (ESAN, 2015).

La empresa AURUM, consultoría y mercado, elaboró la Guía de Negocios e Inversión en el Perú (2015) en colaboración con Ernst \& Young. Dicha guía menciona que desde el año 2002 las tasas de variación del PBI a nivel nacional y en Arequipa tienen una tendencia creciente. En el año 2009 hay un evento particular que afecta a todos y provoca una desaceleración, la crisis financiera internacional, desde 2010 hasta 2012 se retoman tasas de crecimiento positivas, y en los últimos años desde 2013 el crecimiento ha sido menor, aunque Arequipa muestra cifras de las más positivas. Este año se proyecta un crecimiento del 5 y $5.5 \%$, esto influenciado en gran parte por la puesta en marcha de proyectos mineros importantes. 


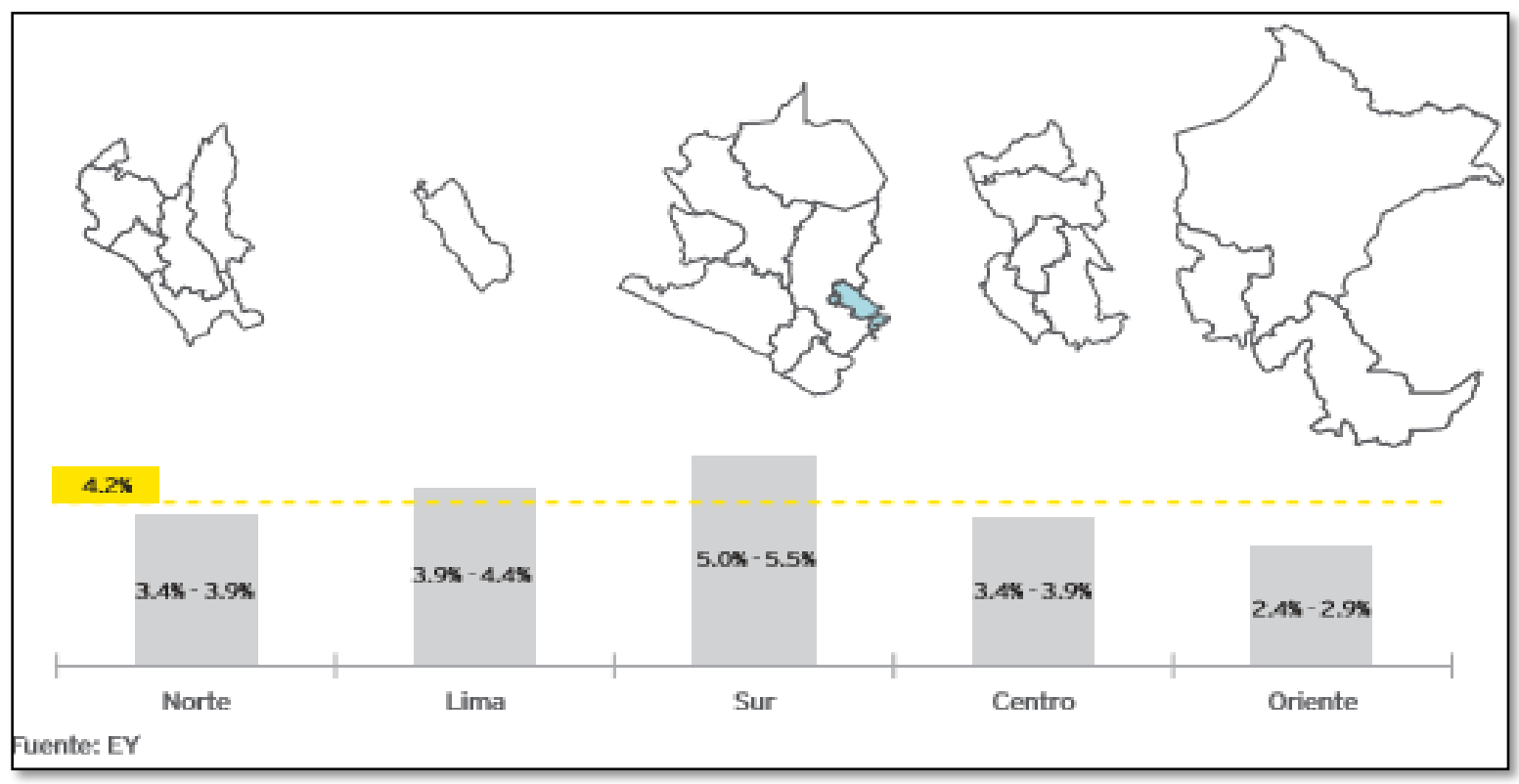

Figura 1. Crecimiento del PBI por Macro Región. Tomado de "Guía de negocios e inversión en el Perú”, por Aurum consultoría y mercado, 2015.

En cuanto a las inversiones, en el Perú en general cuatro de cada cinco empresas medianas y grandes hacen inversiones en capacitación laboral mostrando poco a poco la relevancia que está tomando el desarrollo del personal, así mismo aún son pocas las empresas que han tomado la decisión de invertir de manera constante en este punto. Poco a poco se está estableciendo a nivel internacional un 4 a 5\% del costo laboral, remuneraciones y aportes, para el trabajo en capacitación del personal, el Perú aún está en $1 \%$ del costo laboral en una empresa, esto según el Comité de Recursos Humanos de la Cámara de Comercio Americana en el Perú. Para poder contemplar con mayor claridad el panorama de influencia de trabajar en el recurso humano, la rotación de lo colaboradores genera un costo de entre 3 a 6 meses del sueldo del personal que se retira de la empresa. Solo el 50\% de empresas en el Perú logra retener a su personal. Si queremos evitar una rotación elevada, se debe considerar un proceso correcto de selección, donde haya una adaptación sencilla en el nuevo empleo, y el entendimiento de lo que la empresa espera de 
esa persona. Todo esto se puede medir y entender teniendo reglas claras y que exista un proceso de evaluación y valoración constante.

Con este procedimiento en claro se puede identificar a los mejores talentos para poder ofrecerles, como parte de una estrategia de retención, fidelidad y desarrollo la comodidad necesaria para que se sientan parte de la empresa y alarguen su tiempo dentro de la misma.

\subsection{Análisis estructural del sector industrial}

Para poder efectuar el análisis completo utilizamos las cinco fuerzas de Porter, el modelo permite conocer estrategias que se puedan plantear para ser realmente competitivo y usar eficazmente el uso de nuestros recursos. A continuación el desarrollo de los puntos para examinar:

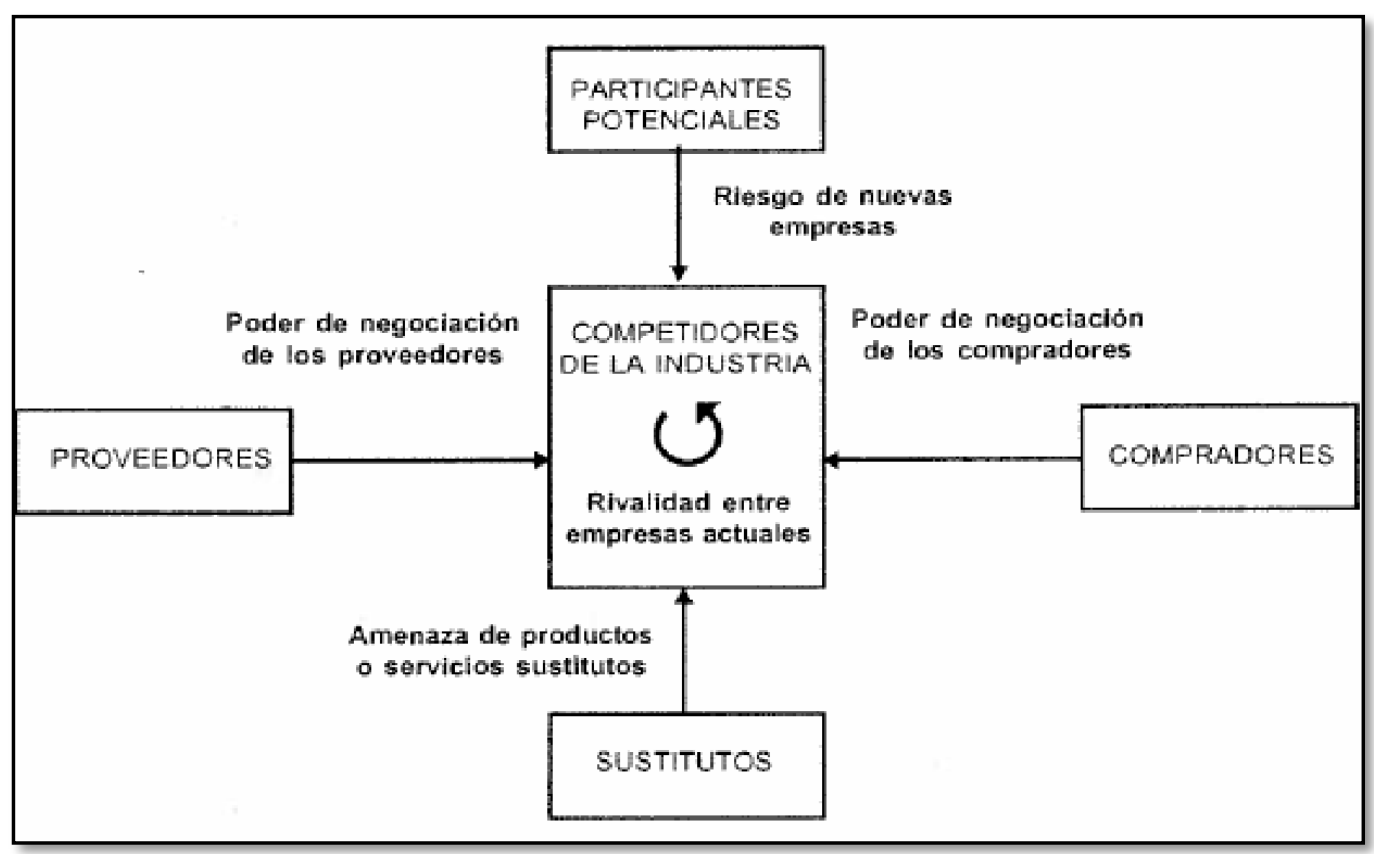

Figura 2. Cinco fuerzas de Porter. Nota. Estrategia Competitiva Michael Porter, 2006 
1. Poder de negociación de los proveedores

Un mercado no es muy atractivo cuando los proveedores están muy bien organizados, tengan recursos que son fuertes y se puedan imponer con sus condiciones de precio y los tamaños de pedido. Esto se ve aún más complicado cuando los insumos son claves, no tienen sustitutos o son difíciles de sustituir o son pocos y tienen un costo muy elevado. Esta situación se puede volver aún más crítica si es que al proveedor le conviene por temas estratégicos integrarse hacia adelante pasando a ser competencia del cliente. Para el caso de los servicios especializados es muy costoso y dificultoso cambiar de proveedor, se tienen que cumplir requisitos como certificaciones y cumplimientos regulatorios. El estado puede regular a los proveedores a través de diferentes normativas (Porter, 2006).

Se han considerado para el presente proyecto barreras de entrada bajas ya que tenemos a disposición una gran cantidad de proveedores y las dinámicas de la empresa no exige ni tiene rigidez en cuanto a los servicios que se van a prestar. En el caso de los insumos son materiales que fácilmente pueden ser negociables o hasta sustituibles.

a. Número de proveedores especializados: Para el caso de estudio existen muchos proveedores en lo que se refiere a lugares y establecimientos donde se puedan desarrollar coaching ejecutivo, así mismo podemos trabajar en formar alianzas que nos ayuden a estandarizar algunos procesos y poder trabajar mejor en la innovación de servicio.

b. Integración hacia adelante por parte de los proveedores: Es poco posible que nuestros proveedores puedan optar por la opción de integrarse hacia adelante, los restaurantes campestres o establecimientos como hoteles tienen un segmento de clientes que están lejos de abandonar, solo las instituciones educativas privadas como el caso de 
universidades podría atacarnos implementando estos servicios ya que cuentan con áreas extensas y aulas cómodas para el servicio que se quiere ofrecer, esto hace que la empresa tenga esta variable como atractiva para el negocio.

c. Fijación de precios: Para poder iniciar este negocio esta variable es atractiva ya que en Arequipa el servicio de coaching ejecutivo es un nuevo ingreso en el mercado por lo tanto la competencia en precios es baja y favorable Intenta Coaching, ya que los servicios similares que se prestan a las empresas tienen origen desde Lima y el costo de traslado genera que el precio es mayor, esto nos hace más atractivos al mercado ya que estamos cerca de nuestros clientes y nuestro tiempo de respuesta es más efectivo.

d. Alianzas estratégicas con proveedores: El logro de la certificación por parte de INCAE con la metodología europea SUN nos coloca a la vanguardia en la ciudad de Arequipa con relación al servicio de coaching, dicha certificación nos sirve de respaldo como una empresa seria y con experiencia en el servicio que ofertamos. Por otro lado también nos podemos asociar con proveedores que nos faciliten instalaciones para grandes grupos de personas tanto en capacitación como en dinámicas de grupo, lo que nos llevará a ser mejor vistos por el mercado y empresas que tienen gran poder y gran número de colaboradores. 
Tabla 4

Matriz de atractividad - Poder de negociación con proveedores

\begin{tabular}{|c|c|c|c|c|c|c|}
\hline $\begin{array}{l}\text { Poder de } \\
\text { negociación } \\
\text { con } \\
\text { proveedores }\end{array}$ & $\begin{array}{l}\text { NO } \\
\text { ATRACTIVO }\end{array}$ & $\begin{array}{l}\text { POCO } \\
\text { ATRACTIVO }\end{array}$ & NEUTRAL & ATRACTIVO & $\begin{array}{l}\text { MUY } \\
\text { ATRACTIVO }\end{array}$ & TOTAL \\
\hline & 1 & 2 & 3 & 4 & 5 & \\
\hline $\begin{array}{l}\text { Número de } \\
\text { proveedores } \\
\text { especializados }\end{array}$ & & & & $\mathrm{X}$ & & \\
\hline $\begin{array}{l}\text { Integración } \\
\text { hacia adelante } \\
\text { con proveedor }\end{array}$ & & & & $\mathrm{X}$ & & \\
\hline $\begin{array}{l}\text { Alianzas } \\
\text { Estratégicas } \\
\text { con } \\
\text { proveedores }\end{array}$ & & & & $\mathrm{X}$ & & \\
\hline $\begin{array}{l}\text { Fijación de } \\
\text { precios }\end{array}$ & & & & $\mathrm{X}$ & & 4 \\
\hline
\end{tabular}

Nota. Elaboración propia. Matriz de atractividad de Porter. Tomado de Estrategia competitiva. Técnicas para el análisis de los sectores industriales y de la competencia. Matriz de atractividad de Porter, M. Porter, 2006, México, DF, México: Continental Copyright 2006 por The Free Press, Macmillan.

Se concluye que la matriz de asertividad presenta un calificativo promedio de 4 , obteniendo un nivel de amenaza alto respecto al poder de negociación con los proveedores.

2. Poder de negociación de los clientes

Existe un poder de negociación por parte de los clientes cuando el producto que se ofrece es estándar o cuando hay muchas empresas que ofrecen el mismo servicio sin una gran diferencia salvo los precios, un punto que nos puede jugar en contra es que los clientes puedan crear sus insumos y materia prima como por ejemplo la inversión en capacitadores que trabajen en la empresa, pero para ellos esto también implica un riesgo. Si se desea tener 
el dominio, se necesitan productos nuevos y diferentes con mínima modificación al precio (Porter, 2006).

Las dificultades de ingreso que podemos considerar son medianas, ya que en la actualidad los colaboradores que ingresan a laborar a grandes empresas están cada vez más capacitados y preparados, aunque no específicamente en coaching ejecutivo.

a. Nivel de oferta en el mercado: El poder de negociación es bajo ya que las empresas que ofrecen el servicio están centralizadas actualmente y hay poca difusión en Arequipa y el sur del Perú, su enfoque va por el lado de empresas que tienen sucursales en provincias y no toman en cuenta a empresas del sur que tienen más de 20 colaboradores.

b. Valoración de alianzas estratégicas: Para la empresa será fundamental contar con alianzas estratégicas como la certificación en INCAE que otorga un mayor porcentaje de aceptación de los clientes.

c. Diferenciación del producto: Que sea diferente es esencial ya que se contara con servicios especializados e integrados para cualquier empresa que requiera uno o más servicios. El segmento seleccionado al inicio será las empresas con gran presencia en Arequipa. 
Tabla 5

Matriz de atractividad-Poder de negociación de los clientes

\begin{tabular}{llllll}
\hline $\begin{array}{l}\text { Poder de } \\
\text { negociación con } \\
\text { los clientes }\end{array}$ & $\begin{array}{l}\text { NO } \\
\text { ATRACTIVO }\end{array}$ & $\begin{array}{l}\text { POCO } \\
\text { ATRACTIVO }\end{array}$ & NEUTRAL & ATRACTIVO & $\begin{array}{l}\text { MUY } \\
\text { ATRACTIVO TOTAL }\end{array}$ \\
\hline & 1 & 2 & 3 & 4 & 5
\end{tabular}

Nivel de oferta del

mercado

$\mathrm{X}$

Valoración de las

alianzas

estratégicas

$\mathrm{X}$

Diferenciación del

Producto

X

3.6

Nota. Elaboración propia. Matriz de atractividad de Porter. Tomado de Estrategia competitiva. Técnicas para el análisis de los sectores industriales y de la competencia. Matriz de atractividad de Porter, M. Porter, 2006, México, DF, México: Continental Copyright 2006 por The Free Press, Macmillan.

En cuanto al poder de negociación de los clientes, el nivel de oferta del mercado es poco atractivo, la valoración de las alianzas estratégicas es muy atractivo y la diferenciación del producto es atractiva. Puede concluirse que el promedio del poder de negociación con los clientes es de 3.6, tendiendo a presentar un riesgo alto.

3. Rivalidad entre competidores

Generalmente es una fuerza de las más poderosas, nos hace referencia la rivalidad entre empresas que compiten directamente en una industria. Una fuerte rivalidad entre competidores podría interpretarse como una gran cantidad de estrategias destinadas a superar a los demás, estrategias que buscan aprovechar toda muestra de debilidad en ellos, esta rivalidad tiende a aumentar principalmente cuando estos van aumentando en número y se ven equiparados en tamaño y capacidad (Porter, 2009). 
En el proyecto el número de competidores locales directos es casi nulo lo cual es un entorno ideal para explotar.

a. Escasez de servicios de coaching ejecutivo formales: En este segmento solo existen algunas universidades que crean talleres de integración pero la principal fuente de coaching está en Lima. Como es nuestro enfoque ya que se ha elevado su atracción.

b. Crecimiento del coaching: El crecimiento del coaching que se ha propagado como una profesión en alza, colabora a que las empresas estén interesadas en el servicio pudiendo ofrecer una diversidad de servicios a favor de la empresa, haciéndonos más atractivos a la empresas que estén interesadas en el servicio. Si bien es cierto el crecimiento es pausado y lento, Arequipa es un mercado a explotar ya que hay gran cantidad de empresas que cuentan con más de veinte colaboradores.

c. Diferenciación del producto: Este servicio se ofrece a todas las empresas de la ciudad de Arequipa que cuenten con más de veinte colaboradores principalmente en los diferentes sectores de Arequipa que tengan como proyección motivar y sacar las mejores competencias de sus colaboradores con la finalidad de retener a sus mejores talentos, tener un excelente clima laboral y mejorar la productividad de sus empleados.

d. Altos desempeños estratégicos: La mayoría de consultoras se encuentran en la ciudad de Lima y han focalizado su trabajo basándose en el coaching, lo que nos otorga una ventaja competitiva es ofrecer un paquete integrado de coaching ejecutivo. 
Tabla 6

Matriz de atractividad - Rivalidad entre competidores

\begin{tabular}{llllll}
\hline $\begin{array}{l}\text { Rivalidad entre } \\
\text { Competidores }\end{array}$ & $\begin{array}{l}\text { NO } \\
\text { ATRACTIVO }\end{array}$ & $\begin{array}{l}\text { POCO } \\
\text { ATRACTIVO }\end{array}$ & NEUTRAL & ATRACTIVO & $\begin{array}{l}\text { MUY } \\
\text { ATRACTIVO TOTAL }\end{array}$ \\
\hline & 1 & 2 & 3 & 4 & 5
\end{tabular}

Escasez de servicios de coaching, endomarketing y teambuilding X

Crecimiento del coaching $\mathrm{X}$

Diferenciación del producto X

Altos desempeños estratégicos X 4

Nota. Elaboración propia. Matriz de atractividad de Porter. Tomado de Estrategia competitiva. Técnicas para el análisis de los sectores industriales y de la competencia. Matriz de atractividad de Porter, M. Porter, 2006, México, DF, México: Continental Copyright 2006 por The Free Press, Macmillan.

En cuanto a la rivalidad entre competidores, la escasez de servicios de coaching, endomarketing y team building es muy atractivo, el crecimiento del coaching es neutral, la diferenciación del producto es atractiva y los altos desempeños estratégicos también es atractiva. Respecto a la rivalidad entre competidores, el nivel es de 4, siendo este de alto riesgo.

4. Amenaza de ingreso de nuevos competidores.

La posibilidad y facilidad con la que pueden entrar nuevos competidores es un elemento importante para poder medir cual es la rentabilidad de una empresa. La facilidad o la dificultad con la que se mide está determinada por la barreras de entrada y pueden ser de muchos tipos, pueden ser naturales o creadas por ejemplo está el alto nivel de inversión 
requerido, están la regulaciones del mercado que mediante el estado puede crear monopolios de estado o legales, las patentes y propiedad intelectual, la localización geográfica necesitamos el espacio adecuado para estar cerca del cliente y poder interactuar con él y su entorno, los accesos a canales de distribución que se puede presentar en el bloqueo de venta para los establecimientos (Porter, 2006).

Para el negocio proyectado las barreras de entrada son muy bajas lo cual le da al negocio también un alto riesgo ya que las empresas de servicios generales en recursos humanos pueden aumentar la línea de los servicios que ofrecen, y otras empresas principalmente de Lima pueden ampliar sus operaciones en Arequipa.

a. Precio: Es una variable que se muestra como muy favorable para el negocio ya que actualmente nuestro servicio se enfoca en Arequipa, lo cual marca un precio diferente al que tienen las empresas que brindan estos servicios en Lima, los cuales toman en cuenta en su costo, algunas variables como los traslados y la estadía.

b. Diferenciación de productos: Es importante mencionar este punto ya que los servicios que se ofrecen en el caso de coaching ya tiene una alta difusión, más no el servicio que se ofrece como una integración, si bien es cierto las empresas competidoras pueden especializarse, el lanzamiento del nuevo producto nos hace más atractivos para el mercado y es una oportunidad para nosotros el poder mantener la constancia en el servicio.

c. Requerimiento de capital: En este punto, los equipos, insumos, materiales y otros no suponen un costo elevado por lo que es punto favorable ya que se pueden concentrar las inversiones en la difusión de la empresa, los servicios que se ofrecen y el reconocimiento de la marca, si se valora como importante a los recursos con los que 
contamos en el caso de personal los cuales son especialistas y personas con elevada experiencia y preparación para el servicio ofrecido.

Tabla 7

Matriz de atractividad - Amenaza de entrada de nuevos competidores

\begin{tabular}{llllll}
\hline $\begin{array}{l}\text { Amenaza de entrada } \\
\text { de nuevos } \\
\text { competidores }\end{array}$ & $\begin{array}{l}\text { NO } \\
\text { ATRACTIVO }\end{array}$ & $\begin{array}{l}\text { POCO } \\
\text { ATRACTIVO }\end{array}$ & NEUTRAL & ATRACTIVO & $\begin{array}{l}\text { MUY } \\
\text { ATRACTIVO TOTAL }\end{array}$ \\
\hline & 1 & 2 & 3 & 4 & 5 \\
Precio & & & $\mathrm{X}$ & \\
$\begin{array}{l}\text { Diferenciación de } \\
\text { Productos }\end{array}$ & & $\mathrm{X}$ & & \\
$\begin{array}{l}\text { Requerimiento de } \\
\text { capital }\end{array}$ & & & & $\mathrm{X}$ & 4 \\
\hline
\end{tabular}

Nota. Elaboración propia. Matriz de atractividad de Porter. Tomado de Estrategia competitiva. Técnicas para el análisis de los sectores industriales y de la competencia. Matriz de atractividad de Porter, M. Porter, 2006, México, DF, México: Continental Copyright 2006 por The Free Press, Macmillan.

En cuanto a la amenaza de entrada de nuevos competidores, el precio es atractivo, la diferenciación de productos es neutral y el requerimiento de capital es muy atractivo. El promedio es 4, siendo el nivel de riesgo alto.

5. Amenaza de ingreso de productos sustitutos.

Los productos sustitutos son los que ponen un límite superior al precio que se puede cobrar por un producto, lo cual nos lleva a que la rentabilidad tenga sus limitaciones. En general lo sustitutos de productos representan una fuerte amenaza para una empresa cuando los clientes enfrentan poco o ningún costo por cambiar de uno a otro y cuando el precio del producto sustituto es más bajo o su calidad y capacidad de desempeño son iguales o mejores que las del producto de la competencia (Porter, 2006). 
a. Innovación de nuevos productos: En la actualidad se está difundiendo mucho la profesión del coaching lo cual tiene un elevado interés por parte de las empresas, algunas de ellas ofrecen un servicio similar como talleres pequeños donde no hay una especialización ni certificación del servicio prestado quitando validez y garantía.

b. Nivel de costos: Para los costos es importante que tomemos en cuenta que además de ofrecer un servicio nuevo y con la posibilidad de integrarlo, podemos brindarle al mercado una marcada diferencia en cuanto a los precios del servicio específicamente en Arequipa, lo cual con el alcance que proponemos también se destina a poder negociar precios con los clientes para que ambos salgan beneficiados.

c. Acceso canales de distribución: El poder acceder a los clientes es una ventaja evidente en Arequipa, salvo los grandes grupos empresariales que tienen sus centrales en la ciudad de Lima y se encargan de hacer las negociaciones con empresas que brindan un servicio similar al que ofreceremos.

d. Cantidad de productos alternativos: Los servicios similares tienen una gran diversidad, la complicación está en identificarlos ya que muchas de las empresas a nivel nacional se han formado como recursos humanos en un inicio pero a medida que han evolucionado los servicios que se pueden prestar, estas han ido adaptándose a la necesidad del cliente o también han efectuado los cambios según su mercado para poder ser rentables. Las alternativas son variadas pero la importancia de contar con una certificación y la experiencia necesaria nos muestra como una empresa con un atractivo diferente y con mayor seriedad. 
Tabla 8

Matriz de atractividad - Amenaza de entrada de productos sustitutos

\begin{tabular}{|c|c|c|c|c|c|c|}
\hline $\begin{array}{l}\text { Amenaza de entrada } \\
\text { de Productos } \\
\text { sustitutos }\end{array}$ & $\begin{array}{l}\text { NO } \\
\text { ATRACTIVO }\end{array}$ & $\begin{array}{l}\text { POCO } \\
\text { ATRACTIVO }\end{array}$ & NEUTRAL & ATRACTIVO & $\begin{array}{l}\text { MUY } \\
\text { ATRACTIVO }\end{array}$ & TOTAL \\
\hline & 1 & 2 & 3 & 4 & 5 & \\
\hline $\begin{array}{l}\text { Innovación de } \\
\text { nuevos productos }\end{array}$ & & & & $\mathrm{X}$ & & \\
\hline Nivel de costos & & & & & $X$ & \\
\hline $\begin{array}{l}\text { Acceso canales de } \\
\text { distribución }\end{array}$ & & & $\mathrm{X}$ & & & \\
\hline $\begin{array}{l}\text { Cantidad de } \\
\text { productos } \\
\text { alternativos }\end{array}$ & & $\mathrm{X}$ & & & & 3.5 \\
\hline
\end{tabular}

Nota. Elaboración propia. Matriz de atractividad de Porter. Tomado de Estrategia competitiva. Técnicas para el análisis de los sectores industriales y de la competencia. Matriz de atractividad de Porter, M. Porter, 2006, México, DF, México: Continental Copyright 2006 por The Free Press, Macmillan.

En cuanto a la amenaza de entrada de productos sustitutos, respecto a la innovación de nuevos productos este es atractivo, el nivel de costos es muy atractivo, el acceso a los canales de distribución es neutral y la cantidad de productos alternativos es poco atractivo. Se concluye que el promedio es 3.5, siendo un nivel medio-alto de riesgo.

\subsection{Análisis de la competencia}

El sector está compuesto por una serie de empresas que ofrecen servicios en diferentes niveles, desde el trabajo exclusivo con niños, hasta la integración de grandes grupos de empresas y el trabajo de unión entre áreas de una empresa.

Cada servicio y sus propiedades intervienen en la selección de la estrategia con la que se intenta penetrar en el mercado. Para estudiar un sector se analiza las fuerzas de 
Porter, interioriza el análisis del rubro y da a conocer las condiciones de la industria. Este diagnóstico nos posibilita de conocer competidores, tasas, barreras y el modo de operación de la competencia. (Porter, 2006)

Para las empresas de recursos humanos que se enfocan en la orientación, desarrollo e integración hay un mercado nuevo el cual es ideal de explotar ya que cada vez está más apreciado el valor de las personas dentro de las instituciones, ya que las personas están cada vez más capacitadas y aptas para desenvolverse en el puesto en el que es requerido o en el que quiere desempeñarse. Hoy en día los contactos dentro de las empresas y los mismos actos de negociación son una ventana para captación de talentos que, si no están en la comodidad de sus labores pueden ser fácilmente atraídos hacia otra empresa. (Martínez, 2002).

\subsubsection{Empresas que of recen el mismo producto o servicio}

Consideramos las empresas que brindan consultoría de coaching en la Ciudad de Lima y como competidores indirectos las empresas que brindan servicios de coaching en la ciudad de Arequipa que brindan servicios de asesoría de manera individualizada (parejas, adolescentes, etc.).

\section{Competencia directa.}

Para realizar el análisis de la competencia, identificaremos las empresas que vendan servicios que se asemejen al proyecto.

Este grupo está conformado por empresas dedicadas a brindar consultoría en coaching ejecutivo y team building para empresas en la capital y Arequipa, a 
continuación se especifica un cuadro entre los servicios que ofrece el proyecto y los servicios que ofrece la competencia. (Crece negocios, 2015).

Tabla 9

Competidores Directos Lima

\begin{tabular}{|c|c|c|c|c|c|}
\hline $\begin{array}{l}\text { Productos / } \\
\text { Servicios }\end{array}$ & $\begin{array}{l}\text { Proyecto Intenta, } \\
\text { Coaching } \\
\text { Ejecutivo y Team } \\
\text { building }\end{array}$ & $\begin{array}{l}\text { Coaching y } \\
\text { Talento }\end{array}$ & $\begin{array}{l}\text { Latam } \\
\text { coaching } \\
\text { network }\end{array}$ & $\begin{array}{l}\text { Joe Quispe } \\
\text { Comunicación } \\
\text { Emocional }\end{array}$ & Inside Up \\
\hline Coaching & $\mathrm{X}$ & $\mathrm{X}$ & $\mathrm{X}$ & $\mathrm{X}$ & $\mathrm{X}$ \\
\hline Teambuilding & $\mathrm{X}$ & & & & \\
\hline PNL & & & $\mathrm{X}$ & & \\
\hline $\begin{array}{l}\text { Gestión del } \\
\text { Cambio }\end{array}$ & & & & & $\mathrm{X}$ \\
\hline $\begin{array}{l}\text { Consultoría } \\
\text { Educa }\end{array}$ & & & & & $X$ \\
\hline $\begin{array}{l}\text { Certificación } \\
\text { coaching }\end{array}$ & & & $\mathrm{X}$ & & \\
\hline $\begin{array}{l}\text { Gestión del } \\
\text { Talento }\end{array}$ & & $X$ & & & \\
\hline Liderazgo & & & & & $X$ \\
\hline
\end{tabular}

Nota. Elaboración propia

En cuanto a la capital de la República, los cuatro principales competidores directos son: Coaching y Talento, Latam coaching network, Joe Quispe Comunicación Emocional e Inside Up. Todos los mencionados brindan el servicio de coaching, siendo inside up, la empresa que ofrece la mayor gama de productos (coaching, gestión del cambio, consultoría educa y Liderazgo). El coaching ejecutivo y el team building solo son ofrecidos por la empresa Proyecto Intenta, es decir el proyecto emanado del actual plan de negocios. 
Tabla 10

Competidores Directos Arequipa

\begin{tabular}{lllll}
\hline $\begin{array}{l}\text { Productos / } \\
\text { Servicios }\end{array}$ & $\begin{array}{l}\text { Proyecto Intenta, } \\
\text { Coaching } \\
\text { Ejecutivo y Team } \\
\text { building }\end{array}$ & T- Impulsa & $\begin{array}{l}\text { Organización } \\
\text { Motiva }\end{array}$ & $\begin{array}{l}\text { Coaching } \\
\text { Mejora }\end{array}$ \\
\hline Coaching & $\mathrm{X}$ & $\mathrm{X}$ & $\mathrm{X}$ & $\mathrm{X}$ \\
Teambuilding & $\mathrm{X}$ & $\mathrm{X}$ & \\
PNL & & $\mathrm{X}$ & \\
$\begin{array}{l}\text { Certificación } \\
\text { coaching }\end{array}$ & & & \\
$\begin{array}{l}\text { Obtención y } \\
\text { dotación de } \\
\text { personal }\end{array}$ & & & \\
\hline
\end{tabular}

Nota. Elaboración propia

En cuanto a la ciudad de Arequipa, los tres principales competidores directos son:

T- Impulsa, Organización Motiva y Coaching Mejora. Todos los mencionados

brindan el servicio de coaching, mientras que coaching mejora brinda los servicios

de coaching ejecutivo y team building, convirtiéndose en el principal competidor

del presente proyecto. .

\section{Competencia indirecta:}

Dentro de las empresas que ofrecen servicios sustitutos. Este grupo estaría conformado por empresas que brindan servicios de certificación de coaching, team building cursos de liderazgo y desarrollo organizacional para empresas de la ciudad de Arequipa que si bien es cierto aún no brindan los servicios que ofrece nuestro proyecto de negocios pero podrían diversificarse y a futuro ser nuestra competencia. 
Estas empresas cuentan con diversos servicios los cuales se comparan en la tabla 11

(Crece negocios, 2015)

\section{Tabla 11}

Competidores indirectos

\begin{tabular}{ll}
\hline Empresa & Actividad \\
\hline Tecsup & $\begin{array}{l}\text { Institución educativa privada con más de 20 años en Arequipa, dedicad a } \\
\text { formar y capacitar profesionales, así como brindar servicios de Tallere } \\
\text { Coaching ejecutivo y desarrollo organizacional }\end{array}$ \\
$\begin{array}{l}\text { Universidad Católica } \\
\text { San Pablo }\end{array}$ & $\begin{array}{l}\text { Universidad con más de } 8 \text { años en la ciudad de Arequipa que ofrece } \\
\text { certificación Internacional en Coaching }\end{array}$ \\
$\begin{array}{l}\text { Escuela de Negocios } \\
\text { San Francisco Xavier }\end{array}$ & $\begin{array}{l}\text { Escuela de postgrado con más de } 5 \text { años en la ciudad de Arequipa que } \\
\text { ofrece certificación Internacional en Coaching }\end{array}$
\end{tabular}

Nota. Elaboracion propia. "Busqueda de coaching en Arequipa". Tomado de https://www.google.com

\subsubsection{Participación de mercado de cada uno de ellos.}

Para el presente plan de negocios no se cuenta con información detallada del porcentaje de participación de empresas de coaching y team building en el mercado, por lo que se muestra la relación de empresas de Recursos Humanos en la ciudad de Arequipa y Lima, observando el mayor detalle en los anexos 01 y 02. 


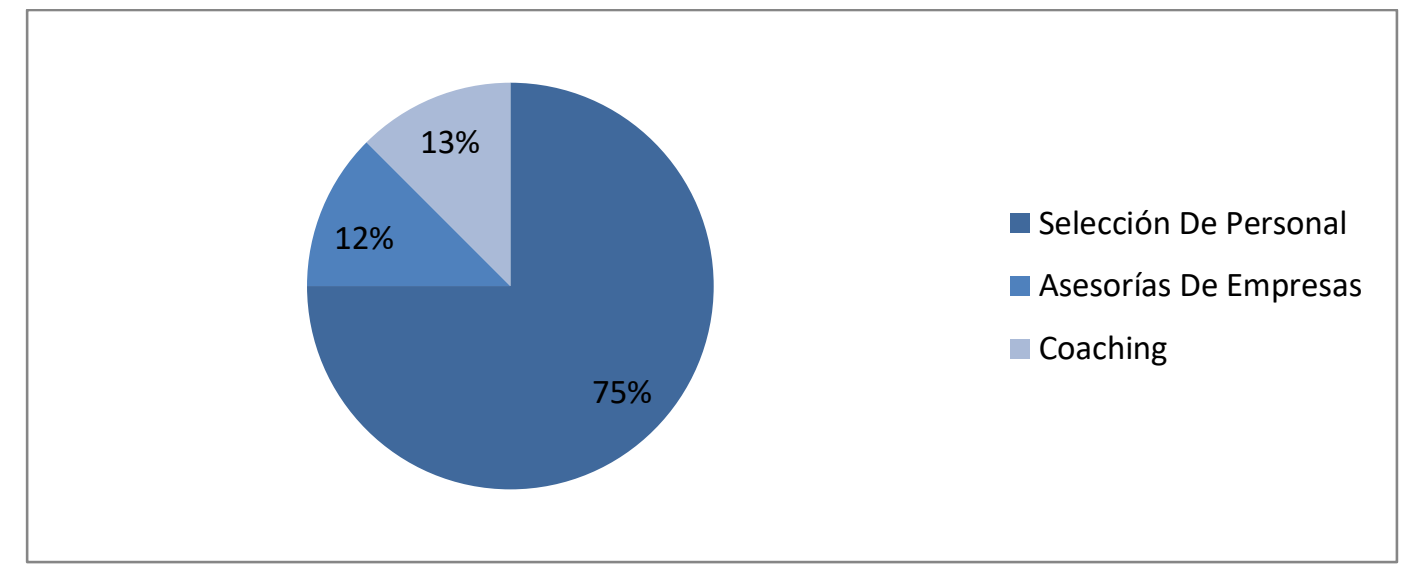

Figura 3. Presencia de empresa de Recursos Humanos Arequipa. Tomado de "Empresas de recursos humanos", 2016. Recuperado de http://www.paginasamarillas.com.pe/b/coaching/

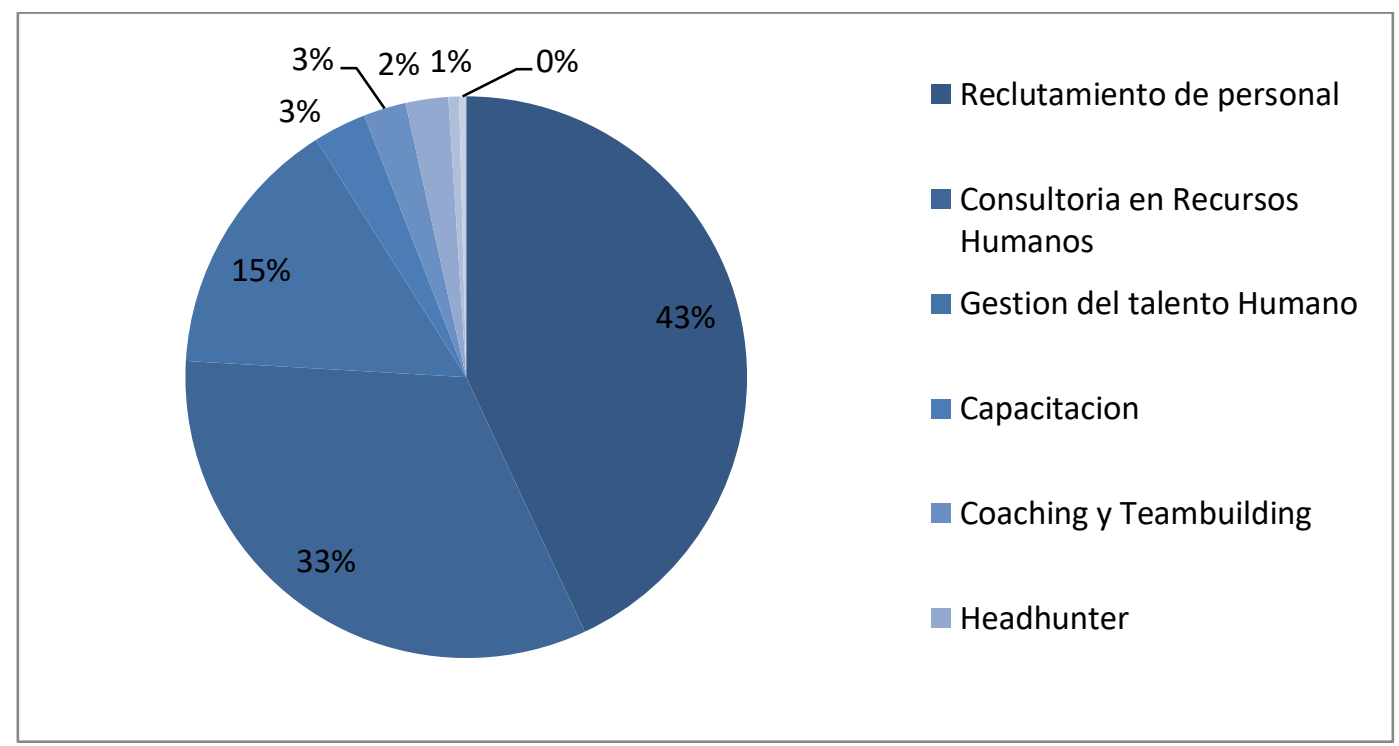

Figura 4. Presencia de empresa de Recursos Humanos Lima. Tomado de "Empresas de recursos humanos en Lima", 2016. Recuperado de hhttp://www.paginasamarillas.com.pe/b/coaching/. 


\subsubsection{Matriz de perfil competitivo.}

La matriz de Kepner muestra fortalezas y amenazas situando a los competidores principales, siendo subjetiva la evaluación de factores y ponderación.

La calificación va del 1 al 4 donde 1 es muy débil y 4 muy fuerte (Kepner, 1992).

Tabla 12

Matriz de perfil competitivo

\begin{tabular}{|c|c|c|c|c|c|c|c|c|c|}
\hline \multirow[t]{2}{*}{ Factores Críticos } & \multirow{2}{*}{$\begin{array}{l}\text { Ponderación } \\
\text { Calificación }\end{array}$} & \multicolumn{2}{|c|}{$\begin{array}{l}\text { Proyecto Intenta } \\
\text { Coaching Ejecutivo }\end{array}$} & \multicolumn{2}{|c|}{ T-Impulsa } & \multicolumn{2}{|c|}{ Latam coaching network } & \multicolumn{2}{|c|}{ Joe Quispe } \\
\hline & & Peso Ponderado & & Calificación & $\begin{array}{l}\text { Peso } \\
\text { Ponderado }\end{array}$ & & Calificación & $\begin{array}{l}\text { Peso } \\
\text { Ponderado }\end{array}$ & \\
\hline $\begin{array}{l}\text { Competitividad de } \\
\text { Precios }\end{array}$ & 0,2 & 2 & 0,4 & 3 & 0,3 & 2 & 0,2 & 2 & 0,2 \\
\hline $\begin{array}{l}\text { Calidad del } \\
\text { servicio }\end{array}$ & 0,3 & 4 & 1,2 & 3 & 0,9 & 2 & 0,6 & 2 & 0,6 \\
\hline Gama de Productos & 0,2 & 4 & 0,8 & 3 & 0,6 & 3 & 0,6 & 3 & 0,6 \\
\hline $\begin{array}{l}\text { Personal } \\
\text { especializado }\end{array}$ & 0,3 & 2 & 0,6 & 3 & 0,45 & 1 & 0,15 & 2 & 0,3 \\
\hline Total & 1,0 & & 3,0 & & 2,25 & & 2,3 & & 2,1 \\
\hline
\end{tabular}

Nota. Matriz del perfil competitivo. Adaptado de "Técnicas participativas de planeación" por Sanchez. G, 2003, México, DF, México: Fundación Ica Copyright 2003 por Fundación Ica. 
En cuanto a la matriz del perfil competitivo, se observa que el proyecto Intenta obtiene la mayor calificación (3), seguido muy de cerca por T-Impulsa (2.95) diferenciándose solo por la gama de productos y al calidad de servicio, factores críticos en los que Intenta obtiene ventaja sobre T-Impulsa.

\subsection{Análisis del contexto actual y esperado}

\subsubsection{Análisis político-gubernamental.}

En estos últimos 10 años, Perú es considerado como uno de los países de América latina con mayor crecimiento económico, reportando un PBI del 5,9\% y un $2.9 \%$ de inflación en promedio. Este crecimiento y baja inflación fueron gracias a un contexto externo favorable, políticas macroeconómicas adecuadas y varias reformas en distintos ámbitos.

Entre los años 2005 y 2015 los índices de pobreza disminuyeron de un $55.6 \%$ a un $21.8 \%$, creciendo la tasa de empleo.

A pesar de la desaceleración que hubo el año 2014, el PBI se fue recuperando para el 2015 incrementando casi un punto porcentual (2.4\% a 3.3\%), uno de los factores que influyeron fueron el incremento de los inventarios (principalmente de cobre) y de las exportaciones (3,3\%). (El Comercio, 2016).

En la ciudad de Arequipa a pesar de la desaceleración que tuvo el país el 2014, en lo que refiere al sector de servicios el PBI muestra un incremento constante año a año lo cual brinda un panorama alentador para los empresarios dedicados a este rubro. 
Tabla 13

Producto Bruto Interno (PBI) del sector servicios

\begin{tabular}{lllllllll}
\hline Departamentos & 2007 & 2008 & 2009 & 2010 & 2011 & 2012 & 2013 & 2014 \\
\hline Arequipa & $2,882,24$ & $3,090,71$ & $3,256,83$ & $3,396,36$ & $3,557,29$ & $3,791,03$ & $3,971,99$ & $4,194,60$ \\
Lima & $44,820,69$ & $47,714,97$ & $48,815,62$ & $52,393,26$ & $55,923,08$ & $59,257,71$ & $63,000,77$ & $67,617,93$
\end{tabular}

Nota. Por el Instituto Nacional de Estadística e Informática, 2014 con información disponible a noviembre de 2015

En lo que respecta al tema de confianza empresarial es la más baja, esto debido a una lenta implementación de algunos proyectos mineros y del bajo dinamismo del sector inmobiliario, la inversión privada se contrajo en un 7,5\%.

Este año 2016 se espera que el crecimiento del Perú sea parecido al 2015 y se vaya recuperando a un ritmo del 3,8\% para los años 2017 y 2018.

No obstante, se espera que para este nuevo gobierno se dé inicio de la fase de producción de grandes proyectos mineros en los próximos dos o tres años así como una mayor inversión en los sectores público y privados del país en proyectos de infraestructura que puedan dar soporte a la demanda agregada, así mismo seguir implementando reformas estructurales que incrementen la confianza de los inversionistas privados. (Banco Mundial, 2016)

Con respecto a los conflictos sociales este 2016 se tienen 212 conflictos registrados en el mes de Junio del 2016, 02 conflictos nuevos en la ciudad de Loreto y Piura, se resolvieron 3 conflictos en los departamentos de Apurímac, 
Huancavelica y La Libertad, las cuales son atendidas por la Defensoría del Pueblo y son todo un desafío para este nuevo gobierno. (Defensoría del Pueblo, 2016).

Tabla 14

Conflictos sociales registrados por mes, Junio 2015-2016 (Número de casos)

\begin{tabular}{lllllllllllll}
\hline 2015 & \multicolumn{10}{c}{2016} \\
\hline Jun & Jul & Ago & Sep & Oct & Nov & Dic & Ene & Feb & Mar & Abr & May & Jun \\
210 & 209 & 213 & 214 & 214 & 215 & 211 & 211 & 208 & 208 & 209 & 212 & 212
\end{tabular}

Nota. Por Defensoría del Pueblo, 2016

Tabla 15

Conflictos sociales, según principal competencia del gobierno, Junio 2016 (Número de casos)

\begin{tabular}{lll}
\hline Nivel de Gobierno & $\mathrm{N}^{\mathrm{o}}$ casos & $\%$ \\
\hline Total & 212 & $100 \%$ \\
Gobiernos nacional & 144 & $67.9 \%$ \\
Gobierno regional & 36 & $17.0 \%$ \\
Gobierno local & 20 & $9.4 \%$ \\
Poder Judicial & 6 & $2.8 \%$ \\
Org. Const. Autónomo & 5 & $2.4 \%$ \\
Poder Legislativo & 1 & $0.5 \%$ \\
\hline
\end{tabular}

Nota. Por Defensoría del Pueblo, 2016 


\subsubsection{Análisis económico.}

Según datos del Instituto Nacional de Estadística e Informática, INEI (2016)

el crecimiento del PBI tuvo una buena evolución debido al crecimiento del consumo final privado en un $4,1 \%$, principalmente por las mayores compras de bienes de consumo de origen nacional; así como, los mayores gastos en consumo del gobierno (12,7\%); contribuyó también el incremento de las exportaciones de bienes y servicios (5,3\%). Contrariamente, la formación bruta de capital fijo se redujo en 2,2\%, debido a la contracción de la inversión privada (-9,2\%), atenuado por el incremento de la inversión pública (29,7\%); en tanto que, las importaciones crecieron en $0,5 \%$.

El gasto de consumo final privado aumentó $(4,1 \%)$ por los mayores ingresos de los hogares, el crecimiento del empleo y la disponibilidad de créditos de consumo de la banca múltiple. El gasto de consumo final del gobierno $(12,7 \%)$ se expandió, por la provisión de mayores servicios de administración pública y defensa.

La inversión bruta fija disminuyó (-2,2\%) por las menores adquisiciones de maquinaria y equipo, tanto de origen nacional como importado, a pesar del incremento en las nuevas construcciones. (INEI, 2016). 
Tabla 16

Oferta y Demanda global trimestral

\begin{tabular}{lllllll}
\hline \multirow{2}{*}{ Oferta y demanda global } & \multicolumn{2}{l}{$2015 / 2014$} & & & & $2016 / 2015$ \\
\cline { 2 - 7 } & I Trim & II Trim & III Trim & IV Trim & Año & I Trim \\
\hline Producto bruto interno & 1.8 & 3.1 & 3.2 & 4.7 & 3.3 & 4.4 \\
Extractiva & 3.1 & 6.7 & 7.9 & 11.7 & 7.4 & 11.4 \\
transformación & -5.6 & -2.7 & -3.8 & -0.2 & -3 & -1.4 \\
Servicios & 4.9 & 4.9 & 4.8 & 5.1 & 4.9 & 4.8 \\
Importaciones & -1.4 & -2.4 & 0.6 & -0.2 & -0.8 & 0.5 \\
Oferta y demanda global & 1.1 & 1.9 & 2.7 & 3.7 & 2.4 & 3.6 \\
Demanda interna & 2 & 2.6 & 2.9 & 2.7 & 2.5 & 3.2 \\
Consumo final privado & 3 & 3.4 & 3.6 & 3.6 & 3.4 & 4.1 \\
Consumo de gobierno & 3.2 & 6.9 & 5.1 & 7.5 & 5.8 & 12.7 \\
Formación bruta de capital & -0.9 & -0.8 & 0.6 & -1.5 & -0.7 & -3 \\
Formación bruta de capital fijo & -7.8 & -8.8 & -6.4 & -3.6 & -6.6 & -2.2 \\
Exportaciones & -2.3 & -1.1 & 1.5 & 8.4 & 1.6 & 5.3 \\
\hline
\end{tabular}

Nota. Del Instituto Nacional de Estadística e Informática, 2016

En el sector servicios actualmente existe un crecimiento de $4,8 \%$, siendo resaltantes la producción de electricidad, gas y agua (10,6\%), los servicios financieros, seguros y pensiones $(8,8 \%)$ y las telecomunicaciones y otros servicios de información $(7,7 \%)$. 


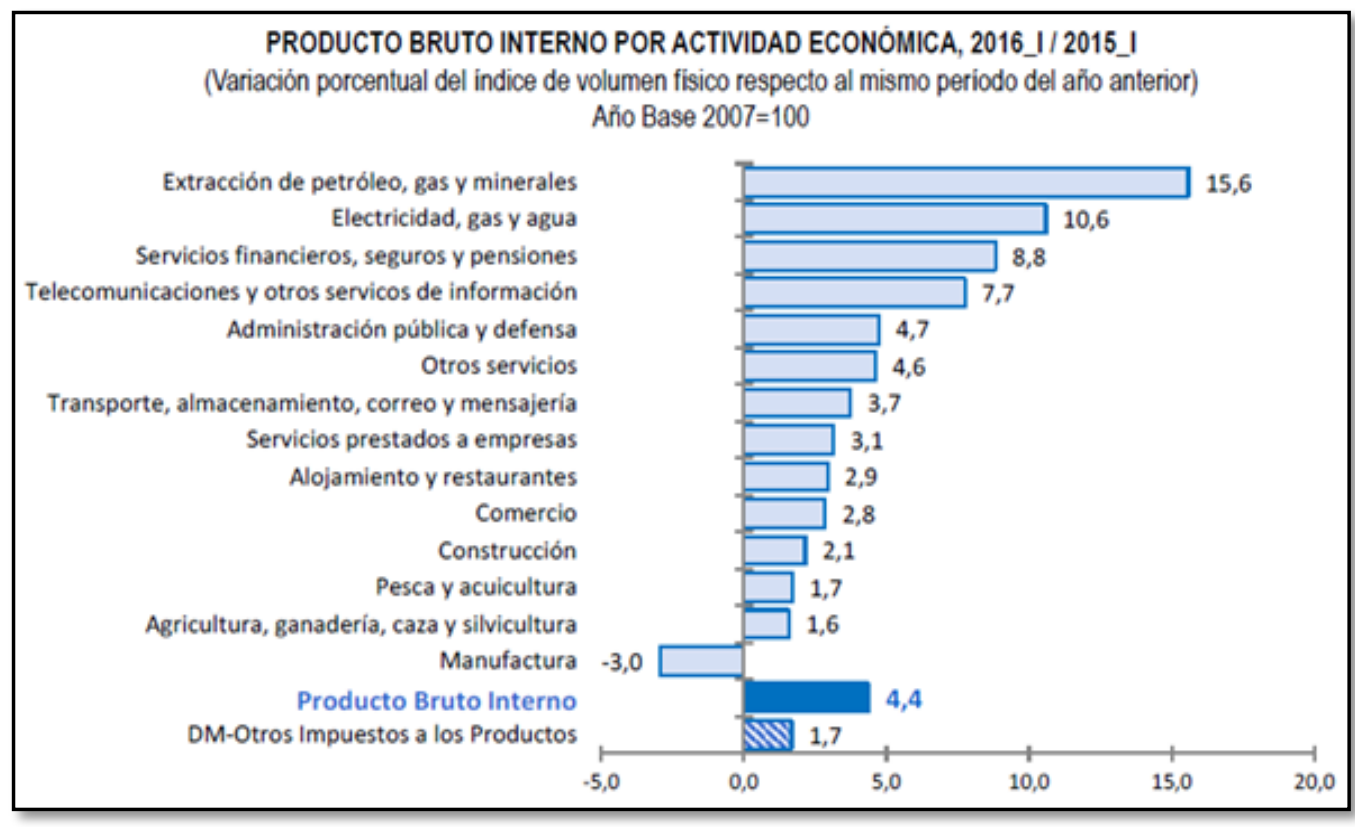

Figura 5. Producto bruto interno por actividad económica por el Instituto Nacional de Estadística e Informática, 2016.

El valor agregado bruto del primer trimestre del 2016 a precios constantes de 2007, de la actividad otros servicios creció en 4,6\% respecto al mismo período del año anterior. El incremento de esta actividad se explica por el favorable desempeño de las actividades: educación $(5,4 \%)$, servicios mercantes y no mercantes prestados a los hogares $(5,3 \%)$ y salud $(5,2 \%)$. La actividad otros servicios está conformada por: servicios inmobiliarios, alquiler de vivienda, educación, salud, servicios sociales, asociaciones u organizaciones no mercantes, arte entretenimiento y esparcimiento, reparación de computadoras y enseres de uso personal y otras actividades de servicios personales.

Para el cálculo del valor agregado de estas actividades, las principales fuentes de información estadística son: el Sistema Integrado de Administración Financiera (SIAF) y la Encuesta Nacional de Hogares (ENAHO). 
Tabla 17

Valor Agregado Bruto sector servicios

OTROS SERVICIOS: VALOR AGREGADO BRUTO

(Variación porcentual del índice de volumen físico respecto al mismo periodo del año anterior)

Valores a precios constantes de 2007

\begin{tabular}{lllllll}
\hline \multirow{2}{*}{$\begin{array}{l}\text { Actividades } \\
\text { 2015/2014 }\end{array}$} & & & \multicolumn{2}{c}{ 2016/2015 } \\
& I Trim & II Trim & III Trim & IV Trim & Año & I Trim \\
\hline Otros servicios & 4.5 & 5.0 & 4.1 & 4.2 & 4.4 & 4.6 \\
\hline
\end{tabular}

Nota. Por Instituto Nacional de Estadística e Informática, 2016.

Si bien es cierto se pasa una etapa de crecimiento económico, es importante tener en cuenta que, existen factores externos e internos que podrían impactar en el crecimiento económico como:

1. Externos.

- La desaceleración económica en China, uno de los socios comerciales, lo que podría afectar en la baja de los precios de materias primas.

- El ajuste monetario de Estados Unidos que podría causar un periodo de volatilidad financiera.

2. Internos.

- La lenta implementación de programas de inversión pública y privada.

- El Fenómeno de El Niño y el impacto que causa en nuestra economía

- La capacidad del nuevo gobierno para seguir implementando reforma estructurales para incrementar la productividad y competitividad nacional (Banco Mundial, 2016). 


\subsubsection{Análisis legal.}

El 2016 inició con el nuevo marco legal para las Asociaciones público privadas (APP), dándole una mayor participación en sus funciones al Ministerio de Economía y Finanzas (MEF), lo cual también significa que para que los nuevos proyectos sean aprobados deberán pasar por más trámites y filtros, ya que el MEF deberá emitir opiniones sobre las versiones finales de los contratos de APP y debe revisar los proyectos antes de que sean lanzados al mercado aunque estas sean iniciativas privadas autofinanciadas. (El Comercio, 2016)

\subsubsection{Análisis cultural.}

El crecimiento del país en lo que refiere al entorno empresarial hace que estas den importancia a contar con ejecutivos que se encuentren preparados y retenerlos en sus empresas para ayudarlos a tener línea de carrera. Hoy en día las empresas saben que no es suficiente con tener personal preparado académicamente sino además que sus habilidades de gestión sean potenciales.

Esta nueva óptica hace que las organizaciones entiendan y valoren el invertir en sus líderes y además tener un buen clima laboral, en este punto el coaching es una tendencia estos últimos años, por ende la inversión en capacitación, coaching ejecutivo, team building y temas de liderazgo va en ascenso en las empresas a nivel de Latinoamérica.

En Perú actualmente varias empresas recurren principalmente al coaching para mejorar las habilidades blandas de sus ejecutivos para que así puedan estar preparados a asumir desafíos que se vayan presentando en su trabajo 
Según una encuesta realizada por la empresa DBM en Perú (empresa internacional especializada en coaching ejecutivo, outplacement) dio como resultado que el 33\% de los ejecutivos le dedican menos de una hora al mes al desarrollo de líderes en sus respectivas organizaciones y que el $41 \%$ le brinda a esta actividad entre uno a cinco horas, lo cual significa que los jefes aún no están muy enfocados en desarrollar la habilidades de gestión de su personal, esta encuesta también se pudo verificar que un buen porcentaje de ejecutivos peruanos no tenían un buen desempeño esto debido a factores como la incapacidad de poderse adaptar en su organización como consecuencia de no existir una buena comunicación interna, el no poder apartarse a situaciones de cambio y la mala interrelación con los demás miembros de su organización. (El Portal del Capital Humano, 2010)

Otra nueva tendencia estos últimos años es el concepto de Clima Organizacional. Ya existen muchos aportes e investigaciones sobre el comportamiento organizacional que va tomando mayor importancia en las empresas que buscan una mejora en el ambiente de su organización de manera continua y así lograr un incremento de su productividad. Una de las más importantes en este tema es la asociación Great Place To Work que presentó su $13^{\circ}$ Ranking Anual "Las Mejores Empresas para Trabajar en América Latina edición 2016”, donde 24 empresas del Perú se encuentran en el ranking. En la categoría de Empresas Nacionales que cuentan entre 50 y 500 colaboradores, el primer lugar lo obtuvo la empresa peruana Visanet cuyo gerente general, Diego Conroy, dijo deberse al compromiso que tienen sus colaboradores con la cultura corporativa y de programas 
que buscan desarrollar las capacidades, potenciar el talento de los colaboradores así como programas que ofrecen beneficios en favor de sus familias.

Perú este 2016 es considerado el tercer país de la región con más empresas reconocidas por el Great Place to Work, Liderman fue otra de las empresas premiadas en la categoría de Empresas Nacionales con más de 500 colaboradores.

Otra empresa peruana premiada es COFIDE que alcanzó el puesto 16 este año después de haber sido puesto 26 el año pasado. Otra firma en el Perú de ascenso importante fue DHL Express que llegó al puesto seis desde el 22.

Entre las multinacionales que están el Perú, junto a DHL Express, destacaron también Atento y Belcorp por ser las únicas empresas de sus rubros en ser premiadas. Las nuevas filiales peruanas en ingresar al ranking fueron British American Tobacco, Diageo, Hilton, Mapfre, Natura y Oracle.

Great Place to Work destacó también que el Grupo Falabella en Perú estuvo representado por tres empresas (Hipermercados Tottus, Saga Falabella y Sodimac), mientras que el Grupo Intercorp tiene empresas en la lista desde 2004 con Interbank, incorporándose luego Cineplanet e Interseguro desde el 2008, Supermercados Peruanos desde el 2010 y Real Plaza desde el 2012 (El Comercio, 2016)

El análisis anterior muestra que un adecuado clima organizacional en el que se desenvuelven los colaboradores es directamente proporcional a su desempeño en el trabajo razón por la cual se convierte en un nuevo pilar estratégico para las empresas. 
Según el especialista brasileño en estrés laboral, Ruddy Facci, las pérdidas para las empresas son de US\$2,800 por cada trabajador al año, lo que ha podido ser confirmado en diversos estudios realizados en varias partes del mundo. (Gestión, 2014).

\subsubsection{Análisis tecnológico.}

En el país alrededor del 70\% no tiene una página web, lo cual se muestra como una oportunidad para desarrollo y mejoras, el Perú escalo diez posiciones y ahora es puesto 90 en el ranking mundial tecnológico. (Sociedad Nacional de Industrias, 2015)

Inicialmente el área de RR.HH. planteó la necesidad de que los empleados tuvieran acceso a su carpeta personal para poder realizar modificaciones de datos personales tales como cambios de domicilio, títulos obtenidos y cursos finalizados, solicitud de fecha de vacaciones, etc., estos cambios las podía hacer el mismo colaborador desde su propia maquina; actualmente, se puede acceder a la carpeta personal en forma remota y desde cualquier dispositivo móvil con conexión a Internet.

Las nuevas maneras de comunicarse a nivel en una organización son variados desde e-mails de trabajo que se envía por celular hasta mensajes por Whatsapp de grupos de trabajo, redes sociales como Facebook, Twitter, etc. llamadas sin costo, a través de los cuales coordinan reuniones y organizan eventos. Y todos los estratos de la organización deben actualizarse y aprovechar los beneficios de esta nueva manera de estar en contacto entre directivos y empleados así como entre pares. 
Todas estas nuevas formas de comunicación dentro de las organizaciones son mucho más que una moda en RR.HH. ya que cambia el paradigma de la comunicación, la interrelación y la forma de trabajar en las organizaciones.

Asimismo, se puede compartir información, conocimientos, capacitaciones más entretenidas, mensajes lúdicos que despierten el interés en el equipo de trabajo.

Para maximizar las ventajas de la Gestión electrónica de los Recursos Humanos debe haber compromiso y convencimiento por parte de los gerentes y directivos, de lo contrario no se explota al máximo su capacidad. (Gestión, 2016).

Hoy en día es bastante útil la gestión electrónica de los Recursos Humanos, el crecimiento económico y las nuevas tecnologías de información hacen que sea necesario el uso de nuevas herramientas que permitan el gerenciamiento de los Recursos Humanos de manera electrónica de manera sistematizada en la mayoría de los casos. Así podemos ver que actualmente se usan estas nuevas tecnologías en muchos casos como la Gestión electrónica de los Recursos Humanos (eHRM) para atracción de talento, capacitación, planificación estratégica de la plantilla y gestión de competencias. Esta herramienta de eHRM genera mayor información para la toma de decisiones, sirve tanto para ahorrar costos como para reforzar el papel del área de RR.HH. en su rol de asesor, como aliado de negocios.

El líder del área de Recursos Humanos hoy es asesor del resto de los sectores, por eso siempre debe tener una clara visión de lo que requiere el negocio, lo que permitirá extraer la información adecuada y agregar valor en sus conclusiones. 
Es fundamental que el nivel directivo/gerencial esté convencido y comprometido con la nueva forma de gestionar el capital humano.

Permite que los líderes de RR.HH. cuenten con mayor tiempo para poder trabajar de manera más estratégica.

Las herramientas de Gestión electrónica de los Recursos Humanos, para altas y bajas de personal, nóminas y datos personales, comienzan a ser utilizadas para atracción de talento, gestión de competencias, cuadro de reemplazos, ascensos, etc. (Gestión, 2016)

\subsubsection{Análisis ecológico.}

Hoy en día no se puede considerar a una empresa como "socialmente responsable" si su departamento de recursos humanos no cumple con cuidar del capital humano que administra, de sus stakeholders y del medio ambiente.

La responsabilidad social tiene que ver con su principal cliente, el empleado y los stakeholders de la empresa, especialmente clientes y proveedores.

Colaboradores que se encuentren frustrados y estresados atenderán de manera negativa a sus clientes los cuales tomarán la decisión de preferir a nuestra competencia afectando la rentabilidad, lo cual no es más que una mala gestión interna por parte de sus ejecutivos. (Moreno, 2014).

Es importante contar con un entorno laboral saludable para el medioambiente, los ambientes de trabajo productivos generan desperdicios y es importante crear una cultura sobre temas como el reciclado de papel, ahorro de energía, la prohibición de fumar en la empresa, el uso de elementos biodegradables 
para la limpieza, incluso de ser posible proponer la separación de desperdicios en orgánicos, vidrio y papel. Todas estas medidas medioambientales hablan de una empresa responsable con sus colaboradores y con el medio ambiente.

Además de todo lo antes mencionado es importante fomentar las relaciones con la comunidad, promoviendo entre los empleados colectas de ropa o libros para hacer donaciones a instituciones que lo necesiten así como también dar unas horas para poder ayudar a los menos favorecidos a aprender oficios. Organizar visitas guiadas con estudiantes de diferentes niveles a las oficinas y/o fábricas. Difundir a la prensa programas y acciones que lleva a cabo el departamento (como por ejemplo capacitaciones, acuerdos con universidades, RSE, etc.) ayuda a forjar lazos perdurables en el tiempo con la comunidad. (Los Recursos Humanos, 2009)

\subsection{Oportunidades y amenazas}

\section{Oportunidades}

- El Perú es uno de los países de Latinoamérica con mayor crecimiento económico y con baja inflación.

- La ciudad de Arequipa presenta un incremento constante del PBI en el sector de servicios.

- Mayor inversión en los sectores públicos y privados del país gracias al cambio de Gobierno.

- Incremento de las exportaciones de bienes y servicios.

- Crecimiento en el sector de servicios.

- Nuevo marco legal para las Asociaciones público privadas con mayor participación del Ministerio de Economía y Finanzas. 
- Mayor importancia al desarrollo de habilidades blandas en los altos mandos.

- Aparición de nuevas tendencias como el Clima Organizacional.

- Desarrollo de Tecnología de Información en el Perú mejor posicionado.

- Mayor dinámica de comunicación entre empresas a nivel tecnológico.

2. Amenazas

- Baja confianza empresarial debido a que existe una lenta implementación en proyectos mineros y bajo dinamismo del sector inmobiliario.

- Los conflictos sociales han ido en incremento hacia finales del 2016.

- Infraestructura inadecuada a nivel nacional por las redes y comunicaciones. 


\section{Capítulo III: Estudio de mercado}

Un estudio de mercado lleva a cabo un desarrollo que comprende en reunir información, guiarla, analizarla y entenderla para derivarlo a las personas que tomaran un decisión (Hair, Bush \& Ortinau, 2010).

Teniendo en cuenta que la empresa consultora de coaching y team building es un modelo de negocio $\mathrm{B} 2 \mathrm{~B}$, se realizará la recolección de datos cuantitativos y cualitativos que nos ayudaran a descubrir el grado de entendimiento y uso de la herramienta del coaching ejecutivo y team building en las empresas de la ciudad de Arequipa.

La finalidad de realizar el análisis del mercado es encontrar y dar valor a las oportunidades que se presenten; por lo cual se buscará reunir información del mercado para poder anticiparse a los cambios. Regularmente en la recolección de información aparecen tres métodos:

1. Análisis de contenidos, que toma bases de datos, artículos, publicaciones o hasta información académica para conocer una tendencia.

2. Entrevistas exhaustivas, formales y estructuradas que realizan a los especialistas de un campo.

3. Procedimientos de calificación, utilizando cuestionarios estructurados para conocer lo que pasa en el medio. (Hair, et al., 2010)

\subsection{Descripción del servicio o producto}

Se eleva la atención a los servicios por su incremento en importancia a nivel global. Los servicios son en conjunto actividades, beneficios o satisfacciones brindados en venta, 
son intangibles y no tienen como resultado alguna propiedad física (Kotler \& Armstrong, 2012).

El presente plan de negocios está enfocado en la creación de una Empresa en la ciudad de Arequipa que brinde servicios de consultoría y asesoría mediante coaching y team building. El nombre propuesto para esta empresa es Intenta coaching y team building.

Esta empresa brindará un servicio personalizado mediante el cual ayudará a empresas de diferentes rubros a aprovechar al máximo el talento y potencial profesional de sus colaboradores a través del uso y manejo de herramientas poderosas que presenta el coaching ejecutivo y team building. Esta labor tendrá como resultado un incremento en la motivación, compromiso y rendimiento del personal de forma consecuente, una mayor rentabilidad para dichas empresas.

A continuación, se detallará la cartera de servicios que se brindarán a través del Coaching ejecutivo y team building.

\section{Programa Líder Coach:}

El término Líder proviene del inglés leader, y hace referencia a conducir o guiar La innovación es un medio por el cual se propaga el cambio y es una estrategia competitiva muy importante (Goleman, 2014).

Objetivo: Desarrollar las habilidades para el ejercicio de un nuevo liderazgo, sustentado en las competencias de un Coach.

Duración: 3 a 4 meses; 24 a 32 horas de formación (puede incluir sesiones de coaching grupal e individual)

Publico meta: Directores, gerentes, mandos medios. 
Ejes temáticos: Liderazgo, competencias conversacionales, pensamiento sistémico, desarrollo de equipos, mejora del desempeño.

Con este servicio se busca sentar las bases de los conceptos de cambio, aprendizaje, acciones reactivas y proactivas, zona de confort e innovación.

Este programa busca que el ejecutivo aprenda a liderar dirigiendo, asumiendo una responsabilidad dentro de un equipo de trabajo. Se generará la toma de conciencia animando, motivando y cuidando a cada miembro del equipo y a uno mismo.

Con este programa el ejecutivo se llevará herramientas para liderar desde el ser y no desde el hacer, aprenderá a escuchar y resolver las inquietudes de los clientes internos y externos potenciando acciones eficientes tales como el respeto, compromiso y aprendizaje continuo.

\section{Coaching de Equipos Comercial}

El coaching de equipos consiste en mejorar el rendimiento para sacar el máximo potencial de cada miembro del equipo (Whitmore, 2015).

Objetivo: Desarrollar competencias para que los lideres sean capaces de observarse y observar la organización, los equipos y sus prácticas de manera diferente y con ello puedan invertir de manera más efectiva.

Duración: 3 a 4 meses; 24 a 32 horas de formación

Público Meta: Equipos comerciales de cualquier rubro, equipos gerenciales, equipos de atención al cliente.

Ejes temáticos: Procesos de formación de equipos, conversaciones poderosas de equipos, caos de equipos, alineación de equipos. 
Este programa permitirá incrementar la interacción existente entre los miembros del equipo estableciendo así una comunicación interna fluida y positiva entre las diferentes áreas de la organización.

3. Desarrollo de competencias organizacionales

Feedback es una palabra en inglés que significa retroalimentación, es subjetivo y descriptivo, brinda el éxito y motivación en los equipos de trabajo y a su vez incita a sacar todo el talento dentro de la organización (Whitmore, 2015).

Objetivo: Desarrollar competencias conversacionales de los líderes relativas a los diversos tipos de conversaciones que existen.

Duración: 2 a 3 meses; 16 a 24 horas de formación

Publico meta: Todo nivel.

Ejes temáticos: Tipología de conversaciones, la escucha, el habla, el arte de indagar, re encuadrar e interpretar, percepción de escucha, la danza de la comunicación, etc.

Este programa permitirá al ejecutivo aprender a dar y recibir un feedback poderoso para acompañar a los miembros del equipo en su crecimiento personal y profesional.

4. Team Building Estratégico organizacional

Fomenta las relaciones personales y refuerza el espíritu de equipo lo cual ayudará a tener un mejor desempeño por parte del personal. Se desarrollarán Team Building que estén orientados a alcanzar los objetivos empresariales que propongan los altos directivos de las empresas a asesorar.

Objetivo: Incrementar la efectividad de equipos directivos y gerenciales, mediante la mejora en las prácticas de coordinación, colaboración. 
Duración: 2 a 3 meses

Publico meta: Gerencias, Jefaturas, equipos comerciales, todo nivel.

Ejes temáticos: Construir equipos de alto rendimiento, la teoría de los equipos en la organización, metodología de Coaching de equipos,etc..

\section{Team Building Solidario}

Se trabajará con diferentes organizaciones no gubernamentales (ONG) de la ciudad de Arequipa para que estas puedan colaborar y vivir una jornada distinta de trabajo en equipo. El objetivo central será que las organizaciones vivan la satisfacción de ayudar al prójimo y puedan valorar el día a día.

6. Desarrollo de competencias conversacionales

El poder de las conversaciones en las organizaciones influye de manera positiva en el desarrollo de una cultura organizacional transformadora (Whitmore, 2015).

Objetivo: Desarrollar competencias conversacionales para que los lideres sean capaces de detectar oportunidades de mejora entre las áreas para construir estrategias internas.

Duración: 3 a 4 meses; 24 a 32 horas de formación Publico meta: directores, Gerentes y Jefaturas de área.

Público Meta: directores, gerentes.

Ejes temáticos: Liderazgo sistémico, pensamiento sistémico, teoría de la presencia, neurociencias aplicadas al liderazgo.

Este programa permitirá incrementar la interacción existente entre los miembros del equipo estableciendo así una comunicación interna fluida y positiva entre las diferentes áreas de la organización. 


\section{Actividades personalizadas}

Juegos de aprendizaje en donde los colaboradores de la organización aprenderán y se alinearán a las estrategias planteadas por el área de Recursos Humanos.

\subsection{Selección del segmento de mercado}

Existen diferentes tipos de estudios para el análisis e identificación de los segmentos de mercado, su finalidad es obtener gran cantidad de información del comportamiento de los clientes, preferencias y beneficios. Junto a información básica como la edad, se elaboran perfiles para el entendimiento de las características del consumidor (Hair, et al, 2010).

Considerando las variables de análisis a nivel general de la empresa, se ha visto por conveniente mantener una focalización en los mercados urbanos de la ciudad de Arequipa, principalmente de zonas industriales predominantes en empresas medianas, grandes y pequeña empresa.

Es importante enfatizar en la comunicación y articulación de acciones para empresas de diferentes rubros de la ciudad de Arequipa con más de tres años de experiencia en el mercado y cuyo número de colaboradores sea de veinte personas a más, esto engloba mediana, gran empresa y pequeña empresa.

Cabe resaltar, de acuerdo a lo expuesto anteriormente, que la estrategia de segmentación del presente plan de negocios no debe ser rígida ni general, debido a la pluralidad de las diversas zonas de intervención, por lo cual se ha realizado en el plan de negocios una segmentación detallada acorde a la demanda. Las variables adecuadas de segmentación seleccionadas son:

1. Sector económico: 
Focalización en actividades por rubro seleccionado, sin dejar de lado actividades tales como empresas de agricultura, minería y pecuario.

En cuanto a transporte, hotelería y construcción, se le debe prestar cierta atención ya que son actividades que comienzan a tener mayor presencia en las zonas de intervención de la empresa.

2. Tipo de zona Geográfica:

Empresas enfocadas en áreas urbanas, principalmente en aquellas que poseen cierto grado de concentración industrial ya que esto permitirá generar ciertas barreras de entrada a potenciales competidores.

3. Demográfica:

Los segmentos con mayor receptividad ante los servicios de Coaching ejecutivo y Team building, son aquellos que se encuentran entre los rangos de medianas, grandes y pequeña empresa con un número de 20 empleados a más; ya que entre estos rangos se puede encontrar mayor experiencia en la actividad de recursos humanos y se desarrollan de igual forma en mayor amplitud de opciones a la hora de recibir estos servicios.

Para este plan de negocio se ha considerado las principales empresas de la ciudad de Arequipa de los diferentes rubros con más de tres años de experiencia en el mercado y cuyo número de colaboradores es de 20 personas a más. Según la Cámara de Comercio de Arequipa se considera sólo a 720 empresas que cumplen estos requisitos. 
Tabla 18

Segmentación por sectores

\begin{tabular}{|c|c|}
\hline \multicolumn{2}{|c|}{ EMPRESAS AREQUIPA } \\
\hline SECTOR & CANTIDAD DE EMPRESAS \\
\hline SERVICIOS & 522 \\
\hline Industriales & 65 \\
\hline Textiles & 15 \\
\hline Turismo & 110 \\
\hline Financieras & 25 \\
\hline Transporte & 117 \\
\hline Telecomunicaciones & 7 \\
\hline Clínicas de salud & 20 \\
\hline Farmacéutico & 15 \\
\hline Publicidad & 55 \\
\hline Audio y video & 6 \\
\hline Asesoría y consultoría & 20 \\
\hline Automotriz & 19 \\
\hline Organización de eventos & 32 \\
\hline Seguros & 16 \\
\hline MANUFACTURA & 109 \\
\hline Textiles & 10 \\
\hline Alimentos y Bebidas & 21 \\
\hline Constructoras & 25 \\
\hline Cementeras & 2 \\
\hline Aceros y metales & 7 \\
\hline Mineras & 14 \\
\hline Agroindustria & 30 \\
\hline COMERCIO & 89 \\
\hline Retail & 12 \\
\hline Bebidas & 10 \\
\hline Exportadoras & 50 \\
\hline Tecnologías de Información & 17 \\
\hline TOTAL & 720 \\
\hline
\end{tabular}

Nota: Adaptado de "Cámara de Comercio de Arequipa”, 2016. 


\subsection{Investigación cualitativa}

Esta investigación se ha considerado de menor confianza que la cuantitativa, a pesar de que la recaudación y análisis de datos es bastante cuidadosa. La investigación cualitativa es un trabajo de entendimiento al participante, no de acomodar respuestas en un texto que deja poco margen para la explicación de las mismas. Es común ver que después de este procedimiento haya una investigación cuantitativa para validar los resultados obtenidos

Algunas herramientas de investigación cualitativa son las siguientes: (a) entrevista a profundidad, (b) investigación en grupos de enfoque, (c) estudio de casos, (d) entrevistas a expertos (e) entrevista de protocolo, y (f) entrevistas articuladoras. (Hair, et al., 2010).

En el plan de negocios se empleó la técnica de entrevista a expertos, según Hair et al. (2010), se usa para averiguar un asunto determinado mediante personas que conocen del tema que se quiera investigar. Para el presenta plan de negocios son personas con amplia experiencia en las áreas de Coaching, Team building y Recursos Humanos, las cuales se muestran en detalle en el Anexo 03 y 04.

\subsubsection{Proceso de muestreo.}

Se utilizó el muestreo no probabilístico por el método de juicio o conocimiento del investigador, porque permitirá consolidar criterios de especialistas en los temas de los que se requiere testimonio, determinándose los siguientes objetivos:

Objetivo general: Investigar sobre la importancia del uso del coaching ejecutivo y team building y si son usadas como herramientas en el área de recursos humanos 
para solucionar y/o mejorar temas relacionados a su talento humano de las empresas.

Objetivos específicos:

1. Identificar las características de las empresas que contratan los servicios que ofrece el plan de negocios

2. Conocer de la industria de recursos humanos en el mercado de Arequipa.

3. Conocer de la importancia del coaching ejecutivo y team building en la ciudad de Arequipa.

4. Conocer el aporte del coaching ejecutivo y team building en la rotación del personal

5. Determinar los factores que influyen en el desempeño de personal dentro de las organizaciones.

6. Identificar los factores principales por el que existe fuga de talentos dentro de las organizaciones.

7. Conocer las expectativas de las empresas con respecto al servicio que ofrece el plan de negocios

Para el presente plan de negocios se vio la necesidad de conocer información actual sobre el coaching ejecutivo, team building y recursos humanos, por ello se consideró realizar tres entrevistas a especialistas dirigida a Jefes y Gerentes de las áreas de Recursos Humanos, cuyas edades oscilan entre 30 a 55 años de edad con más de cinco años de experiencia laboral. Para mayor detalle se definen a continuación los perfiles de los expertos a entrevistar: 
Tabla $\mathrm{N}^{\mathrm{o}} 19$

Perfil de participantes para la entrevista a expertos

\begin{tabular}{|c|c|c|c|}
\hline & Perfil $N^{\circ} 1$ & Perfil $N^{\circ} 2$ & Perfil $\mathbf{N}^{\mathbf{o}} 3$ \\
\hline Profesión & $\begin{array}{l}\text { Marketing, Ingeniería } \\
\text { Industrial, Psicología, } \\
\text { Administrador de } \\
\text { empresas, Ingeniería } \\
\text { Comercial, entre otras } \\
\text { carreras. }\end{array}$ & $\begin{array}{l}\text { Ingeniería industrial, } \\
\text { psicología, administrador } \\
\text { de empresas, ingeniería } \\
\text { comercial o carreras } \\
\text { afines. }\end{array}$ & $\begin{array}{l}\text { Ingeniería industrial, } \\
\text { psicología, administrador } \\
\text { de empresas, ingeniería } \\
\text { comercial o carreras } \\
\text { afines. }\end{array}$ \\
\hline $\begin{array}{l}\text { Grado de } \\
\text { instrucción }\end{array}$ & $\begin{array}{l}\text { Maestría en coaching } \\
\text { ejecutivo, certificado por } \\
\text { la Federación } \\
\text { Internacional de coaching, } \\
\text { que sea un trainer coach } \\
\text { acreditado. Además de } \\
\text { tener certificación en } \\
\text { programación } \\
\text { neurolingüística }\end{array}$ & $\begin{array}{l}\text { Maestría en Gestión del } \\
\text { talento humano }\end{array}$ & $\begin{array}{l}\text { Maestría en Gestión del } \\
\text { talento humano }\end{array}$ \\
\hline $\begin{array}{l}\text { Experiencia } \\
\text { laboral }\end{array}$ & $\begin{array}{l}\text { Director académico de } \\
\text { alguna universidad o } \\
\text { escuela de negocios, con } \\
\text { más de } 10 \text { años en } \\
\text { coaching ejecutivo, team } \\
\text { building }\end{array}$ & $\begin{array}{l}\text { Mínimo } 7 \text { años de } \\
\text { experiencia en puestos } \\
\text { referidos a recursos } \\
\text { humanos, con más de } 3000 \\
\text { personas a cargo en } \\
\text { puestos de gerencia de } \\
\text { recursos humanos. }\end{array}$ & $\begin{array}{l}\text { Mínimo } 5 \text { años de } \\
\text { experiencia en puestos } \\
\text { referidos a recursos } \\
\text { humanos, con más de } 200 \\
\text { personas a cargo, con } \\
\text { puestos de jefatura. }\end{array}$ \\
\hline
\end{tabular}

Nota. Adaptado de las guías de entrevista a expertos (anexos 3 y 4 )

\subsubsection{Diseño de instrumento.}

Se crearon guías de entrevista (Ver anexos 5 y 6) aplicadas a los especialistas.

Las entrevistas se pueden dividir en tres partes, la primera que incluye los datos del participante, día, lugar y hora de la entrevista, la segunda parte que tiene una breve reseña del experiencia que tiene el experto y donde se indica el tema que 
se quiere abordar y la tercera parte que contiene que consta de 05 preguntas semiestructuradas acerca de lo que se quiere investigar.

\subsubsection{Análisis y procesamiento de datos.}

Gracias a los avances de la tecnología, el análisis y procesamiento de datos en lo referente a investigación de mercados, se realiza de manera más rápida, productiva y eficiente. Estos nuevos métodos de investigación, brindan muchos beneficios en la recolección e informe de datos, siendo más sencillo el procesamiento y análisis de los mismos (Hair, et al., 2010).

Las guías de preguntas de entrevistas a expertos fueron aplicadas, obteniéndose lo siguiente:

1. La experta en coaching ejecutivo indica que el coaching ejecutivo es una herramienta poderosa que ayuda a los colaboradores de una empresa a trabajar en equipo, fomentar el aprendizaje, el liderazgo y liberar su potencial. Por otro lado, esta misma especialista indica que el team building ayuda a las organizaciones con actividades de trabajo en equipo y cohesión entre los colaboradores, dentro de los beneficios que nos resalta la experta menciona la motivación en el personal, refuerza el autoestima de los colaboradores, mejora las relaciones entre el directivo y jefaturas, desarrollo el potencial de la gente en el trabajo. Menciona además que para requerir de estos servicios las empresas no deben necesariamente contratar el servicio cuando tienen problemas, ya que el coaching ejecutivo y team building también sirven para mejorar varios aspectos como por ejemplo cuando algún empleado merece ser felicitado o cuando algún colaborador clave debe de mejorar alguna destreza en el trabajo, 
cuando se busca construir equipos sólidos y la mejora de la comunicación y confianza entre los equipos de trabajo.

2. La experta en Recursos Humanos, nos menciona que actualmente en el Perú tiene las más altas tasas de rotación de personal en las empresas, ya que el promedio normal es de 4\%, estando el sector retail en un $10 \%$ de rotación. Los motivos por los que un empleado decide cambiar de trabajo no necesariamente es por un mejor sueldo. La experta indica que existen otros motivos como la falta de motivación, falta de línea de carrera y mala comunicación con el jefe inmediato. Actualmente la experta trabaja con coachs ejecutivos y programas de team building para temas específicos como toma de decisiones, trabajo en equipo, compromiso, amor a la marca, productividad.

La experta menciona en la entrevista que en las sedes que tienen en provincias, no aplican mucho de estas herramientas debido a los costos que genera enviar toda la logística de Lima. Este problema se debe a que no conocen empresas confiables en Arequipa que den dicho servicio. Actualmente el coaching ejecutivo y team building son considerados dentro de las políticas de recursos humanos, incluso ya los tienen programados en su plan anual, los temas a mejorar son de acuerdo a los resultados de la evaluación de 360 grados que aplican. Finalmente indica que hace poco se aplicó coaching ejecutivo a las principales jefaturas de su empresa, obteniendo mejoras en un $80 \%$ en lo referente a productividad y comunicación interna.

3. Para concluir, la tercera experta en recursos humanos que es de la ciudad de Arequipa, mencionó que actualmente contratan coachs ejecutivos de la ciudad de Lima esto según ella, debido a que en Arequipa no conocen de una empresa 
que sea especializada que cuente con coachs certificados en coaching ejecutivo lo cual explica hace que se eleven sus costos. Con respecto al team building este se implementa dos veces al año en tanto que el coaching ejecutivo para los cargos de gerencia lo contratan cuando el directorio lo solicita. Se le preguntó en la entrevista a la experta sobre los rangos de precios que cotizan las empresas de Lima, indicando que para coaching ejecutivo el precio estimado es de S/.4500.00 en tanto que para el team building unos S/6000 soles aproximadamente dependiendo del tipo de actividad que se solicite y la cantidad de personal que participará de estas actividades.

\subsection{Investigación cuantitativa}

Se aplica este método de carácter descriptivo cuando se identifican y definen los problemas de investigación de manera que el investigador conoce las necesidades puntuales de información que necesita (Hair, et al., 2010).

Para este plan de negocios se utilizó la técnica de encuestas personales, en el que el instrumento es un cuestionario estructurado de opción múltiple. Estas encuestas fueron aplicadas a una muestra representativa de la población de estudio, que en este caso son las empresas de la ciudad de Arequipa.

\subsubsection{Proceso de muestreo.}

En este proceso, se aplico el muestreo probabilístico aleatorio estratificado tomandose del universo objeto de estudio del que se ha de extraer la muestra la cual se dividió en estratos de pequeña, mediana y grande empresa. (Hair, et al., 2010). Para tal fin se tomaron en cuenta los siguientes factores: 


\section{La población:}

Establece el grupo de personas a las cuales hay que investigar, es la primera etapa del investigador. La investigación cuantitativa permite recolectar información suficiente y necesaria (200 o más) de la población definida, esto permite al investigador realizar predicciones deductivas sobre los factores y fenómenos del mercado que se investiga (Hair, et al., 2010).

Tomando en cuenta estos criterios se tomará en primera instancia el total de 720 empresas, mostradas en la Tabla 17 con empresas de la ciudad de Arequipa de diferentes sectores, con un mínimo de tres años de funcionamiento y que cuenten con 20 trabajadores a más.

2. Tamaño de la muestra:

Al ser la población una cantidad conocida exacta, su calculó se determinó mediante la fórmula estadística para muestras finitas.

$$
n=\frac{N Z^{2} P Q}{e^{2}(N-1)+Z^{2} P Q}
$$

Dónde:

$\mathrm{Z}=$ Valor que representa el nivel de confianza.

$\mathrm{e}=$ Error .

$\mathrm{P}=$ Probabilidad de aceptación del servicio.

$\mathrm{Q}=$ Probabilidad de rechazo.

$\mathrm{N}=$ Población .

$\mathrm{n}=$ Muestra. 
Los valores a usar para el cálculo de la muestra se muestran en la tabla 20:

Tabla 20

Valores a usar para el cálculo de la muestra

\begin{tabular}{cr}
\hline Descripción & Valores \\
\hline $\mathbf{E}$ & 0.05 \\
$\mathbf{N}$ & 481.00 \\
$\mathbf{\Sigma}$ & 0.50 \\
Confianza & 95.00 \\
$\mathbf{Z}$ & 1.96 \\
\hline
\end{tabular}

Se realizaron los cálculos respectivos de acuerdo a la fórmula mostrada:

$$
n=\frac{720 * 1.96^{2} * 0.50 * 0.50}{0.05^{2}(720-1)+1.96^{2} * 0.50 * 0.50}
$$

Luego de la cual se determinó que el tamaño de muestra (n) será de 251 empresas.

\subsubsection{Diseño de instrumento.}

Se utilizó como instrumento un cuestionario. Según describe Hair et al. (2010), haciendo uso de preguntas estructuradas, que limitan las respuestas a opciones ya determinadas para la herramienta seleccionada.

Para este plan de negocios, el cuestionario contiene 19 preguntas las cuales se dividieron en tres partes que en detalle son (a) datos generales de la empresa, que se sub-dividen en 3 preguntas cerradas múltiples unirrespuesta, (b) acerca de la empresa, que se sub-divide en 4 preguntas siendo la primera cerrada dicotómica, la segunda cerrada multirrespuesta, la tercera cerrada multiple unirrespuestay la cuarta cerrada multiple multirrespuesta , (c)acerca de coaching y team building, siendo las preguntas 3.1, 3.2 y 3.4 cerradas dicotómicas, las preguntas 3.3, 3.8 y 3.11 
cerrada multiple unirrespuesta, finalmente las preguntas 3.5, 3.6, 3.7, 3.9 y 3.10 cerrada multiple multirrespuesta. (Ver anexo).

\subsubsection{Análisis y procesamiento de datos.}

Para el análisis y procesamiento de datos se utilizara la tabulación que consiste en contar la cantidad de respuestas que hay en las categorías (Hair, et al., 2010).

Una vez realizada la tabulación, los datos obtenidos de las encuestas aplicadas fueron ingresadas a una hoja de cálculo Excel que permitió hacer un cruce de información con el fin de obtener resultados relevantes. Esta hoja de cálculo permite procesar los datos y realizar un análisis estadístico ideal para estudios de este tipo. Los resultados obtenidos se muestran en la figura 6:

- Datos generales de la empresa

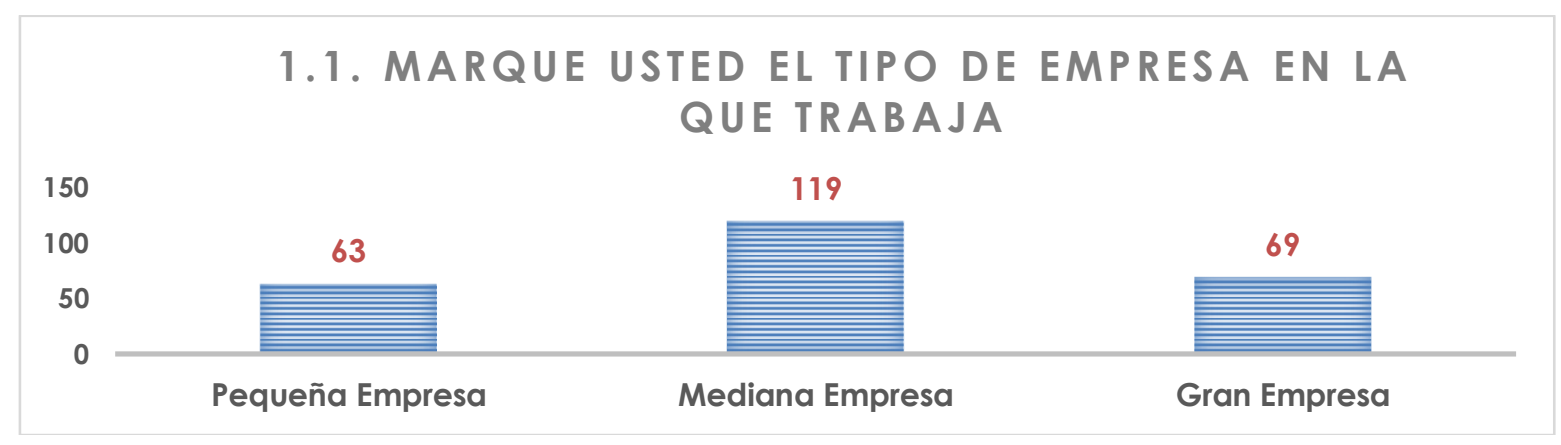

Figura 06. Pregunta 1.1. Adaptado de la Recolección de datos del Cuestionario

De las 251 empresas encuestadas, el 119 empresas pertenecen a las medianas empresas y representan el $47 \%$, seguido por 69 empresas que pertenecen a las grandes empresas (27\%) y 63 representas a las pequeñas empresas (25\%), lo que demuestra que el mercado potencial se encuentra englobado en las medianas y grandes empresas de la ciudad 


\subsection{MARQUE CUAL ES LA ANTIGÜEDAD DE LA EMPRESA}

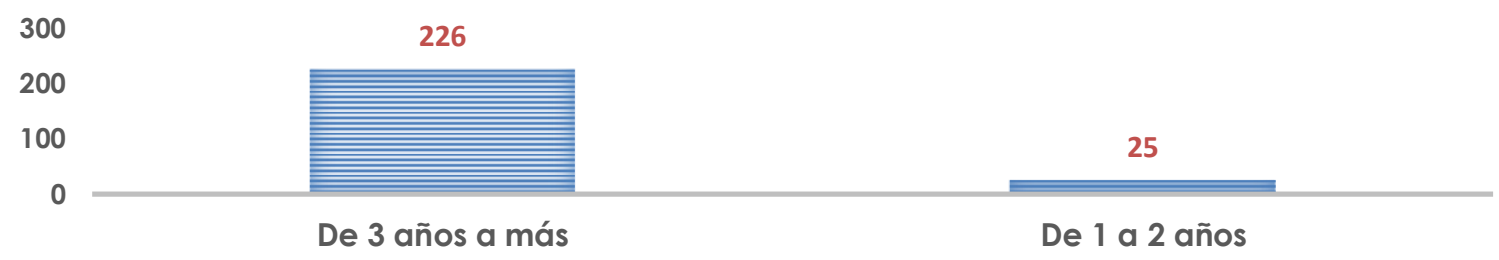

Figura 07. Pregunta 1.2. Adaptado de la Recolección de datos del Cuestionario

Entre las empresas encuestadas se encontró que un 90\% (226 empresas)

tiene más de tres años de antigüedad pasando el primer filtro de la investigacion, seguido por un $10 \%$ (25 empresas), en el rango de 1 a 2 años de antigüedad en el mercado de la ciudad de Arequipa.

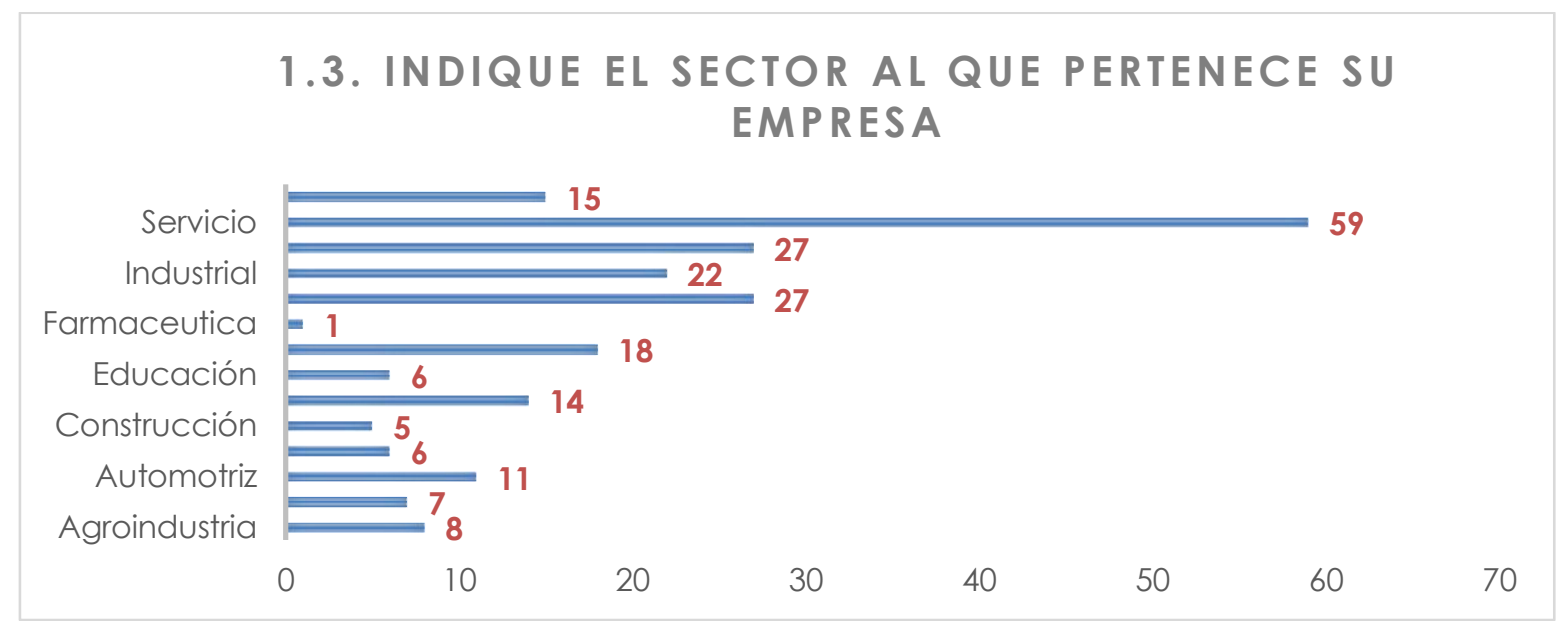

Figura 08. Pregunta 1.3. Adaptado de la Recolección de datos del Cuestionario

Se pregunto a los encuestados el sector de la empresa al que pertenecen, siendo 101 empresas pertenecientes al sector servicios, 49 empresas al sector industrial, 19 empresas que pertenecen al sector farmacéutico, 22 empresas al sector educación, 11 empresas al sector construcción, 18 empresas al sector automotriz y 8 empresas al sector agroindustrial. Siendo de predominancia en la ciudad de Arequipa el sector de servicios. 
- Acerca de la empresa:

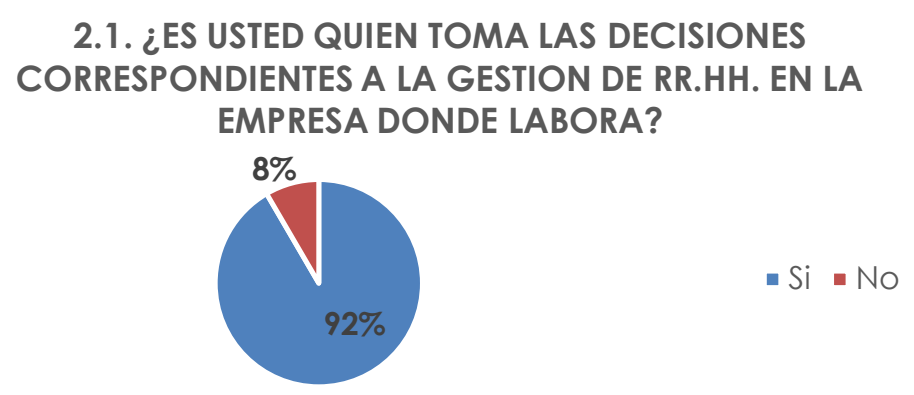

Figura 09. Pregunta 2.1. Adaptado de la Recolección de datos del Cuestionario

El 8\% de encuestados (19 empresas), respondieron que no son los que toman las decisiones en el área de RR.HH, resaltando que la toma de decisiones llega desde la capital del Perú, un $92 \%$ indico que la toma de decisiones cae sobre su responsabilidad en la organización, pasando un total de 207 empresas el segundo filtro de la investigación.

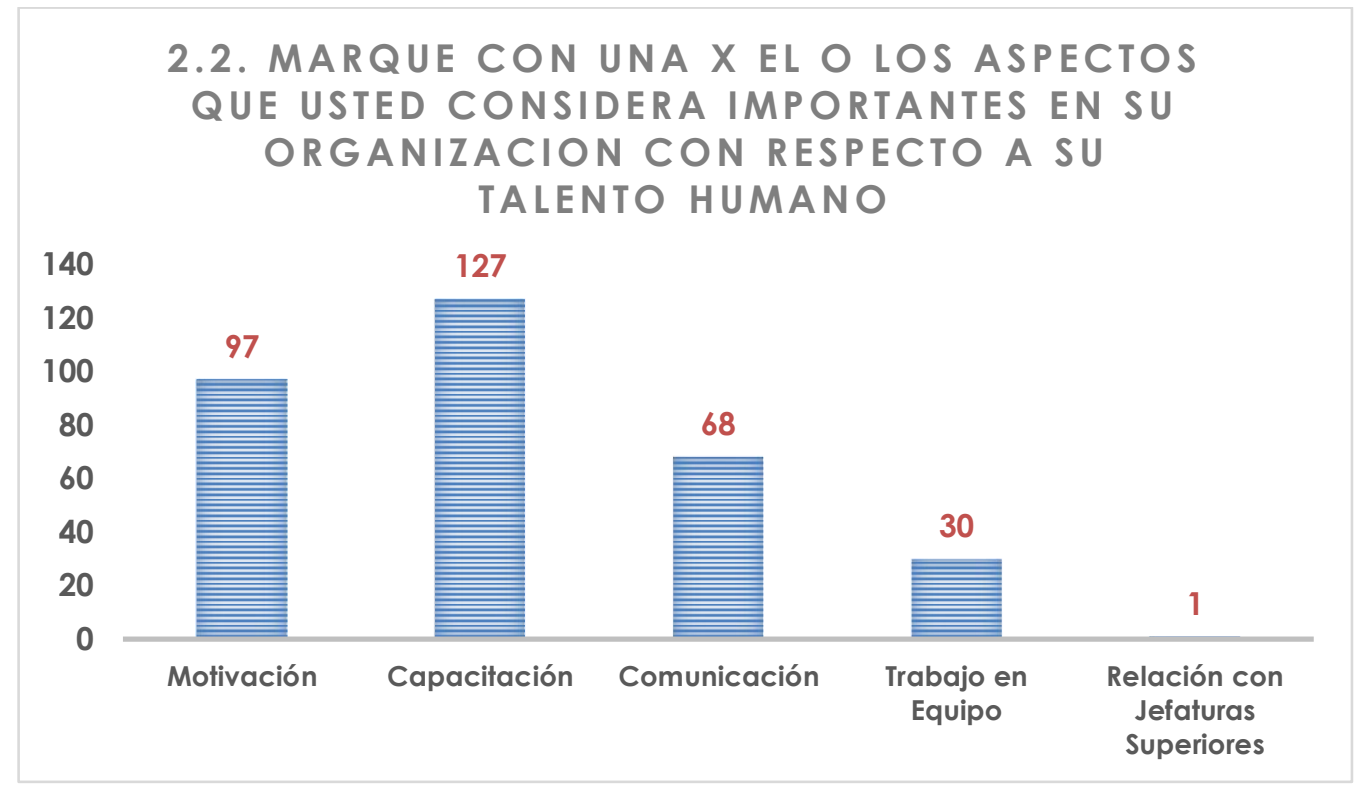


Figura 10. Pregunta 2.2. Adaptado de la Recolección de datos del Cuestionario

Al preguntar a los encuestados que aspectos consideran importantes respecto al talento humano de su organización, 127 empresas manifestaron que la capacitación es fundamental, seguido de 97 empresas que manifestaron que la motivación de los colaboradores es importante, 68 empresas indicaron la variable comunicación, 30 empresas la variable trabajo en equipo y finalmente 1 empresa la variable relación con jefaturas superiores, que indica que la empresa Intenta coaching y team building creara productos orientados a repotenciar la capacitación y motivación interna de la empresa. Se promocionara productos sobre los temas de trabajo en equipo, y team building para que las empresas le tomen la debida importancia.

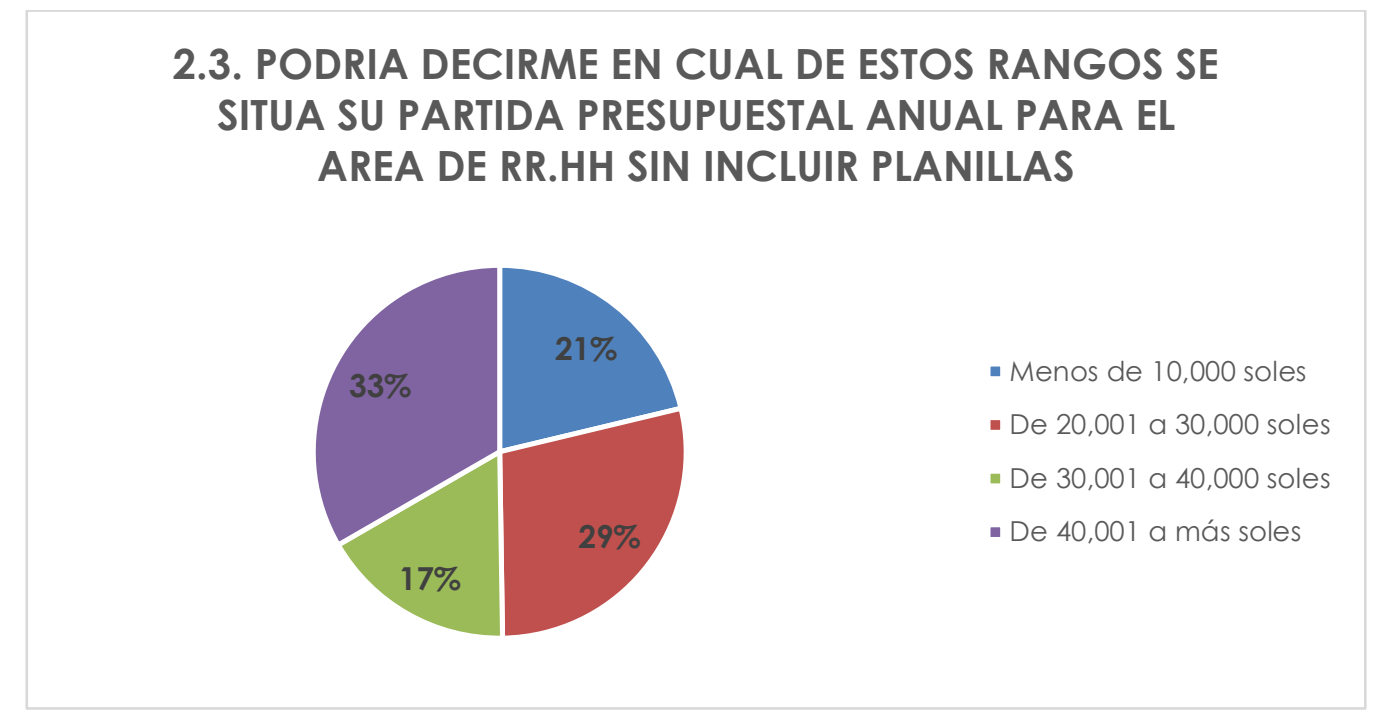

Figura 11. Pregunta 2.3. Adaptado de la Recolección de datos del Cuestionario En el cuestionario se incluyo una lista con el rango de las partidas de presupuestos anuales destinados para el área de RR.HH. tal como se observa en la figura 11 un 33\% (69 empresas), indicaron que el rango presuñpuestal oscila de 40, 000 a mas, seguido por un $29 \%$ (59 empresas), que indico que el presupuesto anual del area 
esta en los rangos de 20,001 a 30,000 soles y un 21\% (44 empresas) indico que el rango anual de la partida presupuestal es menor a 10,000 soles anuales.

Esta informacion sera de importancia al momento de determinar la variable precio de los paquetes que se ofreceran al mercado.

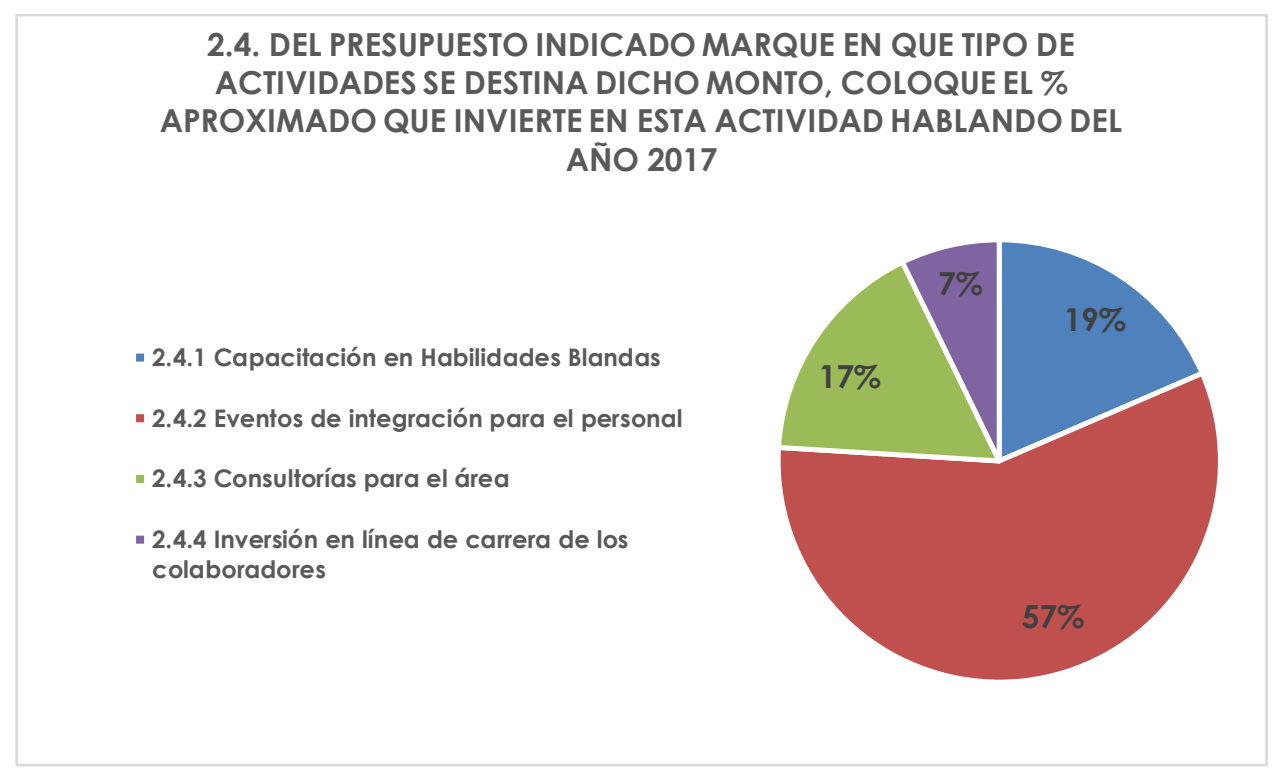

Figura 12. Pregunta 2.4. Adaptado de la Recolección de datos del Cuestionario

En el cuestionario se incluyo una lista de actividades en la que se destina el presupuesto anual de RR.HH., siendo un 57\% destinado para eventos de integración para el personal, seguido de capacitación en habilidades blandas (19\%), consultorías para el área (17\%), e inversión en línea de carrera un 7\%. Esto nos demuestra que un $93 \%$ del presupuesto destinado encaja con los productos que ofrecerá Intenta coaching y team building.

- Acerca del coaching y team building 


\subsection{EN LOS ULTIMOS DOS AÑOS HA HECHO USTED USO DE LAS HERRAMIENTAS DE COACHING EJECUTIVO}

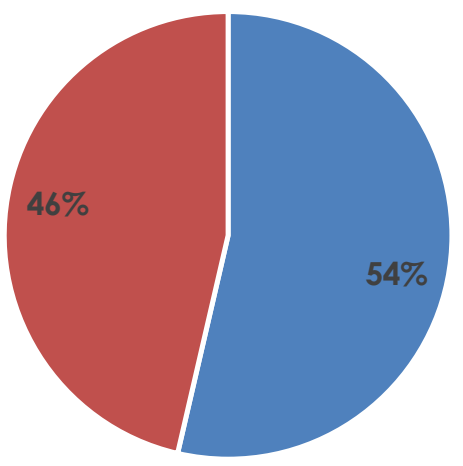

- No - Si

Figura 13. Pregunta 3.1. Adaptado de la Recolección de datos del Cuestionario

Un 54\% (111 empresas), indicaron no utilizar dicha herramienta, sin embargo un $46 \%$ (96 empresas) manifestaron que si hicieron uso de la herramienta pasando el tercer filtro.

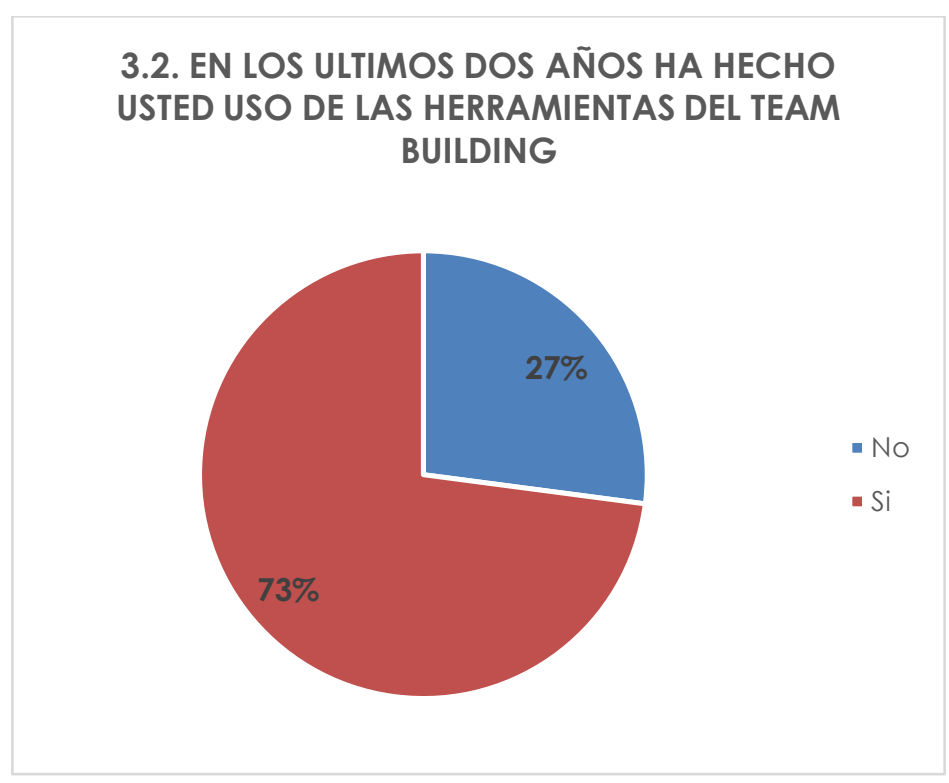

Figura 14. Pregunta 3.2. Adaptado de la Recolección de datos del Cuestionario 
Un 27\% (26 empresas), indicaron no utilizar dicha herramienta, sin embargo un $73 \%$ (70 empresas) manifestaron que si hicieron uso de la herramienta pasando el tercer filtro
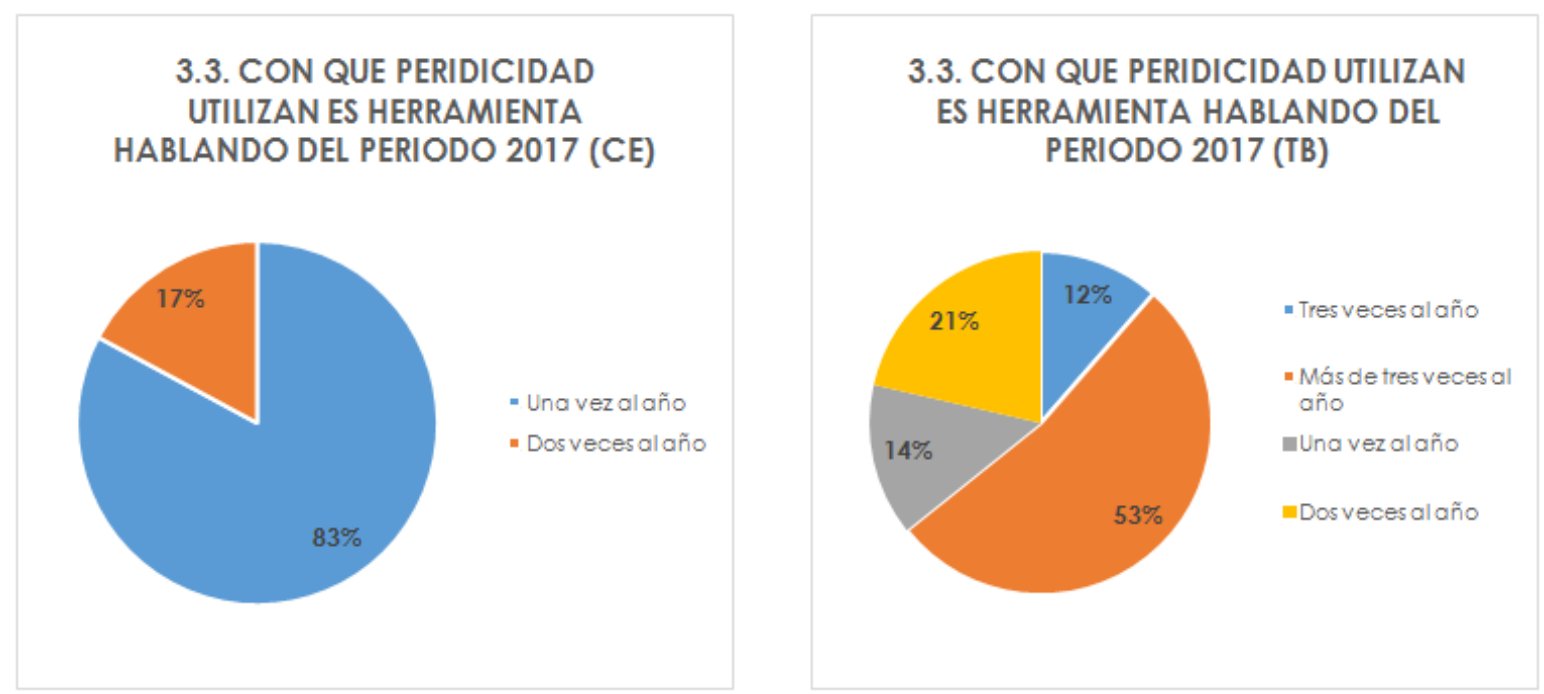

Figura 15. Pregunta 3.3. Adaptado de la Recolección de datos del Cuestionario

Con respecto al coaching $83 \%$ (58 empresas), indicaron que el lo utilizan una vez al año, seguido por un 17\% (12 empresas) que manifestaron que aplican la herramienta dos veces al año lo que nos demuestra un escenario positivo para incrementar el uso promocionando dicha herramienta en las empresas que la utilizan. Por otro lado referente al Team building un 53\% (37 empresas), indicaron que utilizan dicha herramienta más de tres veces al año, seguido de un 21\% (15 empresas) que lo utilizan dos veces al año, 14\% (10 empresas) una vez al año y $12 \%$ (8 empresas) indicaron que los utilizan 3 veces al año. Esto indica que la herramienta de team building es trabajada con mayor frecuencia en las empresas de la ciudad de Arequipa, que muestra que Intenta coaching y team building tiene un mercado potencial para ofrecer el servicio (ver figura 15). 


\subsection{CUENTA LA EMPRESA CON UN AREA RESPONSABLE EN COACHING INTERNO}

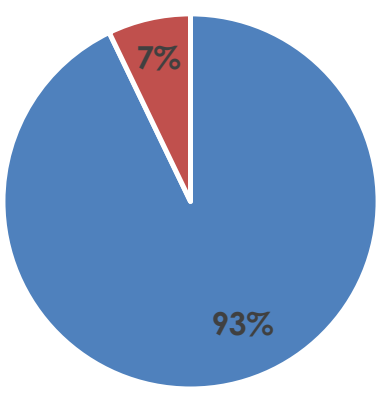

Figura 16. Pregunta 3.4. Adaptado de la Recolección de datos del Cuestionario

Las empresas en la ciudad de Arequipa 65 empresas (93\%), respondieron que no cuentan con un área responsable de coaching interno, solo 5 empresas (7\%) indicaron que cuentan con esta área las cuales no pasan el cuarto filtro de la investigación de mercado.(ver figura 16).

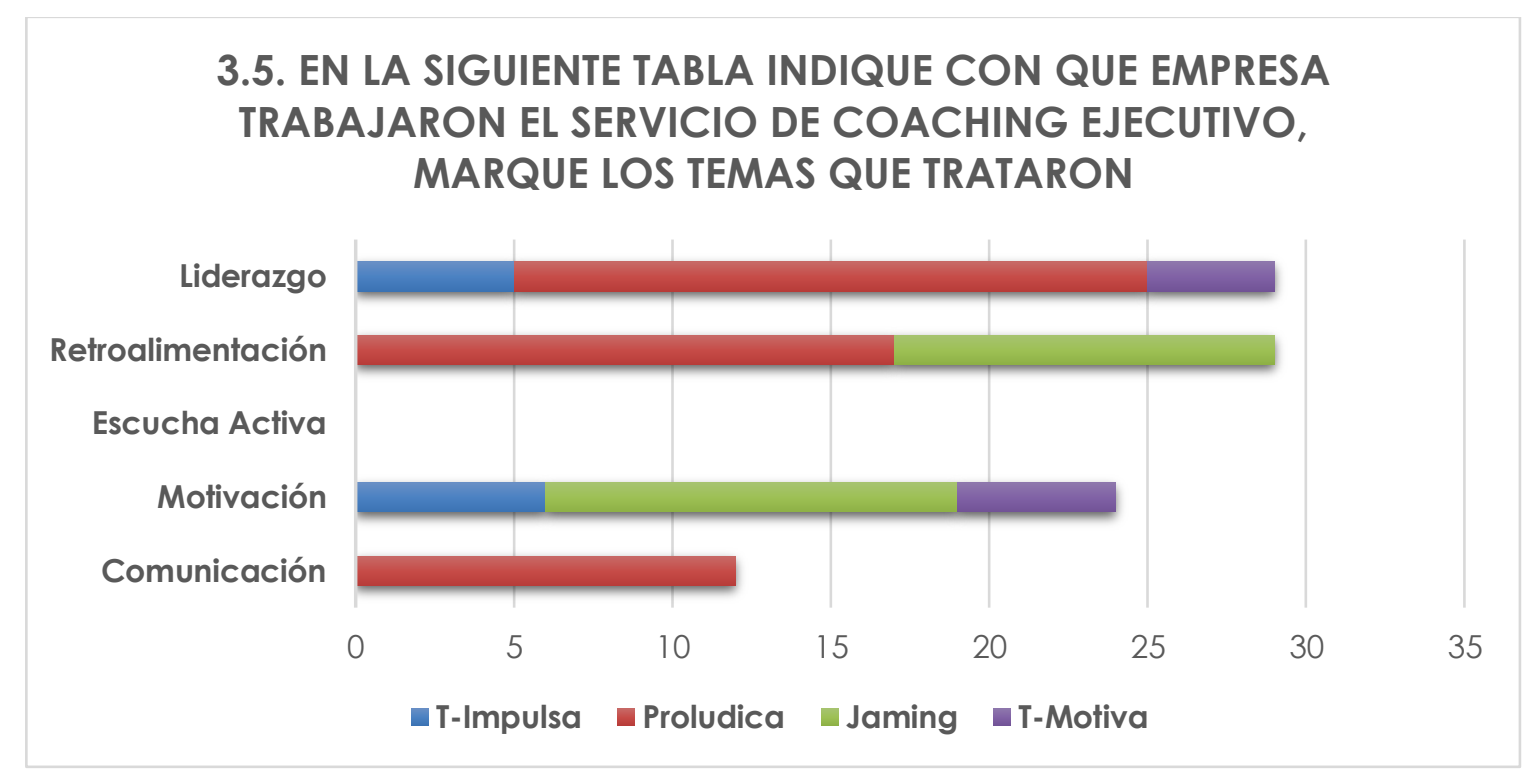

Figura 17. Pregunta 3.5. Adaptado de la Recolección de datos del Cuestionario 
En el cuestionario se colocaron los temas que las empresas entrevistadas trabajaron con empresas que brindan el servicio de coaching ejecutivo, dando como resultados que 12 empresas contrataron los servicios de la empresa Proludica (empresa de Lima) para temas referente a comunicación interna, referente al tema de motivación 13 empresas manifestaron que trabajaron con la empresa Jaming (empresa de Lima), seguida por 6 empras que contrataron los servicios de la empresa Arequipeña T-Impulsa y 5 empresas indicaron que trabajaron con la empresa T-motiva (empresa Arequipeña). Por otro en lo que respecta a los temas de retroalimentación 17 empresas manifestaron haber contratado los servicios de la empresa Proludica, seguida por 12 empresas que contrataron los servicios de la empresa de Jamin. Por ultimo 20 empresas manifestaron haber contratado a la empresa Proludica para trabajar temas en liderazgo, 5 trabajaron con la empresa TImpulsa y 4 empresas contrataron los servicios de la empresa T-Motiva. Este panorama nos demuestra que las empresas de Lima tiene una fuerte participación en el mercado Arequipeño, además podemos identificar a nuestros competidores directos en la ciudad de Arequipa que son las empresas T-Impulsa y T-Motiva. (ver figura 17). 


\subsection{EN LA SIGUIENTE TABLA INDIQUE CON QUE EMPRESA TRABAJARON EL SERVICIO DE TEAM BUILDING, MARQUE LOS TEMAS QUE TRATARON}

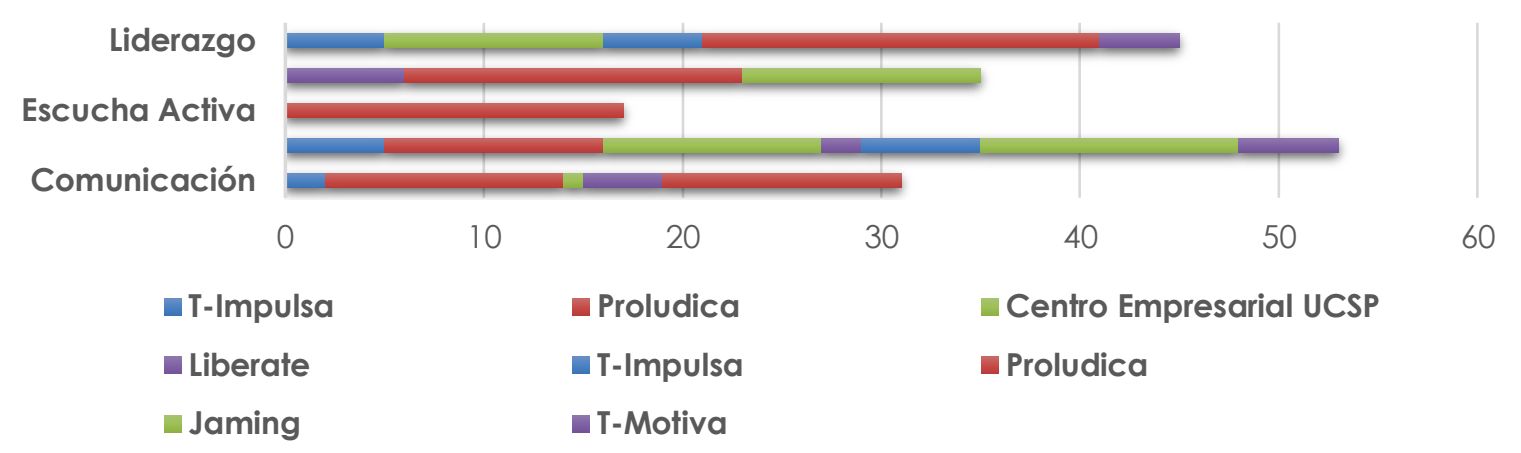

Figura 18. Pregunta 3.6. Adaptado de la Recolección de datos del Cuestionario

40 empresas indicaron trabajar temas en motivación, trabajo en equipo y construcción de equipos con la empresa Proludica, 23 empresas contrataron los servicios del centro de emprendimiento y liderazgo de la Universidad Catolica San Pablo en los temas de motivación y trabajo en equipo y liderazgo, seguido de 12 empresas que contrataron a T-Impulsa para trabajar motivación y trabajo en equipo, finalmente 12 empresas trabajaron con Libérate (de la ciudad de Lima), temas enfocados en motivación y trabajo en equipo. (ver figura 18).

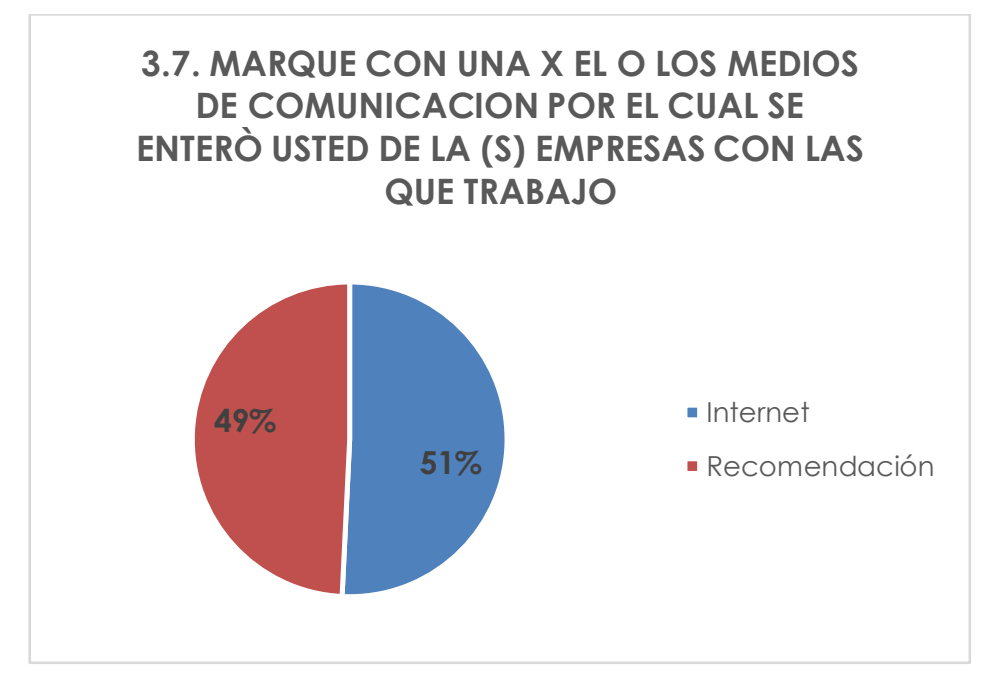

Figura 19. Pregunta 3.7. Adaptado de la Recolección de datos del Cuestionario 
Se obtuvo que un 51\% (33 empresas), se entero de la empresa que contrato por medio de internet, por otro lado un 49\% (32 empresas), indicaron que fue por recomendación de conocidos en su misma área. Estos resultados nos orientan enfocar nuestro plan de marketing a través de medios digitales como internet (google apps, linkedin, otros), nos compromete a brindar un buen servicio que nos permitirá ser recomendados por las mismas empresas que contraten el servicio que Intenta coaching y team building (ver figura 19).
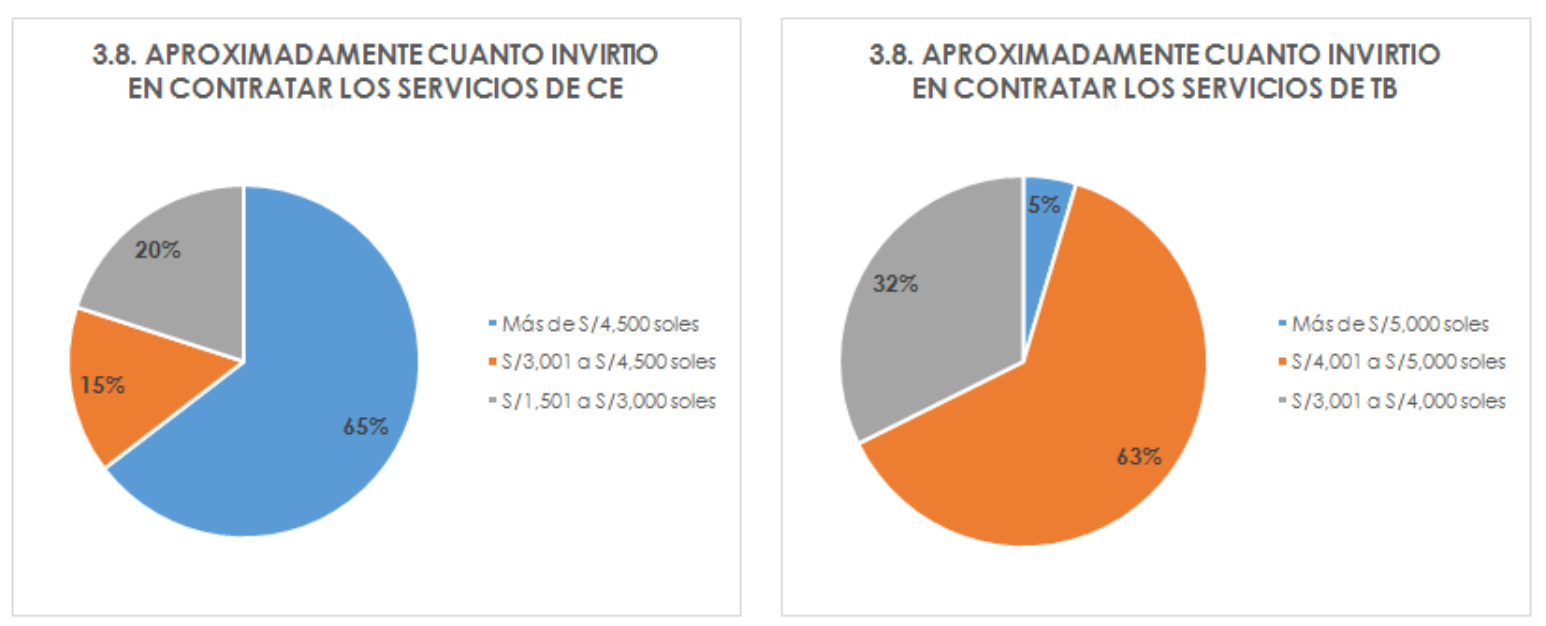

Figura 20. Pregunta 3.8. Adaptado de la Recolección de datos del Cuestionario

Con respecto al coaching ejecutivo un 65\% (42 empresas), invirtió más de S/. 4500.00 soles, $20 \%$ (13 empresas) invirtió en un rango de 1501 a 3000 soles y un 15\% (10 empresas) invirtió entre 3001 a 4500 soles, lo cual permite establecer el rango de precios de los paquetes que invertirá Intenta coaching y team building.

Un 63\% (41), invirtió de 4001 a 5000 soles en team building, seguido de un 32\% (21empresas), que indico haber invertido 3001 a 4000 soles, finalmente un 5\% (3 empresas), invirtió mas de 5000 soles en dicho servicio. Este escenario nos 
permitirá establecer el rango de precios en los productos a ofertar al mercado Arequipeño. (ver figura 20).

\begin{tabular}{|c|c|c|c|c|c|}
\hline \multicolumn{6}{|c|}{$\begin{array}{l}\text { 3.9. INDICAR POR ORDEN DE IMPORTANCIA DONDE } 1 \text { ES MUY IMPORTANTE Y } 5 \text { NADA IMPORTANTE LOS MOIIVOS PC } \\
\text { QUE USTED CONTRATO LA EMPRESA CONSULIORA MENCIONADAS EN LA PREGUNTA } 3.5 \text { CON RESPECTO AL CE }\end{array}$} \\
\hline & 1 & 2 & 3 & 4 & 5 \\
\hline Empresa reconocida & 15 & 11 & 23 & & \\
\hline Decisión de Sede Central & 31 & 4 & & & \\
\hline Profesionales certificados & 3 & 24 & 14 & 8 & \\
\hline \multicolumn{2}{|l|}{ Precio } & 5 & 9 & & \\
\hline \multicolumn{6}{|l|}{ Antigüedad de la empresa } \\
\hline \multicolumn{2}{|l|}{ Programas presentados } & 5 & 3 & 30 & 11 \\
\hline \multicolumn{2}{|l|}{ Herramientas usadas } & & & 3 & 11 \\
\hline \multicolumn{2}{|l|}{ Experiencia de la empresa } & & & 8 & 27 \\
\hline
\end{tabular}

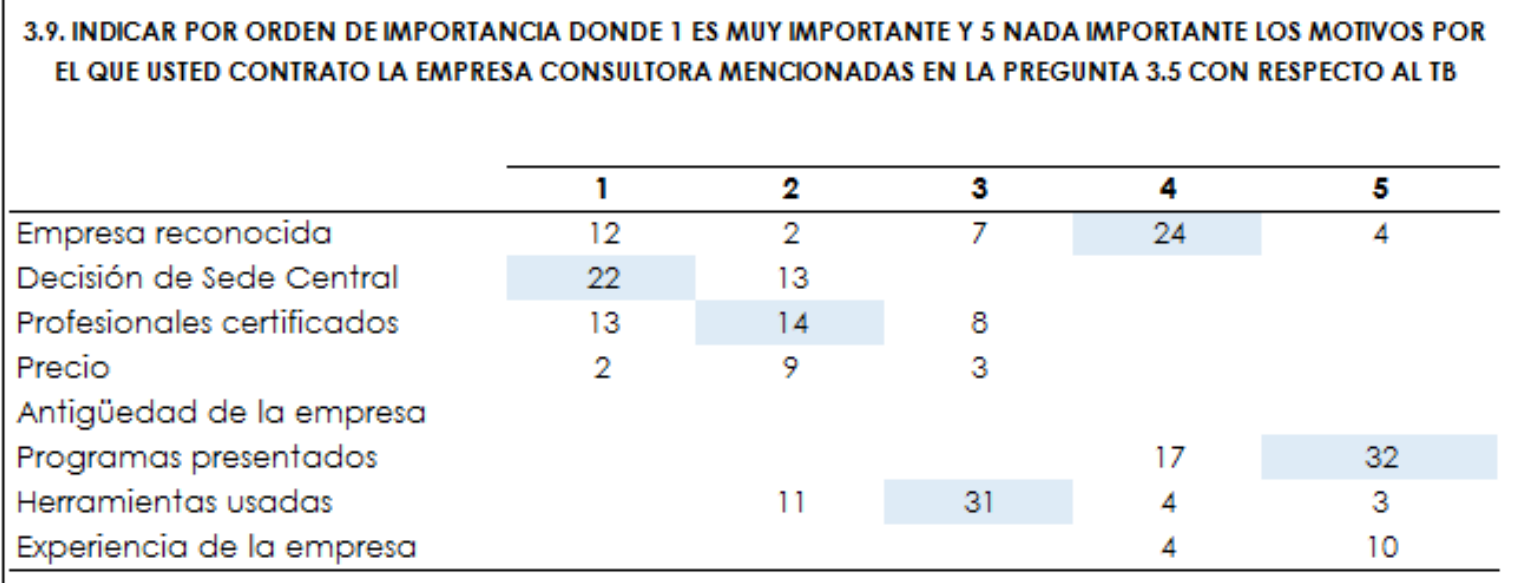

Figura 21. Pregunta 3.9 Adaptado de la Recolección de datos del Cuestionario

En lo que refiere a coaching ejecutivo, el motivo de mayor importancia es por decisión de la sede central (31 empresas), seguido por profesionales coach certificados (24 empresas), 23 empresas valoran que la empresa sea reconocida, 30 empresas valoran los programas que presentas las empresas a contratar y la de menor importancia (27 empresas) consideran la experiencia. 
Para la contratación del servicio de team building, la contratación del servicio depende mucho de la sede central (22 empresas), 14 empresas le dan valor a los profesionales certificados, 31 empresas valoran las herramientas que ofrecen las empresas a contratar, 24 empresas le dan importancia al reconocimiento y finalmente 32 empresas valoran los programas presentados.

Podemos concluir para ambos servicios que el plan de marketing deberá estar orientado no solo a la ciudad de Arequipa sino también a la ciudad de Lima en donde se encuentran la mayoría de las sedes principales, por otro lado se puede identificar una ventaja competitiva el hecho que las empresas valoren contratar profesionales certificados, se orientara la publicidad para resaltar la certificación internacional otorgada por la escuela de negocios INCAE con la que cuenta Intenta coaching y team buildig.con la (ver figura 21).

\begin{tabular}{|c|c|c|c|c|c|c|c|c|c|}
\hline & 1 & 2 & 3 & 4 & 5 & 6 & 7 & 8 & 9 \\
\hline Certificaciones confiables & 23 & 12 & & & & 2 & 9 & 3 & \\
\hline Asesores profesionales & 5 & 9 & & & & & 28 & 7 & \\
\hline Atención personalizada & & 5 & 9 & 10 & 18 & 7 & & & \\
\hline Moderna e innovadora & 12 & 12 & 16 & 9 & & & & & \\
\hline Productos adaptados & & & & 12 & 15 & 22 & & & \\
\hline Precios accesibles & 9 & & 2 & 3 & & & & 13 & 22 \\
\hline Antigüedad de empresa & & & & & & & 7 & 17 & 25 \\
\hline Paquetes de servicios & & 13 & 22 & 2 & 9 & 3 & & & \\
\hline Herramientas usadas & & & & & 20 & 15 & 3 & 9 & 2 \\
\hline
\end{tabular}

Figura 22. Pregunta 3.10 Adaptado de la Recolección de datos del Cuestionario 
Los atributos más valorados para la contratación de una empresa que brinde estos servicios son certificaciones confiables ( 23 empresas), seguido de paquetes de servicios (35 empresas), por otro lado34 empresas valoran que los productos sean adaptados a sus necesidades, 20 empresas indicaron herramientas usadas, 28 empresas indican que los asesores deben ser profesionales en la materia y de menor importancia es la antigüedad de la empresa (42 empresas).

Este resultado nos demuestra que las empresas buscan contratar servicios brindados por profesionales que cuenten con certificaciones confiables, la innovación en los productos será de mayor importancia que la antigüedad de la empresa que contratan, tema que será considerado dentro del plan de marketing de Intenta coaching y team building.

\subsection{ESTARIA USTED INTERESADO EN ADQUIRIR LOS SERVICIOS DE DICHA EMPRESA}

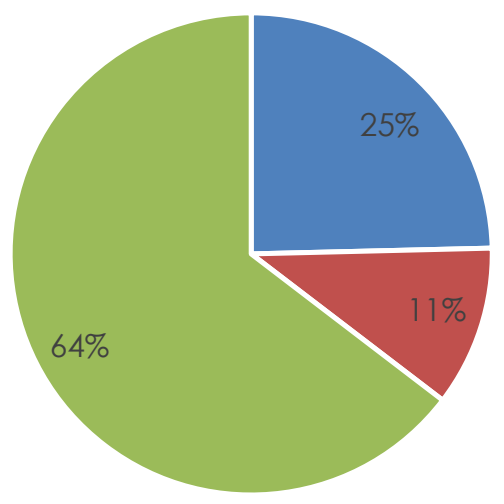

- Definitivamente si

- Me sería indiferente

- Posiblemente si

Figura 23. Pregunta 3.11 Adaptado de la Recolección de datos del Cuestionario

Después de cuatro filtros aplicados en la investigación de mercado, se puede concluir que solo el $89 \%$ que conforman 58 empresas pasan el quinto y último filtro, dato 
con el cual se trabajara el pronóstico de la demanda. Descartando el 11\% (07 empresas), que marcaron la opción "me seria indiferente".

\subsection{Conclusiones y recomendaciones del estudio cualitativo y cuantitativo}

\section{Conclusiones:}

En lo que respecta a la entrevista a expertos, se puede concluir que el coaching y team building son herramientas eficaces para mejorar la productividad y la cultura organizacional de las empresas, incluso como refiere uno de los expertos, que tanto el coaching ejecutivo y team building podrían ayudar a reducir las altas tasas de rotación de personal que se tienen en el sector retail, afirmando además que en la empresa en la que labora ya se encuentran trabajando con coachess para aliviar puntos álgidos como la falta de motivación, retención de talento humano, toma de decisiones, liderazgo, trabajo en equipo, entre otros.

Los expertos mencionan que el coaching y team building puede ser solicitado por la empresa en el momento que lo considere, sin la necesidad de tener problemas con el personal siendo incluso una herramienta útil para trabajar incentivos, premiaciones a los colaboradores. Lo cual hace que nuestra cartera de servicios pueda ser diversificada no solo para mejorar las falencias que existan en las empresas, sino para potenciar su talento humano, reforzar la autoestima de sus colaboradores, entre otros servicios que pueden ofrecer dentro de la cartera productos a ofrecer.

Los servicios de coaching ejecutivo y team building según refiere uno de los expertos, ya se están empezando a considerarse como parte del presupuesto anual del área de recursos humanos, lo cual abre grandes oportunidades de crecimiento y éxito para el 
plan de negocios, pues las empresas en la ciudad de Arequipa están empezando a tomar mayor relevancia a estas actividades ya que observan que hay un retorno de la inversión realizada y una mejora en sus empresas.

En el estudio cuantitativo, claramente se tiene un mercado potencial al cual debe dirigirse la empresa. Se puede observar que los encargados del área de recursos humanos en la mayoría de empresas de Arequipa no tienen un concepto claro o en su defecto un concepto tergiversado de lo que es el coaching ejecutivo y team buildiing, y de la potencia que estas herramientas tienen al ser aplicadas, lo cual hace que orienten sus esfuerzo de retención de personal, motivación, trabajo en equipo y otros inconvenientes de personal por otros caminos, como por ejemplo planificar capacitaciones a sus colaboradores (30\% de encuestados toman como opción esta herramienta), que si bien es cierto es útil pero no necesariamente aplica en todos los casos.

\section{Recomendaciones:}

a. Debido a la falta de conocimiento de coaching ejecutivo y team building los esfuerzos de la empresa deben centrarse en una buena estrategia de penetración de mercado.

b. Es importante considerar a la competencia actual, por lo tanto será de vital importancia el desarrollo de una estrategia que permita un adecuado posicionamiento frente a las empresas en la ciudad de Lima y Arequipa.

c. Dentro de nuestra cartera de productos debemos brindar importancia a un producto que mejore la falta de motivación del personal (123 de las 251 empresas indicaron tener este problema), ya que existe una alta demanda por parte de las empresas en la ciudad de Arequipa. 
d. Se debe realizar una estrategia de comunicación agresiva al $28 \%$ y $48 \%$ de empresas (preguntas 6 y 7), que aún no tiene conocimiento que el coaching ejecutivo y team building son herramientas potentes que pueden utilizar para mejorar la performance de su talento humano.

\subsection{Perfil del consumidor tipo y sus variantes.}

Habiendo realizado la investigación, se pudo identificar para el presente plan de negocios B2B que el perfil del consumidor es el siguiente:

1. Empresas que operen en el departamento de Arequipa

2. Empresas de diferentes rubros económicos, sin dejar de lado a actividades tales como empresas de agricultura, minería y pecuario. En cuanto a transporte, hotelería y construcción, se le debe prestar cierta atención ya que son actividades que comienzan a tener mayor presencia en las zonas de intervención de la empresa.

3. Empresas enfocadas en áreas urbanas principalmente en aquellas zonas que poseen cierto grado de concentración industrial ya que esto permitirá generar ciertas barreras de entrada a potenciales competidores.

4. Empresas que se encuentran entre los rangos de pequeñas, medianas y grandes empresas con un número de 20 empleados a más; ya que entre estos rangos se puede encontrar mayor experiencia en la actividad de recursos humanos y se desarrollan de igual forma en mayor amplitud de opciones a la hora de recibir estos servicios. 


\section{Capítulo IV: Proyección del Mercado Objetivo}

\subsection{El Ambito de la Proyección}

Para el trabajo de investigación no existen informes estadísticos que puedan indicar el crecimiento de las empresas de coaching y team building en el Perú, razón por la cual se toma como referencia el boletín estadístico del Instituto Nacional de Estadística e Informática, tal como se muestra en la tabla 21.

Tabla $\mathrm{N}^{\circ} 21$

Evolución de la actividad de servicios prestados a empresas

\begin{tabular}{llllll}
\hline \multicolumn{5}{c}{ Actividades de Consultoría de gestión empresarial } \\
\hline Año/Mes & 2012 & 2013 & 2014 & 2015 & 2016 \\
Enero & 3.14 & 3.99 & 17.3 & -2.75 & 4.95 \\
Febrero & 17.63 & 2.75 & 9.28 & 1.93 & 3.85 \\
Marzo & 1.3 & 10.17 & 8.53 & 4.07 & 6.1 \\
Abril & 2.73 & 4.92 & 9.35 & 8.71 & 7.85 \\
Mayo & 2.8 & 7.94 & 7.3 & 9.84 & 5.85 \\
Junio & -2.41 & 13.42 & 7.16 & 9.46 & 8.61 \\
Julio & -3.48 & 12.94 & 9.32 & 7.3 & 6.15 \\
Agosto & 5.03 & 7.25 & 6.85 & 9.16 & 7.89 \\
Septiembre & 8.37 & -1.82 & 8.33 & 9.79 & - \\
Octubre & 6.11 & 12.49 & 4.55 & 11.89 & - \\
Noviembre & 9.05 & 1.97 & 8.46 & 8.52 & - \\
Diciembre & 13.65 & 9.31 & 11.47 & 8.94 & - \\
\hline Promedio & 5.33 & 7.11 & 8.99 & 7.24 & 6.41 \\
\hline
\end{tabular}

Nota. Adaptado de "Encuesta mensual del sector servicios", por Instituto Nacional de Estadística e Informática, 2016, p.14 


\subsection{Selección del método de proyección}

Para la elección del método se debe conocer el sector en el que se ubica el proyecto. El cálculo proviene de la investigación obtenida. Se ha de escoger una técnica de acuerdo a patrones como lo menciona Krajewski, Ritzman \& Malhotra (2013), y se obtendrá la serie de presentación de la demanda.

\subsubsection{Mercado potencial.}

Comprende a todos los consumidores que optarían por escoger el servicio que se busca ofertar (Kinner \& Keller, 2012).

En el capítulo tres, de acuerdo a la pregunta numero 1.1. se considera 251 empresas pequeñas, medianas y grandes que podrían requerir los servicios de coaching ejecutivo y team building, siendo el mercado potencial.

\subsubsection{Mercado disponible.}

Conformado por los consumidores que tienen el interés de adquirir el servicio (Kinner \& Keller, 2012).

Teniendo el mercado potencial a través del cuestionario, se realizaron tres filtros utilizando las preguntas 1.2, 2.1, 3.1 y 3.2 de la encuesta.

- 1.2. ¿Cuál es la antigüedad de la empresa? $=226$

- 2.1. ¿Es usted quien toma las decisiones correspondientes a la gestión de recursos humanos en la empresa donde labora $?=207$

- 3.1. En los últimos dos años ¿Ha hecho usted uso de las herramientas del Coaching ejecutivo $?=96$ 
- 3.2. En los últimos dos años ¿Ha hecho usted uso de las herramientas del Team building? $=70$

$\mathrm{MD}=70$ empresas de coaching y team building

\subsubsection{Mercado efectivo.}

El mercado efectivo es una parte del mercado disponible y está formado por el conjunto de consumidores que tienen además de la necesidad, la intención de comprar el bien o servicio que ofrece el proyecto (Muller, n.d).

Mercado Efectivo $(\mathrm{ME})=\mathrm{MD} *(\%$ pregunta 3.4$)$

$\mathrm{ME}=70 * 93 \%=65$ empresas

En base a esto se consideraron 65 empresas para el servicio de coaching ejecutivo y team building.

\subsubsection{Mercado objetivo.}

Es la demanda que se desea lograr, es componente del mercado efectivo y es elegida por los inversionistas, por tal motivo el mercado objetivo es al que irán los esfuerzos y acciones de marketing (Kinner \& Keller, 2012).

El mercado objetivo deriva del mercado efectivo del cual se determina el mercado que se pretende atraer $(\%)$.

La pregunta numero 3.11 nos permitió calcular nuestro mercado objetivo, ya que se pregunto la intención de contratación del servicio, obteniéndose que 16 empresas contratarían definitivamente el servicio y 42 empresas posiblemente contratarían el servicio, es así que se logró obtener un mercado meta de 58 empresas: 
Mercado Objetivo $(\mathrm{MO})=\mathrm{ME} *(\%$ pregunta $3.11,25 \%$ definitivamente si $\mathrm{y}$ $65 \%$ posiblemente si)

$\mathrm{MO}=65 * 89 \%=58$ empresas de coaching ejecutivo y team building

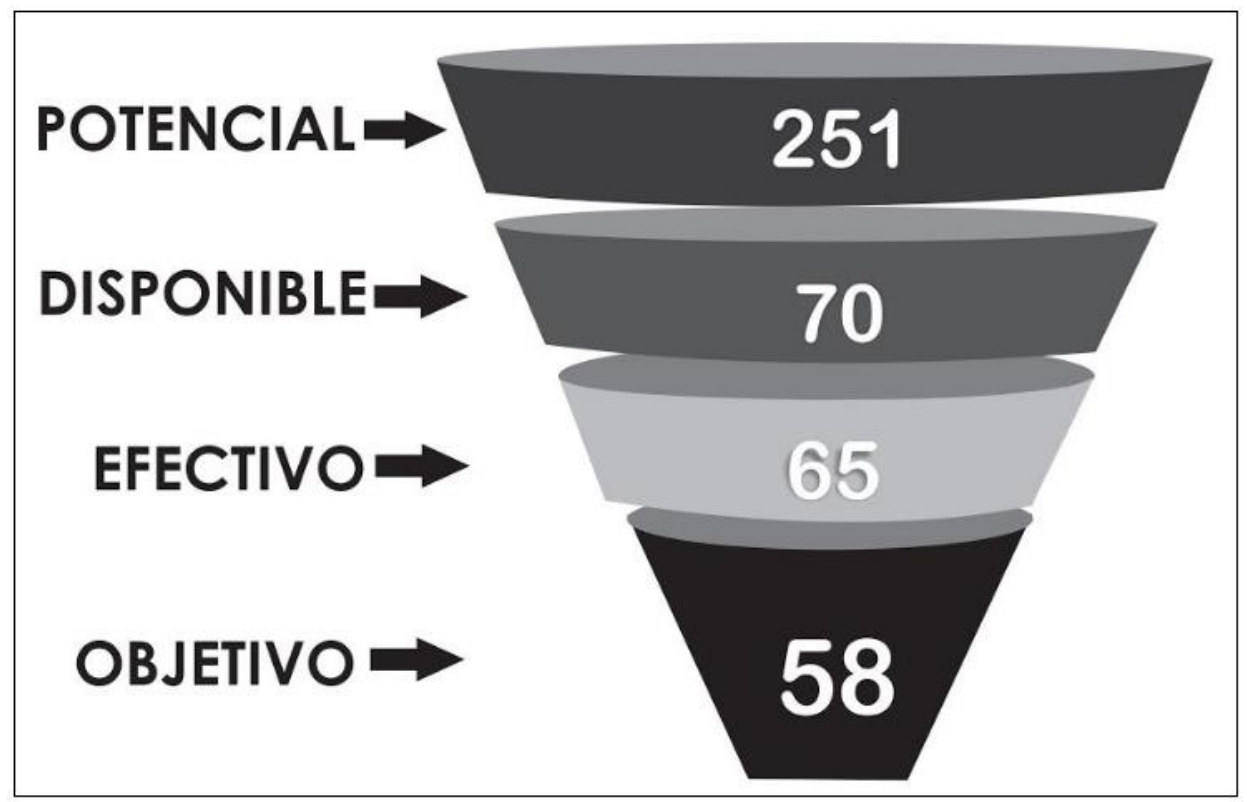

Figura $N^{o} 24$ : Selección de proyección de mercado

\subsection{Pronóstico de ventas}

El método usado es el de Juicio, tomando en cuenta el crecimiento del sector Servicios en lo que respecta al rubro de actividades de consultoría en el sector empresarial (ver tabla 20). Ahora bien realizándose el promedio móvil simple tomando dos periodos se pudó establecer que este tiene un patrón horizontal como lo proponen Krajewski, Ritzman \& Malhotra (2013) (ver figura 22). 


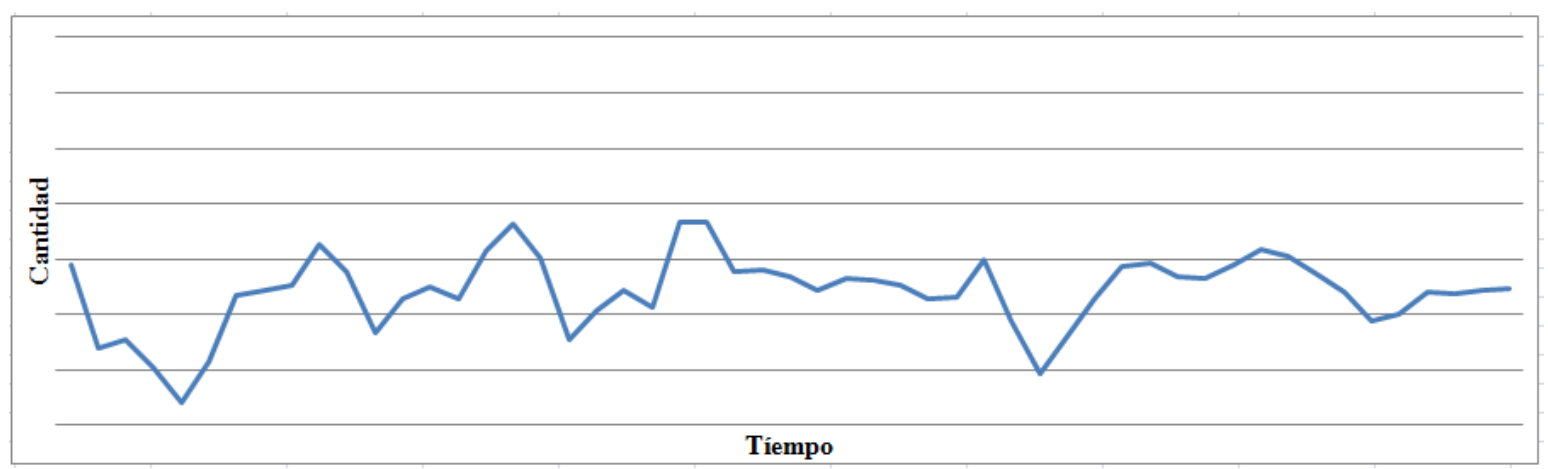

Figura 24. Patrón de datos horizontal del sector de actividades de consultoría de gestión empresarial. Tomado de "Encuesta mensual del sector servicios", por Instituto Nacional de Estadística e Informática, 2016, p.14

Según el promedio móvil simple el porcentaje de crecimiento anual será de $7.00 \%$ el cual ha sido considerado para la proyección anual del plan de negocio.

Tabla 22

Proyección de ventas anual

\begin{tabular}{|c|c|c|c|c|c|c|c|c|c|}
\hline Proyección Anual & & 2017 & & 2018 & & 2019 & & 2020 & 2021 \\
\hline CE (unidades) & & 29 & & 31,03 & & 33,2021 & & 35,526247 & 38,01308429 \\
\hline CE (soles) & $\mathrm{S} /$. & $87.000,00$ & $\mathrm{~S} /$. & $93.090,00$ & $\mathrm{~S} /$. & $99.606,30$ & $\mathrm{~S} /$. & $106.578,74$ & S/. $\quad 114.039,25$ \\
\hline TB (unidades) & & 29 & & 31,03 & & 33,2021 & & 35,526247 & 38,01308429 \\
\hline TB (soles) & $\mathrm{S} /$. & $145.000,00$ & $\mathrm{~S} /$. & $155.150,00$ & $\mathrm{~S} /$. & $166.010,50$ & $\mathrm{~S} /$. & $177.631,24$ & S/. $\quad 190.065,42$ \\
\hline TOTAL (unidades) & & 58 & & 62 & & 66 & & 71 & 76 \\
\hline TOTAL (soles) & $\mathrm{S} /$. & $232.000,00$ & $\mathrm{~S} /$. & $248.240,00$ & $\mathrm{~S} /$. & $265.616,80$ & $\mathrm{~s} /$. & $284.209,98$ & $304.104,67$ \\
\hline
\end{tabular}

Nota. Elaboración propia

\subsection{Aspectos críticos que impactan el pronóstico de ventas}

Permitirá conocer la cantidad de servicios que se generara, cuánto se necesita de insumos o mercadería, cuánto de personal se va a requerir, cuánto vamos a requerir de inversión, etc., y, de ese modo, lograr una gestión más eficiente del negocio, permitiendo planificar, coordinar y controlar actividades y recursos. Asimismo, el pronóstico de ventas permite conocer las utilidades de un proyecto (al restarle los futuros egresos a las futuras ventas), y, de ese modo, conocer la viabilidad del proyecto; razón por la cual el pronóstico 
de ventas suele ser uno de los aspectos más importantes de un plan de negocios (Crece Negocios, 2010).

- Entorno Político, variaciones en el Gobierno.

- Inflación, variaciones económicas. 


\section{Capítulo V: Ingeniería del Proyecto}

\subsection{Estudio de Ingeniería}

El estudio de ingeniería utiliza datos como los del estudio de mercado, marco regulatorio legal, alternativas de localización y estudio de la tecnología y disponibilidad de personal y financiera (Sapag, 2011).

\subsubsection{Modelamiento y selección de procesos productivos.}

Un proceso se define como una secuencia de operaciones que se encargan de transformar entradas en salidas de mayor valor. A su vez una operación de valor añadido es la que lleva al producto o servicio a su función final. Dicho de otra manera se añade funcionalidad al producto (Suñe, Gil \& Arcusa, 2010).

Se forma el proceso de ventas del servicio de coaching y team building el cual será un desarrollo muestra, el cliente externo y la empresa interactúan constantemente (ver figura 23). 


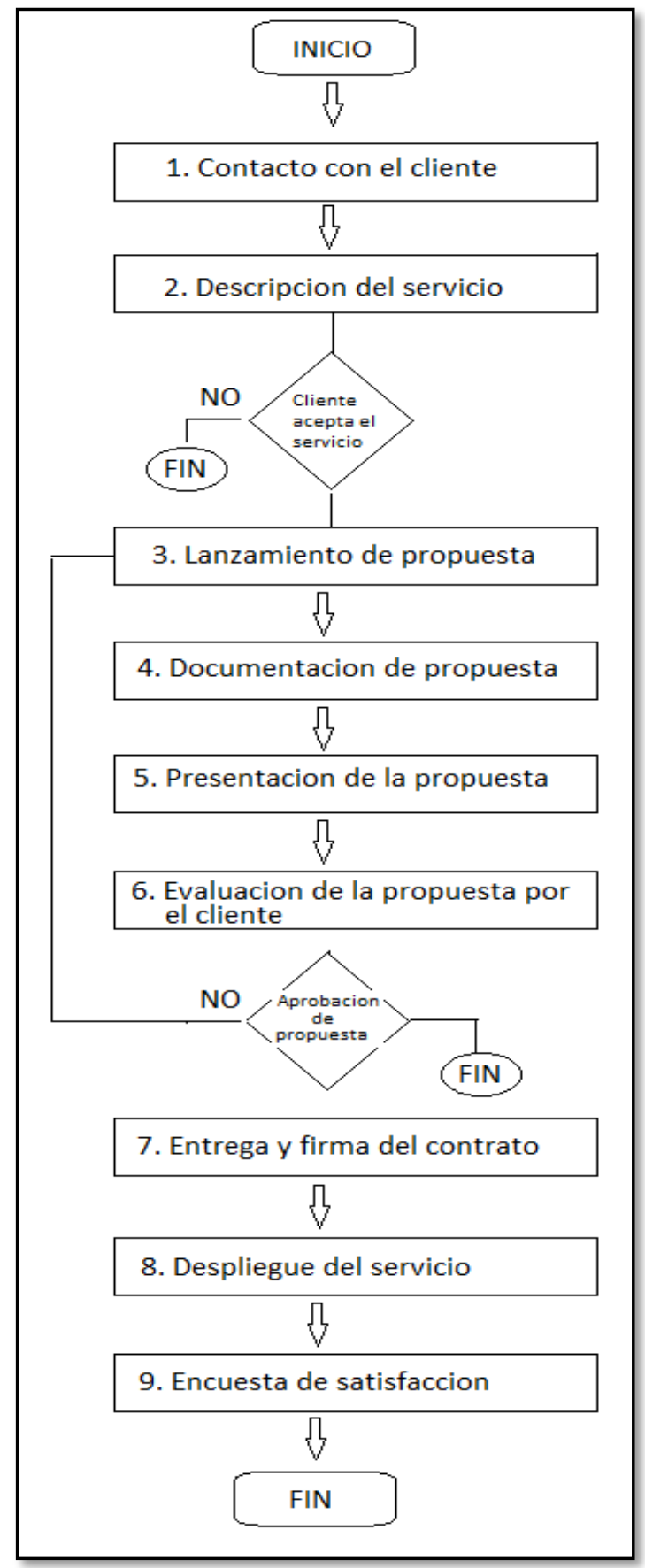

Figura 25. Diagrama de Flujo de Proceso de Venta 


\subsubsection{Selección del equipamiento.}

El equipamiento que se ha seleccionado para el plan de negocios es el que se describe en la tabla 23 y 24 :

Tabla 23

Selección de Equipamiento

\begin{tabular}{|c|c|c|c|c|c|}
\hline Equipo & $\mathrm{N}^{\circ}$ & \multicolumn{2}{|c|}{ Costo Unitario } & \multicolumn{2}{|c|}{ Costo Total } \\
\hline Material lúdico (LEGO) & 1 & $\mathrm{~S} / \mathrm{.}$ & $3,800.00$ & $\mathrm{~S} /$. & $3,800.00$ \\
\hline Papelería de juegos (LAYCONSA) & 1 & $\mathrm{~S} /$. & $1,800.00$ & $\mathrm{~S} /$. & $1,800.00$ \\
\hline Equipo de Sonido (SONY) & 2 & $\mathrm{~S} /$. & $2,400.00$ & S/. & $4,800.00$ \\
\hline Sistema de micros (SONY) & 1 & $\mathrm{~S} /$. & $1,500.00$ & $\mathrm{~S} /$. & $1,500.00$ \\
\hline Pedestales (SONY) & 2 & $\mathrm{~S} /$. & 500.00 & $\mathrm{~S} /$. & $1,000.00$ \\
\hline Cables extensiones (HALUX) & 1 & $\mathrm{~S} /$. & 300.00 & $\mathrm{~S} /$. & 300.00 \\
\hline Lap top (TOSHIBA) & 2 & $\mathrm{~S} /$. & $2,600.00$ & $\mathrm{~S} /$. & $5,200.00$ \\
\hline Ecram y proyector multimedia (EPSON) & 1 & $\mathrm{~S} /$. & $3,000.00$ & $\mathrm{~S} /$. & $3,000.00$ \\
\hline Cámara de fotos (CANON) & 1 & $\mathrm{~S} /$. & $1,000.00$ & $\mathrm{~S} /$. & $1,000.00$ \\
\hline Rollers de públicos (ARTESCO) & 2 & $\mathrm{~S} /$. & 300.00 & $\mathrm{~S} /$. & 600.00 \\
\hline Impresora (HP) & 1 & $\mathrm{~S} /$. & 500.00 & $\mathrm{~S} /$. & 500.00 \\
\hline Celular (SAMSUNG) & 2 & $\mathrm{~S} /$. & 100.00 & $\mathrm{~S} /$. & 200.00 \\
\hline Modem (HUAWEI) & 1 & $\mathrm{~S} /$. & 120.00 & $\mathrm{~S} /$. & 120.00 \\
\hline Total Equipo & & & & S/. & $23,820.00$ \\
\hline
\end{tabular}

Nota. Elaboración propia 
Tabla 24

Mobiliario de oficina

\begin{tabular}{lllrlr}
\hline \multicolumn{1}{c}{ Mobiliario } & $\mathrm{N}^{\circ}$ & \multicolumn{2}{c}{ Costo Unitario } & \multicolumn{2}{c}{ Costo Total } \\
\hline Escritorio & 2 & $\mathrm{~S} /$. & 300.00 & $\mathrm{~S} /$. & 600.00 \\
Estantes & 2 & $\mathrm{~S} /$. & 180.00 & $\mathrm{~S} /$. & 360.00 \\
Silla ejecutiva & 2 & $\mathrm{~S} /$. & 180.00 & $\mathrm{~S} /$. & 360.00 \\
Pizarra acrílica & 2 & $\mathrm{~S} /$. & 100.00 & $\mathrm{~S} /$. & 200.00 \\
Mampara de vidrios & 2 & $\mathrm{~S} /$. & 600.00 & $\mathrm{~S} /$. & $1,200.00$ \\
Letrero & 1 & $\mathrm{~S} /$. & 580.00 & $\mathrm{~S} /$. & 580.00 \\
Cuadros & 3 & $\mathrm{~S} /$. & 100.00 & $\mathrm{~S} /$. & 300.00 \\
Tachos de basura & 4 & $\mathrm{~S} /$. & 50.00 & $\mathrm{~S} /$. & 200.00 \\
Bandejas porta papeles & 2 & $\mathrm{~S} /$. & 30.00 & $\mathrm{~S} /$. & 60.00 \\
Ventilador & 2 & $\mathrm{~S} /$. & 120.00 & $\mathrm{~S} /$. & 240.00 \\
Sillas para recepción & 8 & $\mathrm{~S} /$. & 60.00 & $\mathrm{~S} /$. & 480.00 \\
Mesa de centro & 1 & $\mathrm{~S} /$. & 108.00 & $\mathrm{~S} /$. & 108.00 \\
Dispensador de agua & 1 & $\mathrm{~S} /$. & 50.00 & $\mathrm{~S} /$. & 50.00 \\
\hline Total Equipo & & & & $\mathrm{S} /$. & $4,738.00$ \\
\hline Nota. Elaboración propia & & & & &
\end{tabular}

Las especificaciones técnicas de los equipos y mobiliarios se encuentran en los anexos del presente plan de negocios. 


\subsubsection{Lay out.}

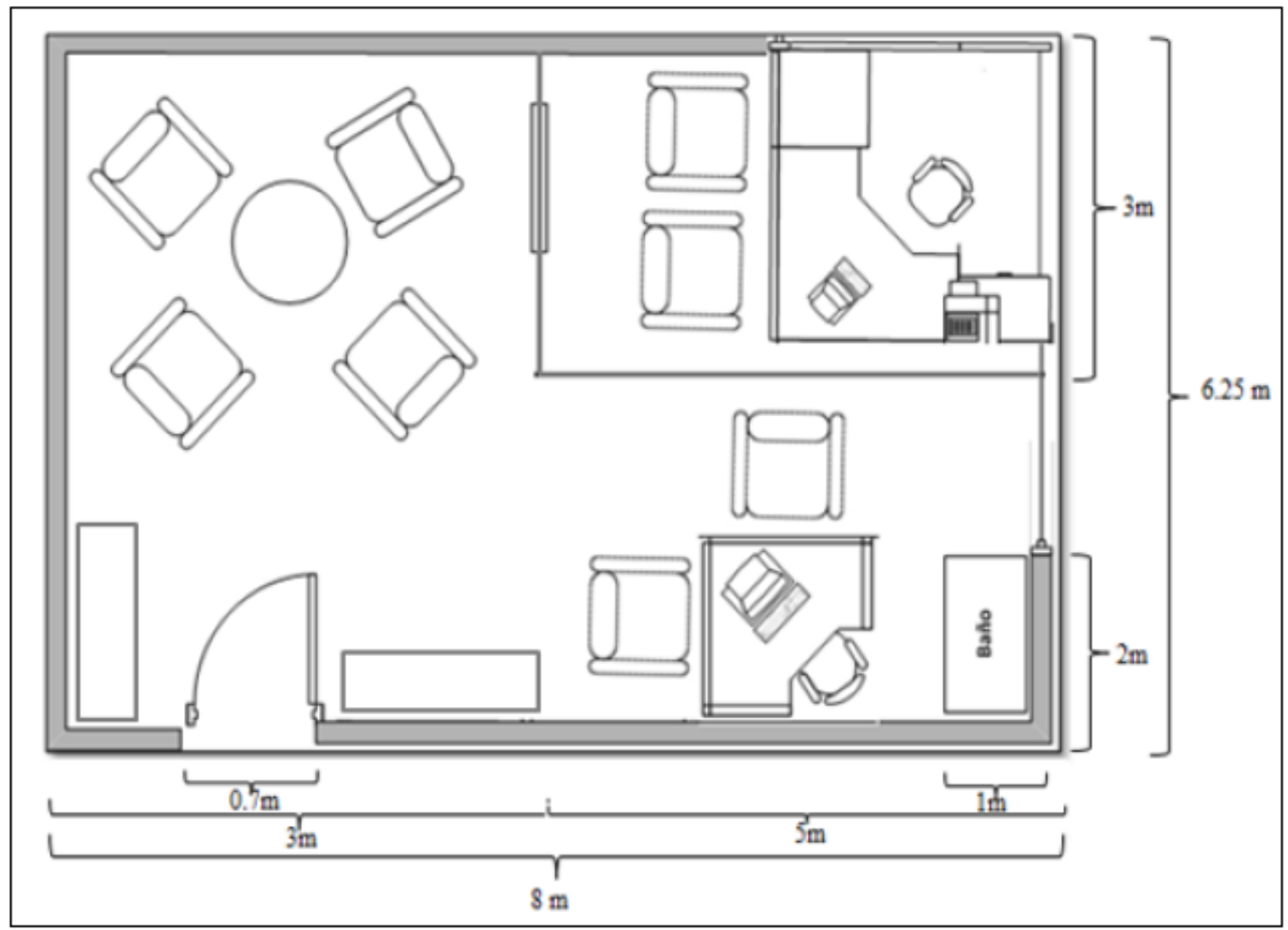

Figura 26. Lay Out Intenta Coaching y Teambuilding

\subsubsection{Distribución de equipos y maquinarias.}

La oficina de la empresa Intenta Coaching y Team building tendrá un área de $50 \mathrm{~m}^{2}$, los cuales estarán distribuidos respetando las normas de seguridad.

La distribución de los equipos está descrita según la figura que se muestra en la figura 25: 


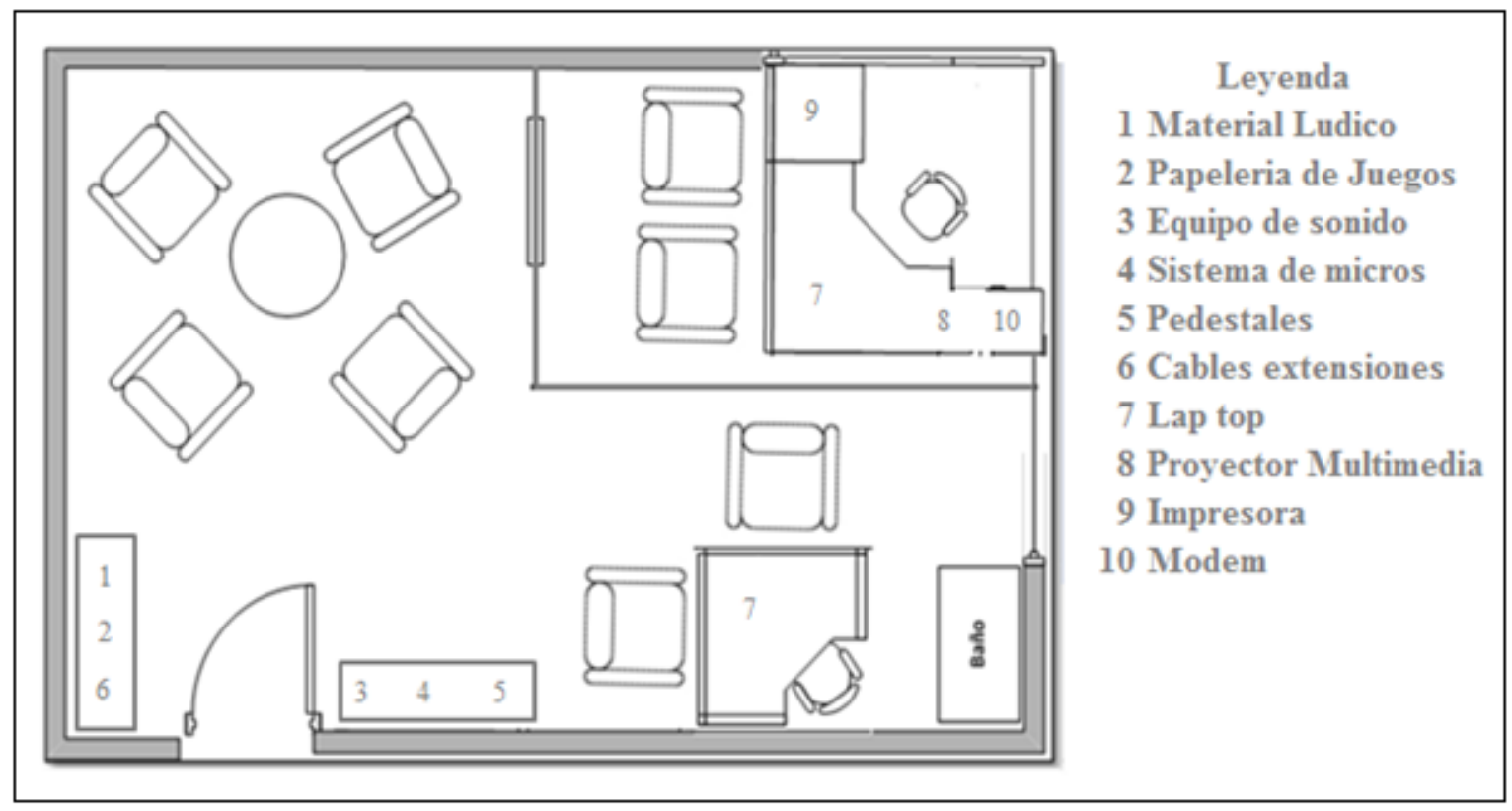

Figura 27. Layout distribución de maquinaria y equipos

\subsection{Determinación del tamaño}

El estudio del tamaño de un proyecto es fundamental para determinar el monto de las inversiones y el nivel de operación que, a su vez, permitirá cuantificar los costos de funcionamiento y los ingresos proyectados. Varios elementos se conjugan para la definición del tamaño: la demanda esperada, la disponibilidad de los insumos, la localización del proyecto, el valor de los equipos, etc. (Sapag, 2011).

El plan de negocio para la empresa Intenta Coaching y Team building ha considerado las siguientes áreas para la atención y funcionamiento de sus operaciones: (a) oficina de gerencia, (b) oficina administrativa, (c) sala de espera, y (d) baño. Las dimensiones de estas áreas se muestran en la tabla 25. 
Tabla $\mathrm{N}^{\mathrm{o}} 25$

Dimensión de áreas de oficina

\begin{tabular}{lr}
\hline Ubicación & Dimensión \\
\hline Oficina Gerencia & $15.00 \mathrm{~m}^{2}$ \\
Oficina Administrativa & $14.25 \mathrm{~m}^{2}$ \\
Sala de espera & $18.75 \mathrm{~m}^{2}$ \\
Baño & $2.00 \mathrm{~m}^{2}$ \\
\hline Total & $50.00 \mathrm{~m}^{2}$ \\
\hline Nota. Elaboración propia &
\end{tabular}

\subsubsection{Proyección de crecimiento.}

El plan de negocios presente tiene como finalidad establecer una empresa Business to business (B2B), motivo por el cual en la proyección de crecimiento no se considera como relevante el crecimiento físico o alquiler de algún otro predio, ya que uno de los pilares del funcionamiento de la empresa es salir a buscar clientes, tratando de reducir los costos y aumentar los ingresos.

Así mismo, ante el crecimiento de la empresa y con el incremento de servicios se propone un régimen de subcontratación laboral de especialistas en Coaching y Team building.

\subsubsection{Recursos.}

Los recursos financieros son una parte vital en la implementación de un proyecto, para el plan de negocios la totalidad de los recursos será aportada por los socios en partes iguales.

En lo referido a Recursos Humanos la empresa estará conformada por: (a) un gerente general, (b) asistente contable, (c) asistente de marketing y ventas, y (d) técnico de apoyo. 


\subsubsection{Tecnología.}

Se considera como uso fundamental el internet de banda ancha y página web de la empresa. En la tabla 26 los costos por material tecnológico:

Tabla 26

Recursos tecnológicos

\begin{tabular}{lcc}
\hline \multicolumn{1}{c}{ Intangibles } & Costo Mensual & Costo Anual \\
\hline Internet Banda Ancha/ Teléfono & 119.00 & $1,428.00$ \\
Página Web & 175.00 & $2,100.00$ \\
\hline Total Intangibles & & $3,528.00$ \\
\hline
\end{tabular}

Nota. Elaboración propia

\subsubsection{Flexibilidad.}

La flexibilidad es una característica de los procesos de una empresa que le permite reaccionar con rapidez y eficiencia ante las necesidades de los clientes. Algunos procesos requieren uno o más de los siguientes tipos de flexibilidad: personalización, variedad y flexibilidad de volumen (Krajewski, Ritzman \& Malhotra, 2013).

En el caso de que la proyección de crecimiento sea superada, se procederá a contratar profesionales especializados en coaching ejecutivo y teambuilding para poder cubrir la demanda del mercado. La aparición de nuevos servicios se considerara conforme el mercado aumente su volumen. 


\subsubsection{Selección del tamaño ideal.}

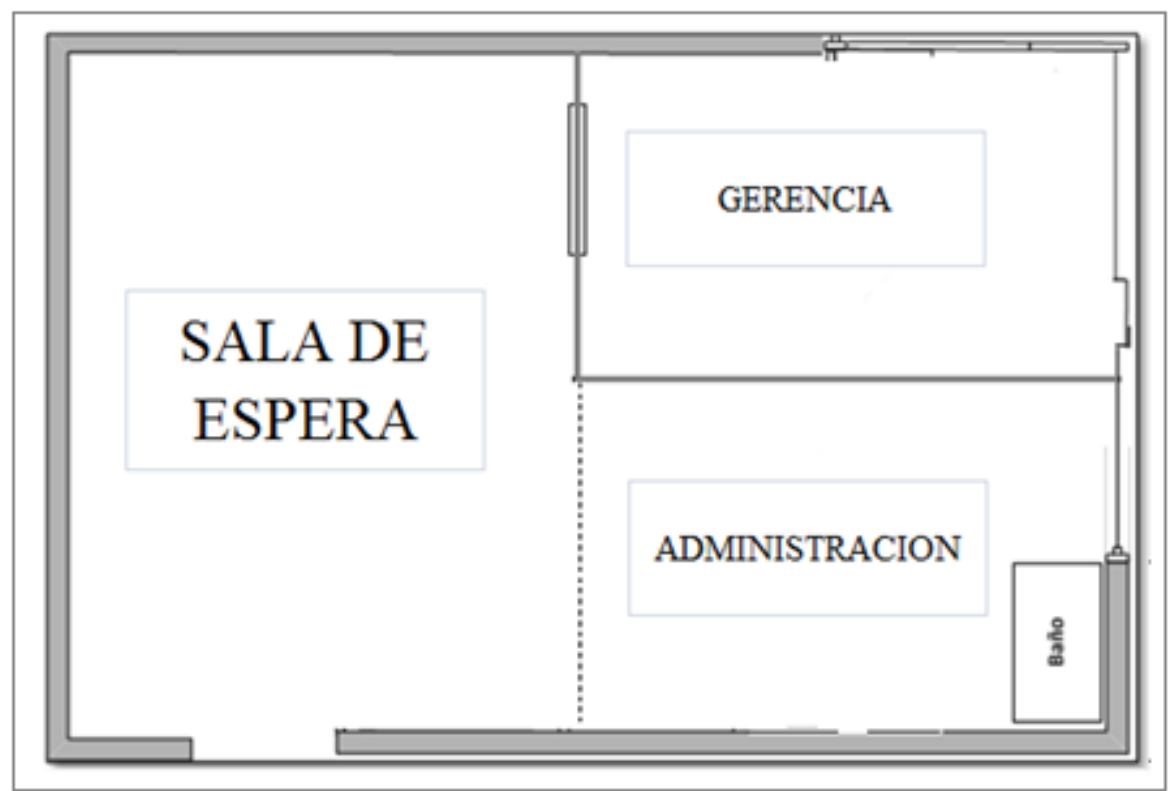

Figura 28. Layout Distribución de Áreas Intenta Coaching y Team building

\subsection{Estudio de Localización}

La localización que se elija para el proyecto puede ser determinante en su éxito o en su fracaso. La mejor ubicación será la que logre alcanzar el objetivo propuesto y ocupará la mayor población para maximizar la rentabilidad (Sapag, 2011).

\subsubsection{Definición de factores locacionales.}

Se define en dos ámbitos, (a) el de la macro localización, y (b) el del micro localización (Sapag, 2011).

Las instalaciones de Intenta coaching y team building se localizaran en la provincia de Arequipa, en el distrito de Arequipa, tiene una ubicación estratégica ya que sus costos de alquiler no son tan elevados y es cercano a los distritos donde se encuentran la mayoría de empresas objetivo (ver figura 27). 


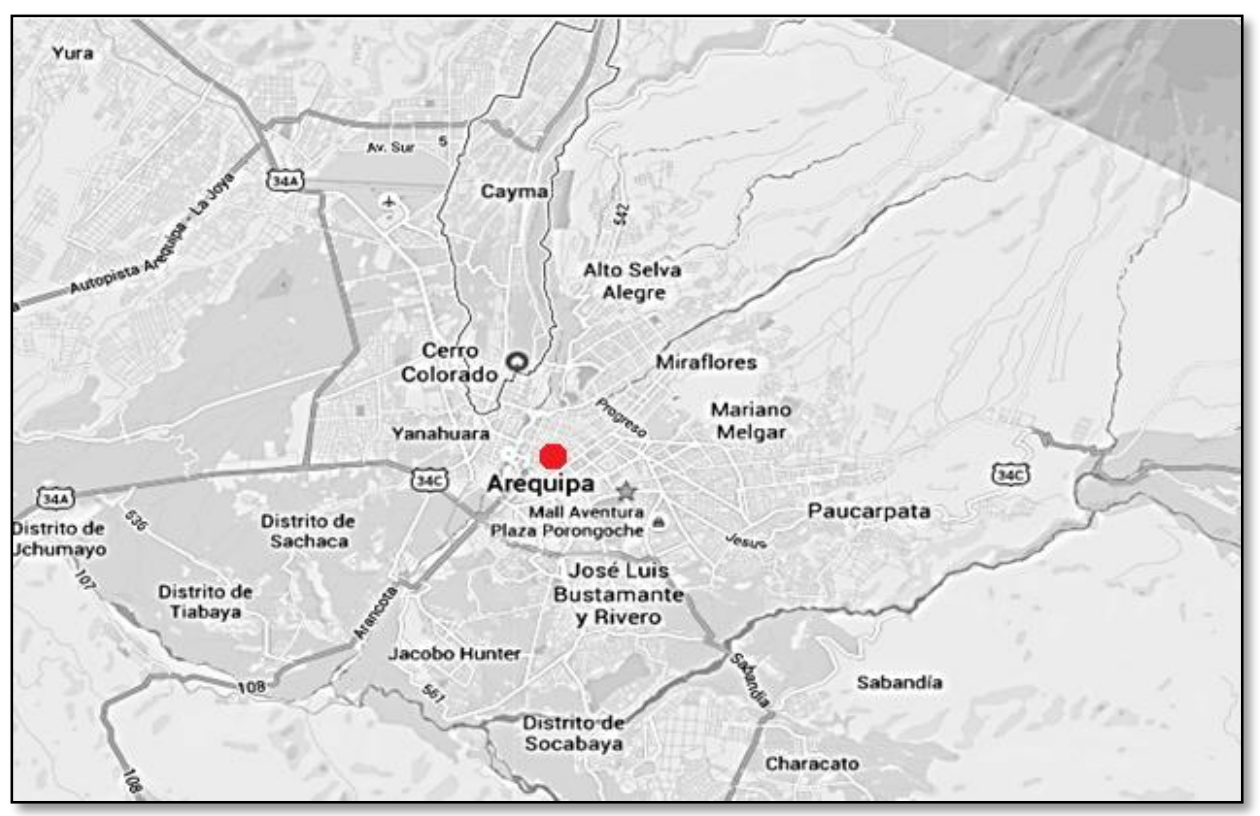

Figura 29. Macro localización del Proyecto. Por Google Earth, 2016.

Para la micro localización del proyecto se tomará en cuenta lo siguiente:

\section{Mercado de interés}

La empresa se encontrara en Arequipa distrito el cual es un punto medio para el acceso a las empresas a servir, además de ser un lugar de conexión rápida a las zonas industriales más relevantes.

2. Transporte y accesibilidad de los usuarios

Es un lugar de acceso rápido a distintos distritos y con vías de comunicación con amplia disponibilidad.

3. Regulaciones legales

Estará sujeta a la ley general de sociedades, Superintendencia Nacional de Administración Tributaria (SUNAT) y normas de la municipalidad distrital de 
Arequipa para la constitución de la empresa, además de Defensa Civil y el Ministerio de Trabajo.

4. Aspectos ambientales

Por ser una empresa de servicios el uso de papelería es mínimo al igual que el consumo de energía, la liberación de ruido y contaminación del suelo, agua y tierra son factores los cuales estarán dentro de los niveles mínimos permisibles.

5. Costo y disponibilidad de terrenos

En el departamento de Arequipa existe gran oferta de oficinas por el crecimiento económico relevante de los últimos años, siendo las zonas más comerciales los distritos de: Cayma, Arequipa, Paucarpata y Yanahuara, en donde los costos de alquiler se muestran en la tabla 27:

Tabla No 27

Costo de Alquiler por distrito

\begin{tabular}{ll}
\hline Distrito & Costo de Alquiler $\left(50 \mathrm{~m}^{2}\right)$ \\
\hline Cayma & $\mathrm{S} / 2,500$ a S/ 3,000 \\
Arequipa & $\mathrm{S} / 500$ a S/ 1,500 \\
Paucarpata & $\mathrm{S} / 500$ a S/ 1,500 \\
Yanahuara & $\mathrm{S} / 2,000$ a S/ 2,500 \\
\hline \multicolumn{2}{l}{ Nota Elaboración propia }
\end{tabular}

\subsubsection{Consideraciones legales.}

\subsubsection{Identificación del marco legal.}

Según el Ministerio de Trabajo (2013) el marco legal del proyecto estará regido por la por la ley $\mathrm{N}^{\circ} 28015$ para la promoción y formalización de la 
micro y pequeña empresa, esta ley establece el marco legal que deben contar las micro y pequeñas empresas.

La micro empresa cuenta con las siguientes características básicas a) número de trabajadores de 1 a 10, b) ventas anuales hasta 150 UIT

Según la ley $\mathrm{N}^{\circ} 26965$ las pymes no están obligadas a ser constituidas como personas jurídicas pero aquellas que opten por ser una de ellas lo deben realizar a través de una escritura pública sin ser obligatoria la presentación de la minuta de constitución y cuenta con los beneficios de la reducción de costos notariales y registrales.

Según el Ministerio de Economía y Finanzas (1993) en su Decreto Legislativo $\mathrm{N}^{\circ} 776$ de la ley de tributación, las licencias municipales provisionales deben ser otorgadas en un plazo máximo de siete días hábiles cumpliendo los requisitos de cada municipalidad. En caso la municipalidad no responda en el plazo indicado, esta licencia automáticamente se extenderá por un plazo de doce meses y se otorgará la licencia permanente, dado este caso la municipalidad no podrá cobrar renovación.

Según la SUNAT las pymes pueden escoger el régimen dependiendo del giro del negocio, régimen único simplificado, régimen especial de renta y régimen general de la renta, debiendo pagar impuesto a la renta e impuesto general a las ventas.

Según la ley general de sociedades las pymes pueden ser de forma societaria e individual siendo las más utilizadas a) Sociedad Anónima Cerrada, b) 
Sociedad Anónima, c) Sociedad Comercial de Responsabilidad Limitada, d) Empresa Individual de Responsabilidad Limitada.

La ley de promoción de la competitividad y del acceso al empleo decente indica que las pymes deben cumplir con ciertos beneficios para sus colaboradores los cuales incluyen: horas de trabajo, vacaciones, remuneración, seguro de salud y compensación por tiempo de servicios.

\subsubsection{Ordenamiento jurídico de la empresa.}

1. Por tipo de empresa

El proyecto será constituido como persona jurídica de tamaño microempresa, bajo la modalidad de Sociedad Anónima Cerrada, como tal está afecta a los siguientes requisitos:

- De 2 a 20 accionistas

- Puede funcionar sin directorio,

- Las acciones pueden ser transferidas de forma parcial o total en cualquier momento a los otros accionistas y también se podrá transferir a terceros no accionistas siempre y cuando hayan transcurrido sesenta días de haber puesto en conocimiento de esta su propósito de transferir, sin que la sociedad y/o los demás accionistas hubieran comunicado su voluntad de compra,

- Las acciones de la sociedad no son inscritas en el Registro Público del Mercado de Valores.

2. Por régimen tributario 
Para el orden tributario el proyecto estará bajo el Régimen General de Renta asignado por el tipo de actividad a realizar denominado otras actividades de servicios de apoyo a la empresa no clasificado previamente, Código Industrial Internacional Único (CIIU) número 8299. Como tal esta afecta a la siguiente tributación:

- Comprar exige factura, boleta de venta o ticket

- Vender se debe emitir factura, boleta de venta o ticket

- Puede emitir documentos complementarios como: nota de crédito, nota de débito, y guía de remisión.

- Los comprobantes se pueden emitir electrónicamente.

- Se debe hacer una declaración jurada anual.

- Pagos de tributos mensuales del 1.5\% según la ley del impuesto a la renta y $18 \%$ de impuesto general a las ventas (IGV).

Los libros contables obligatorios son: (a) registro de compras, (b) registro de ventas, (c) libro diario, y (d) los libros deben ser llevados en idioma español, en moneda nacional y legalizado por un notario.

3. Por consideraciones municipales

El proyecto estará ubicado en el distrito de Arequipa, según TUPA municipal del distrito, para obtener la licencia de funcionamiento. Para locales menores de 100 metros cuadrados lo requisitos son los siguientes:

- Formato de solicitud de licencia de funcionamiento, con carácter de declaración jurada, que incluye: (a) número de RUC y DNI del 
solicitante, para personas jurídicas o naturales, según corresponda y (b) número de DNI del representante legal, en caso de persona jurídica u otros entes colectivos.

- Copia de la vigencia de poder de representante legal en caso de personas jurídicas u entes colectivos.

- Indicación del número de comprobante de pago por derecho de trámite.

- Declaración jurada de observancia de condiciones de seguridad

- Certificado INDECI

4. Por régimen laboral

Por ser una microempresa el proyecto contara con los siguientes beneficios para el personal que se presenta en la tabla 28. 
Tabla 28

Régimen Laboral

Beneficios Laborales

Remuneración mínima vital

$\mathrm{S} / 850$

Jornada laboral

$8 \mathrm{~h}$ diarias y $48 \mathrm{~h}$ semanales

CTS

No aplica

Gratificaciones

No aplica

Utilidades

Vacaciones

No aplica

15 días

Despido Injustificado

Indemnización: 10 remuneraciones

diarias por cada año completo de

servicios, con un máximo de 90

Seguro de Vida

remuneraciones diarias.

No aplica

Componente semi subsidiado del

Seguro Integral de Salud. El

Seguro Social

empleador y el Estado aportan cada

uno el $50 \%$, es decir $4.5 \%$ de la

remuneración

Para trabajadores no afiliados a otro

Sistema de Pensiones

sistema previsional

Nota. Por Superintendencia Nacional de Aduanas y de Administración

Tributaria (SUNAT), 2016.

\subsection{Determinación de la localización óptima}

La oficina de la empresa Intenta coaching y team building se localizará en Arequipa provincia, en el distrito de Arequipa, tiene una ubicación estratégica por la cercanía a los distritos donde se encuentran la mayoría de empresas objetivo tales como Yanahuara, Jose Luis Bustamante y Rivero, Cayma y Cerro Colorado. Se emplearon los factores ponderados como metodología en la definición de la ubicación, reconoce costos que relacionan la ubicación de las instalaciones mediante las escalas del 1 al 5 donde 1 es Desfavorable y 5 Muy favorable. Se eligió el distrito de Arequipa debido a que en la suma de puntaje está tiene mayor valoración (ver tabla 29). 
Tabla 29

Factores de localización Óptima

\begin{tabular}{|c|c|c|c|c|c|c|c|}
\hline \multirow{2}{*}{$\begin{array}{l}\text { Factor de } \\
\text { Localización }\end{array}$} & \multirow{2}{*}{ Importancia } & \multicolumn{2}{|l|}{ Arequipa } & \multicolumn{2}{|l|}{ Cayma } & \multicolumn{2}{|l|}{ Yanahuara } \\
\hline & & Calificación & Ponderación & Calificación & Ponderación & Calificación & Ponderación \\
\hline $\begin{array}{l}\text { 1.Mercado que } \\
\text { se desea } \\
\text { atender }\end{array}$ & 0,35 & 5 & 1,75 & 4 & 1,4 & 4 & 1,4 \\
\hline $\begin{array}{l}\text { 2.Transporte y } \\
\text { Comunicación }\end{array}$ & 0,25 & 4 & 1 & 5 & 1,25 & 4 & 1 \\
\hline $\begin{array}{l}\text { 3.Regulaciones } \\
\text { legales }\end{array}$ & 0,1 & 3 & 0,3 & 3 & 0,3 & 3 & 0,3 \\
\hline $\begin{array}{l}\text { 4.Factores } \\
\text { Ambientales }\end{array}$ & 0,1 & 3 & 0,3 & 2 & 0,2 & 2 & 0,2 \\
\hline $\begin{array}{l}\text { 5.Costo y } \\
\text { disponibilidad }\end{array}$ & 0,2 & 4 & 0,8 & 2 & 0,4 & 3 & 0,6 \\
\hline Total & 1,0 & & 4,15 & & 3,55 & & 3,5 \\
\hline
\end{tabular}

Nota. Elaboración propia 


\section{Capítulo VI: Aspectos Organizacionales}

\subsection{Caracterización de la Cultura Organizacional Deseada}

Se entiende por cultura organizacional al modo de vida de la organización en todos sus aspectos: ideas, creencias, costumbres, reglas técnicas, etc. Todos los seres humanos están dotados de cultura, pues forman parte de algún sistema cultural. Resumiendo, se entiende por cultura organizacional al conjunto de creencias, hábitos que son establecidos atreves de normas, valores y actitudes compartidos por todos los miembros de una organización. Intenta coaching y team building tendrá una cultura del tipo "Club” que hará énfasis en la lealtad, el trabajo para bien del grupo y privilegia el derecho de las personas; cree en los generalistas y en el proceso gradual de la carrera profesional. (Chiavenato, 2011)

\subsubsection{Visión.}

Se entiende por visión a la imagen que la organización tiene de sí misma y de su futuro (Chiavenato, 2011).

La visión de Intenta Coaching es:

Ser la mejor empresa de coaching ejecutivo y team building de todo el sur del país.

\subsubsection{Misión.}

La misión representa la razón de existencia de la empresa, es la finalidad o motivo que condujo a la creación de la empresa de la organización. Una misión debe de ser compartida y debe de ser parte del ADN de la organización. (Chiavenato, 2011). 
La misión de Intenta Coaching es:

Ser una empresa que potencia el talento humano de las organizaciones, obteniendo la mejor versión de cada colaborador y construyendo equipos de alto nivel para el alto rendimiento de las organizaciones con personal especializado.

\subsubsection{Principios.}

Los principios son normas y creencias de conducta las cuales deben estar orientadas a cumplir la visión y misión de la empresa, la integración de estos principios a la cultura organizacional de la empresa da como resultado una mejor conexión con la búsqueda de la visión y misión de las empresas (Thompson et al., 2012)

Para el plan de negocios se establecen los siguientes principios:

1. Respeto: Aprecio y valoración de cada uno de los colaboradores.

2. Mejora continua: Orientar esfuerzos para el constante mejoramiento de procesos de la organización.

3. Innovación: Modificar el entorno de manera creativa sin tener temor a los desafíos presentados en el día a día.

4. Responsabilidad social: Asumir la mejora continua social, ambiental y económica del entorno.

5. Satisfacción del cliente: Trabajar tomando en cuenta la percepción del cliente sobre el nivel de trabajo cumplido. 


\subsection{Formulación de Estrategias del Negocio}

Se entiende por Estrategia del Negocio al conjunto de maniobras desarrolladas en un ambiente competitivo para aprovechar oportunidades externas y evitar las amenazas ambientales, al mismo tiempo que se aplican con más intensidad las fortalezas internas y se corrigen las debilidades internas.

La estrategia corporativa representa el camino elegido por la empresa para enfrentar turbulencias externas y aprovechar los recursos de la mejor manera posible.

La estrategia a implementar será una estrategia prospectiva y ofensiva basada en la innovación y flexibilidad. Esta estrategia implica pone énfasis en ser el primero en el mercado y está orientada a resultados, enfoques en las necesidades del personal; evaluación corporativa y divisional (Chiavenato, 2011).

Las estrategias en el plan de negocios de Intenta coaching y team building se describen en las tablas 30 y 31 : 
Tabla No 30

Matriz de estrategias de negocio Intenta Coaching y Team building

\begin{tabular}{|c|c|c|c|c|c|}
\hline OBJETIVO & ESTRATEGIAS & ACTIVIDADES & RESULTADOS & INDICADORES & RESPONSABLE \\
\hline \multicolumn{6}{|c|}{ FINANCIERO } \\
\hline $\begin{array}{l}\text { Obtener rentabilidad a partir del segundo } \\
\text { periodo }\end{array}$ & $\begin{array}{l}\text { Creación de un Plan de Ventas } \\
\text { agresivo en el mercado potencial y } \\
\text { meta. }\end{array}$ & $\begin{array}{l}\text { Implementación del } \\
\text { Plan de ventas }\end{array}$ & $\begin{array}{l}\text { Incremento de los } \\
\text { ingresos de la } \\
\text { empresa }\end{array}$ & $\begin{array}{l}\text { Ingresos en un } \\
15 \%\end{array}$ & Gerente General \\
\hline \multicolumn{6}{|c|}{$\begin{array}{l}\text { RECURSOS HUMANOS } \\
\end{array}$} \\
\hline $\begin{array}{l}\text { Fortalecer la competitividad del cliente } \\
\text { interno }\end{array}$ & $\begin{array}{l}\text { Capacitación constante del ejecutivo } \\
\text { de ventas }\end{array}$ & $\begin{array}{l}\text { Capacitar al } \\
\text { personal en cursos } \\
\text { de coaching } \\
\text { ejecutivo, atención } \\
\text { al cliente y } \\
\text { creatividad }\end{array}$ & Personal capacitado & $\begin{array}{l}100 \% \text { de } \\
\text { colaboradores } \\
\text { capacitados }\end{array}$ & Gerente General \\
\hline $\begin{array}{l}\text { Brindar bonificaciones extraordinarias al } \\
\text { ejecutivo de ventas }\end{array}$ & $\begin{array}{l}\text { Capacitación en técnicas de ventas y } \\
\text { atención al cliente }\end{array}$ & $\begin{array}{l}\text { Bonificaciones por } \\
\text { cumplimiento de } \\
\text { metas }\end{array}$ & $\begin{array}{l}\text { Personal motivado } \\
\text { y comprometido }\end{array}$ & $\begin{array}{l}100 \% \text { de } \\
\text { motivación y } \\
\text { compromiso en } \\
\text { el Ejecutivo de } \\
\text { ventas }\end{array}$ & \\
\hline
\end{tabular}




\section{Tabla No 31}

Matriz de estrategias de negocio Intenta Coaching y Team building

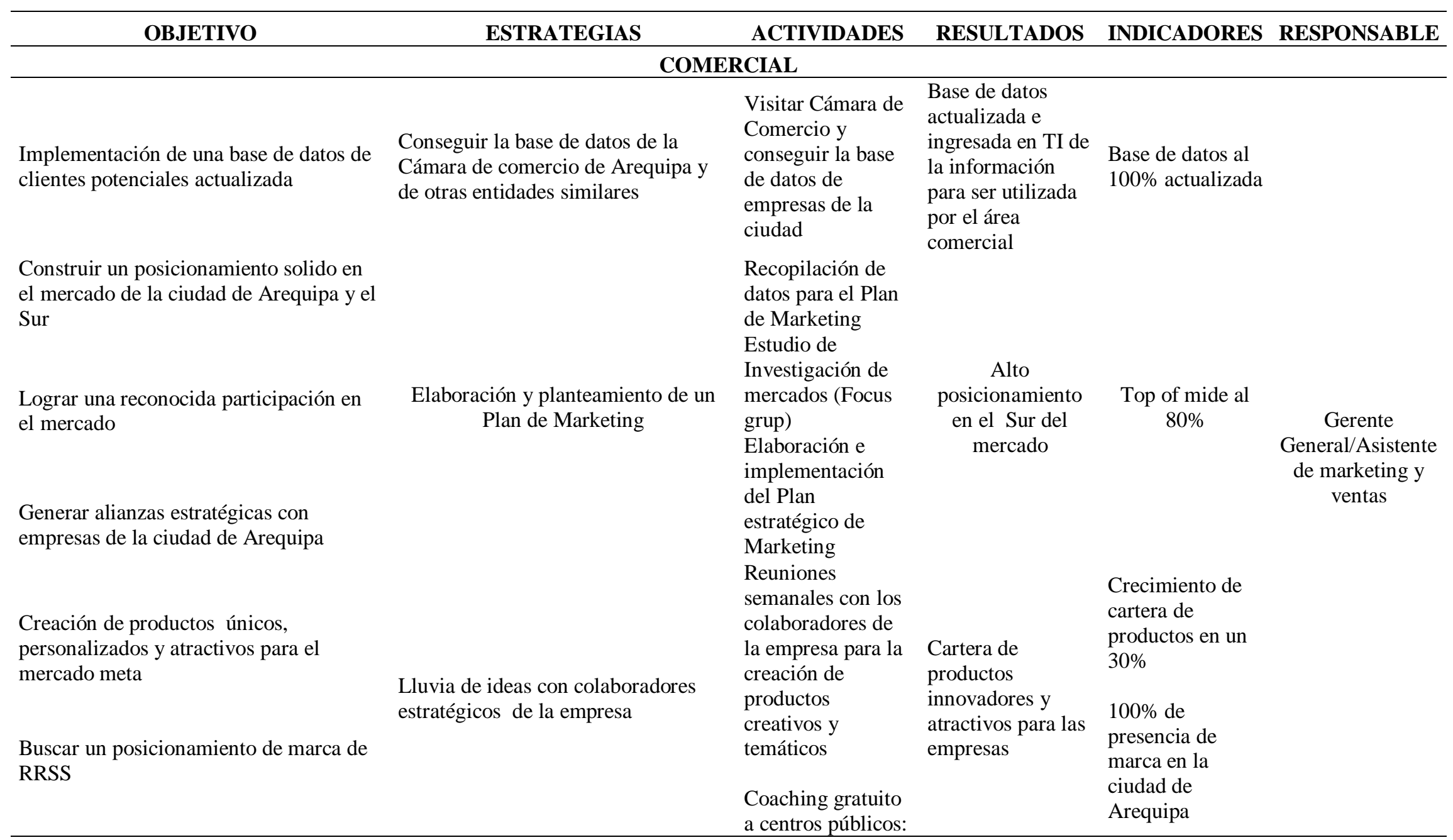


orfanatos acilos,

casa de mujeres

maltratadas, penal

de mujeres.

\section{TECNOLOGIAS DE INFORMACION}

\begin{tabular}{|c|c|c|c|c|c|}
\hline $\begin{array}{l}\text { Adquirir un software adecuado que } \\
\text { permita tener un control de las } \\
\text { Actividades de la empresa }\end{array}$ & $\begin{array}{l}\text { Comprar un software adecuado para } \\
\text { la empresa }\end{array}$ & $\begin{array}{l}\text { Buscar un } \\
\text { proveedor para la } \\
\text { compra del } \\
\text { software }\end{array}$ & $\begin{array}{l}\text { Software de CRM } \\
\text { implementado en } \\
\text { la empresa }\end{array}$ & $\begin{array}{l}\text { Sistema } \\
\text { operativo al } \\
100 \%\end{array}$ & \\
\hline $\begin{array}{l}\text { Estar a la vanguardia en tecnologías de la } \\
\text { información }\end{array}$ & $\begin{array}{l}\text { Elaboración de un Plan de Marketing } \\
\text { Digital }\end{array}$ & $\begin{array}{l}\text { Implementación } \\
\text { del Plan de MKT } \\
\text { Digital }\end{array}$ & $\begin{array}{l}\text { Alto } \\
\text { Posicionamiento } \\
\text { en Redes Sociales }\end{array}$ & $\begin{array}{l}100 \% \text { de } \\
\text { presencia de } \\
\text { marca en redes } \\
\text { sociales }\end{array}$ & Gerente General \\
\hline
\end{tabular}


Tabla 32

Matriz FODA

\section{FORTALEZAS}

F1 Dirección altamente capacitada y especializada

F2 Conocimiento del mercado objetivo Servicio personalizado innovador y de calidad.

F3 Flexibilidad de precios de acuerdo a las necesidades del mercado.

F4 Respaldo financiero por parte de los accionistas

\section{DEBILIDADES}

D1

Poco conocimiento de la empresa Intenta en el mercado

D2 Falta de un software de CRM

D3 Elevada dependencia de los Recursos Humanos

D4 Falta de experiencia en el servicio que se brinda por ser una empresa nueva

F5 Rápido acceso al mercado objetivo

\section{OPORTUNIDADES}

Necesidad de empresas por motivar y

o1 potenciar sus equipos de trabajo para obtener mayor productividad.

02 Alto índice de rotación de personal en las empresas

O3 Pocos competidores en el mercado de la ciudad de Arequipa

Posibilidad de crecimiento en el Sur del

O4 País.

O5 Amplia red de networking de coach certificados

Alta tendencia de crecimiento del

O6 coaching ejecutivo y team Building en el país

\section{AMENAZAS}

A1 Ingreso de nuevas consultoras de la ciudad de Lima

Otros profesionales que comiencen

A2 a brindar el servicio de coaching ejecutivo.

Empresas de recursos humanos que

A3

diversifiquen sus servicios

ofreciendo coaching ejecutivo y

team Building.

Que las empresas capaciten al personal de recursos humanos y/o

A4 gerentes para tener coach internos en las empresas

Obtención masiva de certificados

A5 en coaching por distintas

instituciones 
Tabla 33

Matriz Estratégica

\begin{tabular}{ll}
\hline \multicolumn{1}{c}{ AMENAZAS } \\
\hline & \multicolumn{1}{c}{ Reforzar para reducir riesgos } \\
DA. Alquiler de un local estratégicamente \\
ubicado en el centro de la ciudad de \\
Arequipa. \\
\\
DA. Implementación de un software de \\
CRM para monitorear a los clientes \\
DA. Implementación de un Plan de \\
posicionamiento sólido para la generación de \\
barreras de entradas para la competencia \\
D.A. Estrategia de precios flexibles idóneo \\
al mercado.
\end{tabular}

\section{Defender para superar limitaciones}

DO.Crear paquetes de servicios que sean innovadores frente a los de la competencia

\section{OPORTUNIDADES}

\section{Movilizar para enfrentar desafíos}

DO. Desarrollar un Plan de Marketing orientado a un posicionamiento fuerte en el mercado y a productos innovadores.

DO. Desarrollar campañas agresivas de publicidad para dar a conocer el servicio de la empresa en Arequipa

DO. Implementación de un Plan de Marketing digital alineado a la estrategia principal

DO. Alianzas estratégicas con coach internacionales con la misma o similar certificación (Plan de contingencia)

\section{Atacar para aprovechar potencialidades}

FA. Promocionar la certificación internacional de INCAE con especialización de la metodología SUN de los coachs

FA. Aprovechar la poca competencia que existe en el mercado Arequipeño para

desarrollar nuevos servicios y nichos de mercado en las empresas de Arequipa

FA. Fortalecer red de networking empresarial

FO. Innovar con los productos de servicio de coaching y team building para incrementar el alcance del mercado. FO. Aprovechar el poco ingreso de competencia de la ciudad de Lima en el mercado de Arequipa para prospectar la mayor cantidad de clientes potenciales en la ciudad y el Sur.

FO. Desarrollar un programa de Comunicación integral de marketing (CIM) y posicionar la marca de la empresa como líder indiscutible en la Ciudad de Arequipa 


\subsection{Determinación de las Ventajas Competitivas Críticas}

La ventaja competitiva se refiere a todo aquello especialmente bien que hace una empresa en comparación con sus competidores. El análisis VRIO, fue desarrollado por Jay Barney el año 1991 y permite determinar la ventaja competitiva de una empresa realizando las siguientes preguntas:

1. Valor: ¿el recurso otorga valor a la posición competitiva de la empresa?

2. Raro: ¿el recurso lo poseen pocas empresas?

3. Inimitable: ¿las empresas que no cuentan con el recurso se encuentran en desventaja?

4. Organización: ¿la organización de la empresa es apropiada para el uso del recurso?

Bajos dichos parámetros se puede determinar las siguientes ventajas: (a) VCS = Ventaja Competitiva Sostenible, (b) VCT = Ventaja Competitiva Temporal, (c) $\mathrm{PC}=$ Paridad Competitiva, y (d) DV = Desventaja Competitiva (Jay \& Hesterly, 2010). 
Tabla $\mathrm{N}^{\mathrm{o}} 34$

Matriz VRIO Intenta Coaching y Team Building

\begin{tabular}{|c|c|c|c|c|c|}
\hline Recurso/Capacidad & $\mathrm{V}$ & $\mathrm{R}$ & I & $\mathrm{O}$ & $\begin{array}{l}\text { Implicancia } \\
\text { competitiva }\end{array}$ \\
\hline \multicolumn{6}{|c|}{ Recursos financieros } \\
\hline Recursos financieros propios & SI & $\mathrm{NO}$ & NO & SI & VCT \\
\hline Bajos costos en pago de planillas & SI & NO & $\mathrm{NO}$ & SI & VCT \\
\hline Flexibilidad de precios & SI & NO & NO & SI & VCT \\
\hline \multicolumn{6}{|c|}{ Recursos humanos } \\
\hline \multirow[t]{2}{*}{ Coach internacionales certificados como aliados } & SI & NO & NO & SI & VCS \\
\hline & SI & SI & SI & SI & VCS \\
\hline \multicolumn{6}{|c|}{ Recursos tecnológicos } \\
\hline Software CRM & SI & $\mathrm{NO}$ & NO & SI & VCT \\
\hline \multicolumn{6}{|c|}{ Recursos comerciales } \\
\hline Metodología de coaching SUN y team building & SI & SI & SI & SI & VCS \\
\hline Servicio al cliente personalizado & SI & $\mathrm{NO}$ & SI & SI & $\mathrm{VCE}$ \\
\hline Creación e innovación de servicios & SI & NO & SI & SI & VCE \\
\hline $\begin{array}{l}\text { Creación de productos orientados a la RRSS } \\
\text { (coaching gratuito a entidades públicas y privadas) }\end{array}$ & SI & SI & SI & SI & VCS \\
\hline
\end{tabular}

Nota. Elaboración propia

Se puede concluir que la ventaja competitiva del plan de negocios se centra en el recurso humano especializado que brindara los servicios de coaching ejecutivo y team building con la metodología "Sun” que solo la puede dar un coach que tenga certificación en el INCAE Bussiness School, que si bien es una ventaja competitiva imitable en el tiempo, por el momento ningún coach en la ciudad de Arequipa la tiene y da respaldo al plan de negocios. Otra ventaja competitiva es el nuestra estrategia de responsabilidad social, que aún no la brindan en la ciudad de Arequipa y trata de brindar sesiones gratuitas de coaching y team building a las instituciones del estado como los penales, orfanatos, 
asilos y otros como aporte por parte de Intenta coaching ejecutivo y team building a la sociedad.

\subsection{Diseño de la Estructura Organizacional Deseada}

Se puede definir como diseño organizacional a la metodología usada para construir el organigrama de la empresa, incluyendo cargos que son parte de la estructura. (Louffat, 2010).

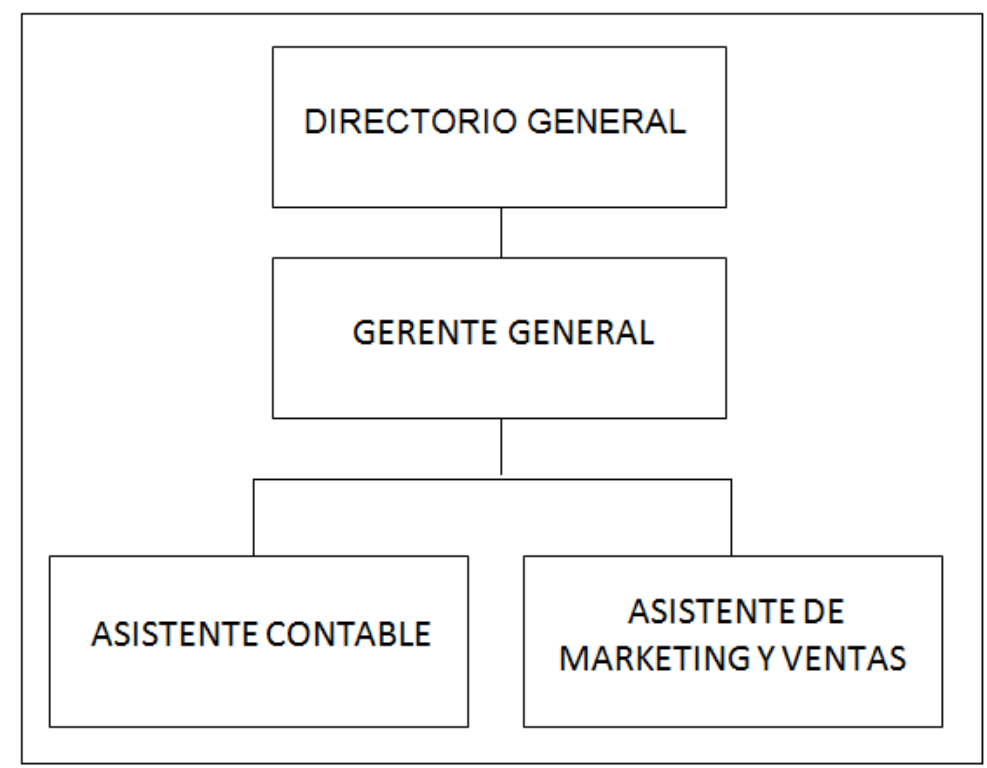

Figura 30. Organigrama de Intenta Coaching

\subsection{Diseño de los Perfiles de Puestos Clave}

El diseño de los perfiles es parte del formato de la organización que determina la distribución, configuración y grado de especialización de los cargos. Intenta Coaching y Team Building tendrá unas estructuras flexibles y adaptables, abiertas y manejables.

Analizar un cargo significa detallar que exige el cargo del ocupante en términos de conocimientos, habilidades y capacidades para desempeñarlo de manera adecuada. 
El diseño de puestos es importante porque estudia y determina los requisitos, responsabilidades y condiciones que el puesto exige para que el colaborador tenga un desempeño adecuado (ver tabla 35) (Chiavenato, 2011).

Tabla $\mathrm{N}^{\circ} 35$

Perfil de puesto del Gerente General 


\begin{tabular}{|c|c|c|c|}
\hline \multicolumn{2}{|c|}{ Requisitos } & Funciones & Competencias \\
\hline Profesión & $\begin{array}{l}\text { Administración, } \\
\text { Economía, } \\
\text { Derecho, } \\
\text { Ingeniería } \\
\text { Industrial }\end{array}$ & $\begin{array}{l}\text { - Velar por la visión de la empresa y el } \\
\text { cumplimiento de su misión. }\end{array}$ & - Desarrollo del equipo. \\
\hline $\begin{array}{l}\text { Grado de } \\
\text { instrucción }\end{array}$ & $\begin{array}{l}\text { Post grado } \\
\text { Maestría }\end{array}$ & $\begin{array}{l}\text { - Planificar los objetivos generales y } \\
\text { específicos de la empresa a corto y largo } \\
\text { plazo. }\end{array}$ & - Liderazgo para el cambio \\
\hline Grado académico & Titulado & $\begin{array}{l}\text { Dirigir, controlar y administrar la } \\
\text { ejecución de las políticas de la entidad en } \\
\text { concordancia con la normatividad legal } \\
\text { vigente. }\end{array}$ & - Pensamiento estratégico. \\
\hline $\begin{array}{l}\text { Conocimiento de } \\
\text { idiomas }\end{array}$ & Ingles intermedio & $\begin{array}{l}\text { - Definir el presupuesto anual de la } \\
\text { empresa y velar por su cumplimiento. }\end{array}$ & - Empowerment \\
\hline $\begin{array}{l}\text { Conocimiento de } \\
\text { informática }\end{array}$ & Nivel intermedio & $\begin{array}{l}\text { - Supervisar financiera y comercialmente } \\
\text { las gerencias y departamentos con un } \\
\text { enfoque minucioso de control de gastos } \\
\text { y gestión }\end{array}$ & - Orientación a resultados \\
\hline $\begin{array}{l}\text { Experiencia } \\
\text { laboral }\end{array}$ & 5 años & $\begin{array}{l}\text { - Evaluar los proyectos que presenta la } \\
\text { gerencia de operaciones con el fin de } \\
\text { integrar los diferentes departamentos } \\
\text { cumpliendo con el lineamiento } \\
\text { estratégico para mantener la eficiencia y } \\
\text { lograr sinergia en la organización }\end{array}$ & - Adaptabilidad al cambio \\
\hline $\begin{array}{l}\text { Experiencia en el } \\
\text { cargo o áreas } \\
\text { similares }\end{array}$ & 2 años & $\begin{array}{l}\text { - Analizar los problemas de la empresa } \\
\text { en el aspecto financiero, administrativo, } \\
\text { personal, contable entre otros y definir } \\
\text { estrategias de solución. }\end{array}$ & - Orientación al cliente interno y externo \\
\hline
\end{tabular}


Tabla 36

Perfil de puesto del Asistente de contabilidad

\begin{tabular}{|c|c|c|c|}
\hline \multicolumn{2}{|c|}{ Requisitos } & Funciones & Competencias \\
\hline Profesión & $\begin{array}{l}\text { Administración, } \\
\text { Contabilidad, } \\
\text { Economía o Ingeniería } \\
\text { Comercial }\end{array}$ & $\begin{array}{l}\text { - Velar por el control de cuentas de } \\
\text { pago y cobro. }\end{array}$ & - Pensamiento analítico \\
\hline $\begin{array}{l}\text { Grado de } \\
\text { instrucción }\end{array}$ & Superior universitario & $\begin{array}{l}\text { - Supervisar el manejo de los recursos } \\
\text { de las sedes. }\end{array}$ & - Búsqueda de información \\
\hline $\begin{array}{l}\text { Grado } \\
\text { académico }\end{array}$ & Bachiller & - Elaborar la programación de pagos. & - Tolerancia a la presión \\
\hline $\begin{array}{l}\text { Conocimiento } \\
\text { de informática }\end{array}$ & Nivel intermedio & $\begin{array}{l}\text { - Presupuestar los flujos de caja } \\
\text { mensuales. }\end{array}$ & - Preocupación por el orden y la claridad \\
\hline $\begin{array}{l}\text { Experiencia } \\
\text { laboral }\end{array}$ & 6 meses & $\begin{array}{l}\text { - Revisar las conciliaciones bancarias } \\
\text { elaboradas por el asistente. }\end{array}$ & - Habilidad analítica \\
\hline $\begin{array}{l}\text { Experiencia en } \\
\text { el cargo o áreas } \\
\text { similares }\end{array}$ & 6 meses & $\begin{array}{l}\text { - Tramitar directamente con los } \\
\text { organismos bancarios las diversas } \\
\text { operaciones financieras y mantener el } \\
\text { vínculo. }\end{array}$ & - Responsabilidad \\
\hline & & $\begin{array}{l}\text { - Controlar el financiamiento y la admin } \\
\text { por la empresa. }\end{array}$ & stración de los préstamos adquiridos y otorgados \\
\hline
\end{tabular}

Nota. Elaboración propia 
Tabla $N^{\circ} 37$

Perfil de puesto del Asistente de marketing y ventas

\begin{tabular}{|c|c|c|c|}
\hline \multicolumn{2}{|c|}{ Requisitos } & Funciones & Competencias \\
\hline Profesión & $\begin{array}{l}\text { Administración, } \\
\text { Marketing }\end{array}$ & $\begin{array}{l}\text { - Elaborar el Plan Anual de Marketing } \\
\text { - Realizar los análisis necesarios sobre la }\end{array}$ & - Proactivo, empático y visionarios \\
\hline Grado de instrucción & $\begin{array}{l}\text { Superior } \\
\text { universitario }\end{array}$ & $\begin{array}{l}\text { competencia en los productos y servicios con } \\
\text { los que cuenta } \\
\text { - Diseñar planes de acción en donde se } \\
\text { establecen los pasos necesarios para }\end{array}$ & - Creatividad e innovación \\
\hline Grado académico & Bachiller & $\begin{array}{l}\text { implementar o ejecutar las estrategias } \\
\text { - Proponer la creación de nuevos servicios de }\end{array}$ & - Capacidad de negociación \\
\hline $\begin{array}{l}\text { Conocimiento de } \\
\text { informática }\end{array}$ & Nivel intermedio & $\begin{array}{l}\text { acuerdo a los estudios e investigaciones } \\
\text { realizadas } \\
\text { - Efectuar visitas a las diferentes empresas para }\end{array}$ & - Lealtad y sentido de pertenencia \\
\hline Experiencia laboral & 1 año & & $\begin{array}{l}\text { - Buenas relaciones } \\
\text { interpersonales }\end{array}$ \\
\hline $\begin{array}{l}\text { Experiencia en el } \\
\text { cargo o áreas similares }\end{array}$ & 1 meses & $\begin{array}{l}\text { - Desempeñar las demás funciones que le sean } \\
\text { encomendadas por la Gerencia General. } \\
\text { - Crear una base de datos con información } \\
\text { relevante para la Institución }\end{array}$ & $\begin{array}{l}\text { - Orientación al logro de objetivos } \\
\text { - Capacidad de comunicación }\end{array}$ \\
\hline
\end{tabular}

Nota. Elaboración propia 


\subsection{Remuneraciones, Compensaciones e Incentivos}

Se define como remuneración a la retribución monetaria por el esfuerzo, habilidades y conocimiento que un trabajador invierte durante las horas en el que labora en una empresa, ésta en algunos casos puede ser equivalente al $60 \%$ de los costos totales de una empresa, y tiene 3 componentes (a) sueldo básico, (b) incentivos salariales, y (c) beneficios.

(Chiavenato, 2011).

Para el presente proyecto, la estructura salarial que se establece está definida acorde a las bandas salariales promedio que se manejan en la ciudad de Arequipa (ver tabla 38).

\section{Tabla $\mathrm{N}^{\mathrm{o}} 38$}

Remuneración de los trabajadores del proyecto

\begin{tabular}{lll}
\hline Puesto & Banda salarial (S/.) & Sueldo mensual (S/.) \\
\hline Gerente General & $4000,00-7000,00$ & 6000,00 \\
Asistente contable & $850,00-1200,00$ & 850,00 \\
Asistente de marketing y ventas & $1000,00-1800,00$ & 1500,00 \\
\hline
\end{tabular}

Nota. Elaboración propia

\subsection{Política de Recursos Humanos}

Para el presente plan de negocios, se consideran las siguientes políticas de recursos humanos:

1. Selección de personal: Tiene como finalidad captar el personal idóneo para los puestos de la empresa cumpliendo con el perfil requerido, según lo siguiente: 
a. Reconocer el puesto a requerir

b. Establecer los perfiles de puestos de trabajo y sus requisitos.

c. Utilizar las mejores técnicas para selección de candidatos.

d. Detallar el medio por el que se da una convocatoria y evaluación de postulantes.

e. Selección de postulantes de acuerdo a perfil.

2. Plan de inducción:

Proceso de formación que brindara al trabajador lo necesario para su desempeño, información de la empresa como la cultura organizacional. Este proceso se da tanto en el puesto de trabajo como en la organización.

3. Plan de capacitación: Permite elevar las habilidades y conocimientos del trabajador, se conformara un plan de capacitación de acuerdo a las necesidades del perfil.

a. Identificar y evaluar las necesidades de la empresa y del colaborador.

b. Determinar el tipo de capacitación sea interna o externa.

c. Cumplimiento del plan de capacitación.

d. Examinar el plan de capacitación.

4. Cultura de desarrollo y formación continua de su capital humano: El cual permitirá la adaptación a la evolución tecnológica, los cambios de gestión, la aplicación de las políticas de calidad, medio ambiente y prevención de riesgos laborales, así como facilitar la integración en el proyecto común de empresa. 


\section{Capítulo VII: Plan de Marketing}

\subsection{Estrategias de Marketing}

Las empresas de servicios focalizan su esfuerzo en los clientes y empleados, conocen la relación servicio-utilidades lo cual aporta mucho a la empresa. A nivel interno, se refleja en la calidad que tendrá el servicio ofrecido con muestras de satisfacción de clientes (Kotler \& Armstrong, 2012).

\section{Objetivo General:}

Desarrollar una base estratégica competitiva, para hacer frente a la principal competencia de Intenta coaching y team building en Arequipa, a partir de la articulación de acciones comerciales y comunicacionales, que influyan de forma directa sobre indicadores de alto impacto de Intenta.

2. Objetivos específicos:

a) Establecer una estrategia de posicionamiento ventajosa frente a los diversos actores del sector.

b) Articular estrategias propias del marketing mix, que contribuyan a la permanencia y fidelización de los actuales clientes de la empresa.

c) Desarrollar herramientas comerciales que permitan mantener e incrementar el crecimiento de la empresa.

d) Implementar planes de fidelización, a partir de atributos relevantes de la empresa Intenta coaching y team building.

\subsubsection{Estrategia de crecimiento.}

El crecimiento de Intenta coaching y team building, estará en función a las oportunidades que se presentan en cada uno de los segmentos en los que se 
participará; por lo cual el planteamiento de lineamientos estratégicos referentes al incremento de clientes, estarán en función de la detección y aprovechamiento de estas oportunidades y la conjunción con las capacidades propias de la empresa.

Las estrategias de crecimiento generalmente van ligadas al aprovechamiento de oportunidades de mercado y producto, las cuales se combinan a fin de disponer una gama de estrategias puntuales. Para la definición de estas opciones se utilizará la matriz de Ansoff, en la cual se definirán los lineamientos generales del crecimiento de la empresa.

Por otro lado se utilizará la estrategia de especialistas en nichos de mercado en lugar de aspirar al mercado completo, o incluso a segmentos grandes se dirigen a sub segmentos, la principal razón de aplicar esta estrategia es comprender de excelente manera a los clientes meta y cubrir sus necesidades. (Kotler \& Armstrong, 2012).

Estrategias de Crecimiento-Matriz Ansoff

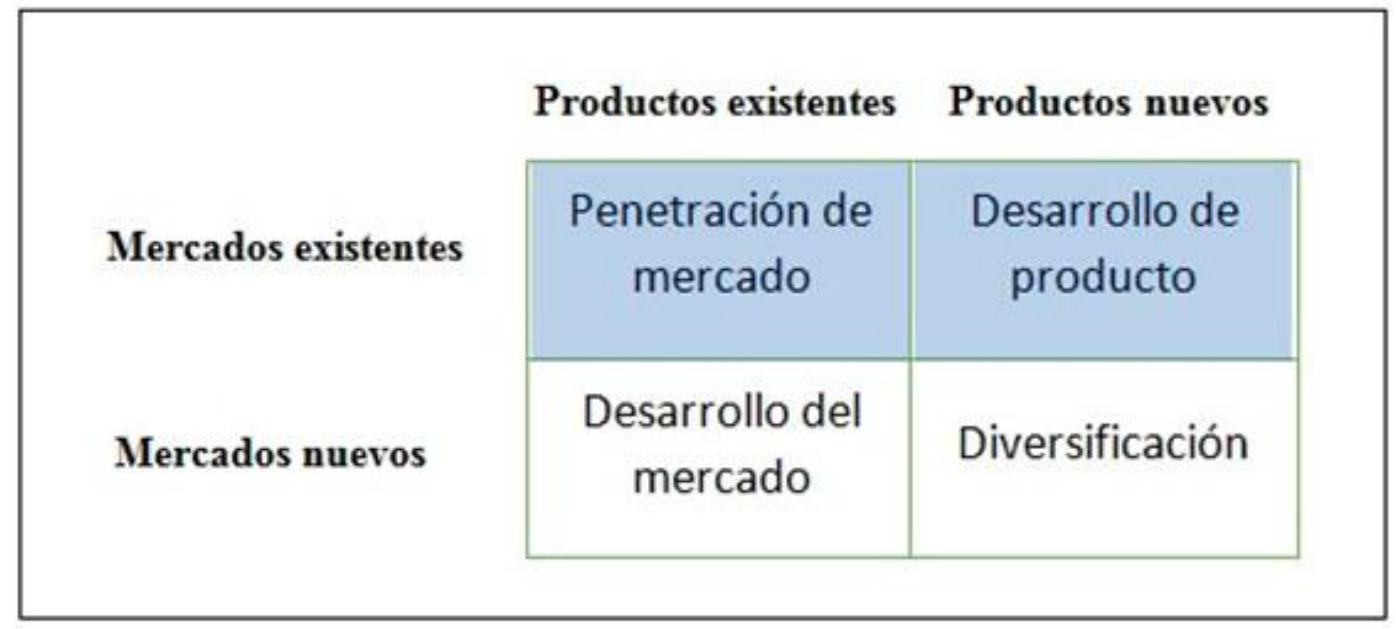

Figura 31. Matriz de expansión de productos y mercados. Tomado de "Marketing", por Kotler \& Armstrong, 2012 
Tal como se observa en la matriz anterior, se ha visto por conveniente definir los lineamientos en base a los productos actuales combinándolos con mercados actuales y potenciales. Lo anteriormente expuesto define un crecimiento intensivo (P.Kotler) en el cual se determinan las siguientes estrategias específicas.

Penetración de Mercado:

1.- Una vez colocado el producto se ofrecerá otro servicio para generar continuidad con el cliente.

2.- Publicidad no convencional.- Se utilizará la publicidad boca-oreja realizando campañas de recomendación, es decir cada empresa que recomiende los servicios de Intenta coaching y team building recibirá una charla gratuita del tema de su preferencia para sus colaboradores.

3.- Mayor promoción.- Se lanzará una campaña publicitaria para generar mayor conciencia en las organizaciones sobre la importancia del Coaching Ejecutivo y el Team buildig con la finalidad que tengan mayor conocimiento de las bondades de los productos.

4.-Organización de charlas gratuitas.- En convenio con la Cámara de Comercio de Arequipa se dictaran charlas gratuitas para los socios de las diferentes empresas de la ciudad, dichas charlas serán direccionadas al Coaching Ejecutivo en las organizaciones y al team building. En cada charla se realizará un levantamiento de una base de datos de clientes potenciales que posteriormente serán contactados por el asistente de marketing para ofrecer los servicios de Intenta coaching y team building.

5.- Participación y auspicios en congresos, coloquios, seminarios, paneles de 
Coaching Ejecutivo para tener una mayor presencia de marca en la ciudad de Arequipa.

Desarrollo del Producto:

1. Responsabilidad con la inclusión social, para ello Intenta coaching y team building desarrollará el programa de Coaching Social enfocado a mujeres que se encuentran privadas de su libertad, adolescentes con problemas de reinserción social y mujeres maltratadas. Se brindará dicho servicio con patrocinio de diferentes empresas interesadas en el programa.

2. Ampliación de gama de productos, si bien Intenta cuenta con ocho servicios enfocados en coaching ejecutivo y team building, se desarrollaran productos enfocados al esparcimiento de las organizaciones como, full days, gincanas corporativas, integra days, olimpiadas corporativas.

3. Creación de un nuevo producto de motivación de alto impacto para el mercado objetivo.

4. Alianza estratégica con la empresa Francisco Villalta Coaching, con la finalidad de ampliar los servicios de coaching Ejecutivo y coaching de equipos, se crearan nuevos productos acordes a las necesidades del mercado.

5. Constante sondeo de las necesidades del mercado en team building y coaching ejecutivo, que se realizará mediante encuestas de satisfacción al cliente para así saber cuáles son las necesidades de nuevos productos.

\subsubsection{Estrategia de Producto.}

Marca

En la actualidad Intenta coaching y team building será una marca asociada, al 
desarrollo del potencial del talento humano en empresas de la ciudad de Arequipa.

Esta asociación con el sector del talento humano permitirá a la marca tener una fuerte presencia en empresas del segmento del mercado objetivo.

La estrategia de marca, estará avocada a la percepción de la imagen de Intenta coaching ejecutivo y team building como una institución dirigida al sector del talento humano, a partir de un manejo de acciones comunicacionales informativas.

En la figura 29 se plasma el isotipo de la empresa.

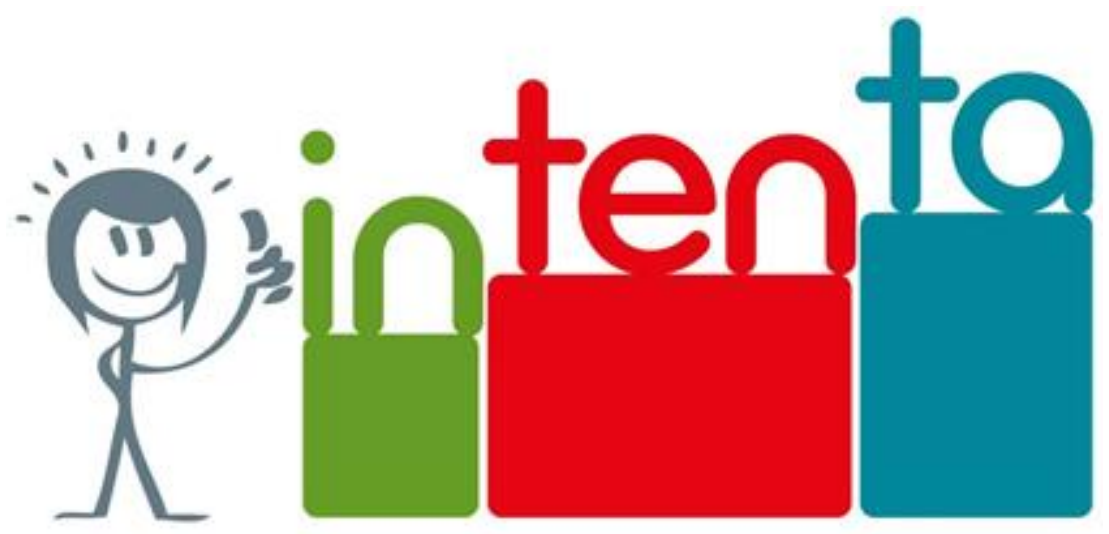

COACHING EJECUTIVO Y TEAM BUILDING

Figura $N^{o} 32$. Isotipo Intenta coaching ejecutivo y team building

La estrategia de desarrollo de productos consiste en realizar constantes sondeos de las necesidades del mercado, adaptación de productos y sub productos acorde a las necesidades del usuario. No se realizó un testeo del logotipo de Intenta coaching y team building por ser una empresa B2B.

\subsubsection{Estrategia de Posicionamiento}

Teniendo en cuenta que la empresa Intenta coaching y team building está recién ingresando al mercado Arequipeño se trabajará con atributos racionales de los productos, basados en el coaching ejecutivo y team building. 
El posicionamiento de la marca Intenta deberá de estar en función de

atributos racionales, resaltando la motivación, apoyo y confianza en el desarrollo del talento humano de las organizaciones de la ciudad de Arequipa.

Entre dichos atributos se tendrá:

- Cercanía con los clientes mediante un servicio personalizado.

- Adaptación a las necesidades de los clientes.

- Compromiso con el desarrollo del talento humano de los clientes.

- Confianza y transparencia con los clientes.

Cabe mencionar, que a partir de la identificación de las necesidades específicas de cada empresa, se articulará con mayor intensidad ciertos requerimientos del mercado en base a sus necesidades.

\subsubsection{Estrategia de Plaza}

La tercera herramienta más importante en el marketing mix es la distribución. La empresa trabaja en equipo con sus socios para la creación de valor para el cliente (Kotler \& Armstrong, 2012).

Entre las principales características de los mercados a los cuales la empresa Intenta se va a dirigir, se tienen empresas pequeñas, medianas y grandes empresas teniendo en cuenta la naturaleza del negocio B2B. 


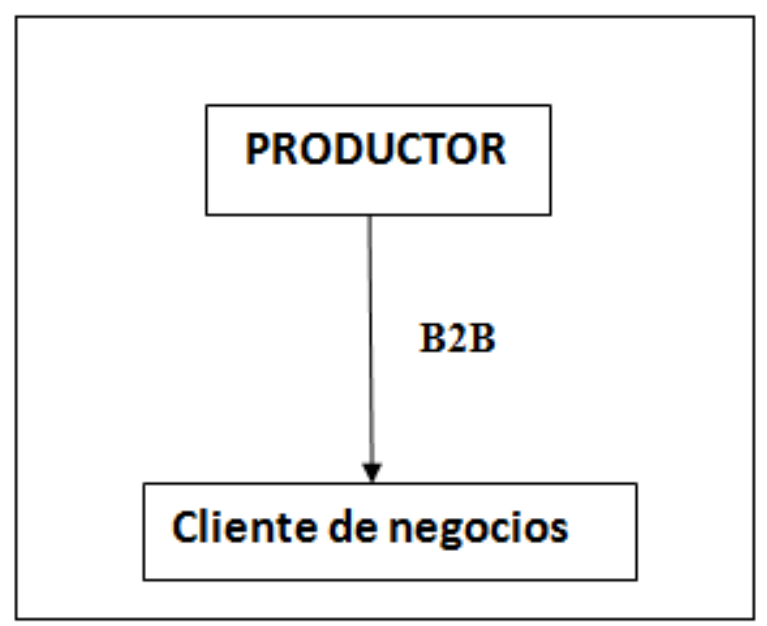

Figura 33. Canales de Marketing de negocio. Tomado de "Marketing", por Kotler \& Armstrong, 2012.

Se ha visto por conveniente establecer el siguiente lineamiento estratégico en este apartado (ver figura 31).

Al ser un nivel de canal directo que no presenta intermediarios la empresa vende directamente a los consumidores (B2B), se contará con visitas agendadas y el ejecutivo de ventas visitará directamente al cliente final en este caso el gerente o jefe de Recursos Humanos para realizar el cierre de ventas.

A continuación se detallan las estrategias de Plaza a implementar:

- Creación de una página web para ofertar los productos.

- Creación de catálogos virtuales con los servicios que ofrece Intenta coaching y team building.

- Ubicar a Intenta en Google adwords

- Presencia en las siguientes redes sociales: Linkedlin y la creación de un fan page en Facebook para tener una mayor presencia de marca en el mercado. 
- Telemarketing, en pre y post venta, para medir la satisfacción de los clientes.

- Creación de campañas email marketing con la finalidad de promocionar la cartera de productos de Intenta.

\subsubsection{Estrategia de promoción y publicidad.}

La promoción presenta una caja de herramientas que permite poder comunicar al cliente los diferentes productos y servicios de la empresa. Por otro lado, también permite comunicar internamente los cambios que viene realizando la compañía, una herramienta fundamental en la mezcla de promoción es la publicidad. La publicidad es cualquier forma pagada de presentación y promoción no personales de ideas, bienes o servicios, por un patrocinador identificado. (Kotler \& Armstrong, 2012).

Cada categoría de la mezcla de promoción es importante para la empresa, ya que sin una buena estrategia de comunicación, tanto interna como externa, el negocio no proyectará el valor agregado que presentará a los clientes. Esta debe de estar articulada con la mezcla del marketing mix para que la comunicación tenga un mayor impacto.

A partir de esta premisa se ha establecido implementar acciones de comunicación que abarquen la vía central de persuasión, las cuales poseen las siguientes características:

1. Redes sociales.-Utilización de redes sociales como linkedln y google adwors con la finalidad de ampliar el alcance de los mensajes publicitarios y 
promocionales.

2. Página Web.- En donde se dará gran énfasis a los servicios ofertados, colocando videos de los trabajos realizados, testimoniales, fotografías de talleres, historias de éxito. Así mismo se colocará un link de los reconocimientos de la directora de empresa consultora.

3. Medios de comunicación especializados.- La articulación de medios especializados dentro del marketing mix planteados para el presente plan de negocios se han basado en su cobertura, forma de adquisición y tiraje aproximado:

- Revista Arequipa Empresarial, publicación de la región Arequipa, con un tiraje bimestral de 2000 ejemplares y es adquirida principalmente vía suscriptores.

- Revista Cámara de Comercio Arequipa, publicación mensual de la región Arequipa con tiraje de 3000 ejemplares y es de distribución directa gratuita para todos los accionistas de la cámara.

- Ferias, foros y seminarios, Intenta Coaching y Team building participará en ferias y eventos especializados referentes al coaching ejecutivo y Team building.

- Marketing directo, en base al manejo sistemático de la base de datos de la empresa de Intenta Coaching y Team building y en consideración con la segmentación del target de la empresa: pequeña, mediana y gran empresa. 
Este tipo de acciones permitirán el desarrollo y mantenimiento de segmentos objetivos propios de campañas diferenciadas

\subsubsection{Estrategia de Precio.}

La fijación de precios es de vital importancia, la empresa debe vender valor y no precio.

El precio es lo que se cobra por un servicio, o los valores que los consumidores dan por los beneficios de obtener el servicio (Kotler \& Armstrong, 2012).

Los pilares para aplicación de la estrategia en mención son los siguientes:

1. Innovación. El elemento principal de los trabajos a realizar será la creatividad, todo se enfocará en crear un sello único a comparación de la competencia, se armarán paquetes focalizados de acuerdo a las necesidades del mercado.

2. Equipo Creativo. Las ideas y aportes de los empleados serán parte fundamental del proyecto, se les entrega la oportunidad de desarrollar una línea de carrera sólida.

3. Crecimiento estratégico. El negocio es un mix de creatividad, innovación, autenticidad y trabajo en equipo, que se verá reflejado en el trabajo realizado.

4. Crear sin límites. La creatividad tiene un valor importante, se evitarán restricciones si existe mayor mercado.

La estrategia de fijación de precios será segmentada, esta estrategia consiste en ajustar los precios de acuerdo con las diferencias entre clientes, productos, lugares. (Kotler \& Armstrong, 2012). 
Los precios estarán colocados de acuerdo al segmento de la empresa como se aprecia a continuación:

Tabla No: 39

Rango de precios por segmento

\begin{tabular}{lcc}
\hline \multicolumn{1}{c}{ SEGMENTOS } & SERVICIOS & RANGO DE PRECIOS \\
\hline PEQUEÑA EMPRESA & COACHING EJECUTIVO & $2500-3000$ \\
MEDIANA EMPRESA & COACHING EJECUTIVO & $3000-3500$ \\
GRANDE EMPRESA & COACHING EJECUTIVO & $3500-4000$ \\
& & \\
\hline \multicolumn{1}{c}{ SEGMENTOS } & SERVICIOS & RANGO DE PRECIOS \\
\hline PEQUEÑA EMPRESA & TEAM BUILDING & $4000-5000$ \\
MEDIANA EMPRESA & TEAM BUILDING & $5000-6000$ \\
GRANDE EMPRESA & TEAM BUILDING & $6000-7000$ \\
& & \\
\hline
\end{tabular}

\section{Nota: Elaboración propia}

Tal como se observa en la tabla los precios varían de acuerdo a los segmentos pequeña, mediana y gran empresa, los rangos colocados serán ajustados de acuerdo a los servicios ofrecidos y serán ajustados de acuerdo a las necesidades de cada cliente.

\subsubsection{Estrategia Personas}

Dentro de este enfoque de la estrategia de clientes, es parte esencial para definir que segmentos deberán ser partícipes de las acciones delimitadas, ya que este es parte de un esfuerzo sopesado por reformular los principios iniciales de la lealtad del cliente, a la luz de la experiencia alcanzada, apostando además por presentar no sólo los conceptos básicos, sino los “porqués" y los “cómos", es decir, la razón por la que aquellos debieran perdurar y la forma de aplicarlos a la realidad. (Lovelock, C. 2009) 
La estrategia de personas basa su rentabilidad en la relación que exista entre los empleados y el cliente, gestionando acciones que le den valor añadido a la gestión de los clientes.

La presente estrategia tiene como objetivo el desarrollo de relaciones a largo plazo con clientes importantes para la empresa, para lo cual se realizará las siguientes actividades:

- Desarrollo de un manual de atención al cliente.

- Desarrollo de técnicas de medición de atención al cliente.

- Potenciar la clasificación de clientes.

- Desarrollar un programa de permanencia y continuidad con los clientes

Las actividades detalladas anteriormente, tienen el objetivo de crear elementos diferenciales que permitirán la retención de clientes y generar una experiencia única en los clientes de Intenta Coaching.

\subsubsection{Estrategia de evidencia física.-}

Mediante esta estrategia se buscará que los clientes de Intenta coaching y team building perciban mayor respaldo y confianza en el servicio a través de un servicio personalizado con la visita de un Coach especializado que les explicará toda la metodología a seguir.

Respecto al servicio de talleres tanto de coaching como team building se contará con material didáctico de última generación, posteriormente se buscará llevar más adelante reformas en el material lúdico de aprendizaje que serán elementos visibles y tangibles en el lugar físico donde se ofrece el servicio. 


\subsubsection{Estrategia de Procesos.-}

Respecto a los procesos en el servicio se irán midiendo paulatinamente durante la atención, se brindará un servicio rápido y oportuno desde el primer contacto del asistente de marketing con el cliente, las proformas de los diferentes servicios ya sea en coaching y team building serán enviados en un plazo máximo de 2 días hábiles, se evitará todo tipo de cuello de botella que obstruya el proceso directo en el servicio. A continuación se detalla el flujograma del proceso de atención al cliente:

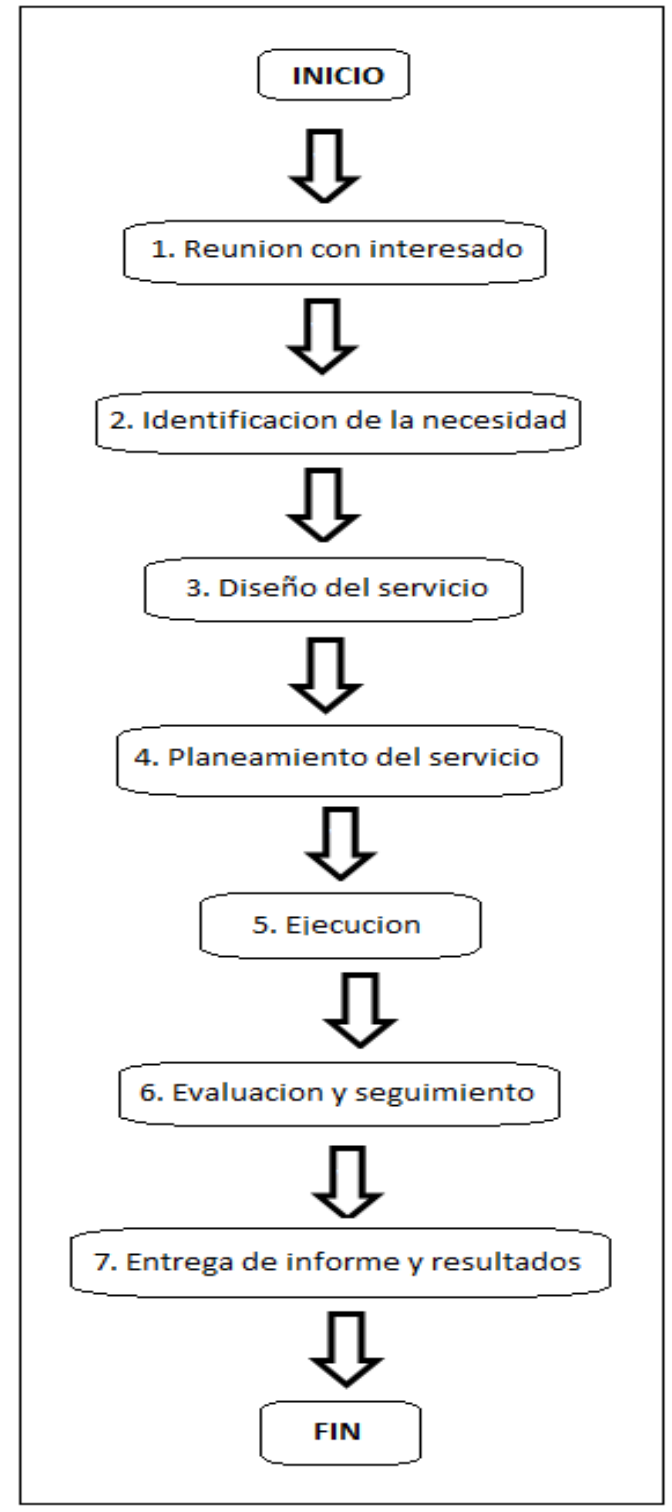

Figura $N^{o} 34$ : Flujograma de procesos de coaching 


\subsection{Estrategia de Ventas}

Anteriormente se trabajó el impacto del mensaje y comunicación. En este punto se trabajará dos elementos más: las ventas personales se comunican con el marketing, el área de ventas genera relaciones con sus clientes actuales y potenciales. La promoción de ventas consiste en incentivos a corto plazo para estimular la compra o la venta del servicio (Kotler \& Armstrong, 2012).

El equipo de ventas estará conformado por el asistente de marketing quien será el responsable de realizar ventas externas vía telefónica, por internet, visitas a clientes potenciales que precisen de información del servicio.

Dentro de las estrategias de ventas se precisan las siguientes:

1. Prospectos de ventas: El asistente de marketing deberán de prospectar como mínimo cinco empresas al día con finalidad de aumentar la base de datos de clientes potenciales de la empresa.

2. Telemarketing: El asistente de marketing se encargará del telemarketing realizando un seguimiento pre y post venta.

3. Internet: Se verificará todos los días el buzón de informes de la página web y del fan page con el objetivo de visualizar cuantos clientes potenciales están interesados en los servicios y productos. Se alineará la estrategia general de marketing con un plan de marketing digital que permita vender de manera más agresiva.

4. Capacitación constante: El asistente de marketing tendrá capacitación constante de los servicios y productos de la empresa Intenta coaching y team building para mejorar relaciones con los clientes, de manera que esté bien entrenado para los diferentes tipos 
de clientes que se puedan presentar. Por otro lado deberá conocer a la perfección el modelo de negocio de Intenta coaching y team building, los productos y servicios que esta ofrece.

5. Supervisión y motivación: El asistente de marketing estará supervisado por el gerente general quien lo acompañará durante todo el proceso de venta. A su vez el gerente general estimulará al asistente de marketing a laborar con energía y pasión.

6. Ventas 2.0: Es la combinación de prácticas innovadoras de ventas con tecnologías web 2.0 para mejorar la eficacia y la efectividad del asistente de marketing de la organización. Se generará listas de posibles clientes a partir de las inscripciones mediante la página web, por otro lado se generaran fichas tecnológicas para la inscripción de congresos, seminarios, coloquios y charlas gratuitas y sitios de redes como Linkedln. Por otro lado se creará dentro de la página web un chat personalizado en donde el asistente de marketing interactuará en tiempo real con posibles clientes potenciales.

\subsubsection{Plan de ventas.}

Tiene como finalidad guiar, liderar y controlar las labores del equipos de ventas en función de los objetivos definidos, que a su vez están de acuerdo a los objetivos globales de la empresa (Kotler \& Armstrong, 2012).

La función del gerente general será la misma que la de un gerente de ventas y deberá de desarrollar todos los procesos directivos como la planificación, organización, provisión de recursos dirección y control de las ventas.

1. Objetivo de Ventas 
Estimular la demanda del consumidor final en un $6 \%$ cada año para captar una mayor cantidad de usuarios en la ciudad de Arequipa.

\section{Planificación}

Dentro de la planificación se resalta el pronóstico de ventas en el cual se ha considerado tener al menos dos servicios de coaching ejecutivo y dos team building. Por otro lado, como incentivo al asistente de marketing se propondrá la creación de cuotas de ventas de acuerdo a la evaluación y rendimiento que este realice.

Dentro de la planificación se desarrollaran las siguientes actividades:

a. Elaboración de un presupuesto mensual de ventas en base a la demanda.

b. Determinación de un objetivo mensual de ventas, para alcanzar el objetivo el área de ventas se organizará en dos fuerzas principales :

- Ventas vía Telemarketing

- Ventas directas

c. Capacitación constante referente a los servicios y productos que ofrece la empresa Intenta.

d. Feedback constante.

e. Reportes financieros quincenales elaborados por el gerente general para tener un seguimiento detallado de la empresa. Controlar si los objetivos mensuales se están logrando. 


\subsubsection{Políticas de servicios y garantías.}

Se ha definido como principios o reglas que sigue una empresa para lograr sus objetivos. Es muy útil para controlar los acontecimientos que aparecen en la empresa (Kotler \& Armstrong, 2012).

A continuación se detallan las políticas de ventas por las que se regirán los vendedores de la empresa Intenta con la finalidad de cumplir con los objetivos de la institución:

1. La empresa solo brindará un descuento del $10 \%$ a clientes recurrentes (de 3 servicios a más)

2. Los pagos en las oficinas se podrán realizar en un horario de 8:30 a 17:00 horas.

3. La empresa solo aceptará pagos completos ó el $50 \%$ de adelanto.

4. La empresa no otorgará crédito alguno.

5. El asistente de marketing no podrán realizar descuento alguno sobre los productos y servicios a menos que la gerencia general lo autorice.

6. El asistente de marketing deberán de llevar al menos una capacitación mensual de ventas. 


\section{Capítulo VIII: Planificación financiera}

\subsection{La inversión}

La mayoría de las inversiones de un proyecto se concentra en aquellas que se deben realizar antes del inicio de la operación, aunque es importante considerar también las que se deben realizar durante la operación del proyecto, tanto por la necesidad de reemplazar activos como para enfrentar la ampliación proyectada del nivel de actividad (Sapag, 2011).

\subsubsection{Inversión pre-operativa.}

La etapa pre-operativa, es aquella en la que se generan los costos de inversión y comprende los siguientes costos (con variaciones dependiendo del tipo de proyecto): (a) estudios de factibilidad, (b) estudios definitivos (ingeniería conceptual, ingeniería de detalle), (c) planos y licencias, (d) terrenos, edificios, instalaciones fijas, bienes de capital (aquellos que sirven para la producción de otros bienes, como maquinarias y equipos); (e) mobiliario, entre otros. Adicionalmente, en la etapa pre-operativa se debe de contar con el capital de trabajo, el fondo de maniobra que sirve para costear los activos corrientes que harán posible el inicio de la etapa operativa del proyecto (Conexión Esan, 2016). En la tabla 39 se puede observar la inversión preoperativa: 
Tabla $N^{\circ} 40$

Inversión pre-operativa (Intangibles)

\begin{tabular}{lcc}
\hline \multicolumn{1}{c}{ Intangibles } & & Costo \\
\hline Escritura Pública & $\mathrm{S} /$. & 300,00 \\
Licencia de Funcionamiento & $\mathrm{S} /$. & 450,00 \\
Alquiler / Garantía & $\mathrm{S} / .2 .000,00$ \\
\hline Total & $\mathbf{2 7 5 0 , 0 0}$ \\
\hline Nota Elaboración propia &
\end{tabular}

Nota. Elaboración propia

Tabla $N^{\circ} 41$

Inversión pre-operativa (Maquinaria y equipos)

\begin{tabular}{|c|c|c|c|}
\hline Equipo & $\mathrm{N}^{\circ}$ & Costo Unitario & Costo Total \\
\hline Equipo 1 : Material lúdico & 1 & S/. 3,800.00 & S/. $3,800.00$ \\
\hline Equipo 2 : Equipo de Sonido & 2 & S/. 2,400.00 & S/. $4,800.00$ \\
\hline Equipo 3: Sistema de micros & 1 & S/. 1,500.00 & S/. $1,500.00$ \\
\hline Equipo 4: Pedestales & 2 & S/. 500.00 & S/. $1,000.00$ \\
\hline Cables extensiones & 1 & S/. $\quad 300.00$ & S/. $\quad 300.00$ \\
\hline Lap top & 2 & S/. 2,600.00 & S/. $5,200.00$ \\
\hline Ecram y proyector multimedia & 1 & S/. 3,000.00 & S/. $3,000.00$ \\
\hline Cámara de fotos & 1 & S/. $1,000.00$ & S/. $1,000.00$ \\
\hline Rollers de públicos & 2 & S/. 300.00 & S/. $\quad 600.00$ \\
\hline Impresora & 1 & S/. $\quad 500.00$ & 500.00 \\
\hline Celular & 2 & S/. 100.00 & 200.00 \\
\hline Modem & 1 & S/. 120.00 & 120.00 \\
\hline Total Equipo & & & S/. 22,020.00 \\
\hline
\end{tabular}


Tabla 42

Inversión pre-operativa (Mobiliario)

\begin{tabular}{|c|c|c|c|}
\hline Mobiliario & $\mathrm{N}^{\circ}$ & $\begin{array}{c}\text { Costo } \\
\text { Unitario }\end{array}$ & $\begin{array}{l}\text { Costo } \\
\text { Total }\end{array}$ \\
\hline Escritorio & 2 & S/. 300.00 & 600.00 \\
\hline Estantes & 2 & S/. 180.00 & 360.00 \\
\hline Silla ejecutiva & 2 & S/. 180.00 & 360.00 \\
\hline Pizarra acrílica & 2 & S/. 100.00 & 200.00 \\
\hline Mampara de vidrios & 2 & S/. 600.00 & $1,200.00$ \\
\hline Letrero & 1 & S/. 580.00 & 580.00 \\
\hline Cuadros & 3 & S/. 100.00 & 300.00 \\
\hline Tachos de basura & 4 & S/. 50.00 & 200.00 \\
\hline Bandejas porta papeles & 2 & S/. 30.00 & 60.00 \\
\hline Ventilador & 2 & S/. 120.00 & 240.00 \\
\hline Sillas para recepción & 8 & S/. 60.00 & 480.00 \\
\hline Mesa de centro & 1 & S/. 108.00 & 108.00 \\
\hline Dispensador de agua & 1 & S/. 50.00 & 50.00 \\
\hline Total Equipo & & & $4,738.00$ \\
\hline
\end{tabular}

\subsubsection{Inversión en capital de trabajo.}

Una inversión fundamental para el éxito o el fracaso de un negocio es la que se debe hacer en capital de trabajo. El proyecto puede considerar la inversión en todos los activos fijos necesarios para poder funcionar adecuadamente. Ahora bien si no contempla la inversión en el capital necesario para financiar los desfases de caja durante su operación, probablemente fracase (Sapag, 2011). 
Tabla No 43

Inversión en Capital de trabajo

(En soles)

\begin{tabular}{lcccccccccccccc}
\hline $\begin{array}{l}\text { Método de déficit } \\
\text { acumulado }\end{array}$ & Enero & Febrero & Marzo & Abril & Mayo & Junio & Julio & Agosto & Septiembre & Octubre & Noviembre & Diciembre \\
\hline CXC & - & 8.000 & 8.000 & 16.000 & 16.000 & 16.000 & 16.000 & 24.000 & 24.000 & 24.000 & 24.000 & 24.000 \\
CXP & 17.552 & 17.552 & 17.552 & 17.552 & 17.552 & 17.552 & 17.552 & 17.552 & 17.552 & 17.552 & 17.552 & 17.552 \\
& -17.552 & -9.552 & -9.552 & -1.552 & -1.552 & -1.552 & -1.552 & 6.448 & 6.448 & 6.448 & 6.448 & 6.448 \\
\hline $\begin{array}{l}\text { Flujo acumulado } \\
\text { deficitario }\end{array}$ & -17.552 & -27.104 & -36.656 & -38.208 & -39.760 & -41.312 & -42.863 & -36.415 & -29.967 & -23.519 & -17.071 & -10.623 \\
\hline
\end{tabular}




\subsubsection{Costo del proyecto.}

La realidad de la administración de proyectos es que siempre hay que sacrificar costo por tiempo o viceversa. Por ejemplo, ocurre con frecuencia que un proyecto puede completarse antes de lo planeado si se contratan más trabajadores o se labora en turnos adicionales. Estas medidas pueden ser ventajosas si se obtienen ahorros o ingresos adicionales por el hecho de terminar el proyecto antes de lo previsto.

Los costos directos, los costos indirectos y los costos de penalización suman los costos totales. Estos costos dependen ya sea de los tiempos de las actividades o del tiempo de terminación del proyecto. Los costos directos incluyen mano de obra, materiales y cualquier otro costo que se relacione directamente con las actividades del proyecto (Krajewski, Ritzman \& Malhotra, 2008).

Tabla $N^{\circ} 44$

Costo del Proyecto (En soles)

\begin{tabular}{|c|c|}
\hline \multicolumn{2}{|c|}{ Costo inversión del proyecto } \\
\hline Intangibles & $2.750,00$ \\
\hline Equipos & $22.020,00$ \\
\hline Muebles y enseres & $4.738,00$ \\
\hline Capital de trabajo & $38.207,67$ \\
\hline TOTAL & $67.715,67$ \\
\hline
\end{tabular}

Nota. Elaboración propia

\subsubsection{Inversiones futuras.}

El objetivo de un estudio técnico que se hace dentro de la viabilidad económica de un proyecto es netamente financiero. Es decir, calcula los costos, inversiones y beneficios derivados de los aspectos técnicos o de la ingeniería del proyecto. Para ello, en este estudio se busca determinar las características de la composición 
óptima de los recursos que harán que la producción de un bien o servicio se logre eficaz y eficientemente. Para esto se deberán examinar detenidamente las opciones tecnológicas posibles de implementar, así como sus efectos sobre las futuras inversiones (Sapag, 2011).

El plan de negocio, en el lapso de cinco años considera ampliar los servicios ofrecidos acorde al crecimiento de mercado, necesidades y requerimientos de los clientes, proyectando así contar con un grupo de profesionales especialistas en los servicios que se implementen, logrando mayor presencia en Arequipa y postulando a la posibilidad de entrar en otra provincias a nivel del sur del Perú. Se requerirá una mayor cantidad de recursos tanto en la parte administrativa como en la parte operativa.

\subsection{Financiamiento}

\subsubsection{Endeudamiento y condiciones.}

Al recurrir a un préstamo bancario para financiar el proyecto, la empresa debe asumir el costo financiero que está asociado a todo proceso de otorgamiento de créditos, el cual, como se explicó anteriormente, tiene un efecto negativo sobre las utilidades y, por lo tanto, positivo sobre el impuesto. Genera un ahorro tributario al reducir las utilidades contables sobre las cuales se calcula el impuesto. La rentabilidad del inversionista se calculara comparando la inversión que el deberá financiar con el remanente de flujo de caja que queda después de servir el crédito; es decir, después de pagar los intereses y amortizar la deuda (Sapag, 2011)

Para el plan de negocios no habrá endeudamiento ya que la inversión por parte de los accionistas será la suficiente para cubrir los costos pre-operativos sin la 
necesidad de buscar un financiamiento bancario que soporte los primeros meses de operación.

\subsubsection{Capital y costo de oportunidad.}

La decisión de utilizar un recurso de una forma en particular ocasiona que un gerente abandone la oportunidad de usar el recurso en otras maneras alternativas. El costo de oportunidad es la contribución a la utilidad en operación que se abandona al no usar un recurso limitado para su siguiente mejor uso alternativo. (Horngren, Datar \& Rajan, 2012).

El modelo de CAPM es manejado como herramienta para lograr conocer el costo de oportunidad de una inversión, y se basa en el rendimiento de valores similares que se ofrecen en los mercados de capitales. Dicho modelo es aplicable del mismo modo en los países emergentes dentro de los cuales se encuentra Perú (ver tabla 44).

Tabla 45

\section{Capital y costo de oportunidad}

\begin{tabular}{ll}
\hline Calculo del Costo de capital & \\
\hline Sector en USA & Intenta Coaching \\
Beta desapalancado & 0.95 \\
Tasa de imptos prom & $12.42 \%$ \\
Relación D/C proyecto: & 1.00 \\
Prima de riesgo de merc. & $6.22 \%$ \\
Tasa Libre de riesgo & $3.51 \%$ \\
Prima de riesgo país & $1.50 \%$ \\
Costo de capital del accionista Perú (KOA) & $10.92 \%$ \\
Beta apalancado & 1.78 \\
Costo de oportunidad del capital en Perú (COK) & $16.09 \%$ \\
\hline
\end{tabular}

Nota. Elaboración propia 
Utilizando las formulas:

$\mathrm{Koa}=\mathrm{Rf}+\mathrm{Boa}(\mathrm{Rm}-\mathrm{Rf})$

$\mathrm{COK}=\mathrm{Rf}+\mathrm{Be}(\mathrm{Rm}-\mathrm{Rf})$

Se calcula un costo de oportunidad del capital en Perú de 16.09\%.

\subsubsection{Costo de capital promedio ponderado.}

La mayoría de las empresas usan el costo promedio ponderado de capital (WACC, del inglés, weighted average cost of capital), que es el promedio del rendimiento requerido del capital en acciones de la empresa y la tasa de interés sobre su deuda, ponderado por la proporción de capital y deuda en su portafolio. Por lo general, el costo de capital es el componente más grande del costo por mantenimiento de inventario, ya que llega a ser hasta de $15 \%$, dependiendo del portafolio de capitalización particular de la empresa (Krajewski, Ritzman \& Malhotra, 2008)

El costo de capital promedio ponderado (WACC) es la combinación del costo de oportunidad (COK) y el costo de la deuda del proyecto. El costo real de la deuda es de $0 \%$ (ya que no se tiene una tasa de interés del préstamo al no haberse optado por un préstamo) y el COK es de $16.09 \%$.

En este caso el WACC es igual al COK ya que la empresa no tiene deuda con terceros (bancos). Esto queda demostrado a través de la fórmula del CAPM frente a la del WACC colocando en kd (costo de deuda), 0 (cero).

Por lo tanto el WACC para el presente proyecto es de $16.09 \%$. 


\subsubsection{Presupuesto de ventas.}

Es habitual que el presupuesto de operaciones arranque con la elaboración del presupuesto de ventas. Como fase previa a su preparación es útil elaborar una previsión de las ventas que se obtendrán si se extrapolase la gestión pasada en el entorno previsto para el próximo ejercicio. Esta previsión se prepara a partir del análisis del mercado, en su doble vertiente de oferta y demanda, de las estimaciones de las tendencias generales de la economía, del estudio de las capacidades y limitaciones de la propia empresa y de sus productos así como las opiniones del personal de ventas (ver tabla 45) (Torres, 2014). 
Tabla 46

Presupuesto de ventas (Cantidad de Servicios)

\begin{tabular}{|c|c|c|c|c|c|c|c|c|c|c|c|c|c|c|}
\hline Servicio Mensual & $\begin{array}{l}\text { Ener } \\
\text { o }\end{array}$ & $\begin{array}{l}\text { Febre } \\
\text { ro }\end{array}$ & $\begin{array}{l}\text { Marz } \\
0\end{array}$ & $\begin{array}{l}\text { Abr } \\
\text { il }\end{array}$ & $\begin{array}{l}\text { May } \\
\text { o }\end{array}$ & $\begin{array}{l}\text { Juni } \\
0\end{array}$ & $\begin{array}{l}\text { Juli } \\
0\end{array}$ & $\begin{array}{l}\text { Agos } \\
\text { to }\end{array}$ & $\begin{array}{l}\text { Septiem } \\
\text { bre }\end{array}$ & $\begin{array}{l}\text { Octub } \\
\text { re }\end{array}$ & $\begin{array}{l}\text { Noviem } \\
\text { bre }\end{array}$ & $\begin{array}{l}\text { Diciem } \\
\text { bre }\end{array}$ & $\begin{array}{l}\text { Tot } \\
\text { al }\end{array}$ & $\begin{array}{l}\text { Porcent } \\
\text { aje }\end{array}$ \\
\hline $\begin{array}{l}\text { COACHING EJECUTIVO POR } \\
\text { COLABORADOR }\end{array}$ & 1 & 1 & 2 & 2 & 2 & 2 & 3 & 3 & 3 & 3 & 3 & 4 & 29 & $50 \%$ \\
\hline COACHING DE EQUIPOS & 1 & 1 & 2 & 2 & 2 & 2 & 3 & 3 & 3 & 3 & 3 & 4 & 29 & $50 \%$ \\
\hline TOTAL & 2 & 2 & 4 & 4 & 4 & 4 & 6 & 6 & 6 & 6 & 6 & 8 & 58 & $100 \%$ \\
\hline
\end{tabular}

Nota. Elaboración propia

Tabla 47

Presupuesto de ventas (Valor de venta por artículos)

\begin{tabular}{|c|c|c|c|c|c|c|c|c|c|c|c|c|c|c|}
\hline Servicio Mensual & Enero & Febrero & Marzo & Abril & Mayo & Junio & Julio & Agosto & Septiembre & Octubre & Noviembre & Diciembre & Total & Porcentaje \\
\hline SERV1 & 3000 & 3000 & 6000 & 6000 & 6000 & 6000 & 9000 & 9000 & 9000 & 9000 & 9000 & 12000 & 87000 & $38 \%$ \\
\hline SERV2 & 5000 & 5000 & 10000 & 10000 & 10000 & 10000 & 15000 & 15000 & 15000 & 15000 & 15000 & 20000 & 145000 & $63 \%$ \\
\hline Total & 8000 & 8000 & 16000 & 16000 & 16000 & 16000 & 24000 & 24000 & 24000 & 24000 & 24000 & 32000 & 232000 & $100 \%$ \\
\hline
\end{tabular}

Nota. Elaboración propia 


\subsubsection{Presupuesto de costos de producción.}

La tabla 47 muestra el flujo de las actividades desde el costo del servicio hasta los gastos de ventas (Welsch, Hilton, Gordon \& Rivera, 2005).

Tabla 48

Presupuesto de costos de producción

\begin{tabular}{lrrrrr}
\hline COSTO DEL SERVICIO & 2017 & 2018 & 2019 & 2020 & 2021 \\
\hline PERSONAL & S/. 133.118 & S/. 155.738 & S/. 178.358 & S/. 200.978 & S/. 200.978 \\
SUB TOTAL & & & & & \\
TOTAL & S/. 133.118 & S/. 155.738 & S/. 178.358 & S/. 200.978 & S/. 200.978 \\
GASTOS ADMINISTRATIVOS & & & & & \\
Alquiler & 12.000 & 12.000 & 12.000 & 12.000 & 12.000 \\
Internet y Teléfono & 3.000 & 3.000 & 3.000 & 3.000 & 3.000 \\
Luz y Agua & 1.080 & 1.080 & 1.080 & 1.080 & 1.080 \\
Investigacion y desarrollo-software & & & & & \\
Mantenimiento & 18.000 & 18.000 & 18.000 & 18.000 & 18.000 \\
Depreciacion & 2.676 & 2.676 & 2.676 & 2.676 & 2.676 \\
Amortización & 275 & 275 & 275 & 275 & 275 \\
Utiles de escritorio & - & - & - & - & - \\
TOTAL & $\mathbf{3 7 . 0 3 1}$ & $\mathbf{3 7 . 0 3 1}$ & $\mathbf{3 7 . 0 3 1}$ & $\mathbf{3 7 . 0 3 1}$ & $\mathbf{3 7 . 0 3 1}$ \\
GASTOS DE VENTAS & & & & & \\
Internet y teléfono-AGUA & 4.080 & 4.080 & 4.080 & 4.080 & 4.080 \\
Marketing & 13.745 & 13.745 & 13.745 & 13.745 & 13.745 \\
Servicios Publicitarios & 4.000 & 4.000 & 4.000 & 4.000 & 4.000 \\
TOTAL & $\mathbf{2 1 . 8 2 5}$ & $\mathbf{2 1 . 8 2 5}$ & $\mathbf{2 1 . 8 2 5}$ & $\mathbf{2 1 . 8 2 5}$ & $\mathbf{2 1 . 8 2 5}$ \\
\hline
\end{tabular}

Nota. Elaboración propia

\subsubsection{Presupuesto de compras.}

Se explica la planificación de los niveles del inventario y las compras para empresas no manufactureras. Una vez completado el plan de ventas, deben desarrollarse otros tres planes (o presupuestos):

1. Plan del inventario, la cantidad de mercancías que debe tenerse disponible al principio del mes 
2. Plan de compras a precios de menudeo, la cantidad de mercancías que deberá comprarse cada mes.

3. Compras (Welsch, Hilton, Gordon \& Rivera, 2005).

\subsubsection{Presupuesto de costo de ventas.}

Tabla $\mathrm{N}^{\mathrm{a}} 49$

Gastos de Personal

\begin{tabular}{lccc}
\hline \multicolumn{1}{c}{ Personal } & & \\
& & Rem. Mensual & Rem Anual \\
\hline Gerente & 1 & $\mathrm{~S} / 7,540.00$ & $\mathrm{~S} / 90,480.00$ \\
Asistente Administrativo & 1 & $\mathrm{~S} / 1,068.17$ & $\mathrm{~S} / 12,818.00$ \\
Asistente Marketing & 1 & $\mathrm{~S} / 1,885.00$ & $\mathrm{~S} / 22,620.00$ \\
Honorarios apoyo técnico & 2 & $\mathrm{~S} / 600.00$ & $\mathrm{~S} / 7,200.00$ \\
& & - & - \\
Total & & $\mathrm{S} / 11,093.17$ & $\mathrm{~S} / 133,118.00$ \\
\hline
\end{tabular}

Nota. Elaboración propia

Tabla $\mathrm{N}^{\mathrm{o}} 50$

Presupuesto de costo de ventas

\begin{tabular}{cccccc}
\hline COSTO DEL SERVICIO & 2017 & 2018 & 2019 & 2020 & 2021 \\
\hline PERSONAL & S/ 133,118 & S/. 155,738 & S/. 178,358 & S/. 200,978 & S/. 200,978 \\
\hline
\end{tabular}

Nota. Elaboración propia

\subsubsection{Presupuesto de gastos administrativos.}

Son todos los gastos que no involucran producción y distribución. (Welsch,

Hilton, Gordon \& Rivera, 2005). 
Tabla 51

Presupuesto de Gastos administrativos

\begin{tabular}{|c|c|c|c|c|c|}
\hline \multicolumn{6}{|c|}{ GASTOS ADMINISTRATIVOS } \\
\hline Alquiler & 12.000 & 12.000 & 12.000 & 12.000 & 12.000 \\
\hline Internet y Teléfono & 3.000 & 3.000 & 3.000 & 3.000 & 3.000 \\
\hline Luz y Agua & 1.080 & 1.080 & 1.080 & 1.080 & 1.080 \\
\hline \multicolumn{6}{|c|}{ Investigación y desarrollo-software } \\
\hline Mantenimiento & 18.000 & 18.000 & 18.000 & 18.000 & 18.000 \\
\hline Depreciación & 2.676 & 2.676 & 2.676 & 2.676 & 2.676 \\
\hline Amortización & 275 & 275 & 275 & 275 & 275 \\
\hline Útiles de escritorio & - & - & - & - & - \\
\hline TOTAL & 37.031 & 37.031 & 37.031 & $\mathbf{3 7 . 0 3 1}$ & 37.031 \\
\hline
\end{tabular}

Nota. Elaboración propia 


\subsubsection{Presupuesto de marketing y ventas.}

Los gastos de marketing incluyen los gastos de ventas, los gastos de promoción y los gastos de distribución (Kotler \& Armstrong, 2012)

\section{Tabla $\mathbf{N}^{0} 52$}

Presupuesto de marketing

\begin{tabular}{lrr}
\hline \multicolumn{3}{l}{ PRESUPUESTO DE MARKETING } \\
\hline Folleteria & $\mathrm{S} /$. & $2.100,00$ \\
Impresos publicitarios & $\mathrm{S} /$. & 400,00 \\
Material Publicitario & $\mathrm{S} /$. & $1.915,00$ \\
Medio Publicitarios & $\mathrm{S} /$. & $5.500,00$ \\
Servicios Publicitarios & $\mathrm{S} /$. & $4.000,00$ \\
Gastos de Publicidad & $\mathrm{S} /$. & $2.800,00$ \\
Artículos de personal & $\mathrm{S} /$. & $1.030,00$ \\
\hline & $\mathrm{S} /$. & $\mathbf{1 7 . 7 4 5 , 0 0}$ \\
\hline
\end{tabular}

Nota: Elaboración propia

\subsubsection{Presupuesto de gastos financieros.}

El plan de negocios no contempla un presupuesto de gastos financieros ya que los accionistas aportaran los montos suficientes para sostener la empresa sin necesidad de acudir a un recurso bancario.

\subsection{Presupuestos de resultados}

\subsubsection{Estado de ganancias y pérdidas proyectado.}

El estado de ganancias y pérdidas, es un estado financiero básico, que en forma resumida de acuerdo con normas de contabilidad y disposiciones legales, proporciona información en términos de unidades monetarias referidas a los resultados obtenidos, es decir, la utilidad o pérdida que haya generado una empresa en un determinado tiempo de trabajo, su objetivo es proporcionar información 
referida a los resultados obtenidos en una empresa para la toma de decisiones (Welsch, Hilton, Gordon \& Rivera, 2005). 
Tabla 53

Estado de ganancias y pérdidas proyectado

\begin{tabular}{|c|c|c|c|c|c|}
\hline ESTADO DE RESULTADOS & 2017 & 2018 & 2019 & 2020 & 2021 \\
\hline VENTAS TOTALES & S/. 232.000,00 & S/. $248.240,00$ & S/. $265.616,80$ & S/. $284.209,98$ & S/. $304.104,67$ \\
\hline COSTO DE VENTA & S/. $133.118,00$ & S/. $155.738,00$ & S/. $178.358,00$ & S/. $200.978,00$ & S/. $200.978,00$ \\
\hline UTILIDAD BRUTA EN VENTAS & S/. $98.882,00$ & S/. $92.502,00$ & S/. $87.258,80$ & S/. $83.231,98$ & S/. 103.126,67 \\
\hline TOTAL GASTOS DE OPERACIÓN & S/. $\quad 58.855,80$ & S/. $\quad 58.855,80$ & S/. $\quad 58.855,80$ & S/. $\quad 58.855,80$ & S/. $\quad 58.855,80$ \\
\hline GASTOS DE VENTAS & S/. $\quad 21.825,00$ & S/. $\quad 21.825,00$ & S/. $\quad 21.825,00$ & S/. $\quad 21.825,00$ & S/. $\quad 21.825,00$ \\
\hline GASTOS DE ADMINISTRACION & S/. $\quad 37.030,80$ & S/. $\quad 37.030,80$ & S/. $\quad 37.030,80$ & $37.030,80$ & $37.030,80$ \\
\hline UTILIDAD DE OPERACIÓN & S/. $\quad 40.026,20$ & S/. $\quad 33.646,20$ & S/. $\quad 28.403,00$ & S/. $\quad 24.376,18$ & S/. $\quad 44.270,87$ \\
\hline \multicolumn{6}{|l|}{ GASTOS FINANCIEROS } \\
\hline \multicolumn{6}{|l|}{ OTROS INGRESOS } \\
\hline UAll & S/. $\quad 40.026,20$ & S/. $\quad 33.646,20$ & $28.403,00$ & $24.376,18$ & $44.270,87$ \\
\hline IMP RENTA & S/. $\quad 11.207,34$ & $9.420,94$ & $7.952,84$ & $6.825,33$ & S/. $\quad 12.395,84$ \\
\hline UILIDAD NETA & S/. $28.818,86$ & S/. $24.225,26$ & S/. $20.450,16$ & S/. $17.550,85$ & S/. $31.875,03$ \\
\hline
\end{tabular}

Nota. Elaboración propia 


\subsubsection{Balance proyectado.}

El balance general presupuestado tiene su origen en los flujos de operación: estado de resultados y flujo de caja. Éstos determinan el valor de cada una de sus cuentas del balance para cada período que se haya previsto. Su fundamento son las dinámicas propias de las operaciones y su pertenencia mínimo a dos flujos como mínimo, en resumen el estado de resultados es de causación, el flujo de efectivo es cuando esa causación se convierte en efectivo, el balance general es acumulativo. (Welsch, Hilton, Gordon \& Rivera, 2005).

Tabla 54

Balance Proyectado 


\begin{tabular}{|c|c|c|c|c|c|c|c|}
\hline DESCRIPCION & 2016 & & 2017 & 2018 & 2019 & 2020 & 2021 \\
\hline \multicolumn{8}{|l|}{ ACTIVOS } \\
\hline \multicolumn{8}{|l|}{ ACTIVO CORRIENTE (corto plazo) } \\
\hline CAJA Y BANCOS & S/. $38.207,67$ & S/. & $69.977,33$ & S/. $97.153,39$ & S/. $120.554,35$ & S/. $141.056,00$ & S/. $175.881,83$ \\
\hline CUENTAS POR COBRAR & & $\mathrm{S} /$. & - & S/. $\quad-$ & S/. $\quad-$ & S/. $\quad-$ & S/. $\quad-$ \\
\hline Total corto plazo & S/. $38.207,67$ & $\mathrm{~S} /$. & $69.977,33$ & S/. $97.153,39$ & S/. $120.554,35$ & S/. $141.056,00$ & S/. $175.881,83$ \\
\hline \multicolumn{8}{|l|}{ ACTIVO NO CORRIENTE (FIJO) } \\
\hline MOBILIARIO Y EQUIPO & S/. $\quad 4.738,00$ & S/. & $4.738,00$ & $4.738,00$ & S/. $\quad 4.738,00$ & S/. $\quad 4.738,00$ & $4.738,00$ \\
\hline MAQ Y EQUIPO & S/. $22.020,00$ & $\mathrm{~S} /$. & $22.020,00$ & S/. $22.020,00$ & S/. $22.020,00$ & S/. $22.020,00$ & S/. $\quad 22.020,00$ \\
\hline DeP ACUMULADA Mob & & $\mathrm{S} /$. & 473,80 & S/. $\quad 947,60$ & $\mathrm{~S} / . \quad 1.421,40$ & S/. $\quad 1.895,20$ & S/. $\quad 2.369,00$ \\
\hline DEP ACUMULADA Maq & & S/. & $2.202,00$ & S/. $\quad 4.404,00$ & S/. $\quad 6.606,00$ & S/. $\quad 8.808,00$ & S/. $\quad 11.010,00$ \\
\hline TOTAL FIJO NETO & S/. $26.758,00$ & $S /$. & $24.082,20$ & S/. $21.406,40$ & S/. $18.730,60$ & S/. $\quad 16.054,80$ & S/. $\quad 13.379,00$ \\
\hline \multicolumn{8}{|l|}{ DIFERIDOS } \\
\hline Intangibles & S/. $\quad 2.750,00$ & S/. & $2.750,00$ & $2.750,00$ & $2.750,00$ & $2.750,00$ & $2.750,00$ \\
\hline AMORTIZACION ACUMULADA & & $\mathrm{S} /$. & 275,00 & 550,00 & 825,00 & $1.100,00$ & $1.375,00$ \\
\hline TOTAL ACT DIFERIDO & S/. $\quad 2.750,00$ & $\mathrm{~S} /$. & $2.475,00$ & S/. $\quad 2.200,00$ & S/. $\quad 1.925,00$ & S/. $\quad 1.650,00$ & S/. $\quad 1.375,00$ \\
\hline TOTAL ACTIVOS & S/. $67.715,67$ & S/. & $96.534,53$ & S/. $120.759,79$ & S/. 141.209,95 & S/. $158.760,80$ & S/. $190.635,83$ \\
\hline TOTAL PASIVO CIRCULANTE & S/. $\quad-$ & $\mathrm{S} /$. & - & S/. $\quad-$ & S/. $\quad-$ & S/. $\quad-$ & $S / . \quad \quad-$ \\
\hline \multicolumn{8}{|l|}{ A LARGO PLAZO } \\
\hline TOTAL PASIVO LARGO PLAZO & S/. & S/. & - & S/. & S/. & $\mathrm{S} /$. & S/. \\
\hline TOTAL PASIVOS & S/. & S/. & - & S/. & S/. & S/. & S/. \\
\hline \multicolumn{8}{|l|}{ PATRIMONIO } \\
\hline PATRIMONIO & S/. $67.715,67$ & $\mathrm{~S} /$. & $67.715,67$ & S/. $\quad 67.715,67$ & S/. $\quad 67.715,67$ & S/. $\quad 67.715,67$ & S/. $\quad 67.715,67$ \\
\hline UTILIDAD A DISTRIBUIR & & $\mathrm{S} /$. & $25.936,98$ & S/. $\quad 47.739,72$ & S/. $\quad 66.144,86$ & S/. $\quad 81.940,62$ & S/. $110.628,15$ \\
\hline RESERVA LEGAL & & $\mathrm{S} /$. & $2.881,89$ & S/. $\quad 5.304,41$ & S/. $\quad 7.349,43$ & S/. $\quad 9.104,51$ & S/. $\quad 12.292,02$ \\
\hline \multicolumn{8}{|l|}{ UTILIDAD ACUMULADA } \\
\hline TOTAL PATRIMONIO & S/. 67.715,67 & S/. & $96.534,53$ & S/. 120.759,79 & S/. 141.209,95 & S/. 158.760,80 & S/. 190.635,83 \\
\hline TOTAL PASIVO Y CAPITAL CONTABLE & S/. $67.715,67$ & S/. & $96.534,53$ & S/. 120.759,79 & S/. 141.209,95 & S/. 158.760,80 & S/. $190.635,83$ \\
\hline
\end{tabular}




\subsubsection{Flujo de caja proyectado.}

Un flujo de caja se encuentra en varias columnas que representan los momentos en que se generan los costos y beneficios de un proyecto. Cada momento refleja dos cosas: los movimientos de caja ocurridos durante un periodo generalmente de un año, y los desembolsos que deben estar realizados para que los eventos del periodo siguiente puedan ocurrir. (Sapag, 2011) Tabla $\mathrm{N}^{\mathrm{o}} 55$

Flujo de caja proyectado 


\begin{tabular}{|c|c|c|c|c|c|c|c|c|c|c|c|}
\hline \multirow{2}{*}{$\begin{array}{l}\text { PRESUPUESTO DE CAJA } \\
\text { INGRESOS POR VENTAS }\end{array}$} & \multicolumn{2}{|l|}{2016} & \multicolumn{2}{|l|}{2017} & \multicolumn{2}{|l|}{2018} & \multicolumn{2}{|l|}{2019} & \multicolumn{2}{|l|}{2020} & \multirow{2}{*}{$\begin{array}{r}\mathbf{2 0 2 1} \\
304.104,67\end{array}$} \\
\hline & $\mathrm{S} /$. & $\mathrm{S} /$. & $232.000,00$ & $\mathrm{~S} /$. & $248.240,00$ & $\mathrm{~S} /$. & $265.616,80$ & $\mathrm{~S} /$. & $284.209,98$ & $\mathrm{~S} /$. & \\
\hline OTROS INGRESOS & $\mathrm{S} /$. & & & & & & & & & & \\
\hline TOTAL INGRESOS & & $\mathrm{S} /$. & 232.000,00 & $\mathrm{S} /$. & $248.240,00$ & S/. & $265.616,80$ & $\mathrm{~S} /$. & $284.209,98$ & $\mathrm{~S} /$. & $304.104,67$ \\
\hline \multicolumn{12}{|l|}{ EGRESOS DE EFECTIVO } \\
\hline INVERSIÓN INICIAL & S/. 29.508,00 & & & & & & & & & & \\
\hline CAPITAL DE TRABAJO & S/. $38.207,67$ & $\mathrm{~S} /$. & $2.674,54$ & $\mathrm{~S} /$. & $2.861,75$ & $\mathrm{~S} /$. & $3.062,08$ & $\mathrm{~S} /$. & $3.276,42$ & $\mathrm{~S} /$. & $50.082,46$ \\
\hline PLANILLA & & $\mathrm{S} /$. & $133.118,00$ & $\mathrm{~S} /$. & $155.738,00$ & S/. & $178.358,00$ & $\mathrm{~S} /$. & $200.978,00$ & $\mathrm{~S} /$. & $200.978,00$ \\
\hline Nueva maquinaria & & & & & & $\mathrm{S} /$. & - & $\mathrm{S} /$. & - & & \\
\hline \multicolumn{12}{|l|}{ Investigación y desarrollo } \\
\hline GASTOS ADM & & $\mathrm{S} /$. & $37.030,80$ & $\mathrm{~S} /$. & $37.030,80$ & $\mathrm{~S} /$. & $37.030,80$ & $\mathrm{~S} /$. & $37.030,80$ & $\mathrm{~S} /$. & $37.030,80$ \\
\hline GASTOS DE VENTAS & & $\mathrm{S} /$. & $21.825,00$ & $\mathrm{~S} /$. & $21.825,00$ & $\mathrm{~S} /$. & $21.825,00$ & $\mathrm{~S} /$. & $21.825,00$ & $\mathrm{~S} /$. & $21.825,00$ \\
\hline IMPUESTO RENTA & & $\mathrm{S} /$. & $11.207,34$ & $\mathrm{~S} /$. & $9.420,94$ & $\mathrm{~S} /$. & $7.952,84$ & $\mathrm{~S} /$. & $6.825,33$ & $\mathrm{~S} /$. & $12.395,84$ \\
\hline TOTAL EGRESOS & S/. 67.715,67 & $\mathrm{S} /$. & $205.855,67$ & $\mathrm{~S} /$. & $226.876,49$ & S/. & $248.228,72$ & $\mathrm{~S} /$. & $269.935,55$ & S/. & $322.312,10$ \\
\hline Utilidad neta & & $\mathrm{S} /$. & $26.144,33$ & $\mathbf{S} /$. & $21.363,51$ & S/. & $17.388,08$ & $\mathrm{~S} /$. & $14.274,42$ & $-\mathrm{S} /$. & $18.207,43$ \\
\hline Depreciación & & $\mathrm{S} /$. & $2.675,80$ & $\mathrm{~S} /$. & $2.675,80$ & $\mathrm{~S} /$. & $2.675,80$ & $\mathrm{~S} /$. & $2.675,80$ & $\mathrm{~S} /$. & $2.675,80$ \\
\hline Amortización & & $\mathrm{S} /$. & 275,00 & $\mathrm{~S} /$. & 275,00 & $\mathrm{~S} /$. & 275,00 & $\mathrm{~S} /$. & 275,00 & $\mathrm{~S} /$. & 275,00 \\
\hline \multirow[t]{2}{*}{ FLUJO DE EFECTIVO } & & $\mathrm{S} /$. & $29.095,13$ & $\mathrm{~S} /$. & $24.314,31$ & $\mathrm{~S} /$. & $20.338,88$ & $\mathrm{~S} /$. & $17.225,22$ & $-\mathrm{S} /$ & $15.256,63$ \\
\hline & & $\mathrm{S} /$. & $2.950,80$ & $\mathrm{~S} /$. & $2.950,80$ & $\mathrm{~S} /$. & $2.950,80$ & $\mathrm{~S} /$. & $2.950,80$ & $\mathrm{~S} /$. & $2.950,80$ \\
\hline SALDO INICIAL & $\mathrm{S} /$. & $\mathrm{S} /$. & $40.882,20$ & $\mathrm{~S} /$. & $72.839,08$ & $\mathrm{~S} /$. & $100.215,47$ & $\mathrm{~S} /$. & $123.830,78$ & $\mathrm{~S} /$. & $191.138,46$ \\
\hline SALDO FINAL & $\mathrm{S} /$. & $\mathrm{S} /$. & $69.977,33$ & $\mathrm{~S} /$. & $97.153,39$ & S/. & $120.554,35$ & S/. & $141.056,00$ & S/. & $\mathbf{1 7 5 . 8 8 1 , 8 3}$ \\
\hline
\end{tabular}

Nota. Elaboración propia 


\section{Capítulo IX: Evaluación Económico Financiera}

\subsection{Evaluación Financiera}

\subsubsection{TIR.}

La tasa interna de rendimiento o retorno (TIR) es una de las técnicas más usadas de las técnicas de elaboración de presupuesto de capital. Es la tasa de descuento que iguala el Van de una oportunidad de inversión con \$0 (debido a que el valor presente de la entradas de efectivo es igual a la inversión inicial); es la tasa de rendimiento que ganara la empresa si invierte en el proyecto y recibe las entradas de efectivo esperadas (Gitman \& Zutter, 2012).

Así, se determina las tasas de retorno de la inversión: la TIRE y la TIRF, de acuerdo a la inversión inicial de S/. 46,711.25 y los flujos mencionados por los 5 años de evaluación; los mismos que se presentan en la tabla 54:

Tabla Nº56

Tasa Interna de Retorno

\begin{tabular}{lcccccc}
\hline Flujos & Inversión & Año 1 & Año 2 & Año 3 & Año 4 & Año 5 \\
\hline $\begin{array}{l}\text { Económicos- } \\
\text { Financieros }\end{array}$ & $-67,715.67$ & $\begin{array}{c}29,095.1 \\
3\end{array}$ & $24,314.31$ & $20,338.88$ & $17,225.22$ & $15,256.63$ \\
\hline
\end{tabular}

Nota. Elaboración propia

Para el plan de negocio la TIR Económica y financiera arroja un resultado de $6,62 \%$ 
Tabla No57

TIR económica y financiera

\begin{tabular}{lll}
\hline WACC $9.95 \%$ & COK 11.00\% & TASA Préstamo Bancario $13 \%$ \\
\hline TIRE $>$ WACC = Genera valor & TIRF > COK = Genera valor & TIR > Tasa Bancaria = Genera Valor \\
\hline
\end{tabular}

Nota. Elaboración propia

Dada su importancia, al momento de evaluar la viabilidad del proyecto, se compara ambas tasas de rentabilidad: la TIRE 6,62\% con el WACC 9.95\%; y la TIRF 6,62\% con el COK 11\%. Producto de ello se puede apreciar la generación de valor de manera importante por ser las tasas de retorno ampliamente superior al WACC y COK calculado, por lo que es positiva la aceptación del proyecto.

Así mismo, se muestra la comparación de las tasas de rentabilidad (TIRE y TIRF). Por tanto, así se tome esta tasa como el costo de oportunidad, alineada a las condiciones del mercado, se observa que igual genera valor y se considera aceptable.

\subsubsection{VAN.}

El método usado por la mayoría de las grandes empresas para evaluar proyectos de inversión se conoce como valor actual neto (VAN). Cuando las empresas realizan inversiones, gastan el dinero que obtienen de una u otra forma, de los inversionistas. Estos últimos esperan un rendimiento sobre el dinero que aportan a las empresas, de modo que una compañía debe efectuar una inversión solo si el valor presente del flujo de efectivo que genera la inversión rebasa el costo de la inversión realizada en primer lugar. Como el método del VAN toma en cuenta el valor de dinero en el tiempo de los inversionistas es una técnica más desarrollada de 
elaboración del presupuesto de capital que la regla del periodo de recuperación. El método del Van descuenta los flujos de efectivo de la empresa del costo de capital (Gitman \& Zutter, 2012).

El valor actual neto (VAN), ha sido determinado en base a los flujos de caja económicos y los flujos de caja financieros del proyecto. De manera independiente, los importes representan a los flujos netos, es decir: ingresos menos gastos actualizados a valor presente; así, se calcula el VANE y el VANF, quitando además la inversión inicial de S/. 67,715.67 y aplicando las tasas de descuento, WACC (9.95\%) y COK (11\%) respectivamente; cuyo detalle se presenta a continuación: Tabla No58

Valor Actual Neto (VAN)

\begin{tabular}{lcccccc}
\hline Flujos & Inversión & Año 1 & Año 2 & Año 3 & Año 4 & Año 5 \\
\cline { 1 - 5 } $\begin{array}{l}\text { Económicos- } \\
\text { Financieros }\end{array}$ & $-67,715.67$ & $29,095.13$ & $24,314.31$ & $20,338.88$ & $17,225.22$ & $15,256.63$ \\
\hline
\end{tabular}

Nota. Elaboración propia

Para el plan de negocio el VAN Económico y financiero arroja un resultado de 30,686.00 soles.

Tabla No59

VAN económico y financiero

\begin{tabular}{cc}
\hline VAN E>0 & VAN F>0 \\
Genera valor & Genera valor \\
\hline
\end{tabular}

Nota. Elaboración propia

Es importante en la evaluación del proyecto determinar la recuperación de la inversión en unidades monetarias; así, se obtiene que los importes del VANE y VANF en S/.30,686.00, ambos son positivos (mayores a 0), por lo que se aprecia la generación de valor, así como la aceptación de la inversión. 


\subsubsection{ROE.}

Por lo general, cuando más alto es el rendimiento sobre la inversión, más ganan los propietarios (Gitman \& Zutter, 2012).

Tabla 60

ROE proyectado por periodo

\begin{tabular}{lrrrrr}
\hline Periodo & $\mathbf{2 0 1 7}$ & $\mathbf{2 0 1 8}$ & $\mathbf{2 0 1 9}$ & $\mathbf{2 0 2 0}$ & $\mathbf{2 0 2 1}$ \\
\hline Utilidad neta & 28818,86 & 24225,26 & 20450,16 & 17550,85 & 31875,03 \\
Patrimonio & 67715,67 & 67715,67 & 67715,67 & 67715,67 & 67715,67 \\
\hline ROE & $42,56 \%$ & $35,77 \%$ & $30,20 \%$ & $25,92 \%$ & $47,07 \%$ \\
\hline
\end{tabular}

Nota. Elaboración propia

El nivel de evaluación es calificado como esperado, ubicándose por encima del estándar en los cinco años (mayor a 10\%), siendo el primer año de 42,56\% e incrementándose a 47,07\% el último año.

\subsubsection{Ratios.}

La información contenida en los cuatro estados financieros básicos (estado de ganancias y pérdidas, balance general, estado de ganancias retenidas y estado de flujos de efectivo) es muy importante para las diversas partes interesadas que necesitan conocer con regularidad medidas relativas del desempeño de la empresa. Aquí la palabra clave es relativa, porque el análisis de los estados financieros se basa en el uso de las razones o valores relativos, el cual incluye métodos de cálculo e interpretación de las razones financieras para analizar y supervisar el desempeño de la empresa. El análisis de ratios no es simplemente el cálculo de una razón específica. Es más importante la interpretación del valor de la razón (Gitman \& Zutter, 2012) 


\section{Tabla 61}

Ratios Financieros proyectados por periodo

\begin{tabular}{|c|c|c|c|c|c|}
\hline Periodo & 2017 & 2018 & 2019 & 2020 & 2021 \\
\hline Pasivo Corrriente & 0,00 & 0,00 & 0,00 & 0,00 & 0,00 \\
\hline Activo Corriente & 26375,35 & 40834,46 & 62853,57 & 96009,64 & 160702,58 \\
\hline Capital De Trabajo & 26375,35 & 40834,46 & 62853,57 & 96009,64 & 160702,58 \\
\hline Ventas & $232.000,00$ & $248.240,00$ & $265.616,80$ & $284.209,98$ & $304.104,67$ \\
\hline Costo De Ventas & $-133118,00$ & $-155738,00$ & $-178358,00$ & $-200978,00$ & $-200978,00$ \\
\hline Utilidad Bruta & 98882,00 & 92502,00 & 87258,80 & 83231,98 & 103126,67 \\
\hline Margen Bruto & 0,23 & 0,27 & 0,30 & 0,34 & 0,29 \\
\hline Utilidad Operativa (EBIT) & 40026,20 & 33646,20 & 28403,00 & 24376,18 & 44270,87 \\
\hline Margen Operativo & $17,25 \%$ & $13,55 \%$ & $10,69 \%$ & $8,58 \%$ & $14,56 \%$ \\
\hline Utilidad Neta & 28818,86 & 24225,26 & 20450,16 & 17550,85 & 31875,03 \\
\hline $\begin{array}{l}\text { Margen Neto } \\
\text { Tasa Efectivo (Escudo Tributario }\end{array}$ & $12,42 \%$ & $9,76 \%$ & $7,70 \%$ & $6,18 \%$ & $10,48 \%$ \\
\hline Efectivo) & $28,00 \%$ & $28,00 \%$ & $28,00 \%$ & $28,00 \%$ & $28,00 \%$ \\
\hline Utilidad Operativa (EBIT) & 40026,20 & 33646,20 & 28403,00 & 24376,18 & 44270,87 \\
\hline (+) Depreciación Y Amortización & 3034,54 & 3034,54 & 3034,54 & 3034,54 & 3034,54 \\
\hline EBITDA & 43060,74 & 36680,74 & 31437,54 & 27410,72 & 47305,42 \\
\hline$\%$ & $18,56 \%$ & $14,78 \%$ & $11,84 \%$ & $9,64 \%$ & $15,56 \%$ \\
\hline Ventas & $232.000,00$ & $248.240,00$ & $265.616,80$ & $284.209,98$ & $304.104,67$ \\
\hline Activos Totales & $24.082,20$ & $21.406,40$ & $18.730,60$ & $16.054,80$ & $13.379,00$ \\
\hline Rotacion Activos Totales & 10,38 & 8,62 & 7,05 & 5,65 & 4,40 \\
\hline Activos Totales & $24.082,20$ & $21.406,40$ & $18.730,60$ & $16.054,80$ & $13.379,00$ \\
\hline $\begin{array}{l}\text { Patrimonio } \\
\text { Multiplicador Apalancamiento }\end{array}$ & $67.715,67$ & $67.715,67$ & $67.715,67$ & $67.715,67$ & $67.715,67$ \\
\hline Financiero & 2,81 & 3,16 & 3,62 & 4,22 & 5,06 \\
\hline $\begin{array}{l}\text { Utilidad Operativa/Activo }=\text { ROA } \\
\text { Utilidad Operativa } *(1-\mathrm{T}) / \text { Activo }=\end{array}$ & $166,21 \%$ & $157,18 \%$ & $151,64 \%$ & $151,83 \%$ & $330,90 \%$ \\
\hline $\mathrm{ROA}+(1-\mathrm{T})$ & $119,67 \%$ & $113,17 \%$ & $109,18 \%$ & $109,32 \%$ & $238,25 \%$ \\
\hline Utilidad Neta/Patrimonio (ROE) & $42,56 \%$ & $35,77 \%$ & $30,20 \%$ & $25,92 \%$ & $47,07 \%$ \\
\hline Margen Operativo & $17,25 \%$ & $13,55 \%$ & $10,69 \%$ & $8,58 \%$ & $14,56 \%$ \\
\hline Rotacion Activos Totales & 10,38 & 8,62 & 7,05 & 5,65 & 4,40 \\
\hline ROA & $166,21 \%$ & $157,18 \%$ & $151,64 \%$ & $151,83 \%$ & $330,90 \%$ \\
\hline
\end{tabular}

Nota. Elaboración propia

La empresa carece de pasivos. Considerando que el pasivo no corriente o fijo son aquellas deudas y obligaciones que tienen un vencimiento superior a un año. Y 
el pasivo corriente o circulante serían las deudas y obligaciones que tienen un vencimiento inferior a un año.

Por ello el proyecto no muestra ratios de liquidez ni de solvencia.

Respecto al margen operativo, este es de $17,25 \%, 13,55 \%, 10,69 \%, 8,58 \%$ y 14,56\%, superiores al 7\% que es el estándar esperado.

En cuanto al margen neto sobre ventas este va de $12,42 \%, 9,76 \%, 7,70 \%$, 6,18\% a 10,48\% el quinto año. A partir del segundo año se encuentra sobre el estándar esperado de 5\%.

Mientras que el rendimiento sobre la inversión da valores de 42,56\%, $35,77 \%, 30,20 \%, 25,92 \%$ y $47,07 \%$. Los porcentajes son bastante elevados en relación al estándar esperado (mayor al 7\%), sin embargo este ratio se debe interpretar en conjunto con los demás ratios, no obstante resulta bastante conveniente para el negocio.

\subsection{Análisis de riesgo}

Todo proyecto cuenta con ciertos riesgos, lo que obliga a poder medirlos y analizarlos. En consecuencia, se ha determinado el punto de equilibrio y el análisis de sensibilidad en tres escenarios.

\subsubsection{Análisis de punto de equilibrio.}

El riesgo del proyecto radica casi totalmente en los flujos de efectivo futuros que generara un proyecto, ya que, por otro lado, existe escaza incertidumbre acerca de la inversión inicial. Los flujos de efectivo futuros, desde luego, incluyen factores como el precio del producto de la compañía y la cantidad que puede vender, los 
costos de las materias primas y la mano de obra, el costo de los servicios públicos y las tasas impositivas. Estos determinantes subyacentes de riesgo son difíciles de pronosticar con exactitud, de modo que los administradores algunas veces intentaran determinar el flujo de efectivo que un proyecto debe generar para alcanzar el punto de equilibrio con base en el VAN y la probabilidad de que el proyecto pueda generar esa cantidad de flujo de efectivo (Gitman \& Zutter, 2012).

Tabla $N^{\circ} 62$

Análisis punto de equilibrio

\begin{tabular}{|c|c|}
\hline COSTOS FIJOS & MONTO ANUAL \\
\hline Depreciacion del activo fijo & 3034,54 \\
\hline Mano de obra indirecta & 133118,00 \\
\hline Desembolsos diversos & 26160,00 \\
\hline \multicolumn{2}{|l|}{ Imprevistos (5\%) } \\
\hline TOTAL & 162312,54 \\
\hline COSTOS VARIABLES & Monto anual \\
\hline Materia prima e insumos & 18000,00 \\
\hline \multicolumn{2}{|l|}{ Mano de obra directa } \\
\hline Imprevistos $(5 \%)$ & 2000,00 \\
\hline TOTAL & 20000,00 \\
\hline INGRESO POR AÑO & Monto anual \\
\hline Precio & 8000,00 \\
\hline UNIDADES & 31 \\
\hline Ingresos por ventas & 244000,00 \\
\hline BENEFICIO ANUAL & Monto anual \\
\hline Total de ingresos por ventas & 244000,00 \\
\hline Total de egresos & 182312,54 \\
\hline Beneficio anual esperado & 61687,46 \\
\hline \multicolumn{2}{|l|}{ PUNTO DE EQUILIBRIO } \\
\hline Relacion: Ingresos por ventas/Egresos & 1,34 \\
\hline V.P.E. (Soles) & 176.805 \\
\hline Q.P.E. (Servicios) & 22 \\
\hline
\end{tabular}

Nota. Elaboración propia 
Para hallar el punto de equilibrio del servicio se ha usado la siguiente

fórmula:

Valor del punto de equilibrio:

V.P.E. = Costo Fijo Total/[1-(Costo Variable Total/Ingresos por Ventas $)]$

\section{Cantidad del punto de equilibrio:}

Q.P.E = V.P.E/Precio

Para alcanzar el punto de equilibrio, la compañía necesita alcanzar y vender cierta cantidad de servicios.

Así se puede demostrar que la compañía; para el servicio de coaching, requiere vender como mínimo 22 servicios en el primer año, y con unas ventas totales de S/.176, 805.00 en el primer año.

Entre más bajo sea el punto de equilibrio, existe mayores probabilidades que el servicio tenga utilidades, y menos riesgo de incurrir en pérdidas; así se puede demostrar que los importes están por encima del punto de equilibrio y los resultados estimados son favorables para el estudio.

\subsubsection{Análisis de sensibilidad.}

Los analistas usan el análisis de sensibilidad para obtener una percepción de la variabilidad de las entradas de efectivo y los VAN. El análisis de sensibilidad es un método conductual en el cual los analistas calculan el VAN de un proyecto considerando escenarios o resultados diversos.

Un enfoque común en el uso del análisis de sensibilidad es calcular los VAN asociados con las entradas de efectivo (precio de los servicios) pesimistas más 
probables y optimistas. El intervalo se puede determinar restando el resultado pesimista del VAN del resultado optimista (Gitman \& Zutter, 2012)

El análisis de sensibilidad del presente estudio, queda representado en la tabla 63:

Tabla 63.

Análisis de Sensibilidad

\begin{tabular}{cccccc}
\hline & $\mathbf{3 5 0 0}$ & $\mathbf{3 0 0 0}$ & $\mathbf{2 5 0 0}$ & $\mathbf{2 0 0 0}$ & $\mathbf{1 5 0 0}$ \\
\hline & & & & & \\
$\mathbf{5 5 0 0}$ & 107.598 & 69.142 & 30.686 & -7.769 & -46.225 \\
$\mathbf{5 0 0 0}$ & 69.142 & 30.686 & -7.769 & -46.225 & -84.681 \\
$\mathbf{4 5 0 0}$ & 30.686 & -7.769 & -46.225 & -84.681 & -123.137 \\
$\mathbf{4 0 0 0}$ & -7.769 & -46.225 & -84.681 & -123.137 & -161.593 \\
$\mathbf{3 5 0 0}$ & -46.225 & -84.681 & -123.137 & -161.593 & -200.049 \\
$\mathbf{3 0 0 0}$ & -84.681 & -123.137 & -161.593 & -200.049 & -238.505 \\
\hline Nota. & Elaboración propia & & & &
\end{tabular}

El análisis de sensibilidad muestra las ventas de los dos servicios que ofrecerá la empresa: coaching ejecutivo y team building. El valor del VAN se ve reflejado de manera positiva dentro de las celdas resaltadas en color celeste. El VAN hallado para el actual proyecto es 41,365 soles (con 5000 y 3000 como precios), observándose que la combinación de precios de 4000 y 3500 soles es uno de los límites del análisis y por el otro extremo 5500 y 2000 soles es el otro extremo. Pasada esta frontera, el VAN se vuelve negativo.

\subsubsection{Análisis de escenarios.}

Es un método conductual basado en estadísticas que aplica distribuciones de probabilidad predeterminadas para estimar resultados riesgoso. El resultado de una simulación constituye un excelente apoyo para tomar una decisión porque facilita al 
en cargado de tomar decisiones visualizar un continuo de combinaciones de riesgo y rendimiento en vez de obtener una sola estimación puntual (Gitman \& Zutter, 2012).

Tabla 64

Análisis de escenarios

\begin{tabular}{llll}
\hline Real & Optimista & Pesimista & \\
\hline Escenario 1 & Escenario 2 & Escenario 3 & \\
\hline 29 & 38 & 12 & Ventas Coaching \\
29 & 38 & 12 & Ventas Teambuilding \\
205885.67 & 226575.67 & 168335.67 & Egresos \\
232000 & 304000 & 96000 & Ingresos \\
\hline 30686 & & & VAN \\
$6.62 \%$ & 211.682 & -339.960 & TIR \\
1.5 & $100.7 \%$ & $0 \%$ & B/C \\
\hline
\end{tabular}

Nota. Elaboración propia

En el caso del escenario 1, se observa la situación real de la empresa, con 29 ventas de cada uno de sus servicios, ingresos por 232,000 soles y egresos por 205885,67 soles. El VAN es de 30686 soles, el TIR es de $6.62 \%$ y el Beneficio/Costo es de 1.5 .

En el caso del escenario 2, se observa el escenario optimista de la empresa, con un incremento del $30 \%$ en las ventas, es decir 38 ventas de cada uno de sus servicios, ingresos 
por 304,000 soles y egresos por 226575.67 soles. El VAN es de 211,682, el TIR es de $100.7 \%$ y el Beneficio/Costo es de 3.8 .

En el caso del escenario 3, se observa el escenario pesimista de la empresa, con un decremento del $60 \%$ en las ventas, es decir 12 ventas de cada uno de sus servicios, ingresos por 96000 soles y egresos por 168335.67 soles. El VAN es de $-339,960$, el TIR es de $0 \%$ y el Beneficio/Costo es de $-3.5 \%$. 


\section{CONCLUSIONES Y RECOMENDACIONES}

\section{Conclusiones}

Se identificaron oportunidades, alcances y limitaciones del servicio de coaching ejecutivo y team building, se ha determinado la viabilidad de implementar una empresa consultora de coaching ejecutivo y team building en la ciudad de Arequipa.

Se reconoce la importancia del departamento de recursos humanos de toda empresa y de la consultoría de recursos humanos que implica un conjunto de actividades orientadas a manejar la transición, que ayuden a que las organizaciones y las personas comprendan, acepten y puedan implementar los cambios necesarios para alcanzar una mejora en el desempeño de la organización.

a. Se identificaron oportunidades, alcances y limitaciones del servicio de coaching ejecutivo y team building, se ha determinado la viabilidad de implementar una empresa consultora de coaching ejecutivo y team building en la ciudad de Arequipa.

b. La estructura económica del sector se encuentra en crecimiento tal como ocurre con la economía nacional y regional.

Tras la ejecución del estudio de mercado en 251 empresas se concluye que los encargados del área de recursos humanos en la mayoría de empresas de Arequipa no tienen un concepto claro de lo que es el coaching ejecutivo y team building, por ello deben utilizarse estrategias de penetración de mercado, de posicionamiento y de 
comunicación agresiva, que permitan dar a conocer estas potentes herramientas y su importancia para mejorar la performance del talento humano.

Se realizó la proyección del mercado objetivo, obteniendo un mercado meta de coaching ejecutivo igual a 35 empresas y de team building de 26 empresas. Al realizar el pronóstico de ventas se obtienen 46 ventas de coaching ejecutivo para el 2021 y 34 de team building.

Tras el desarrollo de la ingeniería del proyecto, se distribuyó la maquinaria y equipos, se seleccionó el tamaño de la empresa y se localizó a la empresa Intenta coaching y team building en la provincia de Arequipa, en el distrito de Arequipa.

c. Se establecieron los aspectos organizacionales del proyecto, declarándose la misión, visión y principios de la empresa, así como la matriz de estrategias en base a la matriz FODA y la matriz VRIO. Además se diseñó la estructura organizacional, los perfiles de los puestos clave y sus remuneraciones compensaciones e incentivos.

Se diseñó el plan de marketing del plan de negocios, avocándose la estrategia de marca, a la percepción de la imagen de Intenta coaching ejecutivo y team building como una institución orientada al sector del talento humano, a partir de un manejo de acciones comunicacionales informativas. Por ello, se definió una estrategia de desarrollo de producto en base a la experiencia y conocimiento del mercado. Además se establecieron las estrategias de precio, distribución y promoción, elaborándose un plan de ventas.

d. Se desarrolló la planificación financiera del plan de negocios, siendo el costo total del proyecto de 67715,67 soles. Para el plan de negocios no habrá endeudamiento ya que la 
inversión por parte de los accionistas será la suficiente para cubrir los costos preoperativos. El saldo final del presupuesto de caja para el año 2021 será de 175881,83 soles.

Se realizó la evaluación económica y financiera del plan del negocio, cuyos resultados fueron positivos y rentables para el inversionista, determinándose una TIR de $6,62 \%$ la cual es atractiva. Por otro lado el VAN es de 30,686.00 soles y el ROE será de 47,07\% para el año 2021. Los ratios financieros son positivos. El análisis del punto de equilibrio, de sensibilidad y de escenarios es adecuado. Por consiguiente, se concluye que el proyecto es viable. 


\section{Recomendaciones}

La creación de una empresa consultora de coaching ejecutivo y team building en la ciudad de Arequipa resulta muy novedoso y viable tanto en la parte financiera como comercial. Es por esta razón que se recomienda lo siguiente:

a. Una pronta implementación, para posicionar a la empresa Intenta coaching y team building; el hecho de posicionarse adecuadamente marcará una ventaja competitiva y pondrá a Intenta a la vanguardia de las empresas consultoras de recursos humanos. b. Analizar constantemente el entorno económico para determinar el momento adecuado de implementación y lanzamiento de los distintos productos que formarán parte de la oferta de capacitación que se irán lanzando a lo largo del tiempo de funcionamiento de la empresa.

c. Dirigir las estrategias de marketing hacia las pequeñas, medianas y grandes empresas teniendo en cuenta la naturaleza del negocio B2B. Una de las estrategias más importantes en Intenta es la de expansión con profundización, la cual se ve traducida en un largo plazo a la apertura de nuevos mercados en el sur del país.

d. Tener en cuenta de manera permanente las estrategias seleccionadas, así como los factores de posicionamiento y comunicación de esta línea de negocio, ya que un adecuado manejo de estos estará íntimamente vinculado al resultado financiero esperado.

e. Tal como quedó evidenciado en el estudio de mercado, los encargados del área de recursos humanos en la mayoría de empresas de Arequipa no conocen qué es exactamente el coaching ejecutivo y el team building, por ello se recomienda utilizar estrategias de penetración de mercado, de posicionamiento y de comunicación agresiva, para que las empresas conozca estas herramientas y su importancia para mejorar la performance del talento humano 


\section{INDICE DE FIGURAS}

Figura $\mathrm{N}^{\circ} 1$ Crecimiento del PBI por Macro región................................... 26

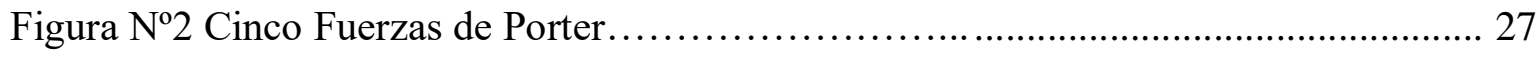

Figura $\mathrm{N}^{0} 3$ Presencia de empresas de recursos humanos Arequipa.................... 43

Figura $\mathrm{N}^{\circ} 4$ Presencia de empresas de recursos humanos Lima............................... 43

Figura $N^{\circ} 5$ Producto bruto interno por actividad económica............................ 50

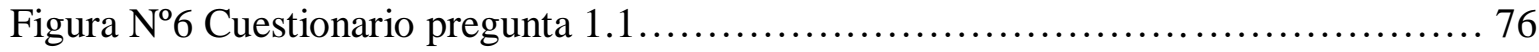

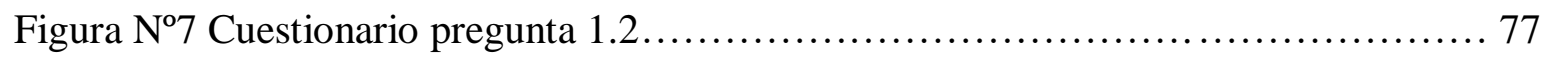

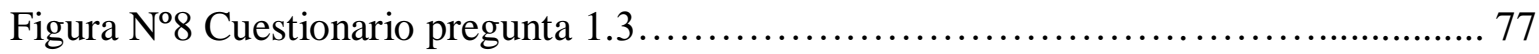

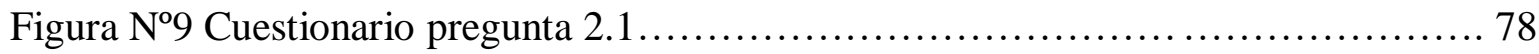

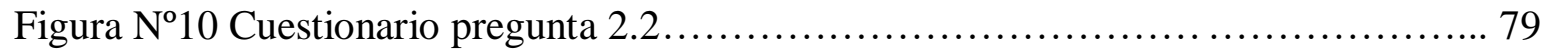

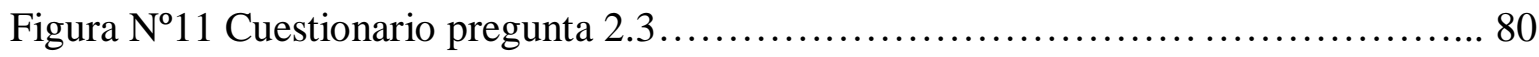

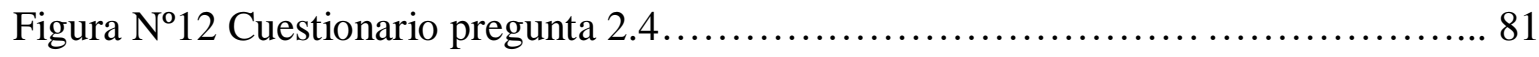

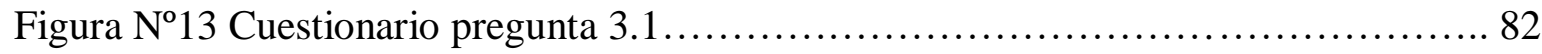

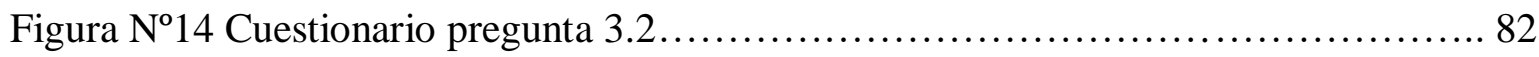

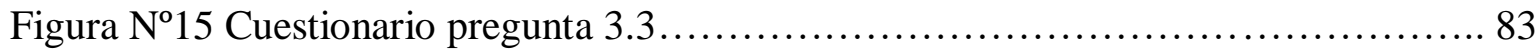

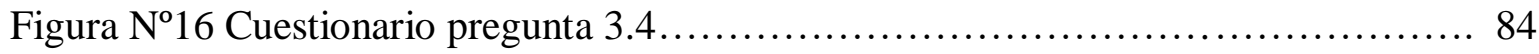

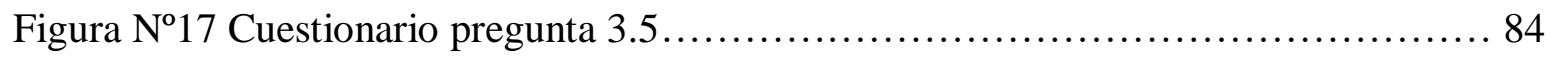

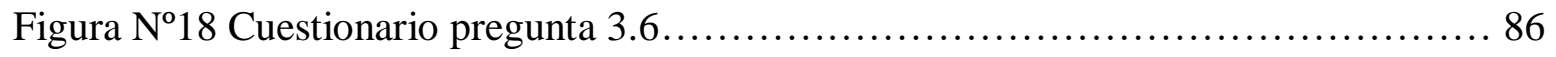

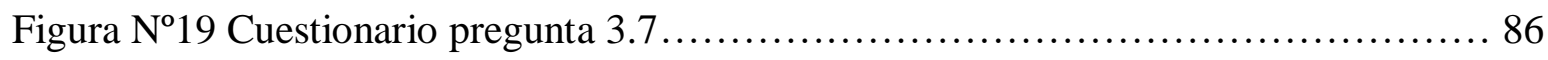

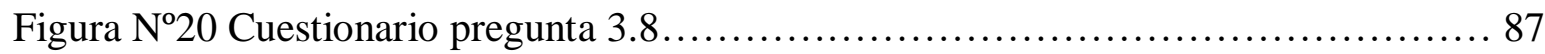

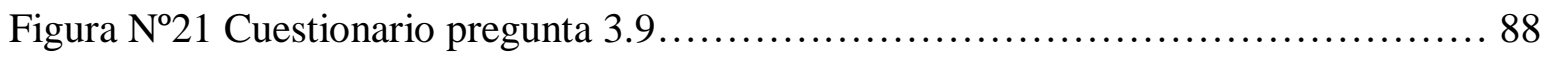




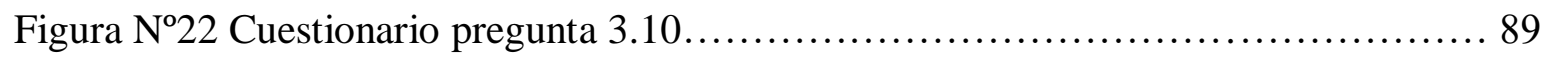

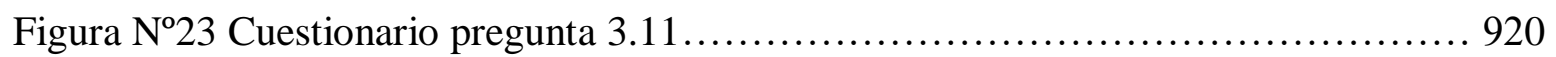

Figura No24 Patrón de datos horizontal del sector de actividades de consultoría........... 97

Figura No25 Diagrama de flujo de proceso de venta..............................102

Figura N²6 Layout Intenta Coaching y Teambuilding.................................106

Figura $\mathrm{N}^{\circ} 27$ Layout distribución de maquinaria y equipos........................... 106

Figura ํ28 Layout distribución de área Intenta Coaching y Teambuilding.............. 109

Figura No29 Macro localización del proyecto...................................... 110

Figura $\mathrm{N}^{\circ} 30$ Organigrama Intenta Coaching y Teambuilding ........................ 128

Figura $\mathrm{N}^{\circ} 31$ Matriz de expansión de ANSOFF …....................................... 136

Figura $\mathrm{N}^{\circ} 32$ Isotipo Intenta Coaching y Teambuilding ................................ 139

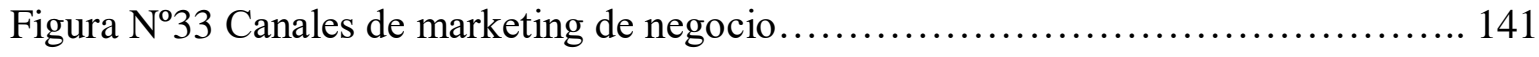

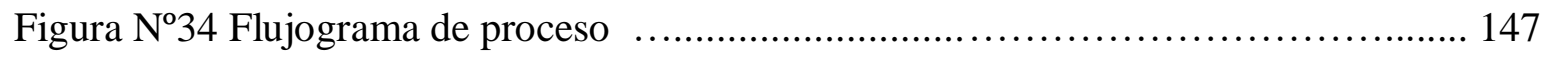




\section{ÍNDICE DE TABLAS}

Tabla $\mathrm{N}^{\mathrm{o}} 1$ : Tipologia del coaching .................................................................. 13

Tabla No2: Empresas de recursos humanos en Arequipa .......................................23

Tabla No3: Empresas de recursos humanos en Lima .............................................24

Tabla No4: Matriz de Atractividad. Poder de negociación con proveedores .....................30

Tabla No5: Matriz de Atractividad. Poder de negociación con los clientes ......................32

Tabla N6: Matriz de Atractividad. Rivalidad entre competidores ...............................34

Tabla No7: Matriz de Atractividad. Amenaza de entrada de nuevos competidores ............36

Tabla No8: Matriz de Atractividad. Amenaza de entrada de productos sustitutos ..............38

Tabla N99: Competidores directos Lima ....................................................... 40

Tabla $\mathrm{N}^{\mathrm{o}} 10$ : Competidores directos Arequipa ........................................................41

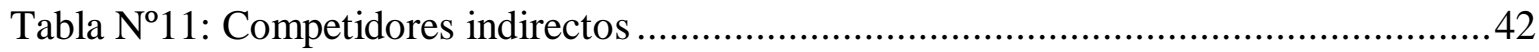

Tabla $\mathrm{N}^{\mathrm{o}} 12$ : Matriz de perfil competitivo ...........................................................44

Tabla No13: Producto Bruto Interno (PBI) del sector servicios .................................46

Tabla $\mathrm{N}^{\mathrm{o}} 14$ : Conflictos sociales registrados por mes...........................................47

Tabla No15: Conflictos sociales según principal competencia del gobierno ...................47

Tabla $\mathrm{N}^{\mathrm{o}} 16$ : Oferta y demanda global trimestral ..............................................49

Tabla $\mathrm{N}^{\mathrm{o}} 17$ : Valor agregado bruto sector servicios .............................................51

Tabla $N^{\mathrm{o}} 18:$ Segmentación por sectores......................................................67

Tabla No19: Perfil de Participantes para la entrevista a expertos ................................. 70

Tabla N²0: Valores a usar para el cálculo de la muestra ......................................75

Tabla N²1: Evolución de la actividad de servicios prestados a empresas ......................94 
Tabla No22: Proyección de ventas anual ......................................................... 97

Tabla No23: Selección de equipamiento ........................................................ 101

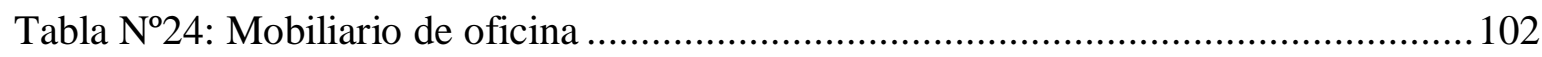

Tabla No25: Dimensión de áreas de oficina....................................... 105

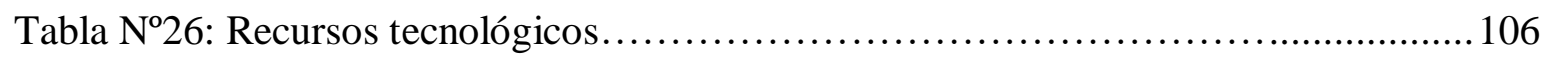

Tabla N 27 : Costo de alquiler por distrito....................................... 119

Tabla No28: Régimen Laboral................................................... 114

Tabla No29: Factores de localización optima.................................. 115

Tabla N³0: Matriz de estrategias de negocio Intenta Coaching y Teambuilding. ......... 119

Tabla N³1: Matriz de estrategias de negocio Intenta Coaching y Teambuilding. ......... 120

Tabla No32: Matriz FODA.............................................. 122

Tabla No33: Matriz estratégica........................................... 123

Tabla No34: Matriz VRIO Intenta Coaching y Teambuilding.......................... 125

Tabla N 35 : Perfil de puesto del Gerente general............................. 128

Tabla No36: Perfil de puesto de Asistente de contabilidad.......................... 129

Tabla No37: Perfil de puesto de Asistente de marketing y ventas...................... 130

Tabla N 38 : Remuneración de los trabajadores del proyecto...................... 131

Tabla N39: Rango de precio por segmentos....................................... 143

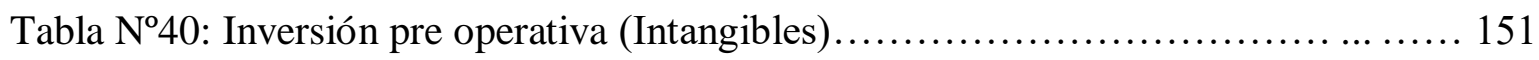

Tabla No41: Inversión pre operativa (Maquinaria y equipos) $\ldots \ldots \ldots \ldots \ldots \ldots \ldots \ldots \ldots \ldots 1$

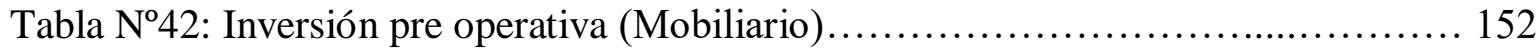

Tabla No43: Inversión en capital de trabajo................................. 153

Tabla No44: Costo del proyecto en soles................................... 154

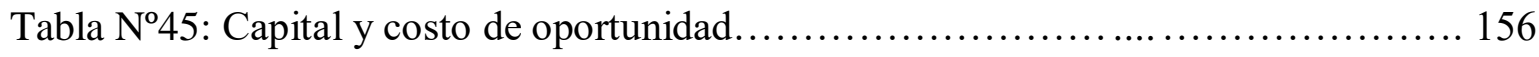


Tabla No46: Presupuesto de ventas (Cantidad de servicios) $\ldots \ldots \ldots \ldots \ldots \ldots \ldots \ldots \ldots \ldots \ldots$

Tabla No47: Presupuesto de ventas (Valor de venta por artículos) $\ldots \ldots \ldots \ldots \ldots \ldots \ldots \ldots \ldots \ldots$

Tabla N48: Presupuesto de costos de producción.............................. 160

Tabla No49: Gastos de personal......................................... 161

Tabla No50: Presupuesto del costo de ventas............................... 161

Tabla No51: Presupuesto de gastos administrativos............................ 162

Tabla No52: Presupuesto de marketing .......................................... 163

Tabla No53: Estado de ganancias y pérdidas proyectado........................ 165

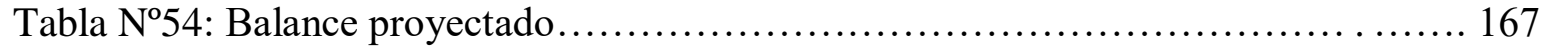

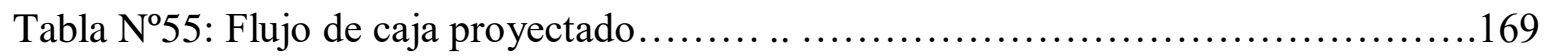

Tabla N $\mathrm{N}^{\mathrm{0}}$ 6: Tasas de retorno de la inversión................................ 170

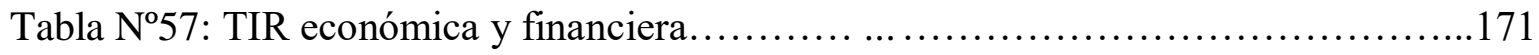

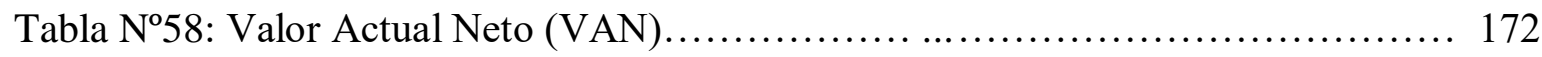

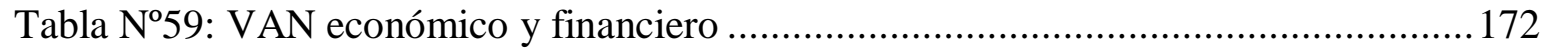

Tabla No60: ROE proyectado por periodo................................. 173

Tabla N61: Ratios financieros proyectados por periodo........................ 174

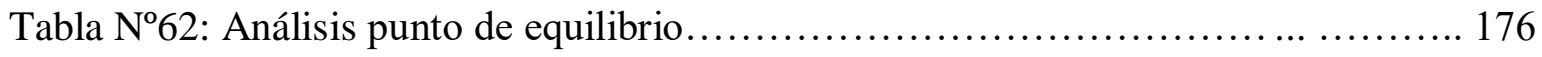

Tabla No63: Análisis de sensibilidad...................................... 178

Tabla No64: Análisis de escenarios....................................... 179 


\section{ANEXOS}

Anexo 1. Listado de empresas de recursos humanos en Arequipa

\begin{tabular}{|l|l|}
\hline $\mathrm{N}^{\circ}$ & Empresas \\
\hline 1 & Asc Consultora de Rr.Hh. \\
\hline 2 & Agencia de Empleos Angelita Mega Norte \\
\hline 3 & Aguilar \& Asociados Sociedad Civil \\
\hline 4 & Corporación de Negocio Y Recursos Humanos \\
\hline 5 & Psicotalentos \\
\hline 6 & Team Work \\
\hline 7 & Team Éxito Consulting \\
\hline 8 & Alianza Service S.R.L. \\
\hline 9 & Grupo Moya E.I.R.L. \\
\hline 10 & Golden Force S.A.C. \\
\hline 11 & Mundo Laboral \\
\hline 12 & Objettivo Lavoro \\
\hline 13 & Cooperativa Santo Domingo \\
\hline 14 & Manpower Peru S.A. \\
\hline 15 & T-Impulsa Coaching \\
\hline 16 & Coaching Mejora \\
\hline
\end{tabular}




\section{Anexo 02. Guía de entrevista a expertos}

\begin{tabular}{|l|l|}
\hline \multicolumn{2}{|c|}{ Guía de entrevista 1 } \\
\hline Día & Hora \\
\hline Nombre & Doris Canchaya \\
\hline Lugar & Lima \\
\hline Edad & 42 años \\
\hline Nacionalidad & Peruana \\
\hline Ocupación & Gerente de recursos humanos empresa retail \\
\hline Profesión & Ingeniera industrial \\
\hline Distrito de residencia & Lima \\
\hline Breve reseña & $\begin{array}{l}\text { Se desempeña como gerente de recursos } \\
\text { humanos en una empresa retail muy } \\
\text { importante del país, es responsable de todo } \\
\text { el personal a nivel nacional }\end{array}$ \\
\hline $\begin{array}{l}\text { Tema : la función del coaching y team building en el desempeño del talento humano en las } \\
\text { empresas }\end{array}$ & $\begin{array}{l}\text { ¿Cómo se encuentra actualmente la rotación } \\
\text { de personal en el sector retail? }\end{array}$ \\
\hline Pregunta 1 & $\begin{array}{l}\text { El coaching ejecutivo y team building } \\
\text { ¿Ayudan a minimizar el bajo desempeño de } \\
\text { personal dentro de la organización? }\end{array}$ \\
\hline Apuntes & \\
\hline Pregunta 2 & $\begin{array}{l}\text { ¿Cuándo se debe dar coaching en una } \\
\text { organización? }\end{array}$ \\
\hline Apuntes & $\begin{array}{l}\text { ¿Cuándo se debe realizar team building en } \\
\text { una organización? }\end{array}$ \\
\hline Pregunta 3 & $\begin{array}{l}\text { ¿Cuáles son los beneficios del coaching } \\
\text { ejecutivo dentro de una organización? }\end{array}$ \\
\hline Apuntes & \\
\hline Pregunta 4 & \\
\hline Apuntes & \\
\hline Pregunta 5 & \\
\hline Apuntes &
\end{tabular}




\begin{tabular}{|c|c|}
\hline \multicolumn{2}{|c|}{ Guía de entrevista 2} \\
\hline Día & Hora \\
\hline Nombre & Patricia Cauqui \\
\hline \multicolumn{2}{|l|}{ Lugar } \\
\hline Edad & 40 años \\
\hline Nacionalidad & Española \\
\hline Ocupación & $\begin{array}{l}\text { Coach profesional, docente de INCAE } \\
\text { business school }\end{array}$ \\
\hline Profesión & Administradora de empresas \\
\hline Distrito de residencia & Madrid \\
\hline Breve reseña & $\begin{array}{l}\text { Se desempeña como consultora de empresas } \\
\text { transnacionales en el área de recursos } \\
\text { humanos, coach ejecutiva que brinda } \\
\text { asesoría internacional a países de centro } \\
\text { américa, Europa y América Latina. }\end{array}$ \\
\hline \multicolumn{2}{|c|}{$\begin{array}{l}\text { Tema : la función del coaching y team building en el desempeño de los colaboradores en } \\
\text { las organizaciones }\end{array}$} \\
\hline Pregunta 1 & $\begin{array}{l}\text { ¿Cuál es la función que cumple el coaching } \\
\text { ejecutivo y team building en las } \\
\text { organizaciones? }\end{array}$ \\
\hline \multicolumn{2}{|l|}{ Apuntes } \\
\hline Pregunta 2 & $\begin{array}{l}\text { ¿Por qué una empresa invierte en coaching } \\
\text { ejecutivo y team building? }\end{array}$ \\
\hline \multicolumn{2}{|l|}{ Apuntes } \\
\hline Pregunta 3 & $\begin{array}{l}\text { ¿Cuándo se debe dar coaching en una } \\
\text { organización? }\end{array}$ \\
\hline \multicolumn{2}{|l|}{ Apuntes } \\
\hline Pregunta 4 & $\begin{array}{l}\text { ¿Cuándo se debe realizar team building en } \\
\text { una organización? }\end{array}$ \\
\hline \multicolumn{2}{|l|}{ Apuntes } \\
\hline Pregunta 5 & $\begin{array}{l}\text { ¿Cuáles son los beneficios del coaching } \\
\text { ejecutivo en una organización? }\end{array}$ \\
\hline Apuntes & \\
\hline
\end{tabular}




\begin{tabular}{|c|c|}
\hline \multicolumn{2}{|c|}{ Guía de entrevista 3} \\
\hline Día & Hora \\
\hline Nombre & Lizeth Ranilla \\
\hline Lugar & Arequipa \\
\hline Edad & 35 años \\
\hline Nacionalidad & Peruana \\
\hline Ocupación & $\begin{array}{l}\text { Jefe de Recursos Humanos de una } \\
\text { institución financiera }\end{array}$ \\
\hline Profesión & Psicóloga \\
\hline Distrito de residencia & Paucarpata \\
\hline Breve reseña & $\begin{array}{l}\text { Se desempeña como Jefe de recursos } \\
\text { humanos en una importante entidad } \\
\text { financiera de la ciudad de Arequipa, con más } \\
\text { de } 5 \text { años de experiencia en la jefatura ha } \\
\text { desempeñado diferentes cargos dentro del } \\
\text { área de talento humano en la ciudad de } \\
\text { Arequipa. }\end{array}$ \\
\hline Tema : mercado del c & a building en la ciudad de arequipa \\
\hline Pregunta 1 & $\begin{array}{l}\text { ¿Cómo se encuentra actualmente el mercado } \\
\text { en servicios de coaching ejecutivo y team } \\
\text { building? }\end{array}$ \\
\hline Apuntes & \\
\hline Pregunta 2 & $\begin{array}{l}\text { ¿Ha utilizado algunos de estos servicios } \\
\text { dentro de su organización? ¿Cuáles? }\end{array}$ \\
\hline Apuntes & \\
\hline Pregunta 3 & $\begin{array}{l}\text { ¿Conoce empresas arequipeñas que brinden } \\
\text { estos servicios? Menciónelas }\end{array}$ \\
\hline Apuntes & \\
\hline Pregunta 4 & $\begin{array}{l}\text { ¿Cada cuánto tiempo realiza usted este tipo } \\
\text { de actividades? }\end{array}$ \\
\hline Apuntes & \\
\hline Pregunta 5 & $\begin{array}{l}\text { ¿Puede mencionar un presupuesto } \\
\text { aproximado que se utiliza en este tipo de } \\
\text { actividades? }\end{array}$ \\
\hline Apuntes & \\
\hline
\end{tabular}




\begin{tabular}{|l|l|l|}
\hline \multicolumn{2}{|c|}{ Guía de entrevista 4 } \\
\hline Día & 11 de Setiembre & Hora \\
\hline Nombre & Carolina Pezo Cano \\
\hline Lugar & Arequipa \\
\hline Edad & 33 años \\
\hline Nacionalidad & Peruana \\
\hline Ocupación & Jefe de Recursos Humanos \\
\hline Profesión & Ingeniero Industrial \\
\hline Distrito de residencia & Yanahuara \\
\hline & $\begin{array}{l}\text { Se desempeña como Jefe de Recursos de } \\
\text { Humanos de una empresa familiar de la } \\
\text { ciudad de Arequipa, que maneja 25 } \\
\text { colaboradores, cuenta con más de 4 años de } \\
\text { experiencia trabajando en áreas de Recursos } \\
\text { Humanos y bienestar social. }\end{array}$ \\
\hline $\begin{array}{l}\text { Tema : la función del coaching y team reseña } \\
\text { colaboradores en las organizaciones }\end{array}$ & $\begin{array}{l}\text { bCuálding en el desempeño de los función que cumple el coaching } \\
\text { ejecutivo y team building en las } \\
\text { organizaciones? }\end{array}$ \\
\hline Pregunta 1 & $\begin{array}{l}\text { ¿Por qué una empresa invierte en coaching } \\
\text { ejecutivo y team building? }\end{array}$ \\
\hline Pregunta 2 & $\begin{array}{l}\text { ¿Cuándo se debe dar coaching en una } \\
\text { organización? }\end{array}$ \\
\hline Pregunta 3 & $\begin{array}{l}\text { ¿Cuándo se debe realizar team building en } \\
\text { una organización? }\end{array}$ \\
\hline Pregunta 4 & $\begin{array}{l}\text { ¿Cuáles son los beneficios del coaching } \\
\text { ejecutivo en una organización? }\end{array}$ \\
\hline Pregunta 5 &
\end{tabular}


Anexo 03: Guía de entrevista a expertos desarrollada

\begin{tabular}{|l|l|}
\hline \multicolumn{2}{|c|}{ Guía de entrevista 1 } \\
\hline Día & Hora \\
\hline Nombre & Doris Canchaya \\
\hline Lugar & Lima \\
\hline Edad & 42 años \\
\hline Nacionalidad & Peruana \\
\hline Ocupación & Gerente de recursos humanos empresa retail \\
\hline Profesión & Ingeniera industrial \\
\hline Distrito de residencia & Lima \\
\hline Breve reseña & $\begin{array}{l}\text { Se desempeña como gerente de recursos } \\
\text { humanos en una empresa retail muy } \\
\text { importante del país, es responsable de todo } \\
\text { el personal a nivel nacional, tiene a su cargo } \\
\text { a 3000 colaboradores entre mandos medios y } \\
\text { bajos }\end{array}$ \\
\hline $\begin{array}{l}\text { Tema : la función del coaching y team building en el desempeño del talento } \\
\text { humano en las empresas }\end{array}$ & $\begin{array}{l}\text { ¿Cómo se encuentra actualmente la rotación } \\
\text { de personal en el sector retail? }\end{array}$ \\
\hline Pregunta 1 & $\begin{array}{l}\text { El Perú actualmente tiene altas tasas de } \\
\text { rotación en el sector retail, estamos hablado } \\
\text { que un promedio debe ser de un 4\% y hoy en } \\
\text { día tenemos un 9\% a 10\% de rotación de } \\
\text { personal, si consideramos que la } \\
\text { competencia en retail esta dura, ahora hay } \\
\text { que cuidar a cada colaborador para que no } \\
\text { cambie de trabajo, un trabajador no siempre } \\
\text { se va por un mejor sueldo, se va porque no } \\
\text { está motivado, porque no tiene línea de } \\
\text { carrera o por el jefe inmediato, son muchos } \\
\text { los factores que hacen la rotación de } \\
\text { personal elevada. }\end{array}$ \\
\hline Apuntes & $\begin{array}{l}\text { ¿El coaching ejecutivo y team building } \\
\text { ayudan a minimizar el bajo desempeño de } \\
\text { personal dentro de la organización? }\end{array}$ \\
\hline Pregunta 2 & $\begin{array}{l}\text { En nuestro caso sí, hemos trabajado con los } \\
\text { líderes coaching ejecutivo para que } \\
\text { fomenten la unión, compromiso y liderazgo } \\
\text { con el personal que tienen a su cargo y si nos } \\
\text { ha dado resultados, otro punto es que el } \\
\text { coaching nos a permitido fidelizar a } \\
\text { colaboradores claves dentro de la } \\
\text { organización. Team Building hemos }\end{array}$ \\
\hline
\end{tabular}




\begin{tabular}{|c|c|}
\hline & $\begin{array}{l}\text { trabajado para temas específicos como toma } \\
\text { de decisiones, trabajo en equipo, } \\
\text { compromiso, amor a la marca, y es más } \\
\text { complicado porque tenemos cedes en } \\
\text { provincia y trasladar toda la logística de } \\
\text { Lima a provincias eleva los costos de } \\
\text { producción de esta actividad y hace que en } \\
\text { provincias trabajemos menos con estas } \\
\text { herramientas. }\end{array}$ \\
\hline Pregunta 3 & $\begin{array}{l}\text { ¿Cuándo se debe dar coaching en una } \\
\text { organización? }\end{array}$ \\
\hline Apuntes & $\begin{array}{l}\text { Cuando se detecta un problema en un área } \\
\text { determinada o cuando se desea sacar a flote } \\
\text { a los colaboradores que son claves para } \\
\text { organización. }\end{array}$ \\
\hline Pregunta 4 & $\begin{array}{l}\text { ¿Cuándo se debe realizar team building en } \\
\text { una organización? }\end{array}$ \\
\hline Apuntes & 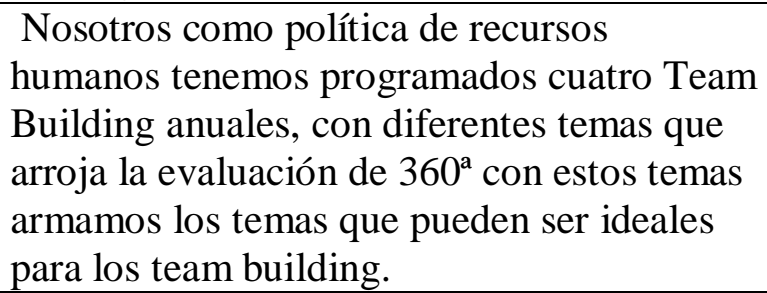 \\
\hline Pregunta 5 & $\begin{array}{l}\text { ¿Cuáles son los beneficios del coaching } \\
\text { ejecutivo dentro de una organización? }\end{array}$ \\
\hline Apuntes & $\begin{array}{l}\text { Mira, para nosotros ha sido la Motivación, } \\
\text { sentido de pertenencia y productividad, } \\
\text { cuando hemos realizado el coaching } \\
\text { ejecutivo con seis líderes que son claves para } \\
\text { el funcionamiento de la organización se ha } \\
\text { visto una mejor en el rendimiento de sus } \\
\text { áreas y por ende también la comunicación a } \\
\text { mejorado en un } 80 \% \text { con sus colaboradores. }\end{array}$ \\
\hline
\end{tabular}




\begin{tabular}{|l|l|l|}
\hline \multicolumn{2}{|c|}{ Guía de entrevista 2 } \\
\hline Día & Hora & 17:30 p.m. \\
\hline Nombre & Patricia Cauqui \\
\hline Lugar & España-Madrid \\
\hline Edad & 40 años \\
\hline Nacionalidad & Española \\
\hline Ocupación & $\begin{array}{l}\text { Master Coach certificado, docente de } \\
\text { INCAE business school }\end{array}$ \\
\hline Profesión & Administradora de empresas \\
\hline Distrito de residencia & Madrid \\
\hline Breve reseña & $\begin{array}{l}\text { Se desempeña como consultora de empresas } \\
\text { transnacionales en el área de recursos } \\
\text { humanos, coach ejecutiva que brinda } \\
\text { asesoría internacional a países de centro } \\
\text { américa, Europa y América Latina. Directora } \\
\text { del programa de liderazgo y coaching } \\
\text { ejecutivo en escuelas de negocios muy } \\
\text { reconocidas. }\end{array}$ \\
\hline $\begin{array}{l}\text { Tema : la función del coaching y team building en el desempeño de los } \\
\text { colaboradores en las organizaciones }\end{array}$ & $\begin{array}{l}\text { iCuál es la función que cumple el coaching } \\
\text { ejecutivo y team building en las } \\
\text { organizaciones? }\end{array}$ \\
\hline Pregunta 1 & $\begin{array}{l}\text { Pues el coaching ejecutivo hoy por hoy es } \\
\text { una herramienta poderosa que actualmente } \\
\text { tiene el sistema más completo para ayudar a } \\
\text { las personas a trabajar en equipo, fomentar el } \\
\text { aprendizaje, el liderazgo y liberar el } \\
\text { potencial que tiene cada colaboración dentro } \\
\text { de la organización. Por otro lado el Team } \\
\text { building ayuda a las organizaciones con } \\
\text { actividades de trabajo en equipo y cohesión } \\
\text { entre los colaboradores, el realizar este tipo } \\
\text { de reuniones fuera del horario de trabajo } \\
\text { hace que tenga un mayor impacto en los } \\
\text { colaboradores haciendo que los mensajes } \\
\text { sean más poderosos y los talleres tengan } \\
\text { mejores resultados. }\end{array}$ \\
\hline Apuntes & $\begin{array}{l}\text { iPor qué una empresa invierte en coaching } \\
\text { ejecutivo y team building? }\end{array}$ \\
\hline Pregunta 2 & $\begin{array}{l}\text { Pienso que las empresas están apostando } \\
\text { más por sus líderes para obtener mejores y } \\
\text { mayores resultados. La velocidad del cambio }\end{array}$ \\
\hline Apuntes & & \\
\hline
\end{tabular}




\begin{tabular}{|c|c|}
\hline & $\begin{array}{l}\text { en el entorno, exige más a los ejecutivos, } \\
\text { ahora no basta con tener un coeficiente } \\
\text { intelectual elevado, ahora lo que buscan las } \\
\text { empresas son líderes bien formados que } \\
\text { sepan orientar a los colaboradores. }\end{array}$ \\
\hline Pregunta 3 & $\begin{array}{l}\text { ¿Cuándo se debe dar coaching en una } \\
\text { organización? }\end{array}$ \\
\hline Apuntes & $\begin{array}{l}\text { Cuando la organización lo solicite, no hay } \\
\text { que esperar a que se agraven las cosas dentro } \\
\text { de la organización por ejemplo cuando no } \\
\text { hay una pobre comunicación hay que } \\
\text { trabajar con coaching, cuando algún } \\
\text { empleado de la organización merece ser } \\
\text { felicitado hay que trabajar coaching como } \\
\text { premio a sus resultados, o cuando algún } \\
\text { colaborador clave debe de mejorar alguna } \\
\text { destreza en el trabajo también se debe de } \\
\text { trabajar coaching, }\end{array}$ \\
\hline Pregunta 4 & $\begin{array}{l}\text { ¿Cuándo se debe realizar team building en } \\
\text { una organización? }\end{array}$ \\
\hline Apuntes & $\begin{array}{l}\text { Cuando se busca construir equipos sólidos y } \\
\text { mejorar la comunicación y confianza entre } \\
\text { los equipos de trabajo. }\end{array}$ \\
\hline Pregunta 5 & $\begin{array}{l}\text { ¿Cuáles son los beneficios del coaching } \\
\text { ejecutivo en una organización? }\end{array}$ \\
\hline Apuntes & $\begin{array}{l}\text { Si resaltamos los beneficios tenemos } \\
\text { numerosos pero entre ellos puedo resaltar } \\
\text { primero fomenta la motivación en el } \\
\text { persona, refuerza el auto estima de los } \\
\text { colaboradores, mejora las relaciones entre el } \\
\text { directivo y jefaturas, facilita la motivación y } \\
\text { el entusiasmo entre los colaboradores y algo } \\
\text { importantísimo es que desarrolla el potencial } \\
\text { de la gente en el trabajo. }\end{array}$ \\
\hline
\end{tabular}




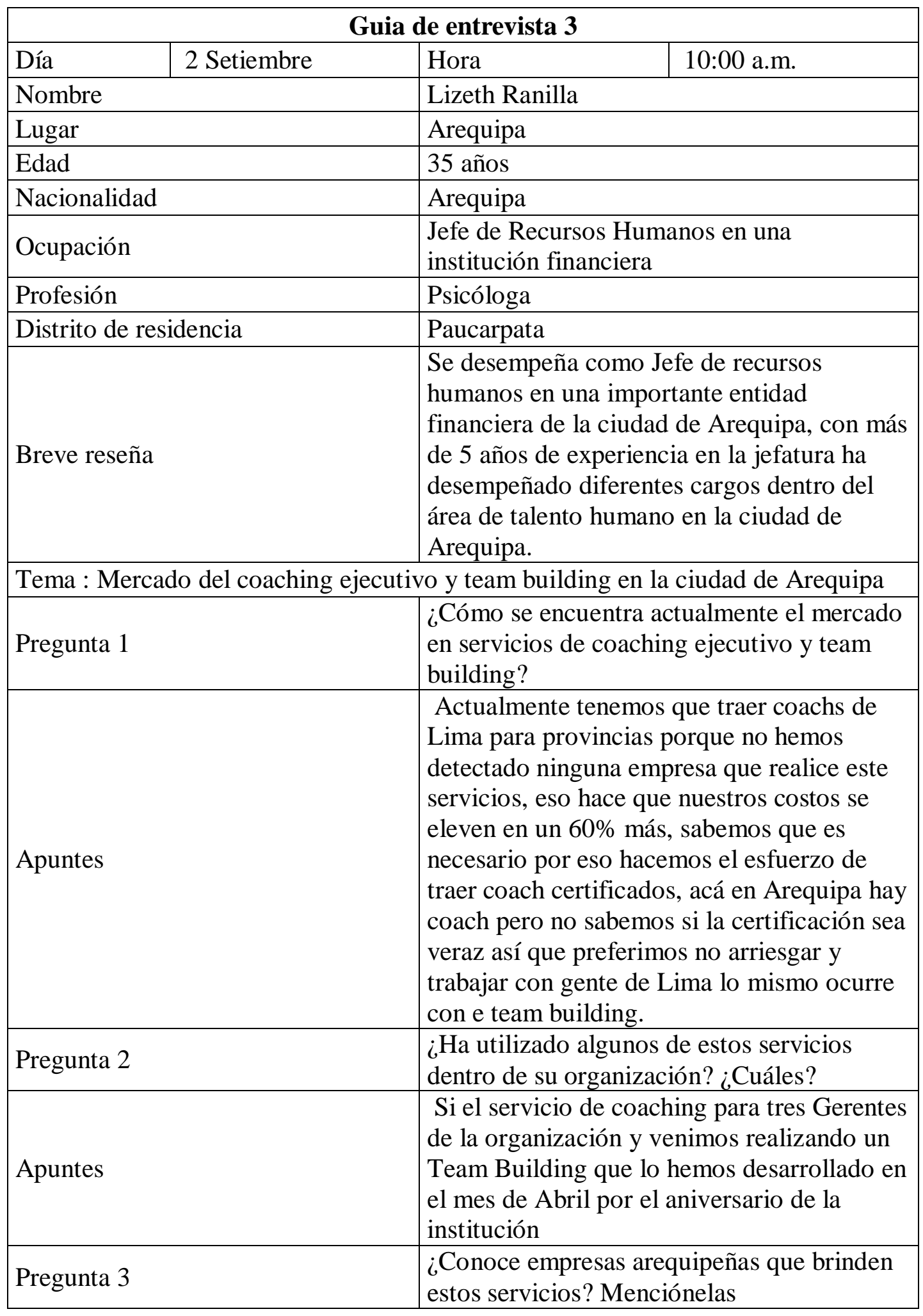




\begin{tabular}{|l|l|}
\cline { 2 - 3 } Apuntes & $\begin{array}{l}\text { Si una que se llama T-Impulsa pero esta } \\
\text { empresa no hace el servicio de Team } \\
\text { Building solo de coaching y si mas no } \\
\text { recuerdo solo hacen certificaciones de } \\
\text { coaching no brindan el servicio en sí. }\end{array}$ \\
\hline Pregunta 4 & $\begin{array}{l}\text { ¿Cada cuánto tiempo realiza usted este tipo } \\
\text { de actividades? }\end{array}$ \\
\hline Apuntes & $\begin{array}{l}\text { Ahora lo estamos haciendo 2 veces al año y } \\
\text { coaching cuando directorio lo solicite o la } \\
\text { gerencia }\end{array}$ \\
\hline Pregunta 5 & $\begin{array}{l}\text { ¿Puede mencionar un presupuesto } \\
\text { aproximado que se utiliza en este tipo de } \\
\text { actividades? }\end{array}$ \\
\hline Apuntes & $\begin{array}{l}\text { Para coaching estamos hablando de unos } \\
\text { S/4500 aproximado y para Team building } \\
\text { unos S/5000 soles también aproximado no } \\
\text { hay una partida definida para este tipo de } \\
\text { actividades, porque tú sabes que hoy en día } \\
\text { recién está tomando importancia, pero para } \\
\text { el próximo año estamos proponiendo en el } \\
\text { Plan de Talento Humano que se aumente la } \\
\text { partida para este tipo de actividades que son } \\
\text { muy importantes. }\end{array}$ \\
\hline
\end{tabular}




\begin{tabular}{|c|c|c|c|}
\hline \multicolumn{4}{|c|}{ Guía de entrevista 4} \\
\hline Día & 11 de Setiembre & Hora & 13:30 p.m. \\
\hline \multicolumn{2}{|l|}{ Nombre } & \multicolumn{2}{|c|}{ Carolina Pezo Cano } \\
\hline \multicolumn{2}{|l|}{ Lugar } & \multicolumn{2}{|c|}{ Arequipa } \\
\hline \multicolumn{2}{|l|}{ Edad } & \multicolumn{2}{|c|}{33 años } \\
\hline \multicolumn{2}{|l|}{ Nacionalidad } & \multicolumn{2}{|c|}{ Peruana } \\
\hline \multicolumn{2}{|l|}{ Ocupación } & \multicolumn{2}{|c|}{ Jefe de Recursos Humanos } \\
\hline \multicolumn{2}{|c|}{ Profesión } & \multicolumn{2}{|c|}{ Ingeniero Industrial } \\
\hline \multicolumn{2}{|c|}{ Distrito de residencia } & \multicolumn{2}{|c|}{ Yanahuara } \\
\hline \multicolumn{2}{|l|}{ Breve reseña } & \multicolumn{2}{|c|}{$\begin{array}{l}\text { Se desempeña como Jefe de Recursos de } \\
\text { Humanos de una empresa familiar de la } \\
\text { ciudad de Arequipa, que maneja } 25 \\
\text { colaboradores, cuenta con más de } 4 \text { años de } \\
\text { experiencia trabajando en áreas de Recursos } \\
\text { Humanos y bienestar social. }\end{array}$} \\
\hline \multicolumn{4}{|c|}{$\begin{array}{l}\text { Tema : la función del coaching y team building en el desempeño de los } \\
\text { colaboradores en las organizaciones }\end{array}$} \\
\hline \multicolumn{2}{|l|}{ Pregunta 1} & \multicolumn{2}{|c|}{$\begin{array}{l}\text { ¿Cuál es la función que cumple el coaching } \\
\text { ejecutivo y team building en las } \\
\text { organizaciones? }\end{array}$} \\
\hline \multicolumn{2}{|l|}{ Apuntes } & \multicolumn{2}{|c|}{$\begin{array}{l}\text { Pienso que el coaching es un arte de trabajar } \\
\text { con los demás para que obtengan resultados } \\
\text { fuera de lo común y mejoren su } \\
\text { desempeño. El coaching es un } \\
\text { "acompañamiento" para lograr resultados } \\
\text { específicos. } \\
\text { El Team building es como construir equipos } \\
\text { para que obtengan alto rendimiento y } \\
\text { motivación. }\end{array}$} \\
\hline \multicolumn{2}{|l|}{ Pregunta 2} & \multicolumn{2}{|c|}{$\begin{array}{l}\text { ¿Por qué una empresa invierte en coaching } \\
\text { ejecutivo y team building? }\end{array}$} \\
\hline \multicolumn{2}{|l|}{ Apuntes } & \multicolumn{2}{|c|}{$\begin{array}{l}\text { Porque desean potenciar la motivación y } \\
\text { rendimiento de su personal. }\end{array}$} \\
\hline \multicolumn{2}{|l|}{ Pregunta 3} & \multicolumn{2}{|c|}{$\begin{array}{l}\text { ¿Cuándo se debe dar coaching en una } \\
\text { organización? }\end{array}$} \\
\hline \multicolumn{2}{|l|}{ Apuntes } & \multicolumn{2}{|c|}{$\begin{array}{l}\text { Pienso que se debe de utilizar esta } \\
\text { herramienta cuando se detecta una falta de } \\
\text { motivación y compromiso por parte de los } \\
\text { colaboradores de la organización. }\end{array}$} \\
\hline \multicolumn{2}{|l|}{ Pregunta 4} & \multicolumn{2}{|c|}{$\begin{array}{l}\text { ¿Cuándo se debe realizar team building en } \\
\text { una organización? }\end{array}$} \\
\hline \multicolumn{2}{|l|}{ Apuntes } & \multicolumn{2}{|c|}{$\begin{array}{l}\text { Cuando se desea construir equipos y mejorar } \\
\text { el sistema dentro del equipo de trabajo. }\end{array}$} \\
\hline \multicolumn{2}{|l|}{ Pregunta 5} & \multicolumn{2}{|c|}{ ¿Cuáles son los beneficios del coaching } \\
\hline
\end{tabular}


ejecutivo en una organización?

Mejora el rendimiento de los colaboradores,

Apuntes

la motivación y el rendimiento en áreas

específicas. 
Anexo 04. Entrevista al Gerente general de la Cámara de Comercio de Arequipa

\begin{tabular}{|l|l|l|}
\hline \multicolumn{3}{|c|}{ Guía de entrevista } \\
\hline Día & 20/01/2018 & Hora \\
\hline Nombre & Cesar Lutgens Zereceda \\
\hline Lugar & Cámara de Comercio de Arequipa \\
\hline Edad & 59 años \\
\hline Nacionalidad & Peruana \\
\hline Ocupación & Gerente \\
\hline Profesión & Administrador de empresas \\
\hline Distrito de residencia & Arequipa \\
\hline Breve reseña & $\begin{array}{l}\text { Se desempeña como gerente en la cámara de } \\
\text { comercio de Arequipa, se desempeño como } \\
\text { presidente ejecutivo del instituto peruano de } \\
\text { Alpaca y Camélidos de Arequipa, es director } \\
\text { de FARBA S.A. en Arequipa. }\end{array}$ \\
\hline Tema : Perfil de las empresas registradas en la Cámara de Comercio de Arequipa \\
\hline Pregunta 1 & $\begin{array}{l}\text { iQué hace la cámara de comercio de } \\
\text { Arequipa? }\end{array}$ \\
\hline Apuntes & $\begin{array}{l}\text { Una cámara de comercio es una } \\
\text { organización formada por empresarios o } \\
\text { dueños de pequeñas, medianas y grandes } \\
\text { empresas cuyo objetivo es elevar la } \\
\text { productividad de los empleados y la } \\
\text { competitividad de sus negocios }\end{array}$ \\
\hline Pregunta 3 & $\begin{array}{l}\text { ¿Cómo funciona la cámara de comercio y } \\
\text { que funciones cumple? }\end{array}$ \\
\hline Pregunta 2 & $\begin{array}{l}\text { Nosotros llevamos un registro detallado de } \\
\text { todas las entidades inscritas, llevamos } \\
\text { también un deposito de los estados } \\
\text { financieros de las empresas asociadas, } \\
\text { nuestra función principal es fomentar el } \\
\text { interés de las posibilidades de los negocios } \\
\text { locales. }\end{array}$ \\
\hline Apuntes & $\begin{array}{l}\text { ¿Quisiéramos saber cuántas empresas } \\
\text { registradas tienen que cumplan más de tres } \\
\text { años de funcionamiento en la ciudad de } \\
\text { Arequipa? }\end{array}$ \\
\hline $\begin{array}{l}\text { Ahora no podría darte un dato exacto pero } \\
\text { es entre 720 a 750 empresas con las que } \\
\text { aproximadamente contamos. }\end{array}$ \\
\hline $\begin{array}{l}\text { ¿Dentro de estas 750 empresas que usted nos } \\
\text { indica se encuentras clasificadas por tamaño } \\
\text { ? }\end{array}$ \\
\hline Pregunta 4
\end{tabular}


Apuntes

$\mathrm{Si}$, pero no tengo los porcentajes a la mano, pero lo comprenden las pequeñas, medianas

y grandes empresas de la ciudad de Arequipa 


\section{Anexo 05. Ficha técnica de la investigación cuantitativa}

\begin{tabular}{|l|l|}
\hline Ámbito geográfico & Arequipa \\
\hline Universo & 720 empresas con 3 años de funcionamiento y \\
& 20 colaboradores a más. \\
\hline Unidad muestral & Pequeñas , medianas y grandes empresas \\
\hline Técnica & Encuestas personales \\
\hline Procedimiento de muestreo & Muestra finita \\
\hline Tipo de muestreo & Muestreo aleatorio simple por cuotas \\
\hline Tamaño muestral & 251 \\
\hline Error muestral & $\pm 5 \%$ \\
\hline Nivel de confianza & $95 \%$ pq=0.5 \\
\hline & \\
\hline
\end{tabular}

Nota. Elaboración propia. Ficha técnica del muestreo. Tomado de Investigación de Mercado para pequeñas y medianas empresas. C. Diaz \& J. Cavazos, 2015, Guadalajara, México : Editorial Universitaria 


\section{Anexo 06. Cuestionario de preguntas}

\section{CUESTIONARIO}

\section{Datos Generales de la empresa}

1.1. Marque Ud. El tipo de empresa en la que trabaja teniendo en cuenta lo siguiente:

1. Pequeña empresa: De 20 a 50 colaboradores

2. Mediana empresa: De 51 a 250 colaboradores

3. Gran empresa : De 251 a más colaboradores

1.2. Marque cuál es la antigüedad de la empresa (Si marca la opción 1 fin de la encuesta

1. De 1-2 años $\square$ Fin de la encuesta

2. De 3 años

1.3. Indique usted al sector que pertenece su organización.

1. Agropecuario

- Ganadero - Pesquero

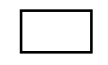

- Forestal

2. Industrial

- Energético

$\square$

- Minero

- Construcción

3. Servicios - comercial

- Transporte

- Comunicaciones $\square$ - Educación

- Finanzas

4.- Otros Especificar: 


\section{Acerca de la empresa}

2.1. ¿Es usted quien toma las decisiones correspondientes a la gestión de recursos humanos en la empresa donde labora? Marque con una X, si elige la opción 1 indique el puesto que ocupa actualmente en la organización

1. SI $\square$ Indique su cargo:

2. NO $\square$ Fin de la encuesta

2.2. Marque con una $\mathrm{X}$ el o los aspectos que usted considera importantes en su organización con respecto a su talento humano.

\begin{tabular}{|c|l|l|}
\hline 1.- & Motivación & \\
\hline 2.- & Capacitación & \\
\hline 3.- & Comunicación & \\
\hline 4.- & Trabajo en equipo & \\
\hline 5.- & Relación con jefaturas superiores & \\
\hline
\end{tabular}

2.3. ¿Podría decirme en cuál de estos rangos se sitúa su partida presupuestal anual para el área de recursos humanos, sin incluir planillas?

1. Menos de 10,000 soles $\square$

2. De 10,001 a 20,000 soles

3. De 20,001 a 30,000 soles

4. De 30,001 a 40,000 soles

5. De 40,001 a más soles 
2.4. Del presupuesto indicado, marque en qué tipo de actividades se destina dicho monto, coloque el porcentaje aproximado que invierte en esta actividad. hablando del año 2017 ?

\begin{tabular}{|c|l|c|}
\hline OPCION & \multicolumn{1}{|c|}{ ACTIVIDAD } & PORCENTAJE \\
\hline $1 .-$ & Capacitación en habilidades blandas & \\
\hline 2.- & Eventos de integración para el personal & \\
\hline 3.- & Consultorías para el área & \\
\hline 4.- & Inversión en línea de carrera de los colaboradores & \\
\hline
\end{tabular}

\section{Acerca del Coaching y Team building}

3.1. En los últimos dos años ¿Ha hecho usted uso de las herramientas del Coaching ejecutivo? (Si la respuesta es SI pasar a la siguiente pregunta, si la respuesta es NO fin de la encuesta)

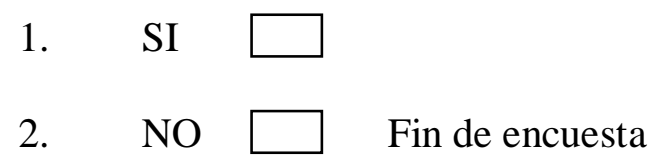

3.2. En los últimos dos años ¿Ha hecho usted uso de las herramientas del Team building?

(Si la respuesta es SI pasar a la siguiente pregunta, si la respuesta es NO fin de la encuesta )
1. SI
2. NO
Fin de encuesta

3.3. ¿Con qué periodicidad utilizan estas herramientas hablando del periodo 2017 ? 


\begin{tabular}{|l|l|}
\hline \multicolumn{2}{|c|}{ COACHING EJECUTIVO } \\
\hline 1 vez al año & \\
\hline 2 veces al año & \\
\hline 3 veces al año & \\
\hline Más de 3 veces al año & \\
\hline
\end{tabular}

\begin{tabular}{|l|l|}
\hline \multicolumn{2}{|c|}{ TEAM BUILDING } \\
\hline 1 vez al año & \\
\hline 2 veces al año & \\
\hline 3 veces al año & \\
\hline Más de 3 veces al año & \\
\hline
\end{tabular}

3.4. ¿Cuenta la empresa con un área responsable en Coaching interno? Si la respuesta es no pasar a la siguiente

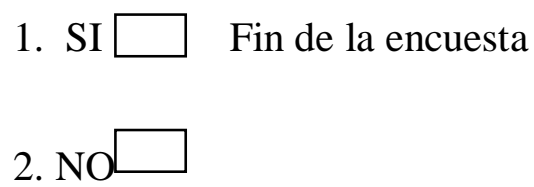

3.5. En la siguiente Tabla indique con qué empresa trabajaron el servicio de coaching ejecutivo? Marque los temas que trataron.

\begin{tabular}{|c|c|c|c|c|c|}
\hline \multirow[b]{2}{*}{ Nombre de la empresa } & \multicolumn{5}{|c|}{ SERVICIOS } \\
\hline & 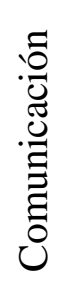 & 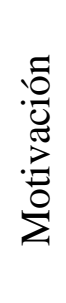 & 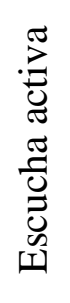 & 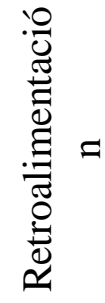 & 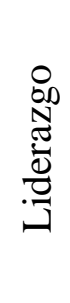 \\
\hline & & & & & \\
\hline & & & & & \\
\hline & & & & & \\
\hline & & & & & \\
\hline & & & & & \\
\hline
\end{tabular}


3.6. En la siguiente Tabla indique con qué empresa trabajaron el servicio de Team building? Marque los temas que trataron.

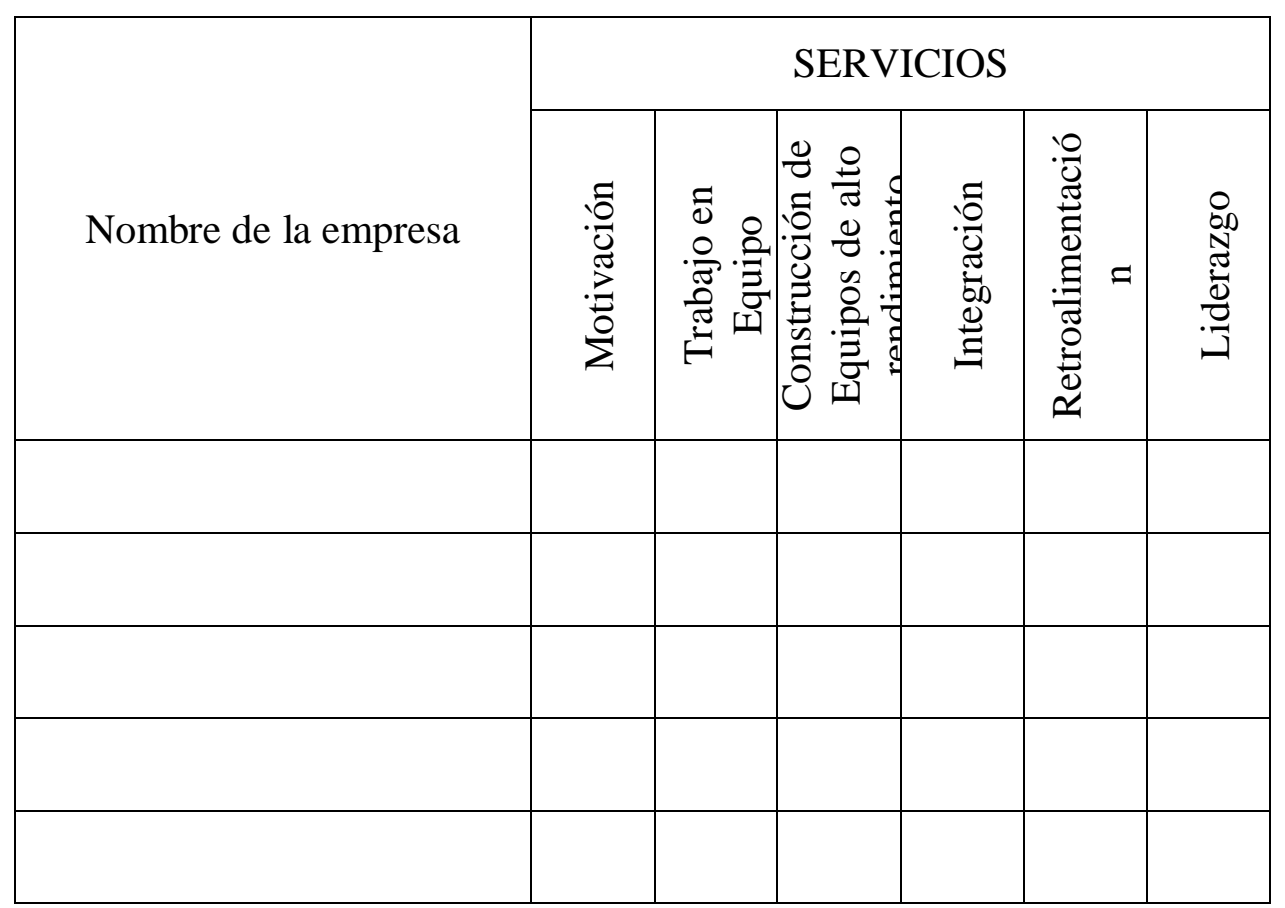

3.7. Marque con una $\mathrm{X}$ el o los medios de comunicación por el cual se enteró Ud. de la/las empresas con las que trabajó 


\begin{tabular}{|l|l|}
\hline Medios Multimedia & \\
\hline Internet & \multicolumn{2}{l|}{} \\
\hline Medios audiovisuales & \\
\hline Televisión & \\
\hline Radio & \\
\hline Videos & \\
\hline Medios Impresos & \\
\hline Prensa escrita & \\
\hline Folleteria & \\
\hline Medios Directos & \\
\hline Recomendación (boca-oreja) & \\
\hline
\end{tabular}

3.8. Aproximadamente ¿Cuánto invirtió en los medios mencionados en la pregunta anterior por cada vez que contrato estos servicios?

\begin{tabular}{|l|l|}
\hline \multicolumn{2}{|c|}{ COACHING EJECUTIVO } \\
\hline S/.1000-S/.1500 soles & \\
\hline S/.1501-S/.3000 soles & \\
\hline S/.3001-S/4500 soles & \\
\hline Más de S/4500 soles & \\
\hline
\end{tabular}

\begin{tabular}{|l|l|}
\hline \multicolumn{2}{|c|}{ TEAM BUILDING } \\
\hline S/.2000-S/.3000 soles & \\
\hline S/.3001-S/.4000 soles & \\
\hline S/.4001-S/5000 soles & \\
\hline Más de S/5000 soles & \\
\hline
\end{tabular}

3.9. Indicar por orden de importancia donde 1 es muy importante y 5 nada importante los motivos porque el que Ud. contrato la empresa consultora mencionadas en la preguntas 3.5 y 3.6 


\begin{tabular}{|l|l|l|}
\hline 1. & Es una empresa reconocida & \\
\hline 2. & $\begin{array}{l}\text { Por decisión de la sede central } \\
\text { de la organización }\end{array}$ & \\
\hline 3. & Profesionales certificados & \\
\hline 4. & Por el precio & \\
\hline 5. & Por la antigüedad de la empresa & \\
\hline 6. & Por los programas presentados & \\
\hline 7. & Por las herramientas usadas & \\
\hline 8. & La experiencia de la empresa & \\
\hline
\end{tabular}

\begin{tabular}{|c|l|l|}
\hline 1. & Es una empresa reconocida & \\
\hline 2. & $\begin{array}{l}\text { Por decisión de la sede central } \\
\text { de la organización }\end{array}$ & \\
\hline 3. & Profesionales certificados & \\
\hline 4. & Por el precio & \\
\hline 5.- & Por la antigüedad de la empresa & \\
\hline $6 .-$ & Por los programas presentados & \\
\hline 7.- & Por las herramientas usadas & \\
\hline 8.- & La experiencia de la empresa & \\
\hline
\end{tabular}

3.10.- Del 1 al 10 donde 1 es muy importante y 10 nada importante ¿Qué aspectos considera Ud. como determinantes para la contratación de una empresa externa que brinde servicios de coaching y team building?

\begin{tabular}{|c|l|l|}
\hline 1.- & Contar con certificaciones confiables & \\
\hline 2.- & Contar con asesores profesionales & \\
\hline 3.- & Atención personalizada & \\
\hline $4 .-$ & Moderna e innovadora & \\
\hline $5 .-$ & Productos adaptados a las necesidades de la organización & \\
\hline 6.- & Contar con precios accesibles acordes al mercado & \\
\hline 7.- & Antigüedad de la empresa & \\
\hline 8.- & Paquetes de servicios & \\
\hline $9 .-$ & Herramientas usadas por la empresa & \\
\hline
\end{tabular}


3.11. Existe la intención de una empresa Arequipeña de brindar los servicios de coaching ejecutivo y team building, con los paquetes de servicios que se presentan a continuación ¿Estaría usted interesado en adquirir los servicios de dicha empresa? (Marque con una X)

\section{PAQUETES COACHING}

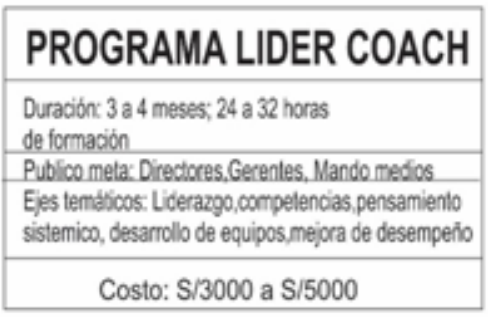

PAQUETES TEAM BUILDING

\begin{tabular}{|c|}
\hline DESARROULO DE HABIUDADES DE UDERAZGO \\
\hline $\begin{array}{l}\text { Duracion: } 3 \text { a } 4 \text { meses, } 24 \text { a } 32 \text { horas } \\
\text { de formacion }\end{array}$ \\
\hline Pibion meta: Directores, Gerentes, Nando medios \\
\hline $\begin{array}{l}\text { Ejes temáficos: Lideraago,competencias pensamiento } \\
\text { sistemico, desamolo de equipos,mejora de desempeto }\end{array}$ \\
\hline Costo: $\mathrm{S} / 3000$ a S/5000 \\
\hline
\end{tabular}

Desarrollo de Competencias conversacionales

Duración: 2 a 3 meses: 16 a 24 horas de formacion

Pibico meta: Todo nivel

Eies temáficos: Tipologia de conversaciones, ka escucha, el habla, el ate de indagar, re cuadrar e interpretrs: percepoion y escusha.

Costo: S/2500 a S/4000

\begin{tabular}{|l|}
\hline Desarrollo de equipos directores de alto desempeño \\
\hline Duracion: 4 a 8 meses \\
\hline $\begin{array}{l}\text { Público meta: Equipos directores, equipos } \\
\text { gerenciales y equipos funcionales }\end{array}$ \\
\hline $\begin{array}{l}\text { Ejes temáticos: Equipos de directores, equipos } \\
\text { gerenciales y equipos funcionales. }\end{array}$ \\
\hline Costo: $S / 3500$ a S/6500 \\
\hline
\end{tabular}

\begin{tabular}{|l|}
\hline \multicolumn{1}{|c|}{ Team Building organizacional } \\
\hline Duracion: 2 a 4 meses \\
\hline $\begin{array}{l}\text { Público meta: Equipos directores, equipos } \\
\text { gerenciales y equipos funcicnales }\end{array}$ \\
\hline $\begin{array}{l}\text { Ejes temáticos: Equipos de directores, equipos } \\
\text { gerenciales, equipos funcionales,equipos de ventas }\end{array}$ \\
\hline Costo: $S / 3500$ a S/6500 \\
\hline
\end{tabular}

\section{Coaching de equipos comercial}

Duracion: 4 meses. 40 horas de formacion y acompantamiento

Publico meta: Lideres, gerentes, directores de vertas y respectivos equipos

Ejes tematicos: Equipos comerciales, equipcs gerenciales, equipos funcionales, equipos de ventas

Costo: $\mathrm{S} / 3500$ a S/6500

1.- Definitivamente si

2.-Posiblemente si

3.-Me seria indiferente

4.-Posiblemente no

5.-Definitivamente no

¡Muchas gracias por su tiempo! 


\section{Anexo 07: Resultados de la encuesta}

\section{CUESTIONARIO}

\section{Datos Generales de la empresa}

1.1. Marque Ud. El tipo de empresa en la que trabaja teniendo en cuenta lo siguiente:

\begin{tabular}{|c|c|c|}
\hline Tipo de Empresa & Cantidad & $\%$ \\
\hline Pequeña Empresa & 63 & $25 \%$ \\
\hline Mediana Empresa & 119 & $47 \%$ \\
\hline Gran Empresa & 69 & $27 \%$ \\
\hline
\end{tabular}

1.2. Marque cuál es la antigüedad de la empresa (Si marca la opción 1 fin de la encuesta9

\begin{tabular}{lccc}
\hline & Antigüedad & Cantidad & \% \\
\hline De 3 años a más & 226 & $90 \%$ \\
De 1 a 2 años & 25 & $10 \%$ \\
\hline
\end{tabular}

1.3. Indique usted al sector que pertenece su organización.

\begin{tabular}{lccc}
\hline & Sector & Cantidad & \% \\
\hline Agroindustria & 8 & $4 \%$ \\
Aseguradoras & 7 & $3 \%$ \\
Automotriz & 11 & $5 \%$ \\
Comunicaciones & 6 & $3 \%$ \\
Construcción & 5 & $2 \%$ \\
Consumo & 14 & $6 \%$ \\
Educación & 6 & $3 \%$ \\
Energético & 18 & $8 \%$ \\
Farmaceutica & 1 & $0 \%$ \\
Finanzas & 27 & $12 \%$ \\
Industrial & 22 & $10 \%$ \\
Minero & 27 & $12 \%$ \\
Servicio & 59 & $26 \%$ \\
Transporte & 15 & $7 \%$ \\
\hline
\end{tabular}




\section{Acerca de la empresa}

2.1. ¿Es usted quien toma las decisiones correspondientes a la gestión de recursos humanos en la empresa donde labora? Marque con una X, si elige la opción 1 indique el puesto que ocupa actualmente en la organización

\begin{tabular}{lcc}
\hline Ud. Toma las decisiones de RRHH & Cantidad & $\mathbf{\%}$ \\
\hline $\mathrm{Si}$ & 207 & $92 \%$ \\
$\mathrm{No}$ & 19 & $8 \%$ \\
\hline Total general & $\mathbf{2 2 6}$ & $\mathbf{1 0 0 \%}$ \\
\hline
\end{tabular}

2.2. Marque con una $\mathrm{X}$ el o los aspectos que usted considera importantes en su organización con respecto a su talento humano.

\begin{tabular}{|c|c|}
\hline Aspectos importantes respecto a TH & Cantidad \\
\hline Motivación & 97 \\
\hline Capacitación & 127 \\
\hline Comunicación & 68 \\
\hline Trabajo en Equipo & 30 \\
\hline Relación con Jefaturas Superiores & 1 \\
\hline
\end{tabular}

2.3. ¿Podría decirme en cuál de estos rangos se sitúa su partida presupuestal anual para el área de recursos humanos, sin incluir planillas?

\begin{tabular}{lcc}
\hline Rango de la Partida Presupuestal anual para RRHH & Cantidad & \% \\
\hline Menos de 10,000 soles & 44 & $21 \%$ \\
De 20,001 a 30,000 soles & 59 & $29 \%$ \\
De 30,001 a 40,000 soles & 35 & $17 \%$ \\
De 40,001 a más soles & 69 & $33 \%$ \\
\hline Total general & $\mathbf{2 0 7}$ & $\mathbf{1 0 0 \%}$ \\
\hline
\end{tabular}

2.4. Del presupuesto indicado, marque en qué tipo de actividades se destina dicho monto, coloque el porcentaje aproximado que invierte en esta actividad hablando del año 2017 ? 


\begin{tabular}{lc}
\hline \multicolumn{1}{c}{ Tipo de Empresa } & $\%$ \\
\hline 2.4.1 Capacitación en Habilidades Blandas & $19 \%$ \\
2.4.2 Eventos de integración para el personal & $57 \%$ \\
2.4.3 Consultorías para el área & $17 \%$ \\
2.4.4 Inversión en línea de carrera de los colaboradores & $7 \%$ \\
\hline
\end{tabular}

\section{Acerca del Coaching y Team building}

3.1. En los últimos dos años ¿Ha hecho usted uso de las herramientas del Coaching ejecutivo? (Si la respuesta es SI pasar a la siguiente pregunta, si la respuesta es NO fin de la encuesta)

\begin{tabular}{lcc}
\hline ¿Ha hecho uso de las herramientas de Coaching Ejecutivo? & Cantidad & $\boldsymbol{\%}$ \\
\hline No & 111 & $54 \%$ \\
Si & 96 & $46 \%$ \\
\hline Total general & $\mathbf{2 0 7}$ & $\mathbf{1 0 0 \%}$ \\
\hline
\end{tabular}

3.2. En los últimos dos años ¿Ha hecho usted uso de las herramientas del Team building?

(Si la respuesta es SI pasar a la siguiente pregunta, si la respuesta es NO fin de la encuesta )

\begin{tabular}{lcc}
\hline ¿Ha hecho uso de las herramientas de Team Building? & Cantidad & \% \\
\hline No & 26 & $27 \%$ \\
$\mathrm{Si}$ & 70 & $73 \%$ \\
\hline Total general & $\mathbf{9 6}$ & $\mathbf{1 0 0 \%}$ \\
\hline
\end{tabular}

3.3. ¿Con qué periodicidad utilizan estas herramientas hablando del periodo 2017 ?

\begin{tabular}{lrr}
\hline Periodicidad de uso de herramientas de Coaching Ejecutivo & Cantidad & \% \\
\hline Una vez al año & 58 & $83 \%$ \\
Dos veces al año & 12 & $17 \%$ \\
\hline Total general & $\mathbf{7 0}$ & $\mathbf{1 0 0 \%}$ \\
\hline
\end{tabular}




\begin{tabular}{lrr}
\hline Periodicidad de uso de herramientas de Team Building & Cantidad & \% \\
\hline Tres veces al año & 8 & $11 \%$ \\
Más de tres veces al año & 37 & $53 \%$ \\
Una vez al año & 10 & $14 \%$ \\
Dos veces al año & 15 & $21 \%$ \\
\hline Total general & $\mathbf{7 0}$ & $\mathbf{1 0 0 \%}$ \\
\hline
\end{tabular}

3.4. ¿Cuenta la empresa con un área responsable en Coaching interno? Si la respuesta es no pasar a la siguiente

\begin{tabular}{lrr}
\hline ¿Tiene área de Coaching Ejecutivo? & Cantidad & $\%$ \\
\hline $\mathrm{No}$ & 65 & $93 \%$ \\
$\mathrm{Si}$ & 5 & $7 \%$ \\
\hline Total general & $\mathbf{7 0}$ & $\mathbf{1 0 0 \%}$ \\
\hline
\end{tabular}

3.5. En la siguiente Tabla indique con qué empresa trabajaron el servicio de coaching ejecutivo? Marque los temas que trataron.

\begin{tabular}{lccccc}
\hline & Comunicación & Motivación & Escucha Activa & Retroalimentación & Liderazgo \\
\hline T-Impulsa & & 6 & & & 5 \\
Proludica & 12 & & 17 & 20 \\
Jaming & & 13 & & 4 \\
T-Motiva & 5 & & 12 & \\
\hline
\end{tabular}

3.6. En la siguiente Tabla indique con qué empresa trabajaron el servicio de Team building? Marque los temas que trataron.

\begin{tabular}{|c|c|c|c|c|c|}
\hline & $\begin{array}{c}\text { Motivaci } \\
\text { ón }\end{array}$ & $\begin{array}{c}\text { Trabajo en } \\
\text { Equipo }\end{array}$ & $\begin{array}{c}\text { Construcción de Equipos de alto } \\
\text { rendimiento }\end{array}$ & $\begin{array}{c}\text { Integraci } \\
\text { ón }\end{array}$ & $\begin{array}{c}\text { Lideraz } \\
\text { go }\end{array}$ \\
\hline T-Impulsa & 2 & 5 & & & 5 \\
\hline $\begin{array}{l}\text { Proludica } \\
\text { Centro Empresarial }\end{array}$ & 12 & 11 & 17 & & \\
\hline UCSP & 1 & 11 & & & 11 \\
\hline Libérate & 4 & 2 & & 6 & \\
\hline
\end{tabular}


3.7. Marque con una X el o los medios de comunicación por el cual se enteró Ud. de la/las empresas con las que trabajó

\begin{tabular}{lrr}
\hline Medios de Comunicación por el cuál se enteró de empresas de CE y TB & Cantidad & \% \\
\hline Internet & 33 & $51 \%$ \\
Recomendación & 32 & $49 \%$ \\
\hline Total general & $\mathbf{6 5}$ & $\mathbf{1 0 0 \%}$ \\
\hline
\end{tabular}

3.8. Aproximadamente ¿Cuánto invirtió en los medios mencionados en la pregunta anterior por cada vez que contrato estos servicios?

\begin{tabular}{lrr}
\hline Monto invertido en Coaching Ejecutivo & Cantidad & \% \\
\hline Más de S/4,500 soles & 42 & $65 \%$ \\
S/3,001 a S/4,500 soles & 10 & $15 \%$ \\
S/1,501 a S/3,000 soles & 13 & $20 \%$ \\
\hline Total general & $\mathbf{6 5}$ & $\mathbf{1 0 0 \%}$ \\
\hline
\end{tabular}

\begin{tabular}{lcc}
\hline Monto invertido en Team Building & Cantidad & $\mathbf{\%}$ \\
\hline Más de S/5,000 soles & 3 & $5 \%$ \\
S/4,001 a S/5,000 soles & 41 & $63 \%$ \\
S/3,001 a S/4,000 soles & 21 & $32 \%$ \\
\hline Total general & $\mathbf{6 5}$ & $\mathbf{1 0 0 \%}$ \\
\hline
\end{tabular}

3.9. Indicar por orden de importancia donde 1 es muy importante y 5 nada importante los motivos porque el que Ud. contrato la empresa consultora mencionadas en la preguntas 3.5 y 3.6

\begin{tabular}{lccccc}
\hline \multicolumn{1}{c}{ COACHING EJECUTIVO } & $\mathbf{1}$ & $\mathbf{2}$ & $\mathbf{3}$ & $\mathbf{4}$ & $\mathbf{5}$ \\
\hline Empresa reconocida & 15 & 11 & 23 & & \\
Decisión de Sede Central & 31 & 4 & & 8 & \\
Profesionales certificados & 3 & 24 & 14 & & \\
Precio & & 5 & 9 & 30 & 11 \\
Antigüedad de la empresa & & 5 & 3 &
\end{tabular}


Herramientas usadas

3

11

Experiencia de la empresa

8

\begin{tabular}{lccccc}
\hline \multicolumn{1}{c}{ TEAM BUILDING } & $\mathbf{1}$ & $\mathbf{2}$ & $\mathbf{3}$ & $\mathbf{4}$ & $\mathbf{5}$ \\
\hline Empresa reconocida & 12 & 2 & 7 & 24 & 4 \\
Decisión de Sede Central & 22 & 13 & & & \\
Profesionales certificados & 13 & 14 & 8 & & \\
Precio & 2 & 9 & 3 & & 32 \\
Antigüedad de la empresa & & & & & 3 \\
Programas presentados & & 11 & 31 & 4 & 10 \\
Herramientas usadas & & & & 4 & \\
Experiencia de la empresa & & & & & \\
\hline
\end{tabular}

3.10.- Del 1 al 10 donde 1 es muy importante y 10 nada importante ¿Qué aspectos considera Ud. como determinantes para la contratación de una empresa externa que brinde servicios de coaching y team building?

\begin{tabular}{|c|c|c|c|c|c|c|c|c|c|}
\hline & 1 & 2 & 3 & 4 & 5 & 6 & 7 & 8 & 9 \\
\hline Certificaciones confiables & 23 & 12 & & & & 2 & 9 & 3 & \\
\hline Asesores profesionales & 5 & 9 & & & & & 28 & 7 & \\
\hline Atención personalizada & & 5 & 9 & 10 & 18 & 7 & & & \\
\hline Moderna e innovadora & 12 & 12 & 16 & 9 & & & & & \\
\hline Productos adaptados & & & & 12 & 15 & 22 & & & \\
\hline Precios accesibles & 9 & & 2 & 3 & & & & 13 & 22 \\
\hline Antigüedad de empresa & & & & & & & 7 & 17 & 25 \\
\hline Paquetes de servicios & & 13 & 22 & 2 & 9 & 3 & & & \\
\hline Herramientas usadas & & & & & 20 & 15 & 3 & 9 & 2 \\
\hline
\end{tabular}

3.11. Existe la intención de una empresa Arequipeña de brindar los servicios de coaching ejecutivo y team building, con los paquetes de servicios que se presentan a continuación ¿Estaría usted interesado en adquirir los servicios de dicha empresa? (Marque con una X) 


\begin{tabular}{lcc}
\hline Interés en adquirir los servicios de una nueva empresa arequipeña & Cantidad & \% \\
\hline Definitivamente si & 16 & $25 \%$ \\
Me sería indiferente & 7 & $11 \%$ \\
Posiblemente si & 42 & $65 \%$ \\
\hline Total general & $\mathbf{6 5}$ & $\mathbf{1 0 0 \%}$ \\
\hline
\end{tabular}




\section{BIBLIOGRAFÍA}

1. Chiavenato.(2009). Gestión del Talento Humano. Elsevier Editora Ltda, México (pp.177).

2. Chiavenato.(2009). Gestión del Talento Humano. Elsevier Editora Ltda, México (pp.177).

3. Chiavenato.(2009). Gestión del Talento Humano. Elsevier Editora Ltda, México (pp.284).

4. Chiavenato.(2009). Gestión del Talento Humano. Elsevier Editora Ltda, México (pp.65).

5. Chiavenato.(2009). Gestión del Talento Humano. Elsevier Editora Ltda, México (pp.67).

6. Chiavenato.(2009). Gestión del Talento Humano. Elsevier Editora Ltda, México (pp.76).

7. Gitman \& Zutter (2012). Principios de Administración Financiera. Decimosegunda Edición. Pearson Educación, México (pp. 367).

8. Gitman \& Zutter (2012). Principios de Administración Financiera. Decimosegunda Edición. Pearson Educación, México (pp. 372).

9. Gitman \& Zutter (2012). Principios de Administración Financiera. Decimosegunda Edición. Pearson Educación, México (pp. 413-414).

10. Gitman \& Zutter (2012). Principios de Administración Financiera. Decimosegunda Edición. Pearson Educación, México (pp. 415).

11. Gitman \& Zutter (2012). Principios de Administración Financiera. Decimosegunda Edición. Pearson Educación, México (pp. 76). 
12. Gitman \& Zutter (2012). Principios de Administración Financiera. Decimosegunda Edición. Pearson Educación, México (pp. 77-81).

13. Guerrero, O.A. (2011). Coaching basado en administración de proyectos (Tesis de maestría). Universidad para la Cooperación Internacional, San José, Costa Rica.

14. Gutierrez, D. (2013). Coaching Deportivo (1ra ed.). Madrid, España: Editorial Cumio.

15. Hair, J.F, Bush,R.P \& Ortinau,David.J.(2008). Investigación de mercados en un ambiente de información digital. McGrawHill, México (pp. 467).

16. Hair, J.F, Bush, R.P \& Ortinau, David.J.(2008). Investigación de mercados en un ambiente de información digital. McGrawHill, México (pp.156).

17. Hair, J.F, Bush,R.P \& Ortinau, David.J.(2008). Investigación de mercados en un ambiente de información digital. McGrawHill, México (pp.311).

18. Hair, J.F, Bush,R.P \& Ortinau, David.J. (2008). Investigación de mercados en un ambiente de información digital. McGrawHill, México (pp.317).

19. Hall, Michael (2010). Metacoaching. Trillas, Estados Unidos. (pp.103)

20. Horngren, Datar \& Rajan, (2012). Contabilidad de costos decimocuarta edición. Pearson Educación, México (pp. 234).

21. Kotler \& Armstrong (2012). Principios de Marketing. Decimocuarta edición. Pearson Educación, México (pp. 53-58).

22. Kotler \& Keller (2009). Dirección de Marketing. Pearson Educación, México (pp. 128).

23. Kotler \& Keller (2009). Dirección de Marketing. Pearson Educación, México (pp. 129). 
24. Kotler \& Keller (2009). Dirección de Marketing. Pearson Educación, México (pp. 130).

25. Kotler,P. \& Armstrong,G. (2012).Marketing. Pearson Educación, México (pp. 38).

26. Kotler,P. \& Armstrong,G. (2012).Marketing. Pearson Educación, México (pp. 44).

27. Kotler,P. \& Armstrong,G. (2012).Marketing. Pearson Educación, México (pp. 543).

28. Kotler,P. \& Armstrong,G.(2012).Marketing. Pearson Educación, México (Apéndice $1)$.

29. Kotler,P. \& Armstrong,G. (2012).Marketing. Pearson Educación, México (pp.290).

30. Kotler,P. \& Armstrong,G. (2012).Marketing. Pearson Educación, México (pp.344).

31. Kotler,P. \& Armstrong,G. (2012).Marketing. Pearson Educación, México (pp.349).

32. Kotler,P. \& Armstrong,G. (2012).Marketing. Pearson Educación, México (pp.449).

33. Kotler,P. \& Armstrong,G. (2012).Marketing. Pearson Educación, México (pp.465).

34. Kotler,P. \& Armstrong,G. (2012).Marketing. Pearson Educación, México (pp.481).

35. Krajewski, Ritzman \& Malhotra (2013). Administración de Operaciones. Pearson Educación, México (pp. 464).

36. Krajewski, Ritzman \& Malhotra (2013). Administración de Operaciones. Pearson Educación, México (pp. 473).

37. Krajewski, Ritzman \& Malhotra (2013). Administración de Operaciones. Pearson Educación, México (pp. 92).

38. Krajewski, Ritzman \& Malhotra (2013). Administración de Operaciones. Pearson Educación, México (pp.234).

39. Krajewski, Ritzman \& Malhotra (2013). Administración de Operaciones. Pearson Educación, México (pp. 245). 
40. Martinez, D. \& Milla, A. (2012). Analisis del entorno. Diaz de Santos, España (pp. 212)

41. McGovern, J., Lindemann, M., Vergara, M., Murphy, S., Barker, L., Warrenfeltz, R. (2001). Maximizing the Impact of Executive Coaching. The Manchester Review, 49.

42. Muñoz-Najar, D., Pantigoso, P., Frias, I., Alcázar, J. (2016). Guía de Negocios e Inversión en el Perú.

43. O’connor. J. \& Lages, A. (2005). Coaching con PNL: Guia practica para obtener lo mejor de ti mismo y de los demás. Primera edición. Urano. España (pp. 109)

44. Porter, M. (2006). Estrategia Competitiva. Mexico DF, Mexico: Compañía Editorial Continental.

45. Sapag, (2011). Proyectos de inversión, formulación y evaluación 2da Edición. Pearson Educación, Chile (pp. 123-124).

46. Sapag, (2011). Proyectos de inversión, formulación y evaluación 2da Edición. Pearson Educación, Chile (pp. 134).

47. Sapag, (2011). Proyectos de inversión, formulación y evaluación 2da Edición. Pearson Educación, Chile (pp. 136).

48. Sapag, (2011). Proyectos de inversión, formulación y evaluación 2da Edición. Pearson Educación, Chile (pp. 200).

49. Sapag, (2011). Proyectos de inversión, formulación y evaluación 2da Edición. Pearson Educación, Chile (pp. 203).

50. Sapag, (2011). Proyectos de inversión, formulación y evaluación 2da Edición. Pearson Educación, Chile (pp. 210). 
51. Sapag, (2011). Proyectos de inversión, formulación y evaluación 2da Edición. Pearson Educación, Chile (pp. 220).

52. Sapag, (2011). Proyectos de inversión, formulación y evaluación 2da Edición. Pearson Educación, Chile (pp. 225).

53. Suñe, Gil \& Arcusa (2010). Manual práctico de diseño de sistemas productivos. Ediciones Diaz de Santos, Madrid, España (pp. 77).

54. Thompson, A. (2012). Administracion Estrategica, teoría y casos. Mexico DF, Mexico: McGraw-Hill Interamericana.

55. Torres (2014). Administración de Ventas. Grupo Editorial Patria, México (pp. 157).

56. Welsch, Hilton, Gordon \& Rivera, (2005). Presupuestos: Planificación y control. Sexta edición. Pearson Educación, México (pp. 105).

57. Welsch, Hilton, Gordon \& Rivera, (2005). Presupuestos: Planificación y control. Sexta edición. Pearson Educación, México (pp. 169).

58. Welsch, Hilton, Gordon \& Rivera, (2005). Presupuestos: Planificación y control. Sexta edición. Pearson Educación, México (pp. 177).

59. Welsch, Hilton, Gordon \& Rivera, (2005). Presupuestos: Planificación y control. Sexta edición. Pearson Educación, México (pp. 189).

60. Welsch, Hilton, Gordon \& Rivera, (2005). Presupuestos: Planificación y control. Sexta edición. Pearson Educación, México (pp. 347).

61. Welsch, Hilton, Gordon \& Rivera, (2005). Presupuestos: Planificación y control. Sexta edición. Pearson Educación, México (pp. 373).

62. Welsch, Hilton, Gordon \& Rivera, (2005). Presupuestos: Planificación y control. Sexta edición. Pearson Educación, México (pp. 68). 
63. Whitmore, J. (2009). Coaching for Performance (4ta ed.). Londres, Reino Unido : Nicholas Brealey Publishing. 


\section{REFERENCIAS ELECTRÓNICAS}

1. Aurum consultoria y mercado (2015). Guía de negocios e inversión en el Peru. Recuperado de aurumoperu.com/pdf/GuiaNegociosInversionPeru2015.pdf

2. Banco BBVA (2013). 10 funciones del departamento de recursos humanos. Recuperado de https://www.bbva.com/es/noticias/trabajo-empleo-empresa/10funciones-del-departamento-de-recursos-humanos/

3. Banco Mundial (2017) Peru Panorama general. Recuperado de http://www.bancomundial.org/es/country/peru/overview

4. Brendel, D., \& Stamell, E.R. (2016). How Mindfulness Improves Executive Coaching. Recuperado de https://hbr.org/2016/01/how-mindfulness-improvesexecutive-coaching

5. Conexión Esan (2016). Costos de inversión y de operación en la formulación de un proyecto. Recuperado de http://www.esan.edu.pe/apuntesempresariales/2016/06/costos-de-inversion-y-de-operacion-en-la-formulacion-deun-proyecto/

6. Crece Negocios (2010). El pronóstico de ventas. Recuperado de http://www.crecenegocios.com/el-pronostico-de-ventas/

7. Defensoria del Pueblo (2016). Confilctos sociales. Recuperado de http://www.defensoria.gob.pe/tema.php?des=3

8. Dreams\&Adventures (2015). ¿Qué es un Team Building?. Recuperado de http://dreamsandadventures.com/que-es-un-team-building/

9. Harvard Business Review (2005). The wild west of executive coaching. Recuperado de https://hbr.org/2005/11/the-wild-west-of-executive-coaching 
10. Mintra (2013). Ley de promoción y formalización de la micro y pequeña empresa. Ley No 28015. Recuperado de http://www.mintra.gob.pe/contenidos/archivos/prodlab/legislacion/LEY_28015.pdf

11. Ravier, L. (2012). Arte y Ciencia del Coaching. Recuperado de http://www.leoravier.com/2012/11/arte-y-ciencia-del-coaching-2012/

12. Universidad de Lima (2016). El futuro de los recursos humanos en el Perú. Recuperado de http://www.ulima.edu.pe/pregrado/administracion/noticias/el-futurode-los-recursos-humanos-en-el-peru

13. Universidad ESAN (2015). Recursos Humano: ocho tendencias de la gestión de personas al 2020. Recuperado de http://www.esan.edu.pe/apuntesempresariales/2015/10/recursos-humanos-ocho-tendencias-de-la-gestion-depersonas-al-2020/ 